\title{
$8 .+20$
}

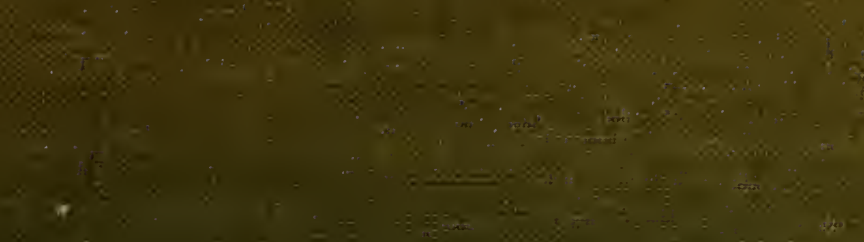

if

$y_{0}=-1,=0$

$x=e^{-}$

$\cos ^{2}$

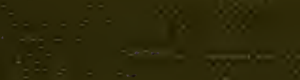

$+2$

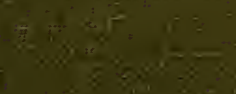

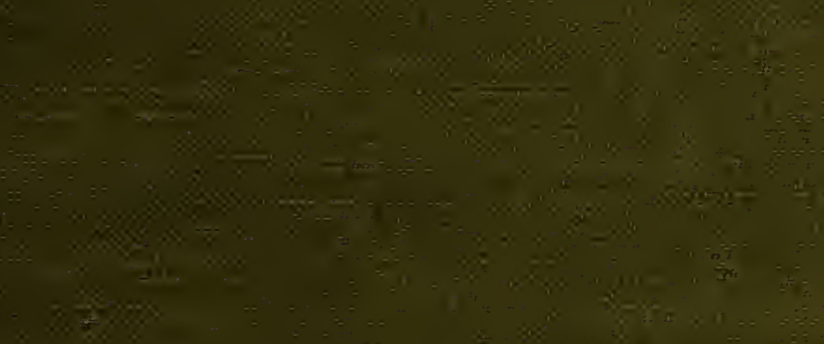
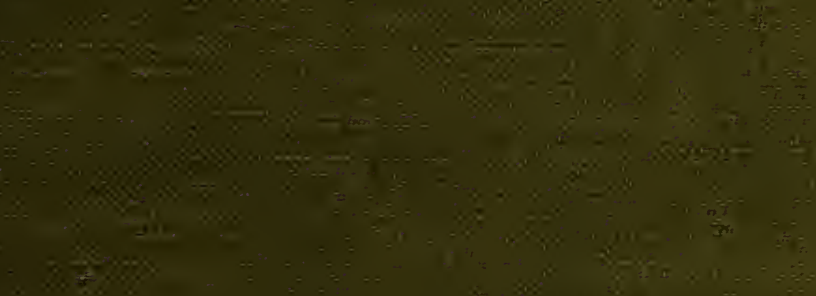
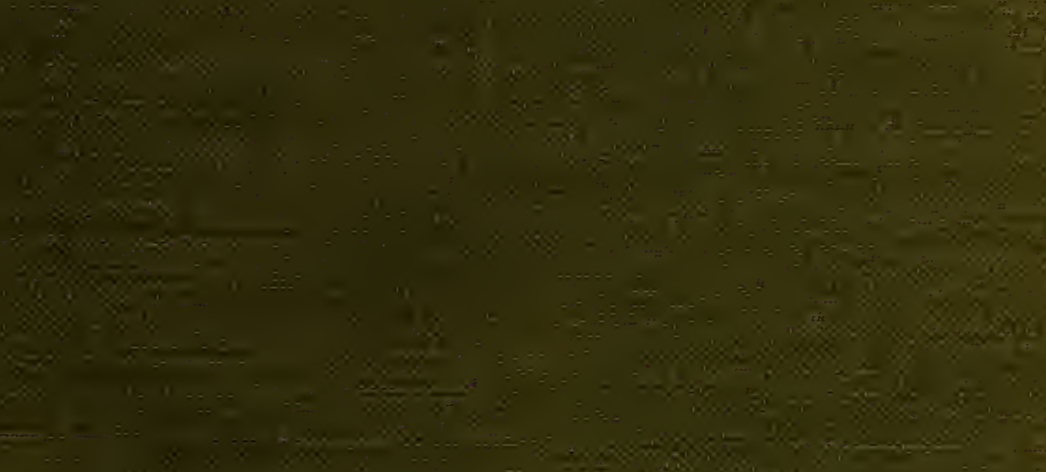

$\rightarrow$

한 


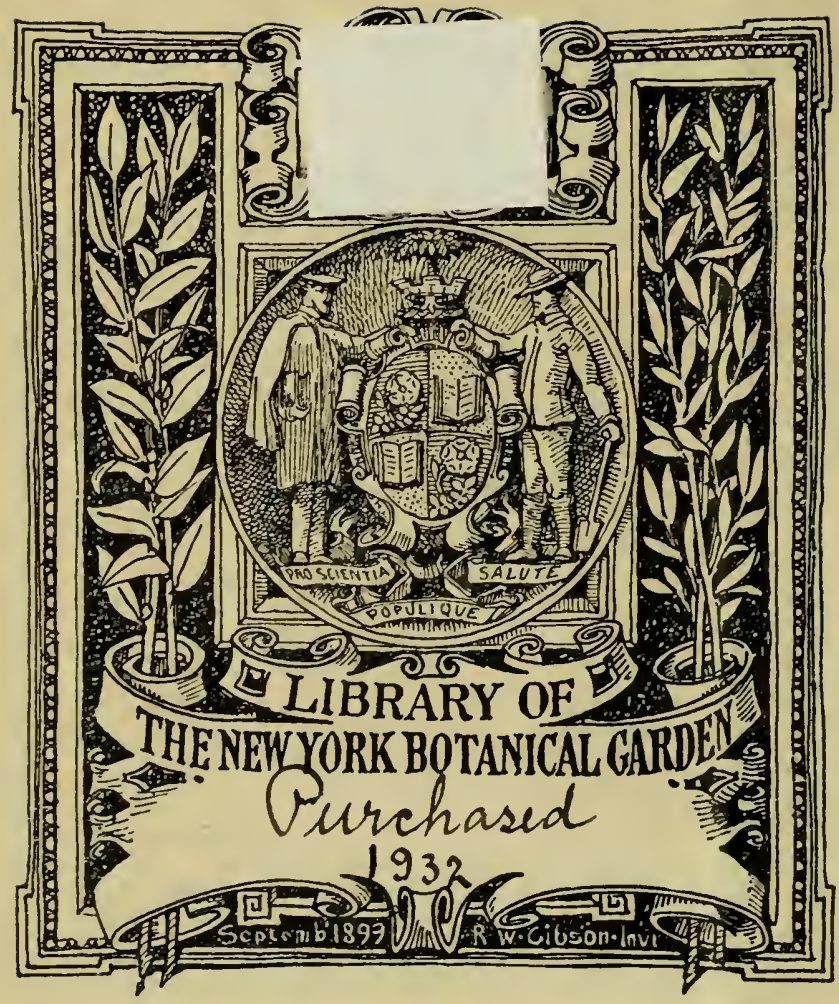





Whis?

$$
\int_{1}^{2 x^{2}+1}
$$




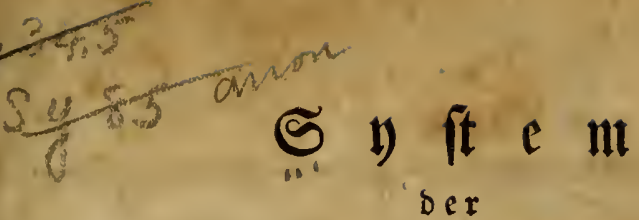

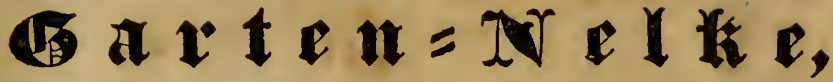 \\ geftitist}

a $\mathfrak{A} \mathfrak{d} \mathfrak{a} \mathfrak{B}$ allgemein geltende

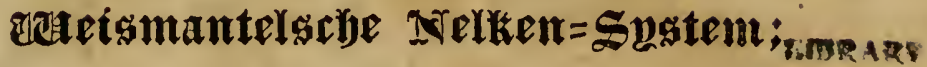

nebfit ciner,

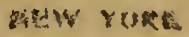

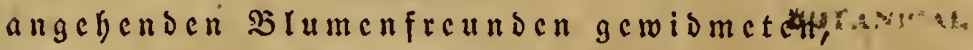

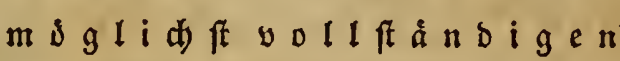

GAk:?:

\section{\& $\mathfrak{n} \mathfrak{l} \mathfrak{i} \mathfrak{t} \mathfrak{u} \mathfrak{n} \mathfrak{g}$}

$$
\text { .. zur }
$$

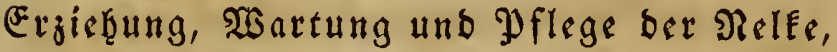
un s

$\mathfrak{c}-\mathfrak{i} \mathfrak{e} \mathfrak{m} \mathfrak{A} \mathfrak{b} \mathfrak{a} \mathfrak{n} \mathfrak{g} e$

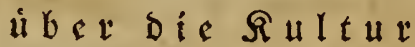

eintger antorn zletblingshlumen.

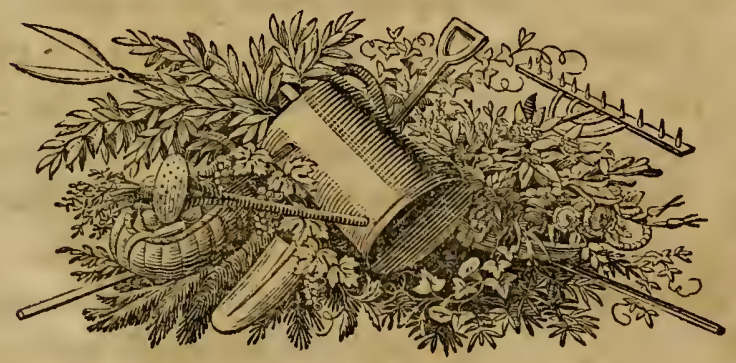

Mit einer na der Ratur gemalten Relfentaberfe.

\section{lieclitt, 1827.}

Berlag Der 2 udblandlung von

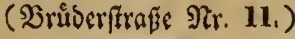




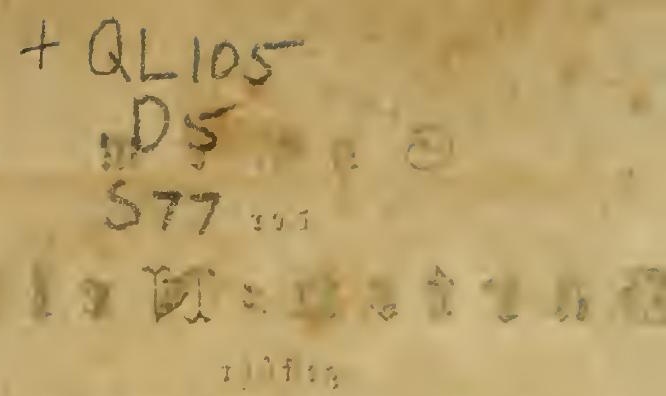

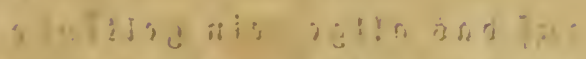

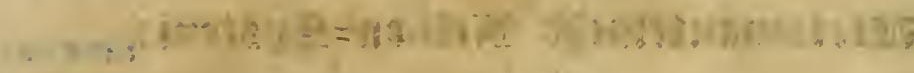

$$
\text { is ic ind: }
$$

,

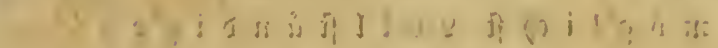

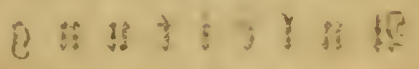

II:

$\therefore$.

$$
\begin{aligned}
& 4 \mathrm{~s}
\end{aligned}
$$

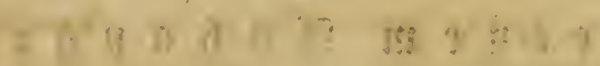

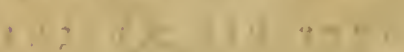

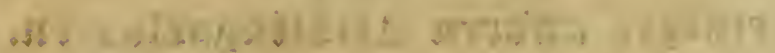

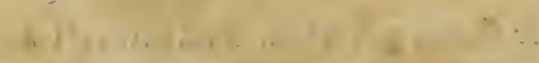




\section{I) $\mathfrak{n}$ b $\quad \mathfrak{a}, \mathfrak{l}$}

\section{E}

inleitung

Seite

3

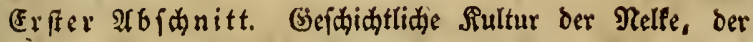
Berfdiedenheit ifrer acidjnungen und bes biernad georoneten Syftems .

3weiter $\mathscr{A}$ bfdnitt. Selfen s Ibcorie, ober fyffematifide

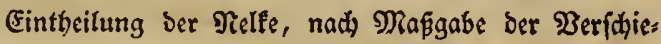
Denbeit ibrer Zaidinungen.

Dritter 2 bf reitung ber fừr Alelfen taugliden Eró . . .

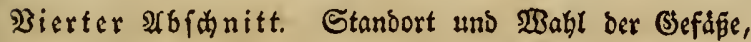

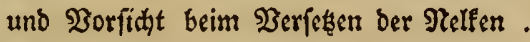

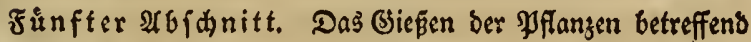

Sedster $\mathfrak{A} b$ fdynitt. Bebandlung ber গelfen vor uno wågreno ber Flor . . . . . . .

Siebenter abidnitt. Die Nermelyrung ber Relfen burd) 2rbleger unb Sdanittlinge . . . . . 80 Ad) ter $\mathfrak{A} b$ fanitt. Heber bic Ergialung bes Saamens und bie Nermebrung bur(h) benfelben . . . 96

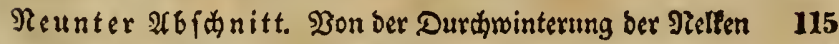

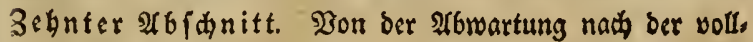
zogenen Durdiminterung. . . . . . 131 
Seite

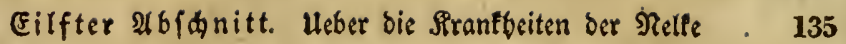
3wolfter 26 fanitt. Pon ben Feinben ber Nelfe . 143 Nadtrag • . . . . - . . . 158 $\mathfrak{A}$ দ Ifurifel . . . . . . . . . 165 Gold, oder Siolbenlact, . . . . . . 174 æofen . . . . . . . . . . 177 Levfoyer . . . . . . . . . 181 Şortenficin . . . . . . . . 184 Beorginen . . . . . : . . 187 Şyagintben . . . . . . : . . 188 


\section{$\mathfrak{A} \mathfrak{n} \mathfrak{i} \mathfrak{i} \mathfrak{t} \mathfrak{u} \mathfrak{n}$}

$$
\text { ชนเ }
$$

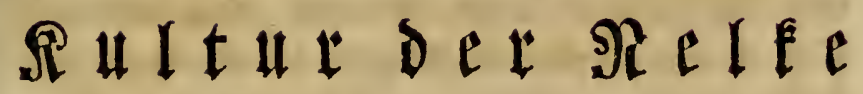

unt

einiger andern Riebrings $=9$ Błumen. 


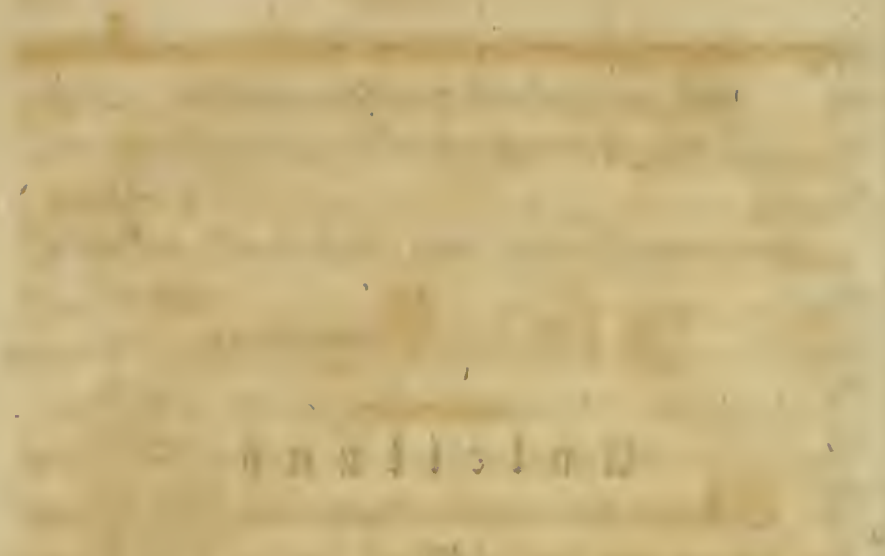

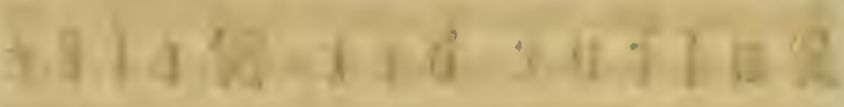

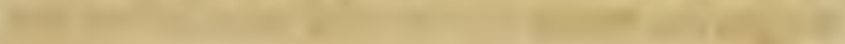

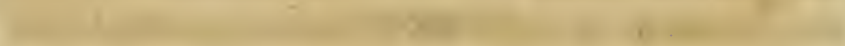

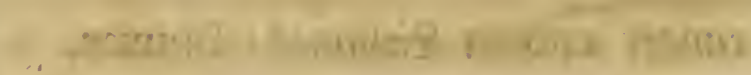

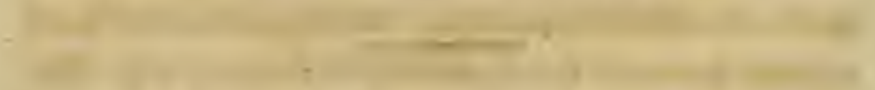

1

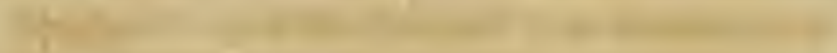
in

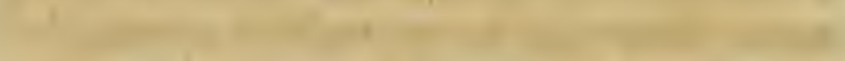
10 (1)

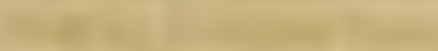

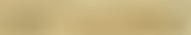

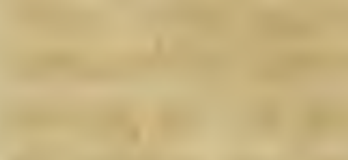<smiles>CCCC</smiles><smiles>CCCC</smiles> 


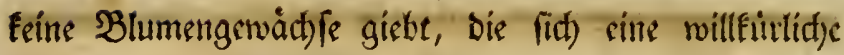
ober irgend vernactláfiigte Beţanblung gefallen laffen, forbern, wenn man an if̧eer Yyflege etwas verifethet, fränfeln und abfterben, ober boch bie innen geworde"

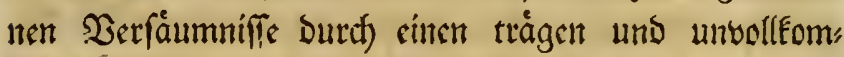

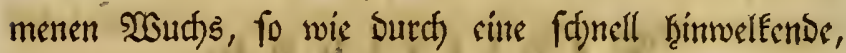
Feine Befricbigung gemáf̨umbe Slor frafen.

So menig Befricbigendes fict jebod) uiker bie

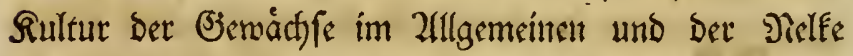
im Serfondern auch angeben láft, indem nufer vielen andern Zufälligfeiten gang befonders bie Berfefieden

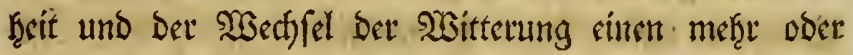
minder verberblichen Einflup auf fie geltens mactst, Dem zu begegnen nitht immer Gadjenntnif uns, Er: faḩrung austeid)en wollen: fo ift Doch bie פiclese Dass!

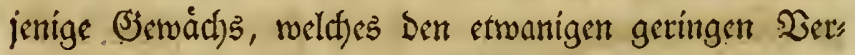

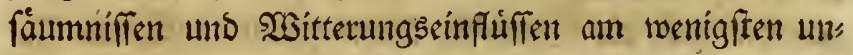
terliegt, ja felbif Falten Wointern ju trof̧en vermag, in fo fern fie nicht burch eine gar zu vorifidtige. $\mathfrak{B}_{e}$ banblung verjärtelt ober siner ju ergveiffenden Rálte idjonungslos Spreis gegeben wurber. Diefe minoer ex

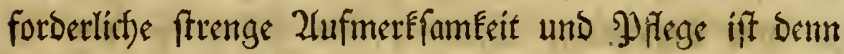

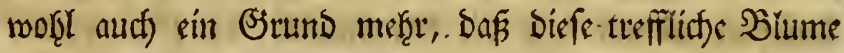
ein - Segenftans: allgemeiner Réebraberei geworben ift, benm meldyer SBlumenfreund befáfe fie nidft, uns in weldaem mur einigermañen freunblid), Eultivirten (Sarten

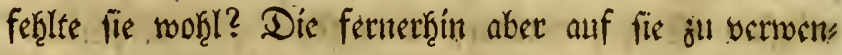
bende 2(d)traméeit und. Mluke ift um fo lohnender, als bet furt bie freuben- Des Menfit)en in Der - Tatur fo unenolich forgfam gewerne Gcjopfer alle mur mig:

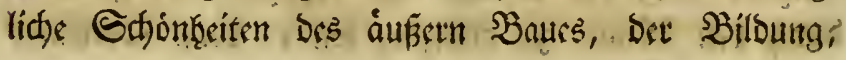




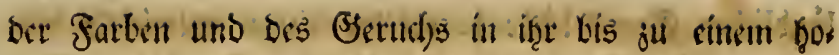
f̧in unt roaf̧r (t) tell Ebrabe vercinigat hat."

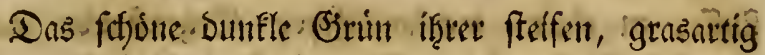
giformten Blátter; Det angenthrme bläulid)e Disif; Sett Diefelben nirit): sinem fie fonft erfrifit)enden Sirgen obet nat) cintem bei boriber gegangenter Sngesfd)wule erfolgten

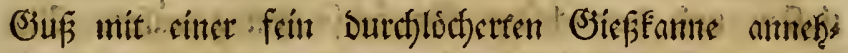
men; Der ftärento Duft, ben fie nady cinet fold)en

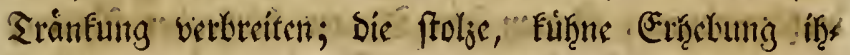
tes. unter ber Sienge féner Rnofpen mur fanft fid)

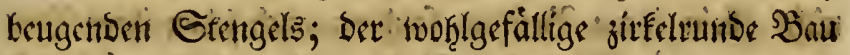

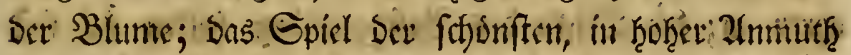

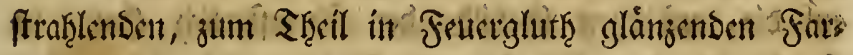

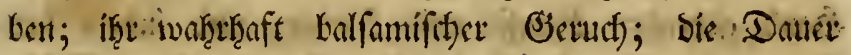

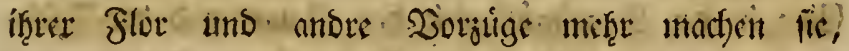
unter ben verffjiedenen mit mef̧i ober múnder Sctuvies

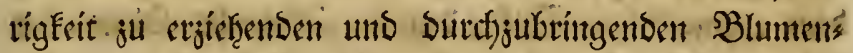

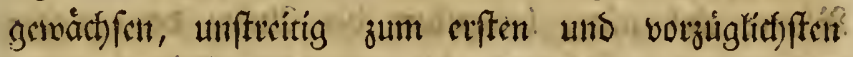
Rieblinge det Saturfirunde, jum Gimbild vollendeter

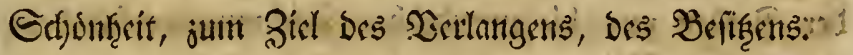

Freilid) fónnen wir nicht alle Blumiften fenn, fo

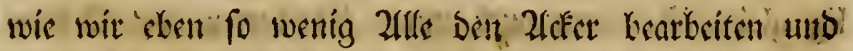
ben 'Gegen' Dev Felber unfer Eigentf̧um ju nentuen

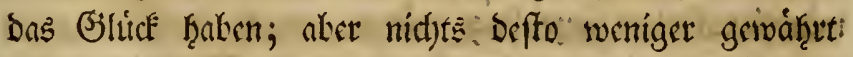
bie 2lbwartung bes Siartens, ber ja fot)on bem erffen

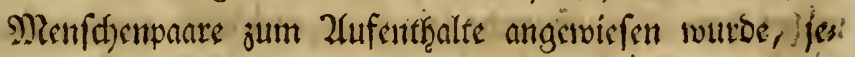

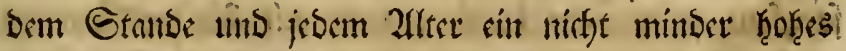
Sergnugan, wemn gleith biefe $\mathfrak{B} e f(j)$ ftigung audf nicflet vermag, cinen Einfus auf unfer áufictes, forgenfurtes!

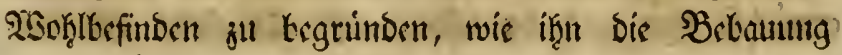


lánblider Brundfticke fo erfolgreid ju entwickeln vets

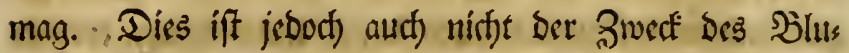

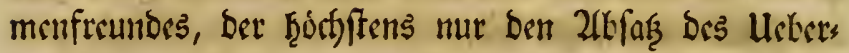
fuffes ju ciutem mettantiliffen Begenftande mactet,

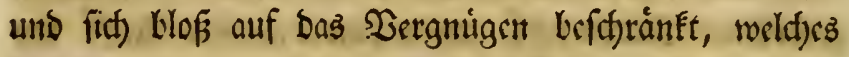
Der immer allgemeiner werbende Trieb nact) Werfdjos nerung unfrer Baaten uno Der Befié Der mannigfals

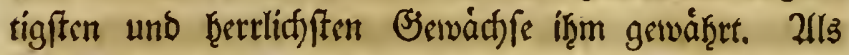
Brempunft erfd)sint in sinem reigeno angelegten uno

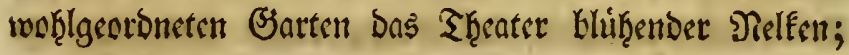

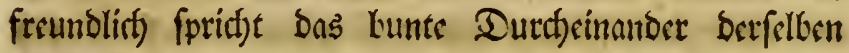

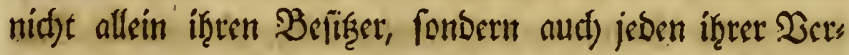

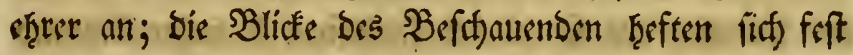
auf bie trefflid)en Sectilbe ber fanefterlid) Şand in

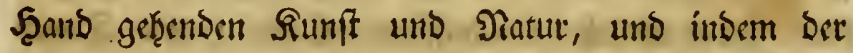
Fine in Der Regelmápigigfeit bes Baurs uno ber Beitfs

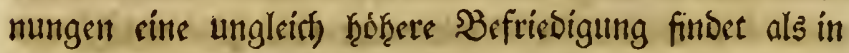
Dem aromatiffen Duft, Den Der 2fllmadft Doem ber Blume cinf̧auct)te, benumbert ber 2 Indre Den ausges

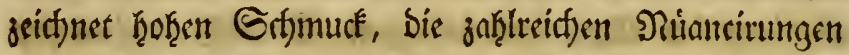
Der Farben und bie unendlid)en Zeirf)mungsber/fficdens freiten ciner Blume, von vellden Eeine ber andern vóls lig gleid) ift, wenn aut) unter Scunderten von Dislen meţrere nat) Denfelben formen uno mit cinerlei Sllus minationsfarben gejeid)net wáren.

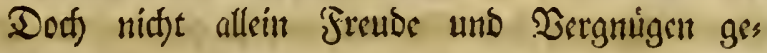

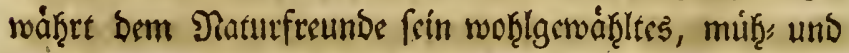
forgfam zufammengebrad)tes uns mit 2(ufmetffameeit gepflegtes Nelfenfortiment und Der unveroroffen tno bुoffmungsteid) yon ibzm bearbeitete Barten, fonbern es

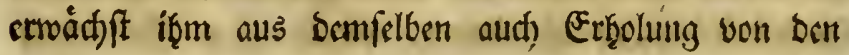




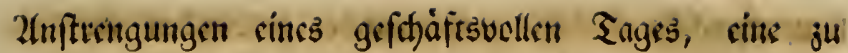

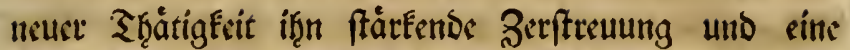

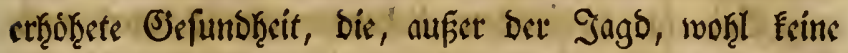

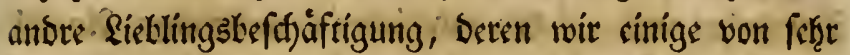

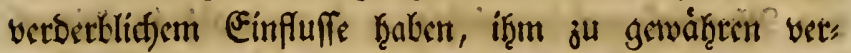
mag. Gelleft weent von ben Etútrnen bes lebelns bie

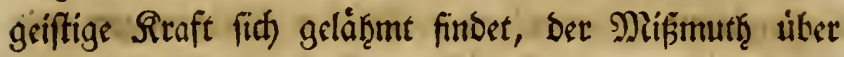
bie ber eignen Bruft emtefdúpften ober von aufen beer

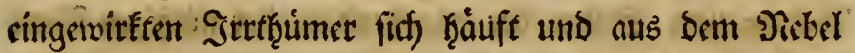

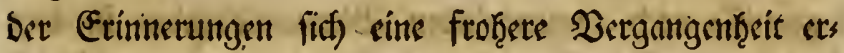
bebt, als bie Segegentuart es ift: fo wirb ber freunts

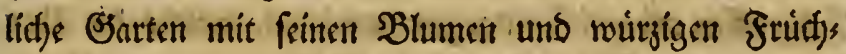
ten bas ffille. 2lfyl für ben Sturm bemegter truiber Empfindungin, und bie Serborieflidjefiten Des gemeineri

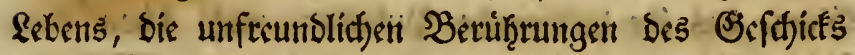

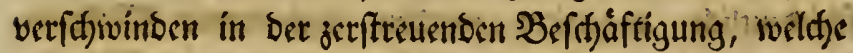

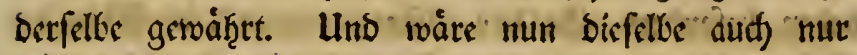
sin Etecfenpferd, wo waáe benn ber Mienfda, ber

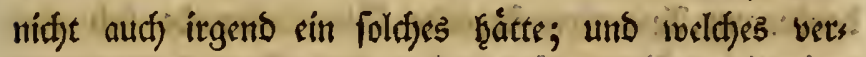

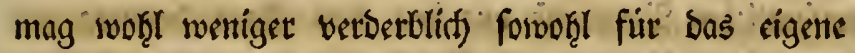
als fút frembes' Wookllergethen einguswirken, als biefes?

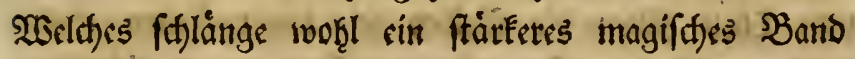

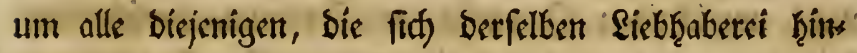
geben, fo baß man find mit ingnen verbunden fuifight, wem man fie aud nismals fabg? Sosie viele intereffante

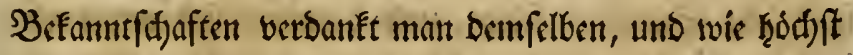
angeneşm wirb bie burd baffelbe eingeleitete fadrifts lidje Untertraltung mit jum Thęil nie gefarnten unt

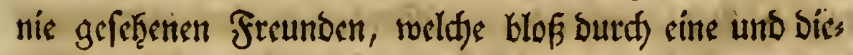
felter, aus ciner glükecnoen Riebe jur Natur bertoorge" gangenen Nerigung cinanber náąer getreten, buerd). 
fimpatţetifine Befrib̨le mit sinander verbunden morden fins.

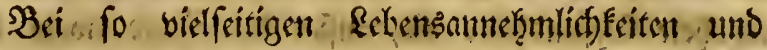

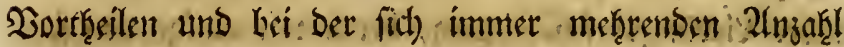
von Blumenfreunden móchte $\mathrm{rs}$ benn wohl -in Eeinem.

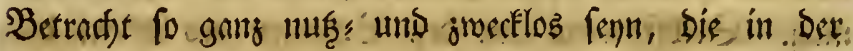
Relfenfultur gefanmelten praftifften Erfahtungen uno. "Die gepruften unt bemáfint gefundenen 2untathungen. Indrer :zum Beften Der angetenden, Der nothigen. Bor" Eenntniffe nof) ermangelnden Blumenlisbraber in bies fer fleincu Gcturift nieberzulegen, um Den mancherlei

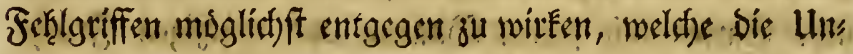

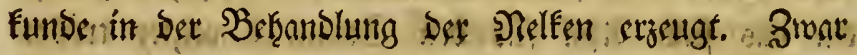

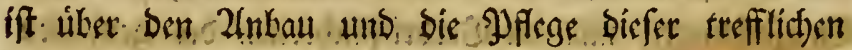

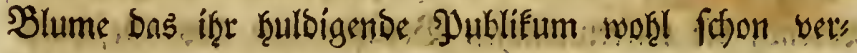

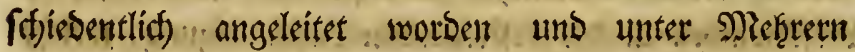

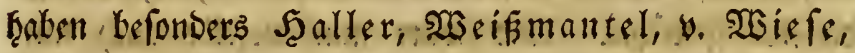
Sd) matcling, Scubner, Rubolphi und andere in DanEbarem Indenten ftȩ̂ende ß̧lumenfreunde fid) ein refentliches Derbienft mit Den von ifrnen . Kerausgege" benen 21nneifungen unt Beleţrungen etworben; allein

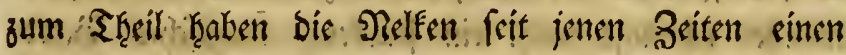

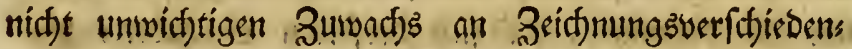
Geiten geroonen, woraus sine notf̧ruendige Ervociterung

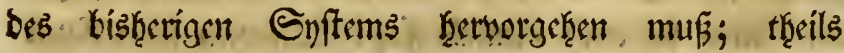
fins jene Struffen felten, uno befinden fid) nut nod) in Den Şänden einjelner ßeteranen Der Blumiftie, in

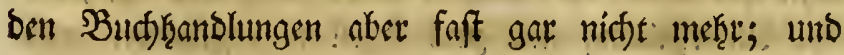

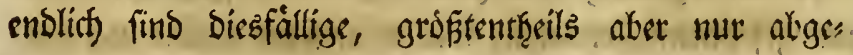
broct)ene. Znnlestungen háafig nur in umfangreid)cu, jum

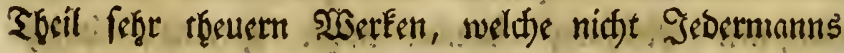




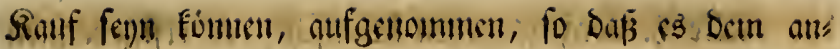

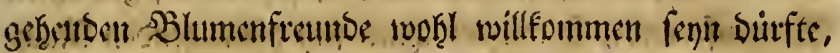

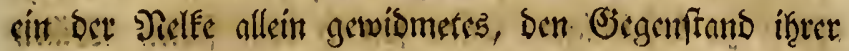

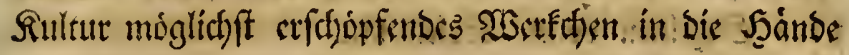
jü befommen.

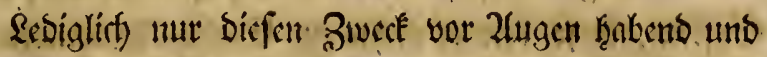
aud) im entfernteften nicht 2(nfprudt) machend, als, blus

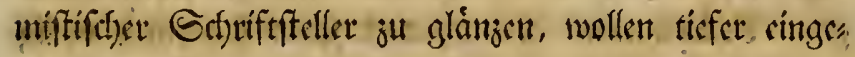
Drungene, oder funfffertig geubte Blumiften Diefe Elcine Ed)rift, in fo fern fie zu iheren Şänoen gelangt, mit:

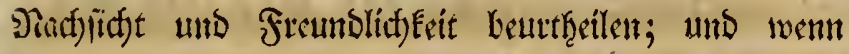

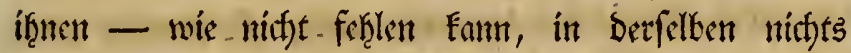
neu, mandfes aber iberflifitg (d)einent mod)te, fidf in bic Gtelle bes angchenton, Der Säatnertemntuiffe uor) ermangelnben Şlumenfreundes verfescen, als fưr

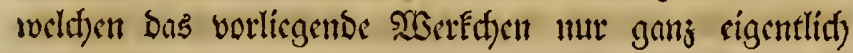
beftimmt ift. Das bargclegte Enftem betreffind, fo wollen fie auch biefes 'mit aller \&eibenfigaftlofigkeit prit:

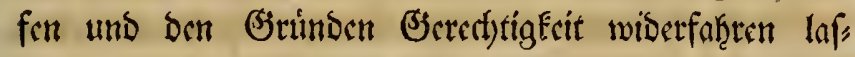
fen, woldye orn Berfoffer bewogen haben, in sin Duret)

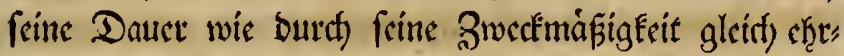

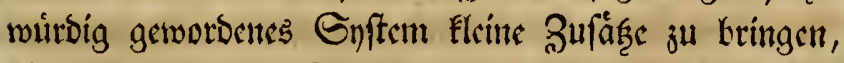
bie Feinen anbern Swect fraben, als bie von eini, gen Blumiften, namentlid) von bem bercits verftorbe" nen Reftor Scúbner unb cinem ungenannten Werfaf, fer ju 2lugsturg in 2(ntrag getruct)ten, bas Enftem

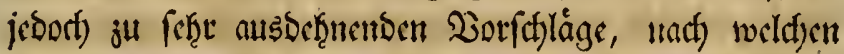

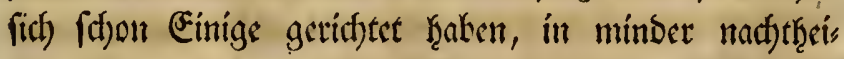
lige Sirengen ju bringen. Dicke Sufáfe verándern bas Weißzmantelfde Enftem nifft im mindeften unt

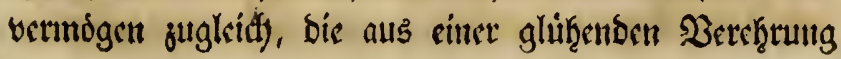




\section{0}

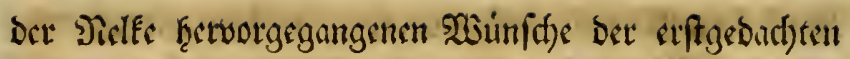

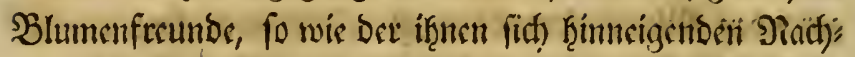

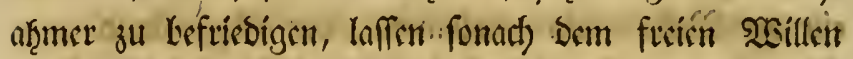
jedes Eimjelnen vollen Epicltaum.

Das grorangtefte und am leichteften ju liberfeţende

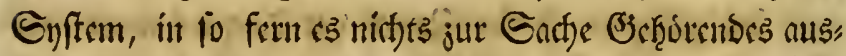

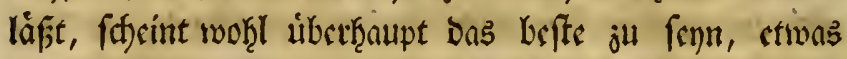
ganj Wolleommenes jeboc), Das jeben Einjelnen bollig ju befricbigen bermodfte, giebt ss leiber auf biefer Erob nicf)t. 


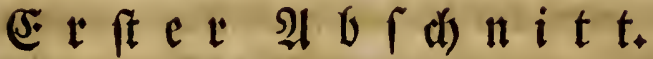

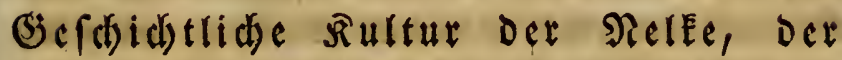
Berfalicbenbeit ilger acidnungen uno des biernath georoneten Syftemb.

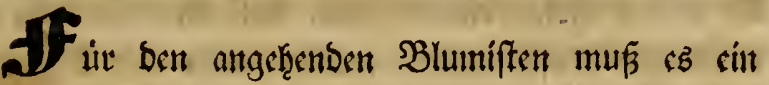
befonderes Sntereffe fenn, von Dem, allen פelleniften und biesfálligen Dilettanten zum Zlnţalt bienenden

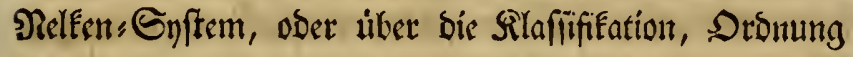
und fonftige Eintheilung ber Nelfen cine genture Siunbe

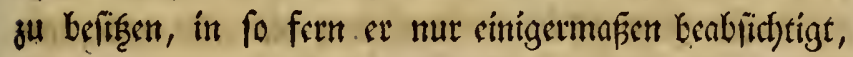

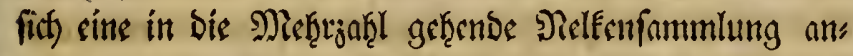

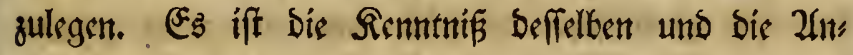

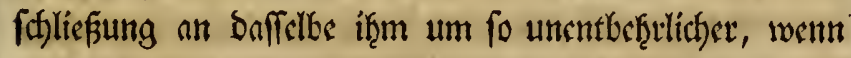

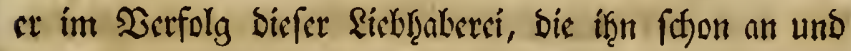
fir fiif) felleft in to mandfe freundlidfe Serkinsung bringt, es feinen Brocken angemeffen fintoet, mit ans Dern Bhlumenfreunden in Saufs und Fauffibertráge ju treter. Ein folcters Enyfem verbanken mir, fo weit

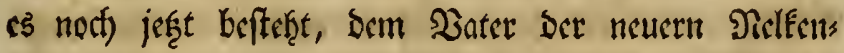
Eunde, bem vor etra $\mathbf{5 0}$ Saf̧ern verftorbenen Doftor

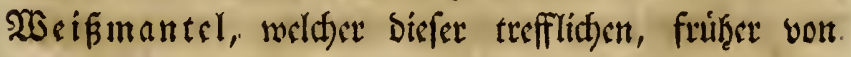
ben Şollánbern, bann aber aud) von işm fultivitten 
Blume alle 2lufmetffamfsit mibnete. In Stalien uno auf ben Edyocijer 2(lpen willo wath) fento, wurbe bie in ifrem urfprunglidsen 3uftande rothgrundig, cinfac) uns of̧ue alle Slluminationsfarben fünfblättrig blithende

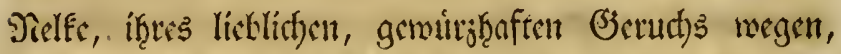

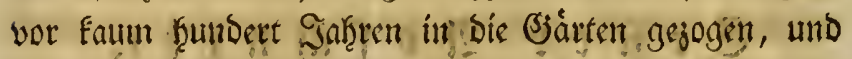
nad) unb inath hat fie unter" ber pflegenden Scand Des

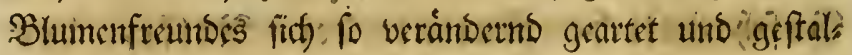
tet, Daßs man nod) Eaum Die Driginale cufennen muros; wenn man fie in Den willoniffen auffiudsen, wollte.

Durch Die Dermifdung bes von Woino und In,

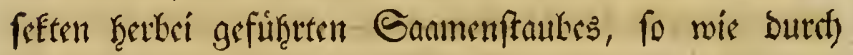
bie in Der Folge cingettetenen vielfad)en Derfud)e sinet Exitfflicfen Beftuct)tung, wutben nicft: nur. Blumen in

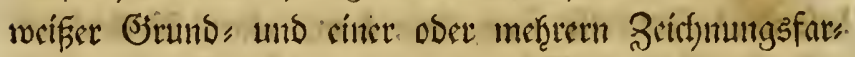
ben gemomnen, fornbèrn nad) und nad) erthielt man jie: aud) meţr ober weniger gefullt blügent, unt woufecn

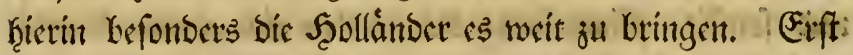
gegen Das Jaher 1740 gewann man bie crfte gelbgutu

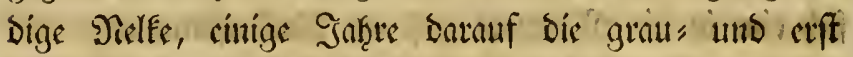
fpåterţin bic Eupfer", Folombin: und pucefarbig gescicl);

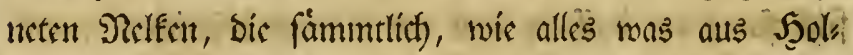

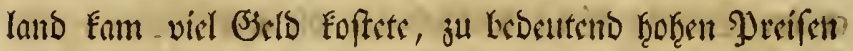

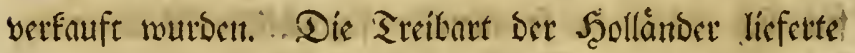
jwar sint in bie 2litgen fallente YPfranje mit SBlumen von befonder Broffe ano mefreen Farten, allein bie

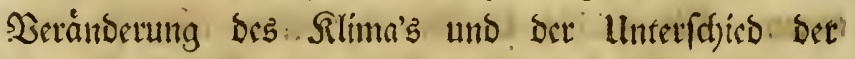

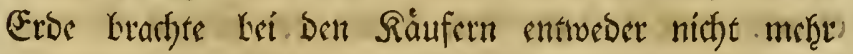
jene grofen, farbenreithen Şlumen beerbor, oder wurbe Die Ulefact)e cincs balbigen : Serluftes, Daher fingen?

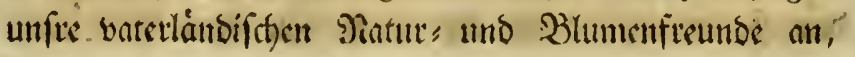




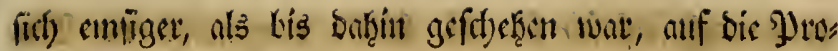
buftion Der Dielfe ju legen, uns gewannen nidft mur eten to reffliche: Gorten, fondorn fie tibertwafen bie

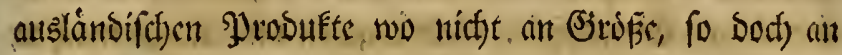

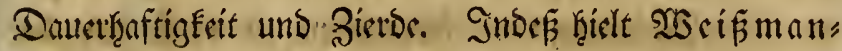

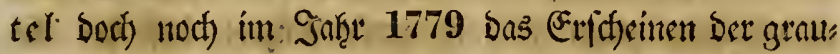
und fupfergrumbígen ! Dirlfent nut fit sin unfict)eres Bielleitft; Ser Eolombin", puces, violett" und feuerfarb: grumbigen Delfen aber, woth)e bie raftlofe, yon ber

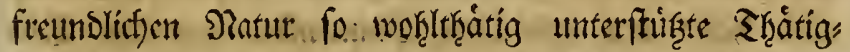

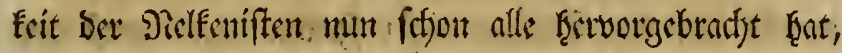
geonefte Derfollbe nect) gar inid)t.

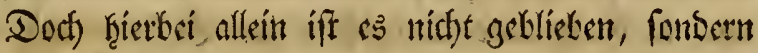

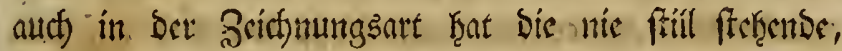

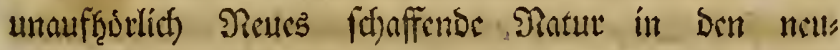
ear Beiten eine Mannigfaltigfeit hervorgetbract)t, weld)e efrebem in biefer Blume nid)t jut finden wai; und bei

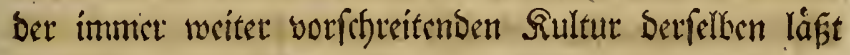

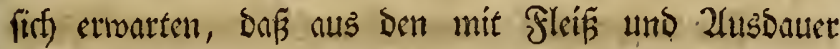
ou machenton, in if̧een Errfolgen fief) bereits fo lof̧nens

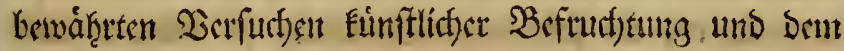
fernern Detein Der Runft mit bet Patur nod), vicl

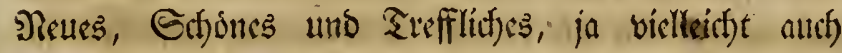
noch) in ber blauen Farbe, welefer wir uns fichon cinis

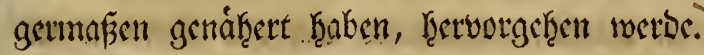

Fiir Diefe, befonders in Den Beiffunngen ber

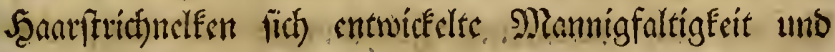

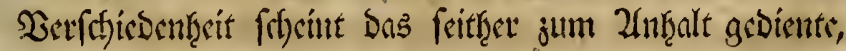

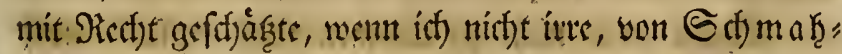

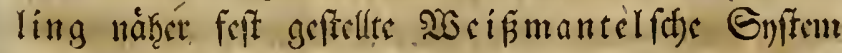

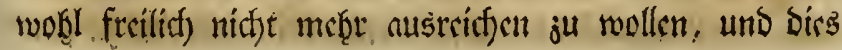




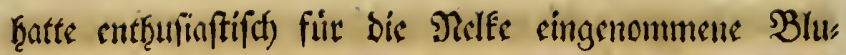
menfreunde veranlap̧t, sin anderweites Syftem in $\mathfrak{B o r}$

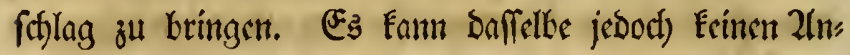

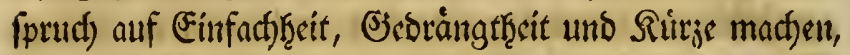

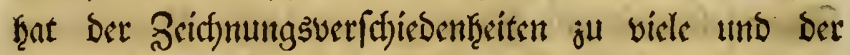

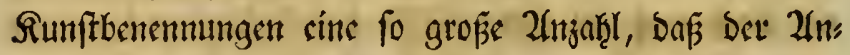

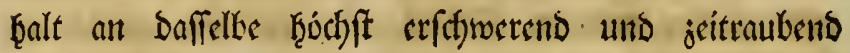
felbft für bénjentigen merben múfte, ber ber Şärtnerei nur alkin feine Beftimmung gerwiomet ḩàtte. Simmer

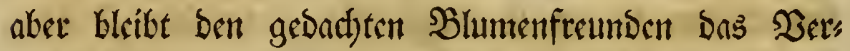
Dienft: auf Das Dafenn bicfer Bcichnungen juerft aufs

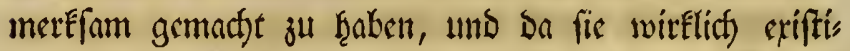

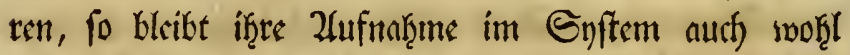
crforderlidy, uns es fragt fid) blof, wie bies auf bem

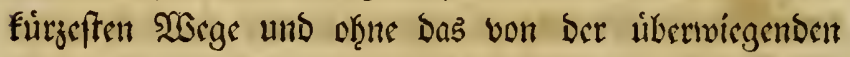
Metrezahl Der Şlumiften und Dirsfälligen Dilettanten als beiberçaltungsmerth crad)tete Syftem anjutaften, errecicft ueroen fóme.

Der anfpructlofe, nur allein fuir bie gute Gadbe

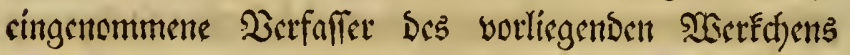

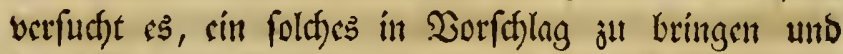

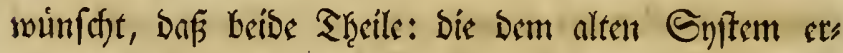
gebenen, fo wic Dic fir bie Ermeiterung Deffelten ges

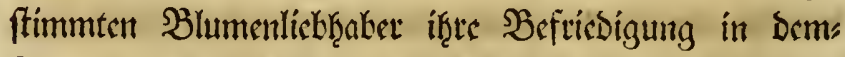
fellen finden mócten, indem se bas alte Gyftem wes ber veránoert nocf) bebeuteno erweitert, unt bod) aud) bie neu fich) entwickelten Seicfmungen mit nufgenom: men hุat.

Ess ift jwat nicht ju läugnen, baf baffelter noch

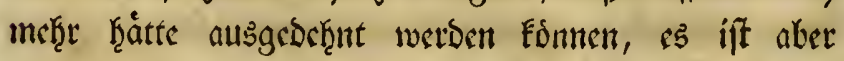
nuch) - und vielleidft nod) weniger in 2fbrede ju frels 


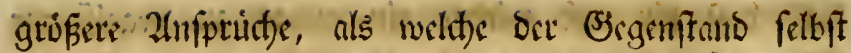

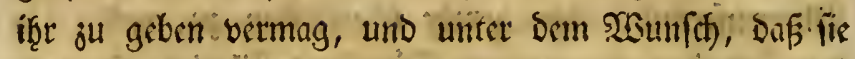
gemeinnlifig etadtet werden moge. Dem Dothrochs

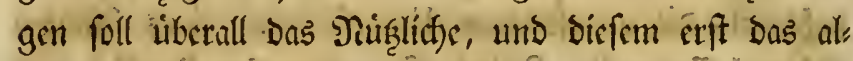

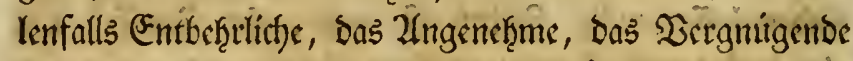

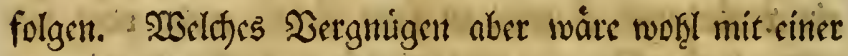

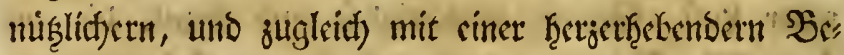
injáftigung verbunoen als bie. Sortenfultur, voir wets

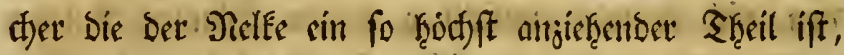

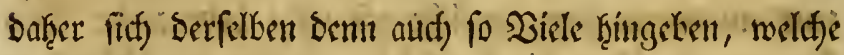
fammelid) if um freundlid) Zufnaţme bes" vorliegen Den Woreftetens erfuthe.

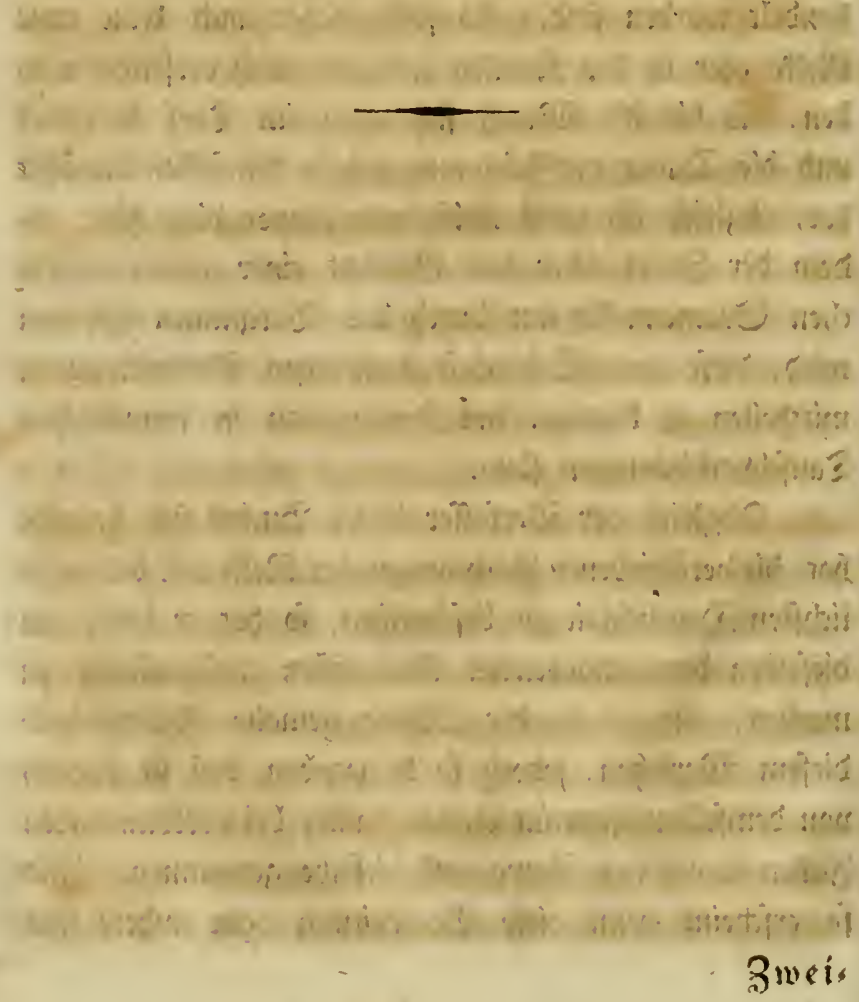




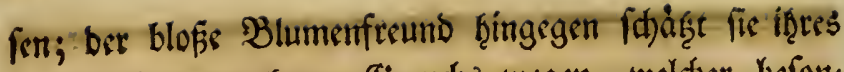

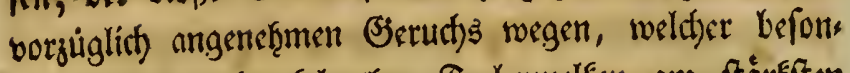
bers bei ben bunfelrotbeen farbennelén am ftárfiften unto gerourgterafteften ift. Die Gorten, in welthe fie eingetbeilt werben, fins

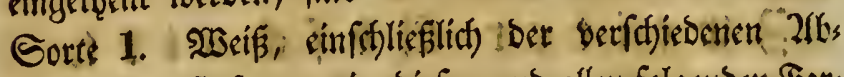
ftufungen in biefer und allen folgenden Fars

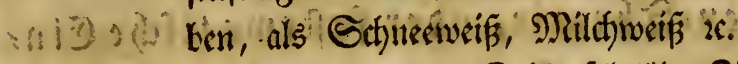

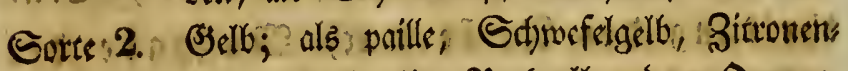
gelb, Siologellb, Rothgelb ober Srange, febergelb ober Eţamois, Jfabell, Fabllgelb ober Stwisbelfarbe u. f. w.

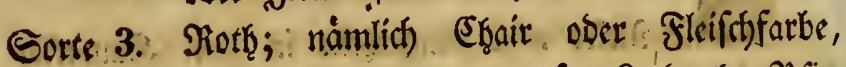
Pofenfarbe, Snfarnatrofa, Lactroth, JPfirs

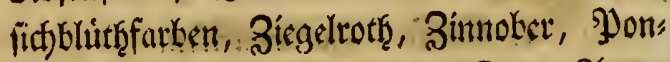
cenu, Sdfarlact, Snfarnat, Feru; Zuror oder Rupferroth, Rarmin, Rarmoilii, Gang be Bocuf oder Blutroth, Eerife, Jompa bur, Braunroth, Dutpur, Durpurblau $x$.

Sorte 4. Sitolett; Şctlviolett, Rilla, Rothliffubiolett, Blaurviolett, 2ffupiolett, Dunf́clviolett, Safwarz" und Braunviolett 2 .

Sorte 5. Braun; Seellbraun, Mlovdere, Rirfafbraun;

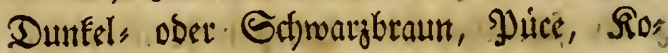
lombin, $2(\{f) b r a u n, ~ \mathfrak{x}$.

Sotte 6. Rupferfarben; als ग्रlatt, B̉a Eupfer, Supferbraun, Siupferblau, 2 (fd) fupferze.

Gorte 7. ઉirau; als Gillergrau, Blaßjgrau, Milds: grau, Bleiftiftfarben, 2lfat)grau, 2(fd)tofe, Supfergrau, Ex)warzgrau, 2(ff)roth, 2(fif); blau, S̉laugrau, Şiolettgrau； Gtab̧lblau z.: 


\section{0}

gemfdaft, nämlith ben Junten bie Mebe ift, fo butfte

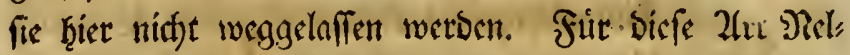

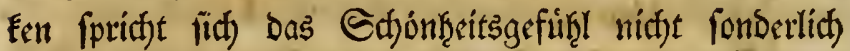
aus, weil fie bes erften Erforderniffes, namlich cinter burdjaus teinen Şrunbfarbe, gánglíth ermangeln. Der

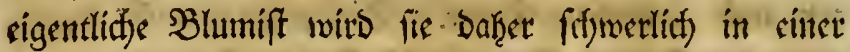

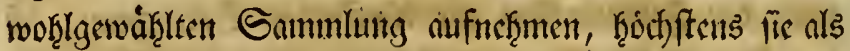
Sonderlinge bulben, wie cin foldfer in Scubuers S)lats morfaule nicht nur gebulbet, fondern aud geact)tet war.

Swcite Dronung. J̧anritridgnelfen.

Diefs unur mit feinen Strictien vom Pianbe ab

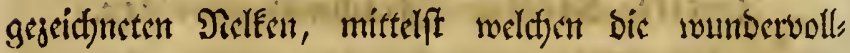

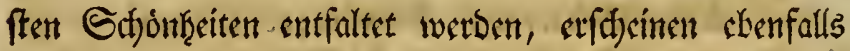
in jwei Sottungen, nls:

1. Sattung. Srocifartig oder DJifotten; fie hraben cine Ortunds und cine Zcichmungsfartbe.

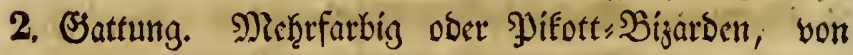
Einigen aud) गDifott SDifotten genamnt; fie babett aufer iferer Otrumbfarbe auth givei ober metre Beidunungsfarben.

Beibe werben wieber in Gorten umb biefe in Formen eingetheilt, Deren jebe cinen unter: ben SBlumiften

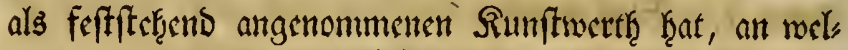
d)em man bie Bcichnung fofort enfennt; wie fold)e aurf) nachfterteno folgen.

Da es fitf in bet gegenmátrigen Sheorie nut um bit Beidfunngs: biefe in Den Difoten wie in Den Diffottşizarben siner und berfelben Form ganj libercinftimment finto, fo ges ben wít nidft enft jede Der beiben Sbattungen befons bers Durtf). 


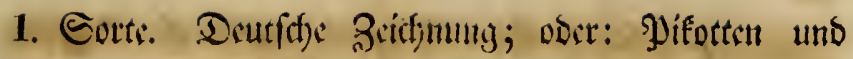

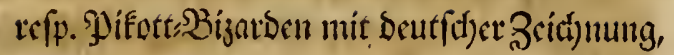
von (Einigen nudl) Epieget-gDif́tten genanut,

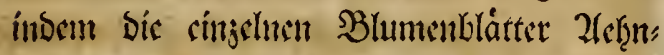

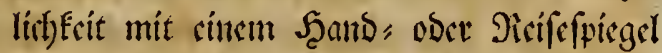
b̧aben, Deffert Pians ober Miaf̨men bier Durcl) Die Zeirfynung grevilbet mírb. Diefe פielfent hinken lesiglidf) sine Minnbsciffunung,

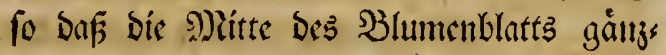

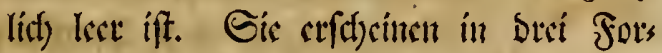
men unb werben als foldje mit folgendert

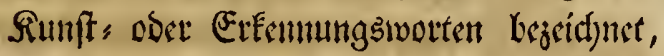
als:

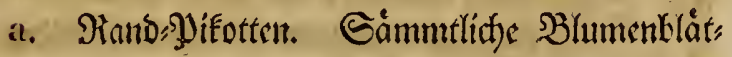

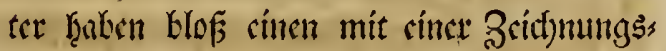
farbe berahermten ober gefáumtent Riand uno

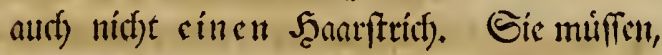
wenn bíc Şlume, was úbrigens nidjt ḩàus fig vorformmt, gefallen foll, nád)jt cinct

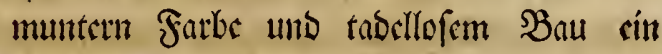

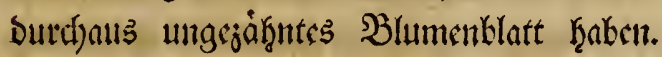
Fig. 1.

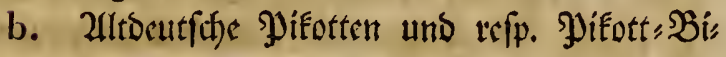

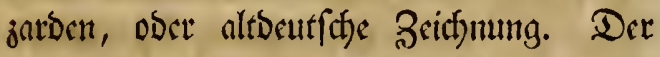
Piand bes Blumenblatţ ḩat ţaarféme vom Siande ab frecunter laufente, nafere an cins: ander ftetrenbe, Furtz abgrfortete, Faum bent

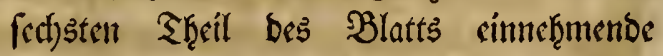

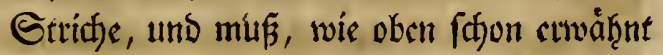
worben ift, ber inmere Siaum ber Branto farbe gánglitid) tein fentr. Fig. 2. 
c. Disubeurfde Wifoten unb refp. Difotts Bizarben, ober ncubeutfade Seidfnung. Die ebenfalls kqaarferin neben cinander befindlis d)en Etrid)e Der Beid)nungsfarbe reid)en vom Rande bis faft in bie Mritte des Blumenblatts. Fig. 3.

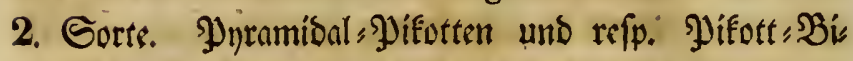
zarben fimb foldse, bie in Der Mitte bes Blumenblatts sinen bis in Den Reld) bect nWlaufenden, geraben Şaarftrich) fraben, jul Deffen reiben Exiten meţrete Dergleidten vom Rande ab fictunter laufende, jebod) immer fuirjer werbende Etridje die Figur siner ungefirţrten Pyramibe bilben, beren fpif̨er Trintel fied) in Den Reld) meţt ober weniger tief hímunter jief̨t. Der ju beiben Eeiten Der Myntunide befindlid) Theil Deş Blumenblatts muF weiter Ecine Etrid)s jeicfinung baben, fontorn gånglid) rein fenn. Fig. 4.

Dicfe IIntamibal:Zeitfunung und bíc obr gebachte beutfite Scid)nung mathen bie Sirumblage aller folgenden jur jweiten Sords mung geţorenden Beidtnungen aus, uno fitto Daber juerft beţandelt worben.

3. Sorte. Syolländifd) Yiffotten uns refp. Yiffotts Bizarben, ober halländifd)e Bcidjnung, bes fteḩt aus ber Eurzgeftrichten altoeutfacm

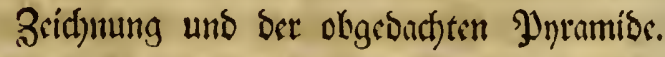
Fig. 5.

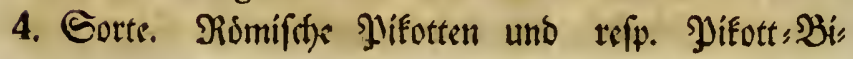


jatben obet tumifore Beictumn, fat langs geftrid)te neuberitfife Ranojeidfnung und ebenfalls गyramide. Fig. 6.

5. Gorte. Tranjólifare Sif́tten uno tefp. Difotts Bizarben, oder פelleen mít franzblififier

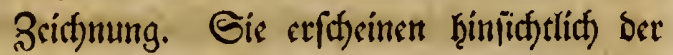
neu fid) entwidfelten hier uno in Den beis Den folgenden Gotten untergebract)ten Beict): nungen in jwei formen, namlich:

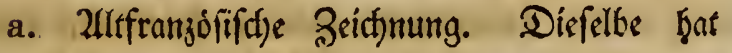
Sianderictinung, gleitfyoiel of alts ober neus beutf(d), Demnád)fit Jintamíbe uno cin paar Scenfel ober Şafen, von benen an jeder - Seite ber Dyramide cincr befindlić) ift. Diefe Seenfel befteh̨en zuweilen aus eincm eingelmen, lantgen, meift getnden Stríf, ţăus

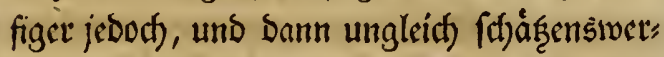
ther, aus gatiz Eurjen, bicht unter sinanost

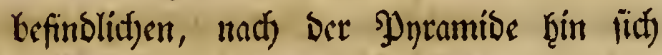
verlaufenoen, feinen Gtrid)eldyen, weld)e zufanment genommett, sine fidfelformige Figut billoen. Sie beutlidfer fidf) biefe Seen fel Darftellen, je weniger fie in cinander fliefent unto je meţe fie von ber Randjecict),

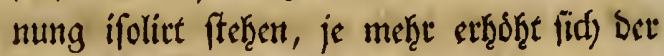
Werth Der Nelfe. Fig. 7.

b. Teufranjofiffue Yiffotten uno wefp. Yifott; Bizarben haben bie obgedactite beutifite Ranozeicfunung uno etbenfalls sin paar Scen, Eel, jeood) feine Yytamibé. Diefe Beid)s mung, Fig. 8., ift in Folge Der fajon mebet 


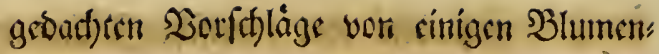

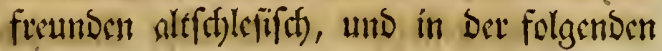
Gorte ad b. neufdilcifif(t) genannt worbent.

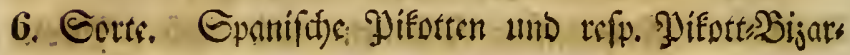
Den, Davon hrat:

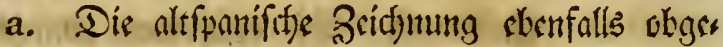

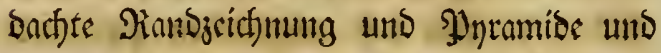

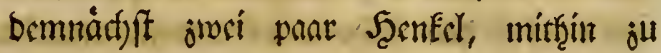
jeber Eeite Der Dynramíbe zwei Der oben

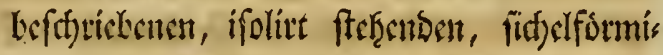
gen Scafen. Fig. 9.

b. 3ienfpanifde Bciffunung hat wiebenum bie obige. Pinnojecidynung neblt jwei paar Şen fel, aber, gleid) ber ucufranjofifficm, frine गुijramít. Fig. 10.

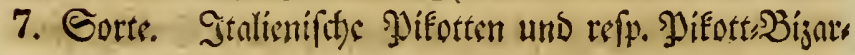
Dent.

a. Erifte Form altitalienifa) zeigt bie liberall

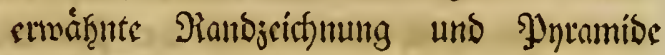
neblt bré pant Jecnfel. Fig. 11.

b. Dicuitalienifd) ober zwoite form frat bei

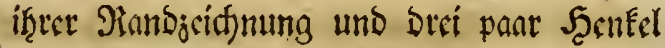
Féíne Dytumibe. Fig. 12.

Scíctmit wåren bie von ber freunblidgen গatur

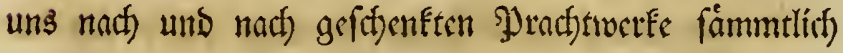

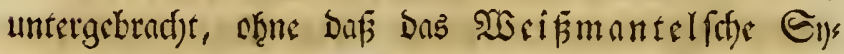

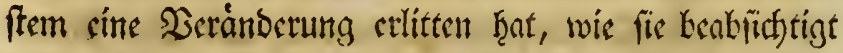
war. Zwwak wollen biefe von Betwunderung ulker bie Maumígfaltigfeit ber verffriedenen Bridmungen finge" riffenen Delfenveref̧rer aurf) nod) in Der furg" uns in Der langgeftriften Pinmbjeiffinung sinen Lnterffies ges 


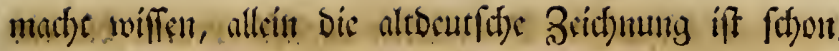
ant uns fiut fiid). felteft fef̧e felten, in ben ad 5. 6. unis 7. Vertandelten Sorten aber formmt fie faft nie.

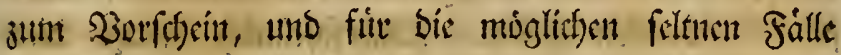

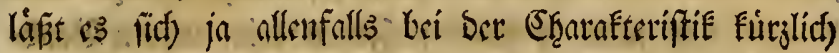

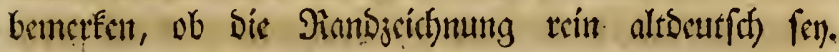

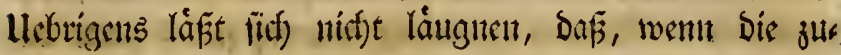

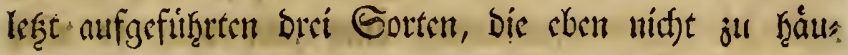
fig arfdyeinen, in fidonen frinen, bidft neben cinander.

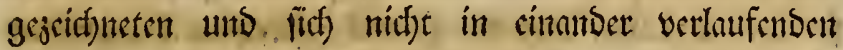

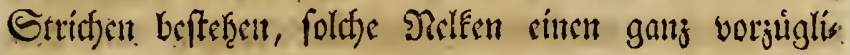
(d)

Ilnter ben fämmelich) vorgebachten Bcicf)nungen

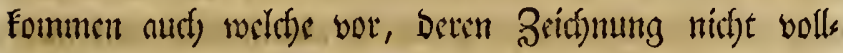
ftändig, fonbern nur mit cinjelnen, meţe ober weniget. fingeworfanen Strichen, jebod) fo angebeutet worden.

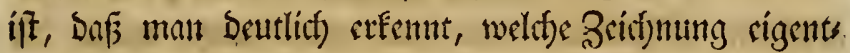
lid) Die Patur hat billsen wollen. Eimb biefellen nidfet

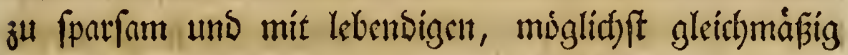

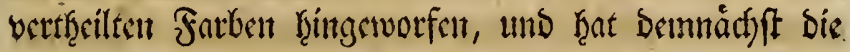

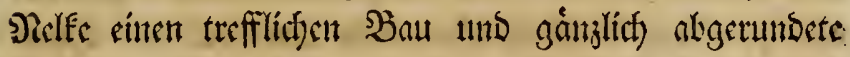

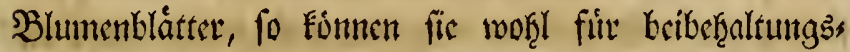
werth erad)tet werbert. San nennt bies cine fparfane

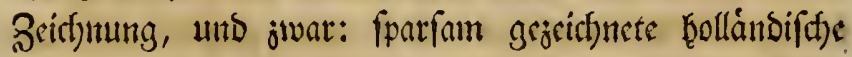

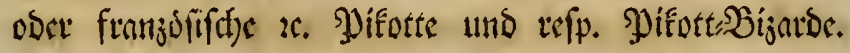

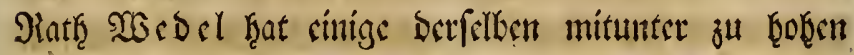
Jrificn verf́auft.

Dritte Dronung. \$andfreifnelfen.

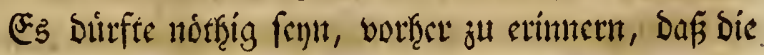

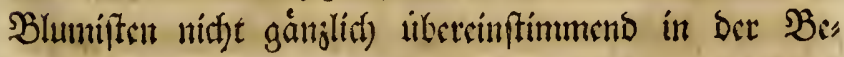

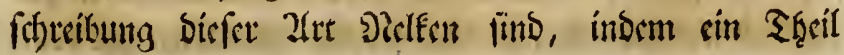


berfelben biejenigen Bantuelesn snglifth nenut, bie ein ftumpf algerundetes Blumenblatt f̧aben, Dagegen bie mit gejáf̨uten ober ausgejnckten SBlumenblättern - beuts

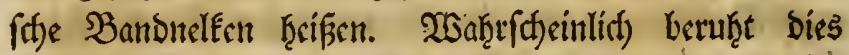
Darauf, Dấs man in fruhtern Beiten Eeine andern Bantos nelfen als mur folthe bulbete, weltife lebiglich) mit ftroh: balmbreiten Etreifen gejeid)net waren; indef F̧atte bas mals die গatur ben Sirlén audf noth nidjt fo viele Farten verlief̧en, wie mir fie gegenwártig ḩaben, uno

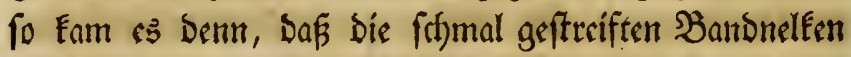
nidjet geachtet wurben. Safęt aber belifen wir bers gleidfen in meţern, ḩódfft abftect)enden Farben, beren

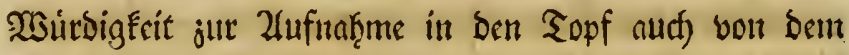
sigentinnigften SBlumenfrante anetfant wits, uns meţs vere berfelleen werden, als ju Den vorjuglicjfert Gels

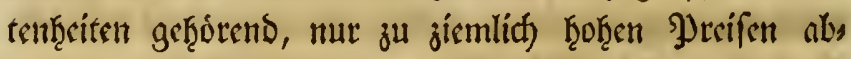
gelaffen. Demnact) Eamn nun woḩl nidft meţi bie Form Des Blumenblatts Den Unterfefied jwiften engs lifa) und beutfeh feftifellen, fondern es muf bicfer Unterferieb vott Der Seichnung fergentommen werben, unt grwar unt fo folgerecteter, als auch) Kci Den Scank;

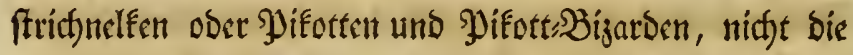
Form bes Ŗlumenblatts, fonbern bie ber Beichnung bes ftimmt, zu weldfer Gorte bie Blume, ob jur beutf(t)en,

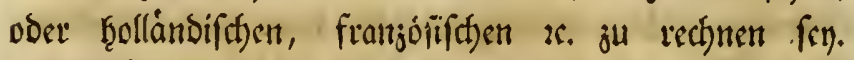

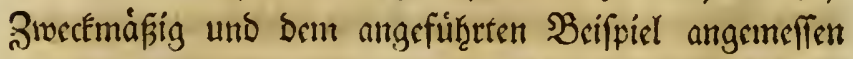
crfacint Daf̧er bie Bewohnnţeit Des andert Tyerils Det

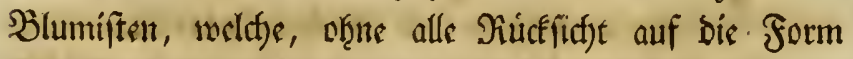
bes Blumentlatts, ob es namlia) akgerunbet ober ges

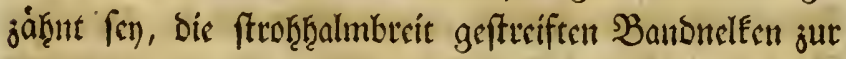
englifden, und bngegen bie fdomal geftreiften jut beuts 


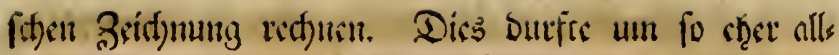
gemein angenommen fu werben verbisnen, ba fefon

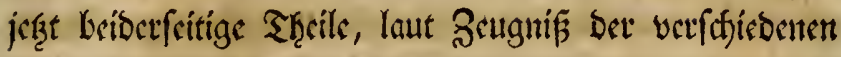

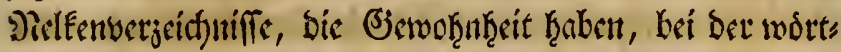

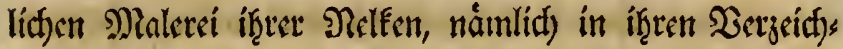
nifien ober Ratalogen, ftets zu Lemerken: ob bie Pelfe ftumpfbláttrig ober sejáb̨nt, faft ftumpf ober Elcinge"

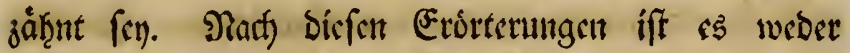

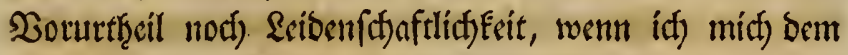

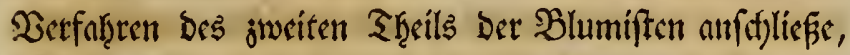
uno fonath, of̧ne Rúcffich)t auf bie form Des ß̉lumen

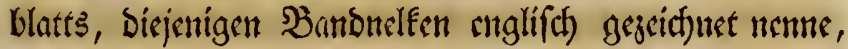

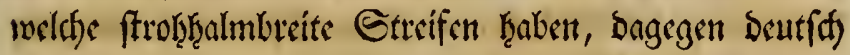

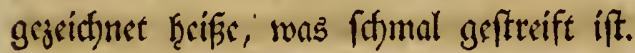

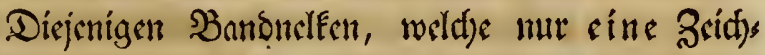
un!ngsfarbe haken, ober als:

1. Ejattung jlucifarbig fins, werden Dubletten genant; bíc

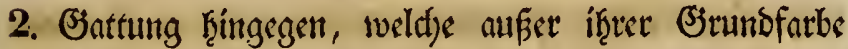
nod) jwei und mef̧ete Scífjumngsfarben vorgeigen, und alfo metruffatbig fino, beifen Bijarben. Je lebhafter biefe Farten find, je meţe lie gegen cinanoer abftertien, je tegelmáfiget fic auf cincm Blatt twie auf bem andern vertbeilt fino, je breiter fie fid) aufgetragen finden, je fujatrfer lie alogefertet uns nicfit in simanoer gefloffen finto, is tiefer fie itt ben Reld) Gíntit geţen uno je reinet cttolich hei allem bicfem bie Stunts farbe ifr, je meţe erficht fich bie Ditle jut Dorjuglidferit, befortors wenn fie aut) 
nod) cin gånjlid) abgerundetes ß̉lumenklnts f̧at. Jjf fir aber mit feinen Etrichen úterlaben, oder gुar mit SुunEten burd)s (d)offen, mectfelln bie Farken nidft in siner

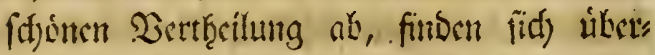
f̧aupt Şefd)affenţeiten gegen bie dirgebad)ten Erforocrniffe, to wirs sine folit) Didlese jur. Iufnaţme ins Gortiment fofwerlid fir murbig erfonnt werosu Eonnen, Kefonts Ders wenn fid) nuch ber Uckelftand ju auss. gezacteter SBlumenblätter kinju gefrilt, weldje jeber nur cinigermâ̄en sigenfinuige Dielfenift vetwoirft, in fo fett nidjt stma cin ganj

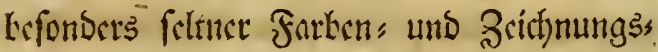

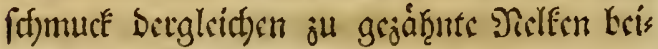

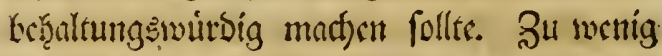
Briffnung entfpridyt clenfalls nidft ben Forberungen cincs richtigen Etfonḩeitge"

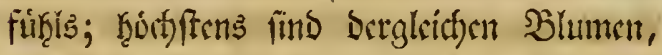
wenn fie fouft alles belifecn, was jur

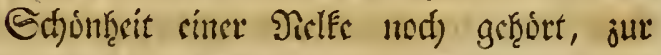

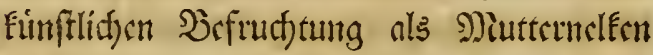

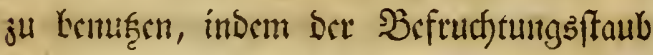
unt bou ben פielfen, bic am tefflidyften gescid)uct fints, genommen werben Darf, auf bic Slutter aber weniger Siucffict)t ju

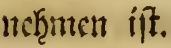

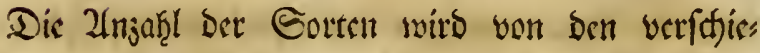
Denen (Grite 18 unt 19 antgrgetenen) Gumbforthen bs"

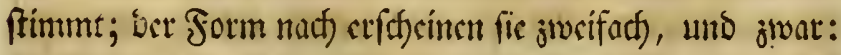
1. Form. Englifdye Dubletten. (Fig. 13.) unto reff. 
Bizarben (Fig. 15.). 2flz fold) 6̧aben fie ftrof̧hূalmbrcite und mur ivernig ober gar Feine famalen Strsifen, Etrids aber gar nict)t.

2. Font. Deutfde Dubletten, (Fig. 14.) und refp. Bijarden, (Fig. 16.). Dicke ḩaben, in Siegenfar ju ben botigen, Iauter fobmale Bambftrifen, mitunter aud Etridfe, bod) nid)t ju viel; breite Streifen aber gar nid)t, wernigftens. nitht auffollent breit.

Sierte Dronung. Tuid) nelfen.

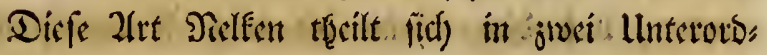
mungen, und fwar:

A. Riandtufdjuclent docr feuerfapen und flamis manter.

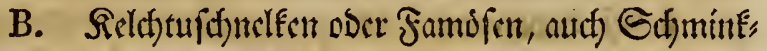
nelét genantrt.

SBeibe 2leten miffen feţe fdjon feyn, wemn fie ciner ausgefudten Gammlung jut Bierbe geteidseit follen, Demn bie lefetem fint ju cinfad), uno bie ct\%

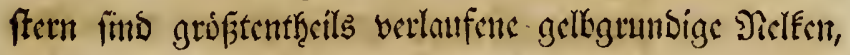
Deren Seidfunng gegen ben Sield). Ju, immer heller

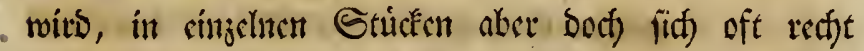
praf̨lents auşnimmt.

Die Rambtuff(t)elfen unterffyeiben fith von ben

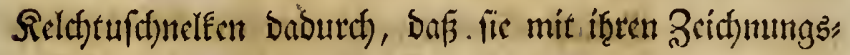
farben vom Siante ab nad) bem Reld)e jul getufd th find unis bie Sichrefeite bes Şlumenblatts faft ourfjaus biefelbe Zcicfnung ḩat; wogegen Dic Beidfunng Der Reldftufduncleen vom Reltife ausggertet uno gegent ben Rano Des SZlumenblatts fich) fo verláuft, Daf ber Ranto 
- felbft bamit unbebecfet ift und fid) in feimer reinen Brunbfarbe jeigt; bie Reţrfseite Des SBlumenblatts aber

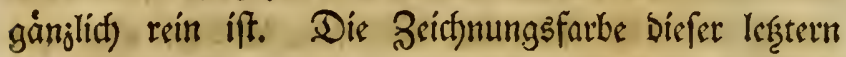

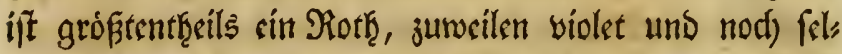

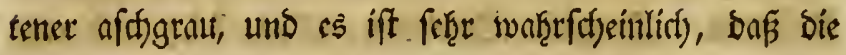
Santur aus if̧nen roth̨", violett! oder aftograugrumbige Syifotten mit weîß ḩat billon wollen, Durch) Den Ein fluf ber Sisitterung aber oder Durd) andere Sufállig" Eeiten Daran berthindert worben ift. Die ţertlic)e Bres noble, pompnourgrundige Difotte mit roeif, iff fáon vou meţreen ß̧lumenfreunden jur Famófe umgewandelt morben, uns bies fateint bie ohíge Betmutḩung bes grunben ju wollen.

Die suftetn betreffens, námliff:

A. Die Dinnotufánelesn,

To ift babon bie

1. Gattung jmeifarbig ober गjifott: uno refp. Dubletts Feuerfaren; bie

2. Battung aber mefretfarbig, uns meroen biefe Difotts bijard: unt rcfp. Bijard: Setucrfarent ges nannt. Die Beid)unugsformen Diefer Well fen, weld)e foft nusfdyliçlict) nur in ben gelben Girundfarben geadytet werbet, fins oder Eonnen bod) eken fo mannigfaltig

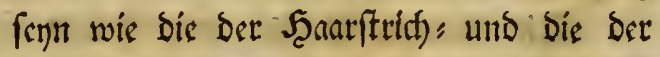
Banbftreifneleen; fie werden Dafger, nads.

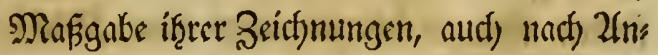
lcitung jener Formen, Deutfdje, F̧oliánbiffue

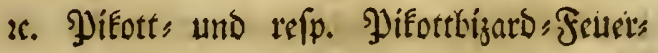
faren, desgl. жc. Dublett, und refp. Bie jurb" Feuetfarelt genamt uno in ben Res. 
talog singetragen. In ben lệtern Fällen,

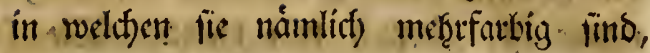
if bie cine Beictunng far farbe immer ges tufath, bie andere abet in fatharfar Etreis

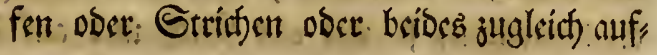
gettagen.

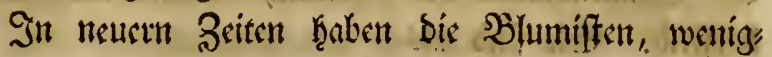

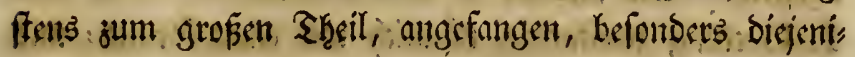

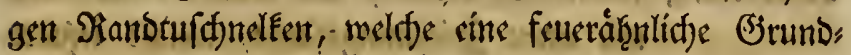

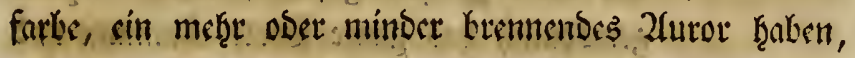
und mit afdjgrau, fupfer ic. fo getufd)t find, baj bie

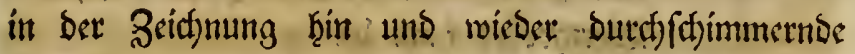

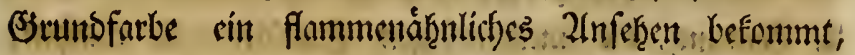

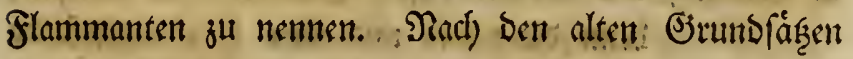
wutroen fie Difotts und refp. Dublett" Feuctfaren ge" nannt werben mulfen, es lafit fidf jebẹt) gegen bic gemáklte Benenmung um fo weniget ctwas Mipbilligen oss bemerten, als auth biefe ineffliche 2lit Ditfen mit

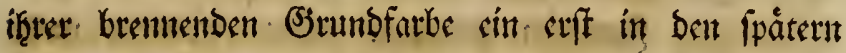
Jaḩeen entifandentes Ecfeffent Der freigebigen, uns im, mer an fich feffelnden Datur ift, uns 2ld)tfame eit verbient.

Die auf Der gemaltent. Delelentnterle befindlidsen

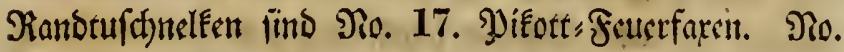
18. B̉ijarb = Feuerfaxen und నo. 19. nebif 20. Pifott: und refp. Dublett: Flammanten.

B. Reld)tufdnelfen ober famófen.

Diefe Bllumen erfdeeinen ḩáufiger unter best weifs als unter ben gelbgrumtoigen Nelén und ḩaben bas Eigene, Daf die Ruucferite Des Blumenblatts-von Det Illuminationsfarbe, mit melther bie Dherfiáche oeffel 
- Len gleithfam nut úberpinfelt, ober angeḩaucht, ủbers raḩmt ift, gänjlich trin Kulcibt. MSie fajon gefagt,

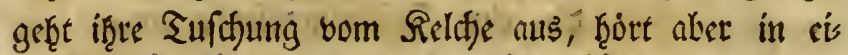
net máfigen Entfertung yoin Rảnde auf, fo baf fich) an Demfelben, fo wic am Relts, uns auf ber Ref̧efsite Der Blumenblätter bie sigentlid) "Otunbfarbe beutlid) Darftellt. Gir fins als

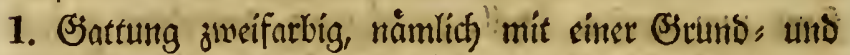
mit riter Seiffinungsfarbe, weldje legetere

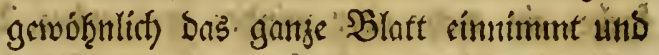
mut folten in pifottirter form erfoseint Weirtf̧uoller fanti bie

2. Battunth, bie methrfarbigen "Tamófen, fie mact)en, Denn biefe find - mit siner. Seifjmungsfartie getuffit und mit ber andern geftrifft, Decty

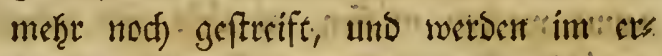

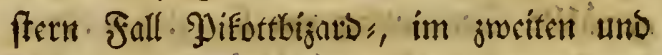
teffer fid) ausneţmenden Fall aber Bijarb\% Famófen genannt. Sic enforbent metrit als jebe andere Pidles cincn fodotten Baar, sin moglichft frumpf abgerunoctes Blu menblatt uns muntre, wof̧l abftect)endec Farben. Fig. 21. ift citt Suft $=$ uno 22. cine SBijarb: Famofe.

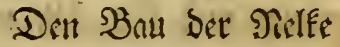

Letreffens, to jaffilt man Dabon fieten berfechicbene Rlafs: fen, von Denen bie brei erfterti bis kelieberfent fint, bie Drei leşten aber nur unter gant befonderti פeeben umftänoen, bie in bie 2lugen fallens fenn múffen, ges Dulbet merden. Sie finto

1. Nelfenbau. Şci bemfalben liegt Şlät auf Şlatt. 
foft fo wie cint Biegclbact), fiud) आufs

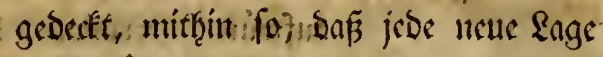
ber Blåtter iur sintem gleict)en Berthált"

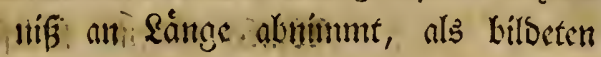
fie Iouter neue Biffel, weldfe immer

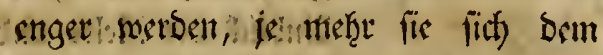
Diittelpunte Der Dielfe náh̨ern.

2. Pinnunfelbau. Dis Şlumenbldttst liegen ebenfalls nuf sinamber, jeopidy nicht fo bidjt,

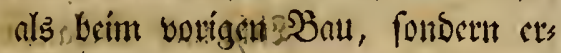

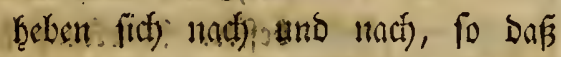

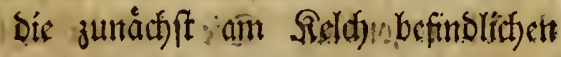
Blateter aufied)t fteţen uno bie ganje Sberfáactbe Der.jBlume cine lucken, lofe Shalbfuget bílbet, Donfer man bicfen trefflityen Bau aud) Şalbeus gelbau nennt, bor barum am mes, ften geffáąt witos, weil man faft auf jedem Blumenblatt bie volle Beictunung úberfeţen Faun.

3. Regelbau. Die áufetn B̉lumenblátter legen fida meţe ober weniger flact), bie imnern

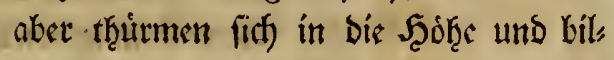

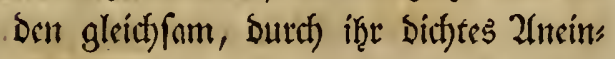
anderfdjließsen, sinen aus bem Relth ber Blume lifferthebẹenden Thutm oder ßegel.

4. Piofenbau. Der Pions Der B̉lumenblätter Erúmmt liif), wie bei ben Rofen, nufwárts, es mufz bies jebod) uict)t ju viel gefd $)$ ehent, weil fonft ber grófte Theil ser Beid)"

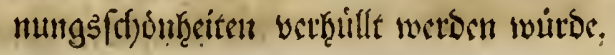


5. Triangslbau. Die Esiten Der Blatter meroen fo aufmártz gefrimmt, baj jie ohen in ber Nlitte- Des Randes cinen fpifen

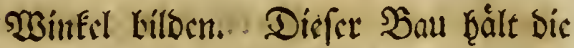
Zeifthung verborgen, raulet ben freien

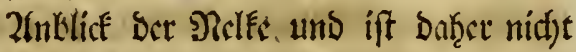
febrelickt, am crften inder nod) bei ben viclfarbig beutfal grjeidjneten Banondfen, wo bic 2(frwect)silung von Ridft unt Edjatten fitc Das Zluge cine beffere Troirfung bervorkringen fam.

6. Dartngonbau. Dí åuß̧ern Şlumenblätter legen

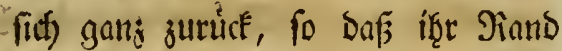

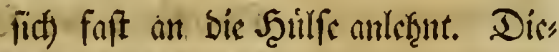

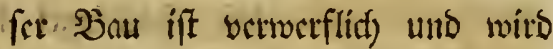
nur nod). Ké ben feltnen fotwarza gumbinen Farkennelesn fir Lribe: bृaltungsiverth erachtet.

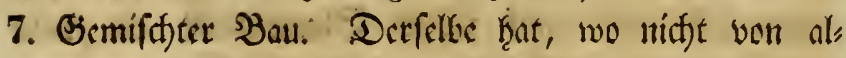
len, bod) bon meḩectn ber ofges Dact)ten Bautrten etwas án fict), und indent bie Dafere cutrfitfectioc

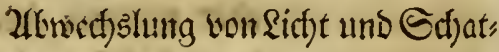
ten bir Sialctei Der farben el" bৃdf̧en fann, to ift bicfer Şau bei Den bielfarkig beutfd) grjeids: neten, afdigrausn uns fupferfarts grumbigen Bigarbin trot) aln füglidyften ju bulben, aud fann Das Infercen bei Tufd)famófan hei Demeltben geivimnen. 


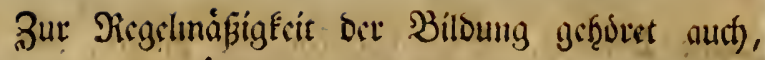

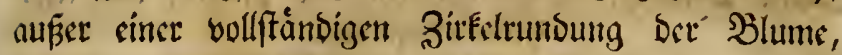

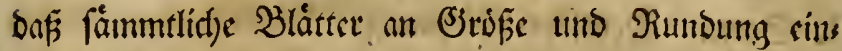
ander gånjlić) gleich). lino uns auf Dem fleinen. Blatte

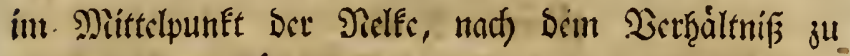
Den: grópern Bláttern ober im verjüngten Miafffake, bicfelbe Malcrei fidfthar fery. Enolid) wuitbe ber befte Bau uns bie trefflichfte Bcict)nung verlieren, wenn bie Dieles Eeinen fteifen, Dis Blume aufiectit trägenden,

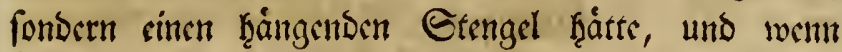

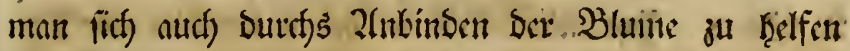
furdet, fo bleibt bés boch immer sin grofer llebelftans,

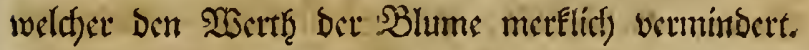

शach) allen bicfen borangefdicftent Evórterungen

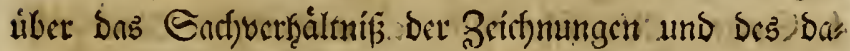
bere georoncten Gyftems, wollin wir bafictlee, ju cinct

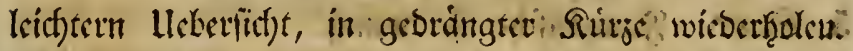

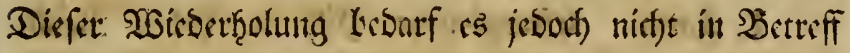

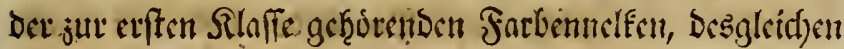
fonnen' wir lie bei ben jut erften : Hnd vietten Sob"

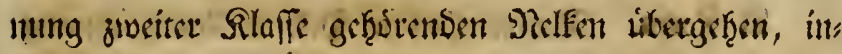
bem jene gebrangt genug angegetsen unt nud) titche

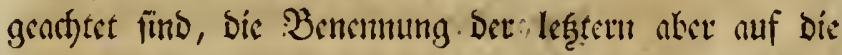
Der jwei mittlen Droumengen, ivelteje: body immer Deb

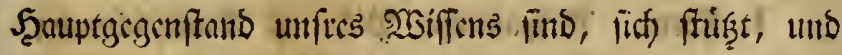

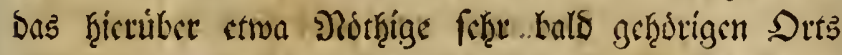

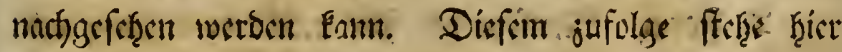
jucenf bic 
Droite Oronung. Şaraftriffuclfen oder Pifotten uns refp. pifott = ¿̇izarien.

1. Gorts. Deutfite Brichung.

1. Form. RanbfaumpiE. Dorr ac. Gaben blos ge" fáumten Ranto.

2. Form. altoeutfde Dif. ober x. Eaben furge Pianoftriffe.

3. Form. neubeutfde গ̧if. xc. bis gegen bie Şálfte Des SBlumenblattż reidfende Randftrict)e.

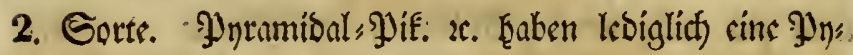
ramide, Librigens aber sin ganj reintes ßlatt.

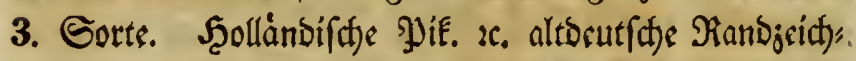
nung uno Dytamioc.

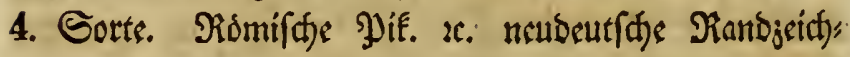
nung und Jyramibe.

5. Gorte. Framjdiffe Beiffinung.

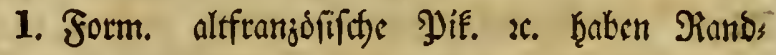
jeiffnung, Dyramibe uno sin paar ŞenEel.

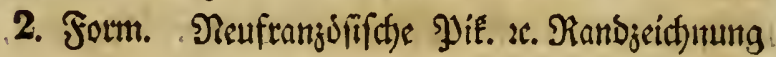
unt sin paar Şentel, jeboch Éine: Yytramíbe.

6. Sorte. Spanifhe 3cictmung.

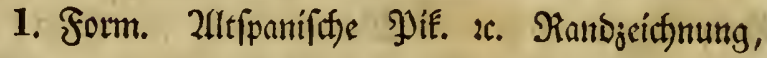
Dyramide und jwei paar SeenEel.

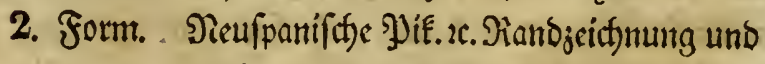
jwei paar J̧enfel, aber Écine Jynramide.

7. Sorte. Stalienifate 3richnung.

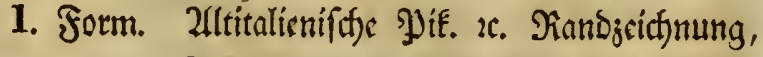
Dyramide uno brei panr Setenkel. 


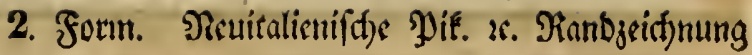
und Drei par Scenfel, jebod) Esine Yyy: ramiber.

Dritte Dronung. Sandfreifnelfen qber Dubletten und refp. Sizaroen.

1. Sorte. Dubletten.

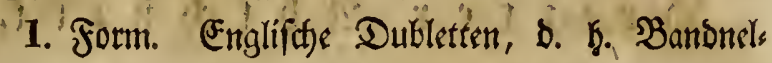
Een mit englifftser Bertanung, fanben ftroh̨halmbureite Streifen.

2. Form. Deutfite Dubletten $x$. Faben nur fifmale Etreifen.

2. Sorte. Bizarden.

- Ebenfalls in 2 Formen úbereinftimmeno mit ber vorfteţenden Beidmung,

ad 1. Englifthe Bizaroen mit ftroḩূ̨almbreiten, uno ad 2. Deutfide Bizarden mit fafmalen Etreifent uns mitunter Strictert. 


\section{Dritter $\mathfrak{A} \mathfrak{b} \mathfrak{f} \mathfrak{d} \mathfrak{n} i t$}

Don Der Befbaffengeit und aubercis tung Der fúr Releen taugliden ExDe.

7) Blumenfreunto am angelegentlityften fenn muß̧, ift: fid) sine für feine Blumen tauglist) (Erbe zu verfd)af:

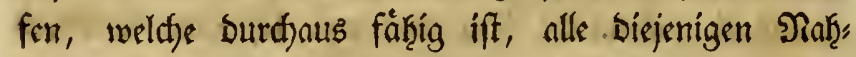

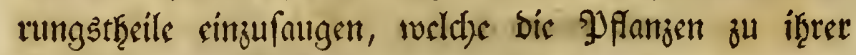
Ernåḩrung bedurfen. Das Bufammenbríngen bet bas zu fid) signenden Eubftanjen ift Feiner befondern Maike unterwoorfen, hingegen ift Die Dzifffung Derfelben etwas fot)mieriger und fann rine biesfällige Gidferţeit nur Dur(f) Llebung unb aus ber narf) meţrmaligen Derfus den ḩervorgegangenen Evtfaḩrung erlangt werden. Der Blumift muf nidft allein fafwere uno leict)te Erbarten volfenmen gut unterfd)ciben lernen, fonocrn aud) mifs

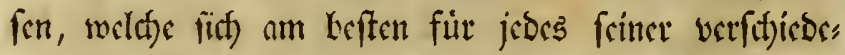
nen (Sicwád)fe rignet, um hicernad) Díe Mifajung ver"

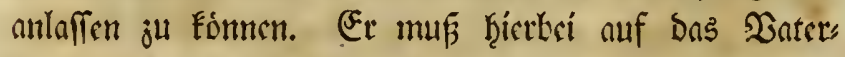
land und ben urfprunglicfen Standort ber PुFnze zus

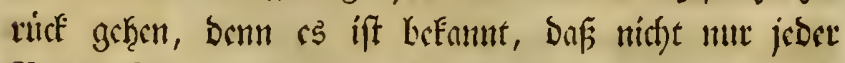

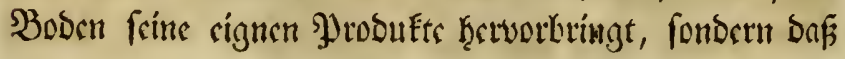




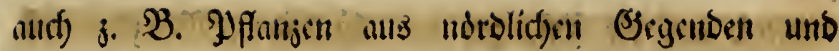

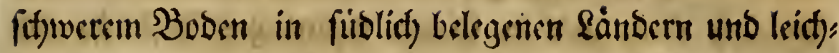
ter Erbe iveniger gut fortfommen; umgeffertert aher an

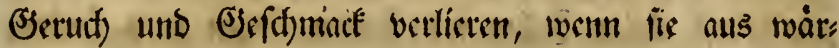
metn Segenden in cin fálteres Rlima verfef̧t werben.

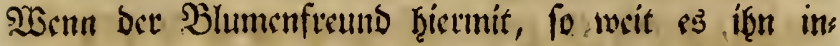
terefiirt, cine Runbe von ben wefendidgen Beftands theilen unb Eigentḩüulid) Esiten ber verfd)irbenen Şaupts Erbarten und waj jede befonders nüręt uns leiffet, fid)

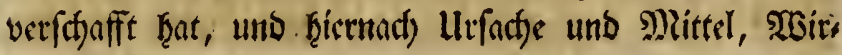
fung uns Sivest geţorig vergleidft, fo wirb ar un to firtret im Stmbe frnn, fict) sine Erbe ju berciten;

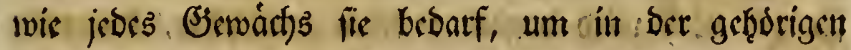
Wollfommentheit unt Fülle wad) fen uns blühen zu foms

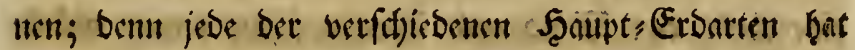

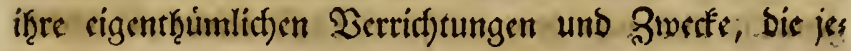

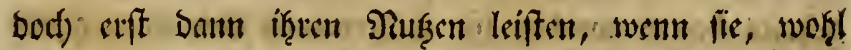

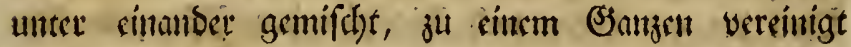

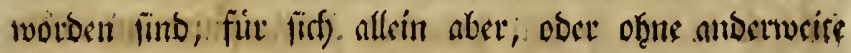
Bermifd)ung, gat nidyt ju braudjen fins.

Der Eeḩinbodent 3. 2., ber fid) buth feine mef̧e doet weniger gelbgraulid)e Farbe, fo wie burd) feime fette

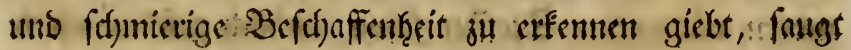

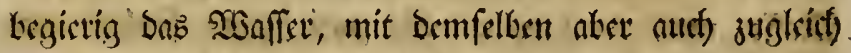

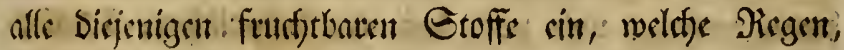

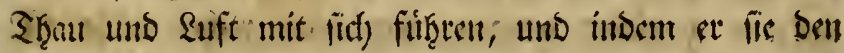

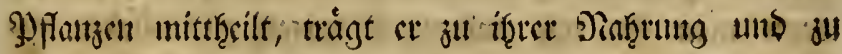

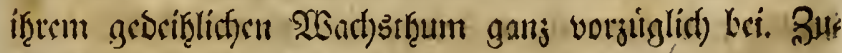
gleidf) beḩålt et bie cingefogene focud)tigfsit längst als jebe andie (Erbatt an jid), swiberftef̧t aud) mef̧r bem Eintoriltuen ber heifan Eommontraf̨len, wirft fonast) 


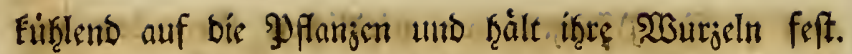

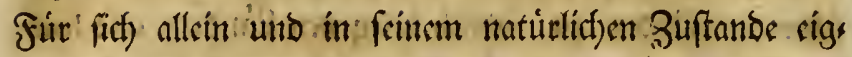

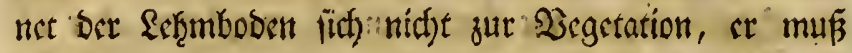
zuborborft sinige: Snhtere im Frcien lieginn uns fauleit, vom froft mirbe gemadtet uns ifters umgearbeitet werber, Damit cr rect) locker und zugleit) von ben

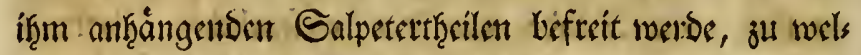

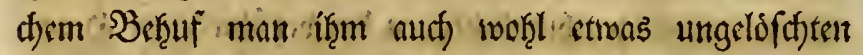

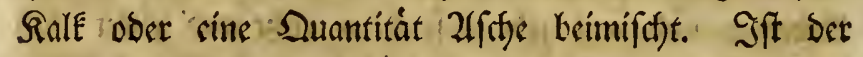

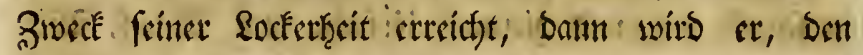
úbrigen : Erbarten in ciner getrórigen Duantitát beige

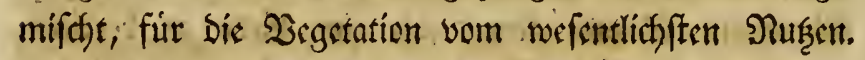

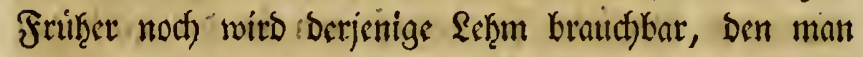
von alten Bjcbáuben uno Bacḱfóft nimmt, inbem ex

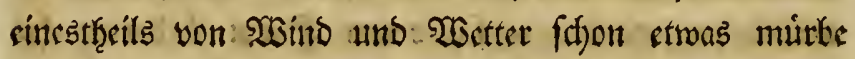
gennadyt uns bon: Dem grof́ften Theil feines Galpeters geţalts befreit worben ift, andernthecils aber cincit guten

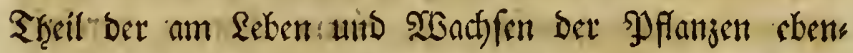

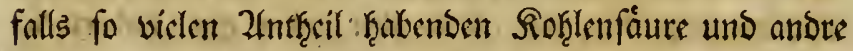

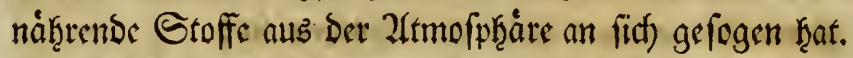

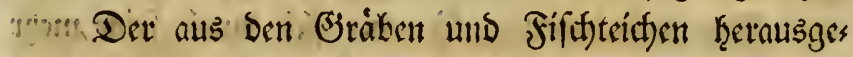
holte Sd)lamm, cbenfalls sime leţmige, jebod) mit

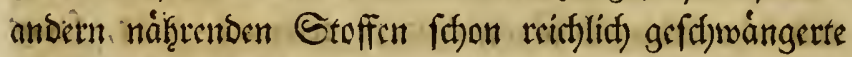
Maffe, muf cbeinfalls cin bis jwei Sahre faulen, gut Durefyearkeitet uns von barunter befinblict)em șaffers unfraut gereinigt werben, Damit et rectst milde ift, wenh man thn mit anden Erbarten ju mifhaen ges Denft; umb Dann ift er Ecinestwegs ju verachten. 1.) Die Riefelerde oder furr Den Blumiften Der Gano,

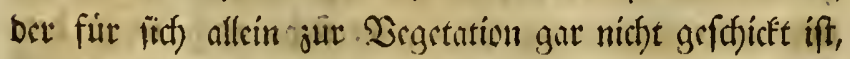

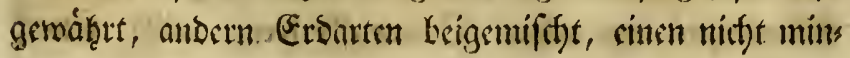




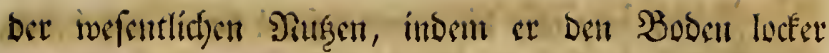

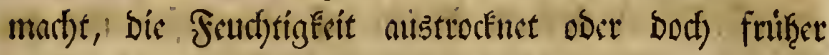
verbunften lápt, uns fonad) bie Billbung Det Den (Je;

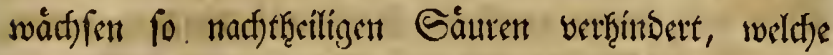

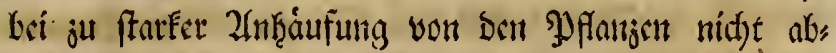

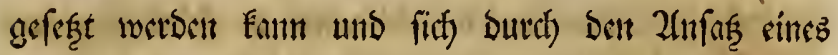

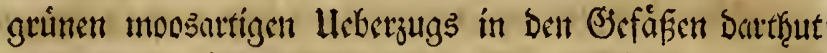

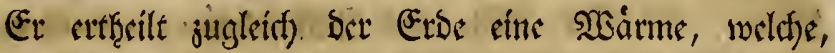
áberfinaut genommen, bas fráftigfte Mlittel ift, bie

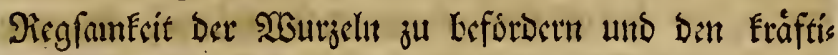

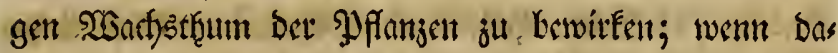

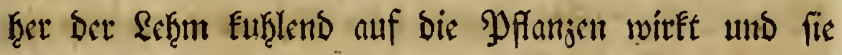

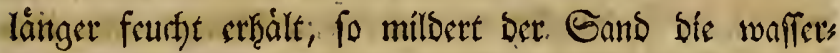
faltende Siraft, uns mit sinander berbunden wirs bie

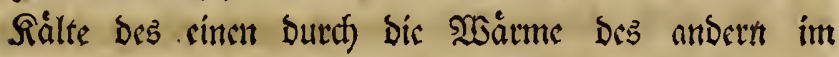
Slleid)gemid)te crḩalten. SBevor jebuch der Sand ges

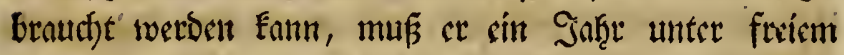
Scimmel gelegen baben, Dann aber gut ausgewaffjen uns von Den fleimen Gtrinten uns fonftigem UIntath gereinigt werben. Der flup̧ans ift ber befte.

Die Ralferbe, eine feine fraubige Maffe, beren

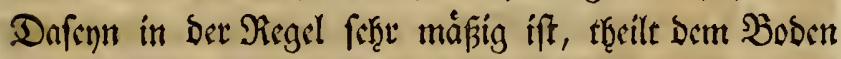
cbenfalls Wánne mit, milbert feíne Feudftigfecit, mad)t

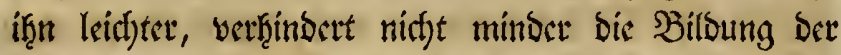
Gáuren uns beforbert yor allem bie 2luflofung ber Dungfráfte, baf̧er bie Dungung Der Ferber und Tstes fen mit Ralk, (Jips, Xff $)$ e u. f. w.

Die Bittererbe foumt cbenfalls nicfet báufig yor,

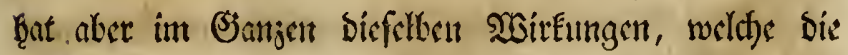
Ralferto betworbringt: Gio ifi fiir ben Blumiftent : Eein Begenftants siner fonoerlid)en ß̧endfuntg. 
Diez ıåren mun Dic Şauptheftandtḩcile, nus benen

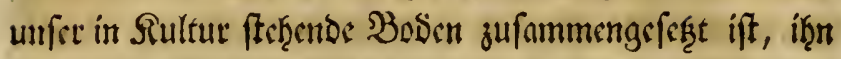

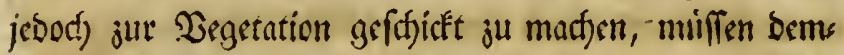
fellen nody antore tauglid)e Gtoffe brigemifots weroen, uns bies gefficht burth ben Dinger. Der Blumift gevinnt benfelben nus verfóiebenen in Fäulníß úlers gegangenen Eubftanjen thierifaner unb vegetabilifater

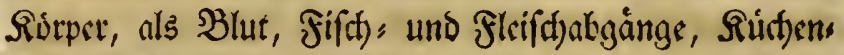
fpúlig, verfof̧lte uns jerftopene Snoctien, Saub, Siras,

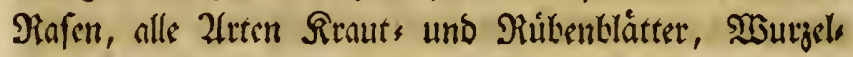

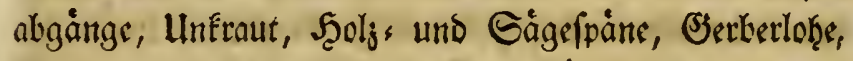

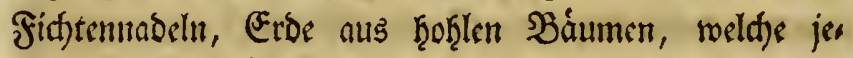
Dod), nid)t hinlänglid) verrottet, eine গ̧isiege vislen Uns

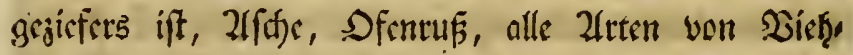
bunger, bod) vorgugstweife ber ftrof̧lofe Ruţmift, $u$. bergl. meţt: 2alle biefe Dinge werben im fogenonnten Unfrautsmngajin, bas. ficifit nuf cincm bem Regen und Dert Ruft jugånglidjen, bod) mur cinige Gtunden bes Tages ber Eonne ausgefȩ́ten Dlaf̧e jufanmmenges

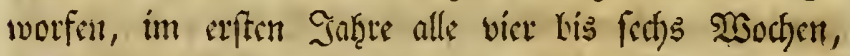

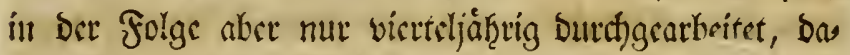
mit alles wobl unter cittunber gemengt werbe, und menn tie nacf) Werlauf von Drci Jah̨ren firf) gánzliaf) nufgeloft b̧aken uns wertottet fints, Durdy sin bei ben

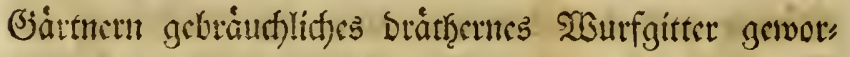
fent unb bant crff ins cigentlid)e Erbmagnjin getbrat)t, um jur 3eit Des Bebarfs ben librigen Erbarten beiges mifidt merden zu Émen.

Diefe Keidfte, locfite, ben sigentlidfen Nathtungs:

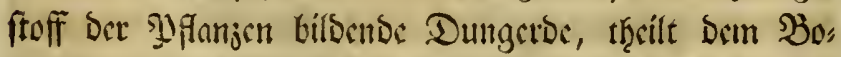

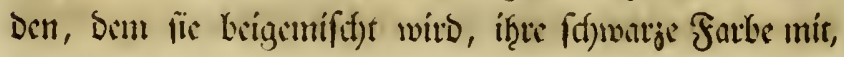


eenlanbe, cs Fommt Daţer mut Darauf an, if̧re Quans tität genau beurtheilen zu Énnen, um hierentad) bie noth crforberlition Bufáse anderer Erbarten ju madjen. Seat

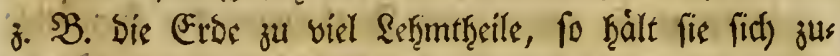

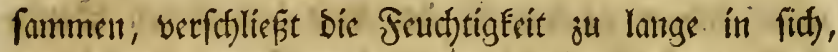
wird leiftet fart und riffing und bedarf Dahere bei ber fernern Mifanung Feiner Sef̧mtheile meţr; ift fie hins gegen leidjt, locker uno bals trocten, fo trat fie zu vies len Gand bei lifi) und bedarf Davon Feines treitern 3ufazecs." "Eine gute Erofe Darf weder zu locker nod) ju leidjt fenn, fie mus weder ju feft jufammentialten,

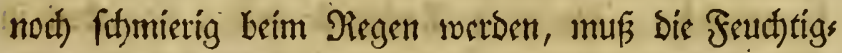
Eeit : nicht ju fancll verbunfen laffen, Demnád)ft sime

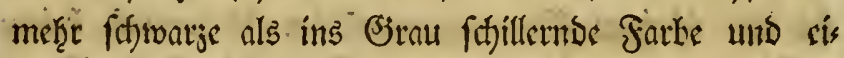
nen guten, fráftigen (Boruch ḩaben. F̧at man num in Folge Diefer Beobactutungen gelemt, leidfte uns fdywete Eroe ju unterfdjeiben, fo wirs man nat) eitigen Wers

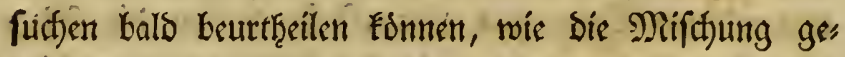
fajeţen muife. Diefe Erfaḩrungen laffen fich allenfalls

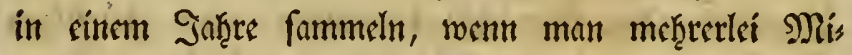
fojungen marbt, in jede Derfelken Syflangen von ciners lei 2 rt, Wuths und Gtárfe verfeçt, unto beobad)tet,

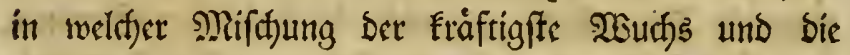
vollfänoigfte flor errcid)t wirb. Diefe Mifídungen

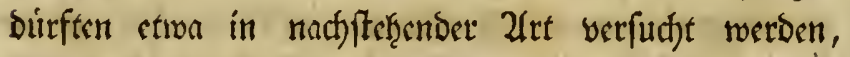

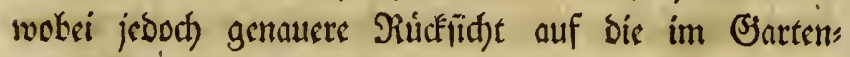
lanbe fajon vorţandenen Beftandthcile ju neţmen ift,

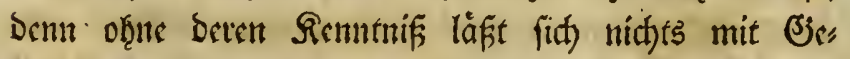
nauigfeit angetern, fondern bas llngefạthe mur butd) Fingeroigige andruten, als: 
1. 5 Theile gut Durthgenvorfene Bartentertoe.

$2 \frac{1}{2}$ bíz 3 Thęile Dammerbs aus besm lltts Etaut= Mlangazin.

1. Theil vertotteten Sefemboden.

1. Theil geteinigten STSafferfand.

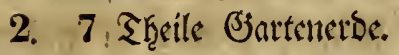

4-5 รhcile Danmerbe.

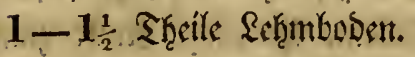

$1 \frac{1}{2}-2$ Thcile Gants.

3. 8 Theile Gartentoden.

4-5 Sherile Dammetde.

$1 \frac{1}{2}-2$ Theile \&ef̧metds.

$1 \frac{1}{2}-2$ Threile Gant.

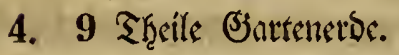

5-6 Th氏ile Dammetos.

2 F̧cile Eef̧mboden.

2-Thcile Gans.

5. 6 Theile Şattenerde.

3 Ţ̧cile Dammeros.

1 Tḩeil \&ctrmboden.

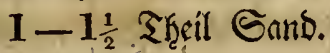

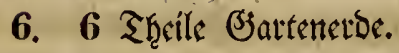

4 Tecile Dammetos.

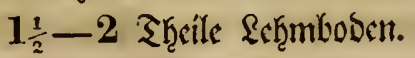

1-1 $\frac{1}{2}$ Theile Gand.

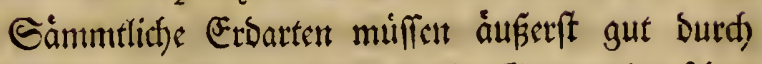
einander geworfen, und im Fall bie (J)artenerbe fid)on

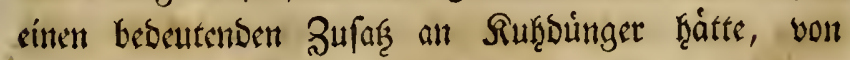
"Derfertben ein Fleineter Shycil nus Dem Mingajin beige" mifat werben. Die Beftandtfeile des Bantentodens

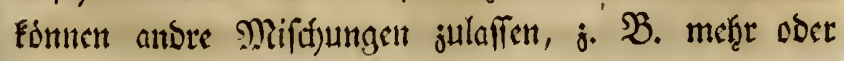




\section{6}

weniger \&eḩmboden oder Gand x.; an ben gimftigften Erfolg aber hált mant fidf feft. Becfonder llmftánde

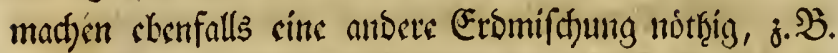

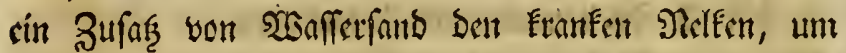

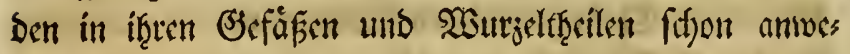
fenden fáaulnífiftoff wo moghlíf wicber ju entfernen, Die 2fusbuinftung ber Pflanze meţr ju beforbern uns

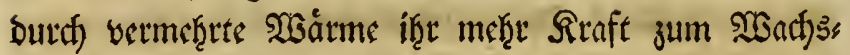

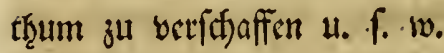

Die alte, ître buingenden Sirafte in bie गJflan, zen abgefertete und Daḩer ausgefogene Erobe lemuf̧t mant

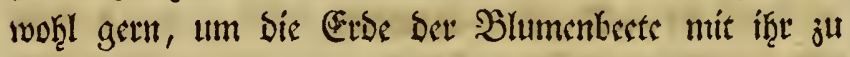

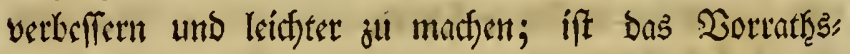
magajin jebod) nidjt ju teichliá) gefúllt, fo láf̈t mant biefelbe unter freism Şimmel auf cinen Scaufen jufam" men, von Zeit fu Zeit aber buth sinander werfen. S⿹at fie in Dem Beitraum cincs Sommets - uno cinen bis

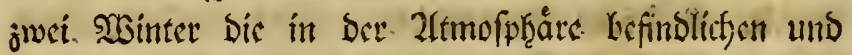

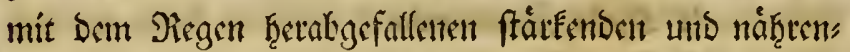
Den Theile cingefogen, fo fonn fic, jutt Scálfte mit neuer Ertoe ober $\frac{2}{3}$ Derfellest vermifdet, wicderum jut Topfoetpflanjung angewendet werben. 


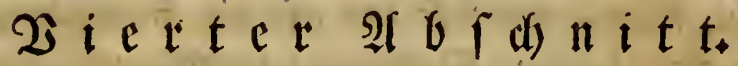

Standort und 2 Babl ber Blumenge" fáke, und Zorficht beim Zerfegen Der Relen.

a

ufer cinet guten tauglicten Eros ift jum bef fert Fortfommen Der Siclest und fämmellid)er SBlt:

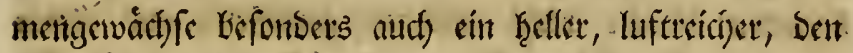

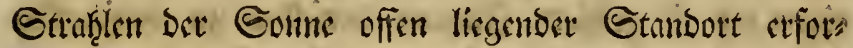

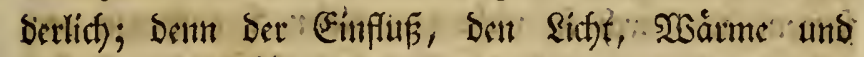

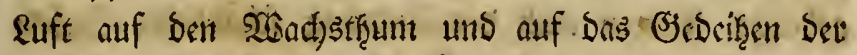

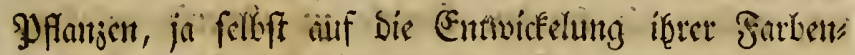

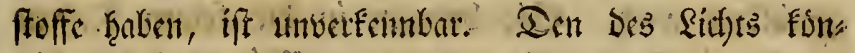

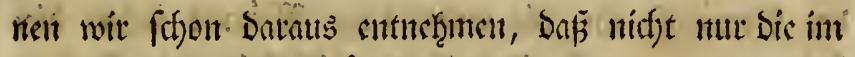

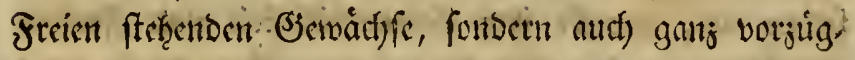

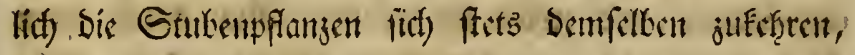

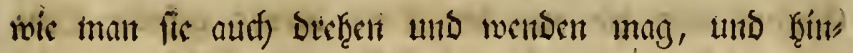

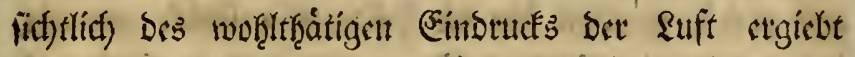

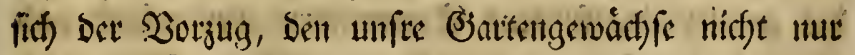
grgen unfie Topfpflanjett, fontsern auth gegent bícjes nigen im Wotaus bzaken, bic an cinter, fuft und Sonte entbeŗentoen Etelle Des Battens oder ḩinter ciner biefe tidjt julaffenden ḩohen Mlauet aufgeftellt doet ge" 
pfianje fteţen. Dis Farbenentwicklung betreffend, fo feţen wir, wie bie Det Eomme hingerid)tete Eeite unfes

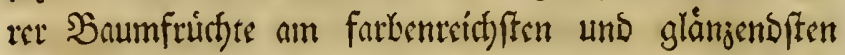
ift, wie bagegen alles bleid) und matt mits, tvas z. $\mathfrak{B}$.

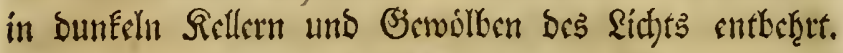

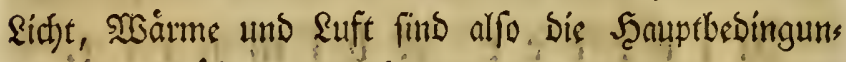
gen cincs Eráftigen Wadjstţums ber DPfanzen, fie nur wectên, vermeţren und erthalten Das Reben Derfelten,

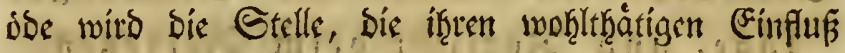

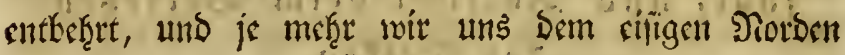
nåbecn, je Eleiner atit Exuppliger finsen wir Die Der Waarme fid) weniger erfeuenden, ful lange unter bem

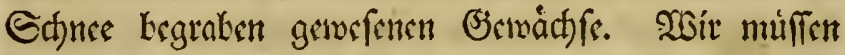
baf̧er rine ganj borjugliche Eorge tragen, baf unfre Sopfgerwádble biefe in Der פintur am allgemeinften vers breiteten Siáfte rect) reicflid) geniefen, und if̧nen cinen um fo grófectn Zugang Derfelben ju verfat)affen fuchen, als burd) fie nicht nur viclen Rrantf̧citen vor:

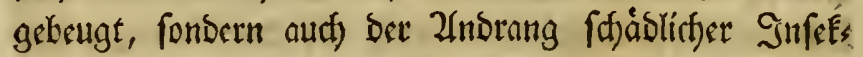
ten, weldbe die franfen Stucke ju allererft anfallen, gemintert wirb. Sir Dringen in Die feimen Mothren

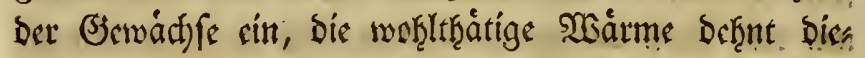

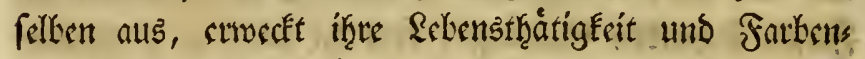

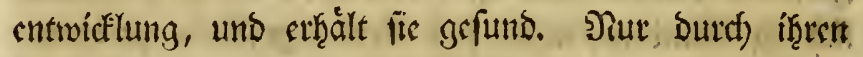

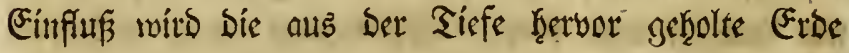

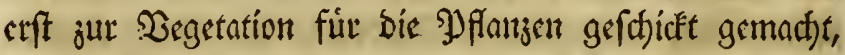
bas ju tief cingefuneme Ganmenforn aber erfticft und geḩt nicht nuf, wenn

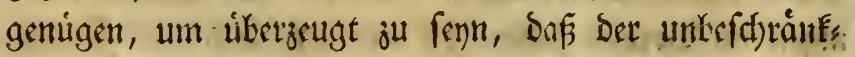
tefte, Der freiefte Plas im Sorten jur 2luffitellung ber Şlumentráget gewáblt merbent múffe, jeboch) ift aud) Darauf 
Darauf ju feţen, Daß $\mathrm{ar}$ ber Eonne nicht länger als

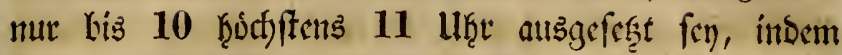

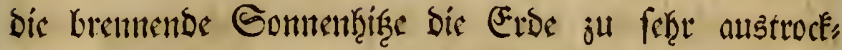
net, bie Birfulation ber Gáfte verminbert, bie flúfiig?

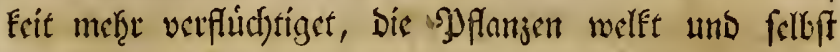
Die farbent Gleid)t, auff alle Fälle aber Die flor zu Feţr

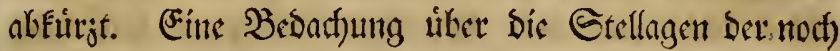

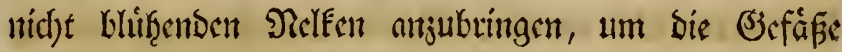

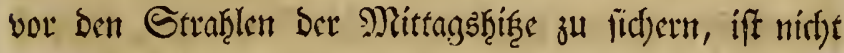
wob̨l anjurathen, índem fie immer Den frsien \&uftjug

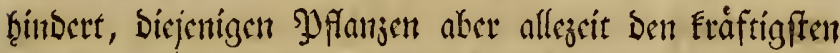
Mad)stţum zrigen, bie gänjlich) firi fretren. Eeffatten aber Die Lage des Startens und anore limftánoe nitft, bie Stellagen anders als in bie शiáţe cintes von ber Sonne zut fetre georicteten Şaufez ober Mauer aufjus fitllen, to wito es freilit) notf̧wendig, fie mit einet Bebacfung ju verfecten, weldfe jebod beweglid, bas

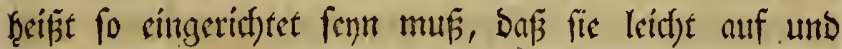

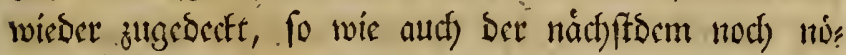

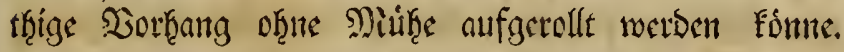

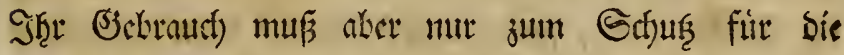

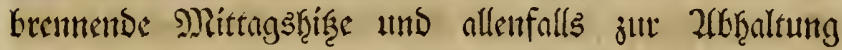

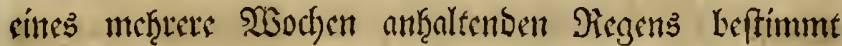

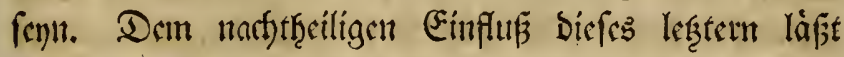

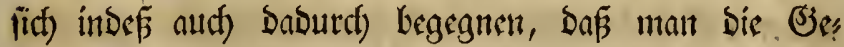
fáfe mit guten 2lbzugslód)ern verfeţen láft, bei lán: gever Dater ber naffen Witterung aber fie nuf bie Geite legt und in biefer lage fo lange läjt, als bie Umftande es erforbert. Ein Gtandort, auf Dem bis

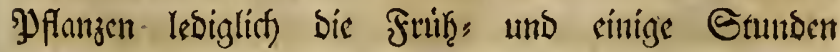

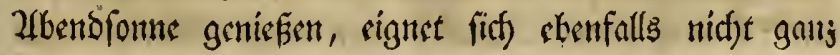


für fie, indom hier bie Erbe ju wenig crwårmt, bie

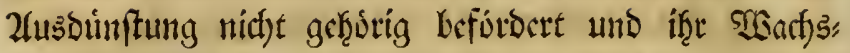
thium aufgcḩalten woirb, fo Dafi man fpatev als rath" fam ift, jum Einfanfen ber jungen Tricke gelangen

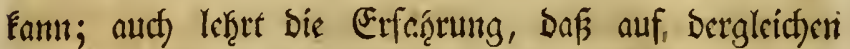
Stanborten wegen Des längern Werţaltents Der Jeud)"

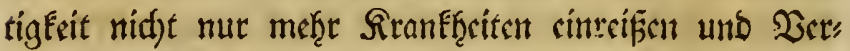

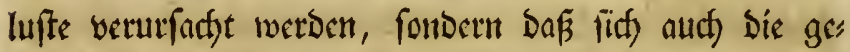

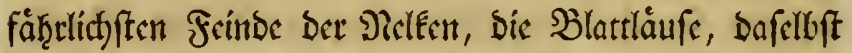
am erften cinfinden und am fdyroctfen wieder ausjus rotten jins.

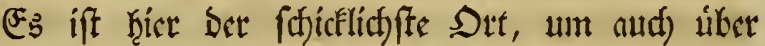
Die Eilurieftung ber jwetmáfigiten 2lut von Blumen, trágetn cinige Worte ju fagen. Das Beftell Derfel ben muf́p treppenformig angelegt werben uns aus vier bis finf Grufen beftef̧en, auf beren jeber jwei ctmas

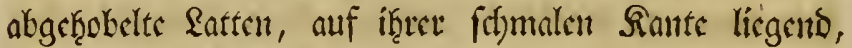
zu befeftigen fino. Inrglcit)en Sráger geftutten nidft nur liberall cinen frein Rufroug, und bie auf ben vor:

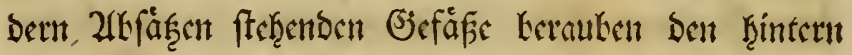
bie Gonne níft), fondern bas Troffer fant aud) ubet"

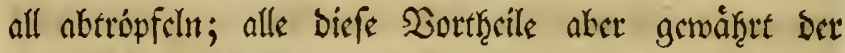

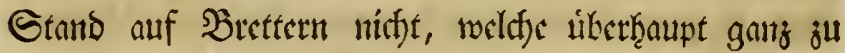
verwerfen fint. Die Füfie der Etcllagen muifien ents

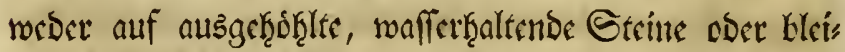

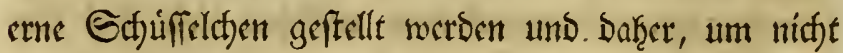
fo leifyt ju faulen, von cidfnem Scolje fenth, ober man läft etwa in ber Mitte berfellben blect)erne Befäáfe bes feftigen, Die ftets mit Waffer gefüllt fernn múffen, um

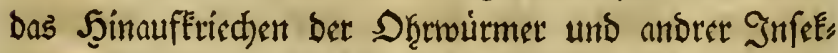
ten ju verfindern. Wolle man bicfe Sorkefrungen 
nud) nidist an allen Etellagen treffen, fo jint fie bods bei bem Tráger anjutatţ̨en, auf weldfem bie blúf̨en, Den Dieleen aufgeftellt werben.

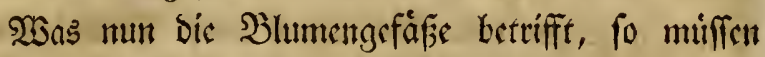

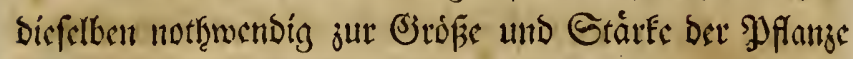

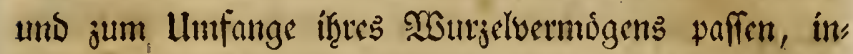

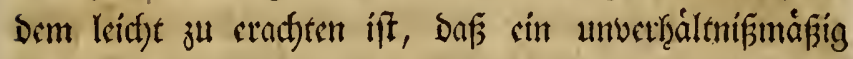

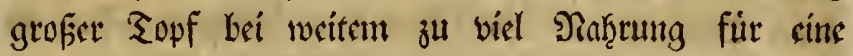

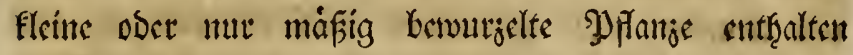

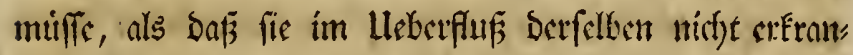
Een, warzelfaulens werben unt abfterben follte. M)an

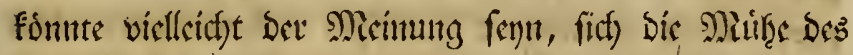

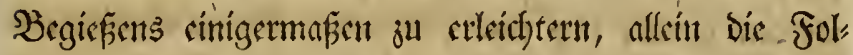
gen cíner ju langfam vor fich) geţenben כetarbsitumg

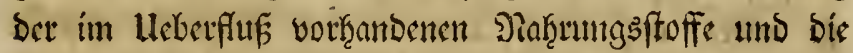
langfome Zustroctuntng ber Eroc, fint ju naţe mit Dem گerluft, befonbers ber jårtliffern Gorten verbum,

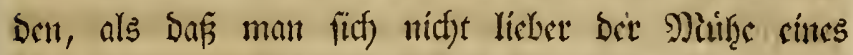

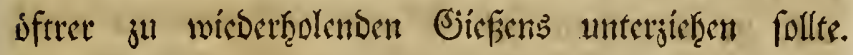

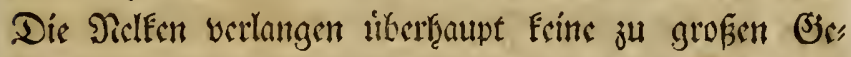
fápe, fondern wach) fen tippiger in Den fleinern, (bie

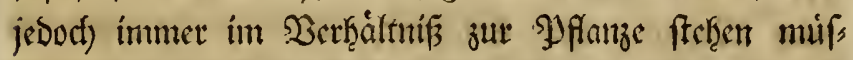
(en), inbem fie bie Feuthtigfeit rafther alsbunften unb

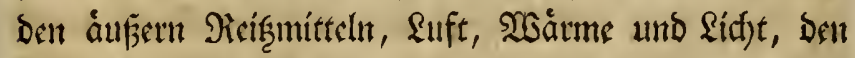
3ugang crlcichtern.

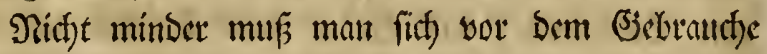
zu ftark' gyebranter, mitf̧ín zu, fefter, allenfalls, für

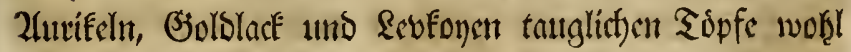

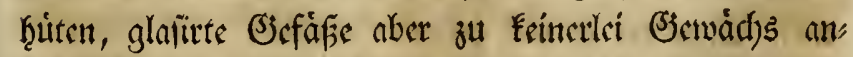
wenden, Denn fie entrialten fämmetlid) zu viel Rálte,

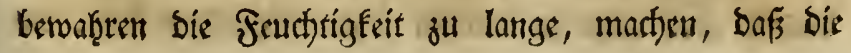




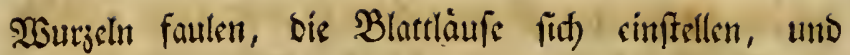
thecilen fonad) alle bie Hebel ber ju grofen Bisfäze in

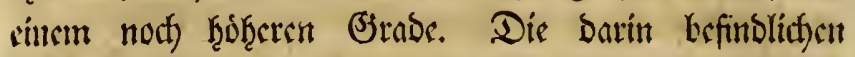

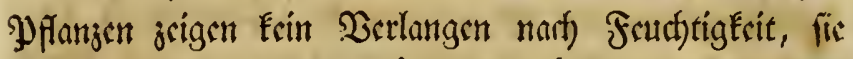
werben Kleich) uns f(f)wáchlich, Eränfeln und frerbern langfam baf̧in. Ulm fie wo moglict) nod) ju tetten, ift nichts bringender, als fie fofort, und jwar fifon

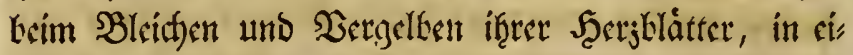
wen fleinern, leidjt gebranten Sopf ju verfescut, vow ber ater bis Eranfen, wáfirig angefdyollenen Tsur" jeln, fo vial als nottrig ift, ju befaneiben uns ber Evide etroas methr geteinigten fluffants beijumiffact. Eis

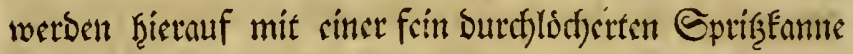
máfjig libergofien, und bamit ber Richtreís meniger auf fie roirke, auf sinige Tage in ben Schatten geftellt. Gollte bas llikel fifout ticfer cingemurjelt fenn, fo

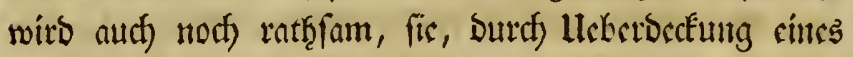

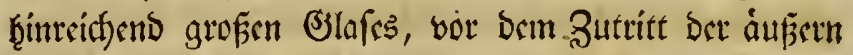
Suft zu verwahten uns fo-alles Mlógliche ju thiun, was if̧r Eranff̧after Buftans crforocrt. פiad) Derrlauf yon cinigen Tagen rublet man fie in bie Fruffonture und

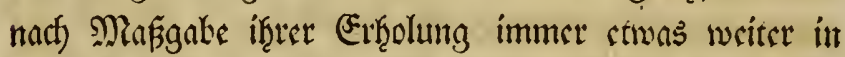
berferlben vor, tränft fie von Seit ju Scit, je 11 actjorm

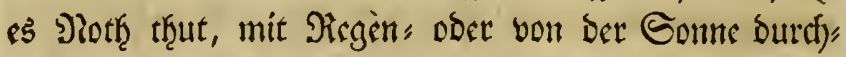
wårmtem Jllufwaffer, uns wenn bei biefer forgfălti:

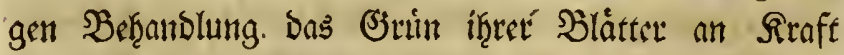

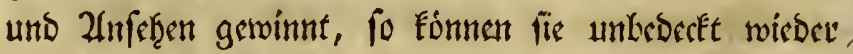
an Suft und Sonme gewdfhnt und fobann auf incent alten Standort jurucef gebractit werben.

Ein tauglíctes Şlumengefáp múz juar feft ge"

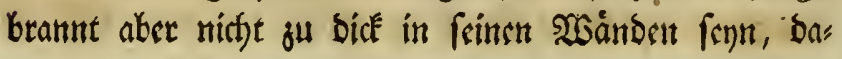


mit es fid) in bit Eoune nitjt ju fihte prthifen, bages

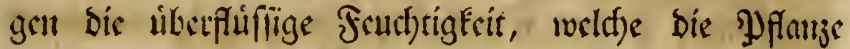
nicht cinjufaugen vermag, geb̧oríg verbumften, ber

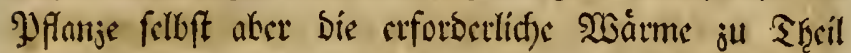
werben Eann. Sm Zllgemeinen ift bic palfandfte Srófie Der Blumentipfe cine Şôhe von 5 bis $5 \frac{1}{2}$ Zoll und cine SBreite oben von 4 bits $4 \frac{1}{2}$ und unten von $3 \frac{1}{2}$ bis 4 3oll. Eilinderformige Sópfe trocfnen mínder gut

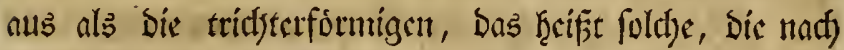
unten ju cincu gernden, ja nidf)t baudfigen 2(bfall ḩa

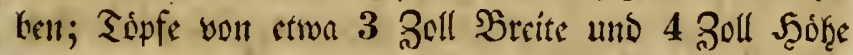
cignen fid) fuir bie flcinern uno fdswád)ern (Stcwådffs, besgleichen fur bic 2 nfertigung von Ed)nittlingen obor Gtopfern, alle aker miffen cin geråumiges 2(kjugslod) mitten im Boden yon ber Giofife cincs 3weigrofdem ftucfs, unt bie grópern nod) cinige fleinere Seffnum

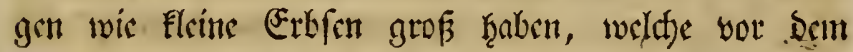
Einfüllen Der Eroe mit Edherben ju belegen fino.

Der verderblidyfte Fetcler, Den man beim Derfas̆

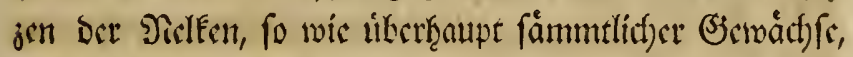
begrţen fann, uns weldyem man ben Derluft feimet vorzuglieffifen Ricklinge keimeffen barf, ift Das ju ticfe

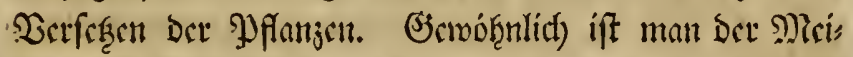
nung, baf bie Eroe fid) nod). Fe(zen, nod) ticfer liid) lagern wetbe, unts bief geffrichtet aud) nllerbings, allein

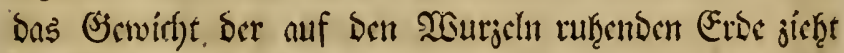
bic Yflanje chenfalls hৃetunter, mitţin bleibt fie in bet

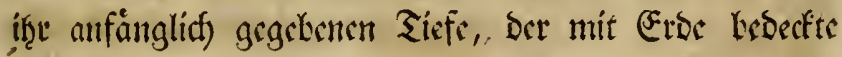
Edyaft der YPfanje wiro des ftärfenden, Kelebenden

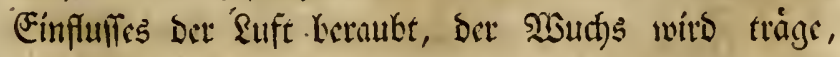
bie Blatter fangen an jul vergellect uno fid) bectak j!t 
ḩàngen, bie jungen Triebe vertroefnen, uno geḩt ber Stock nod in ben Epindel, fo freigt er langfam unto in mattgruiner farbe empor unts bíe Yyflanje ftirbt,

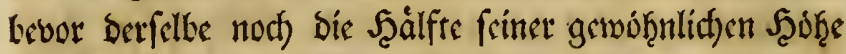
erteicht hant. Die beffern Gorten gef̧en gewodhntid) jus erft ju Serunde, inderm fie in ber Megel aus einer zu

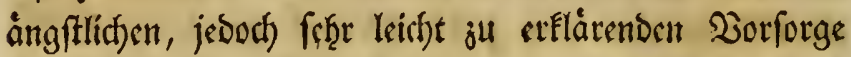
in sine befondre Sbḩut genommen und verjärtelt vees Den. Man muz Dafere alle Gorge tragen, Daß Feine

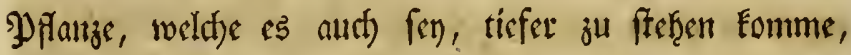
als fie urfprunglich geftanden hat, und foll ja cin feth;

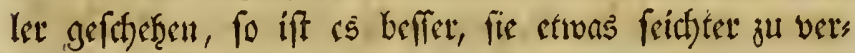
feşen, weil man es ímmer in bev Seswalt bef̧ålt, fo viel (Erbe, als nod) erforberlid) (enu módte, nadjuls

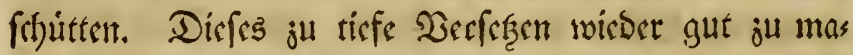

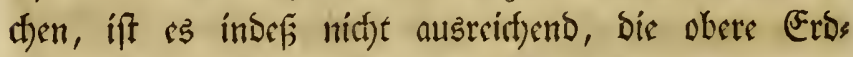

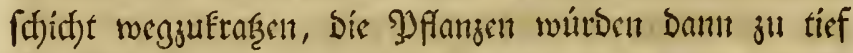

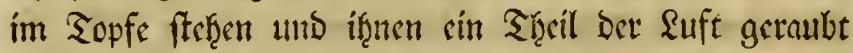

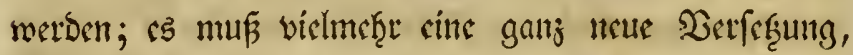

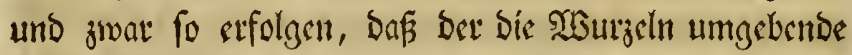
Ballen Erose fid) nicft bedeutent abbrocfle und bie פyfanje fo uenig als moglict) geftort merbe. Sollten bie Mus" zelfpifen fat)on in Fåulnif̧ úbergegangen ober wáfirín

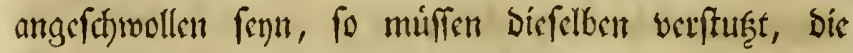

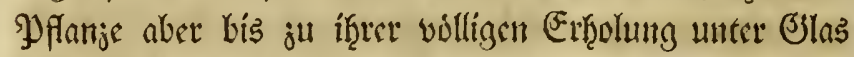
geffellt werden, und blof Fruffonne genieferen.

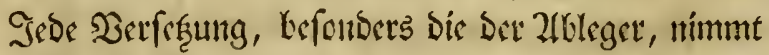
man lieber Des Nartmittags vor, in fo fern Diefrlbe an warmen Gommertngen gefdientet, indem fich) bie

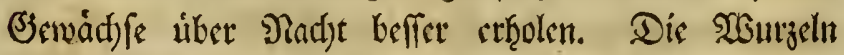

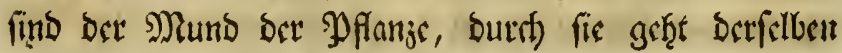




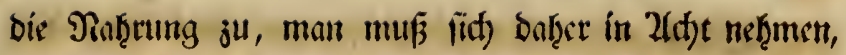

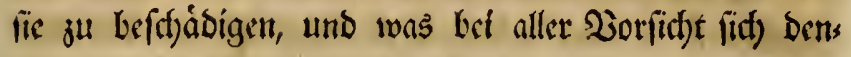
nod) verlef̧t ober gequetfot findet, mußz man mit sis

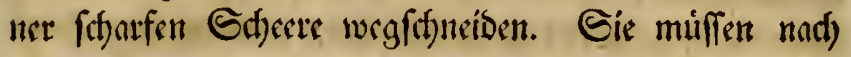
allen Seiten fín ausgebreitet wetben, befonders bie

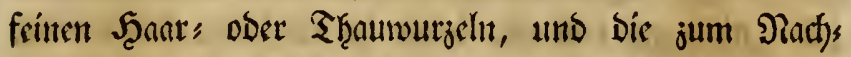
fúllen beftimunte Erbe mußs móglidgft gut gercinigt uno trocken fenn, Damit fich biefelbe liberall anlege und in

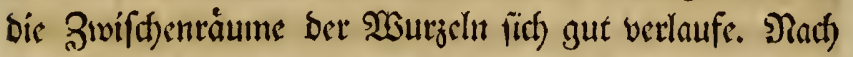
Dor Werfeçung vertrocknen bei jeder SPflanje wenigftens

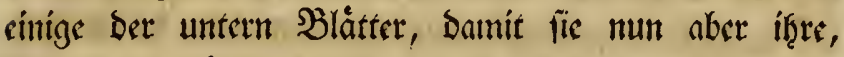

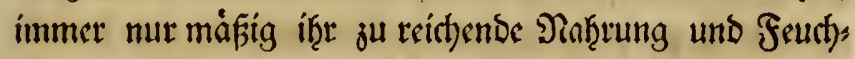
rigfeit nidf)t unnotrigig cinfauge, und bicfalbe ben fie

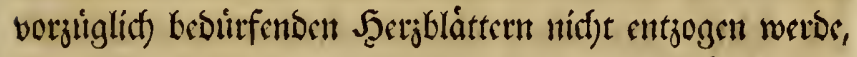
fo verfiurze vitan cinen Shcil ber untern Blątter, bie allerunterften aber fancíbe man ganj bidft am Gd)aft oder Gtamme ab, Dor) of̧ne benfldeat aud) nut im

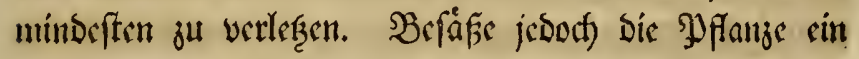

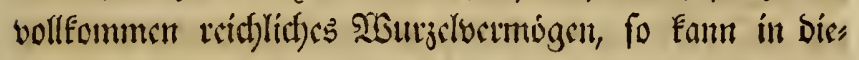

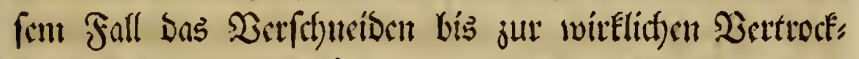

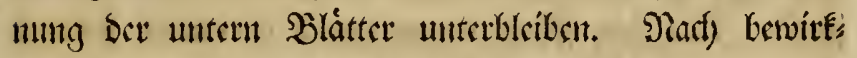

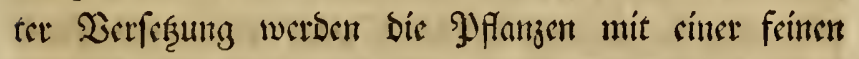
Epríféanne geţurig begoffen, Damit die Evide lich ben Wurjeln vollends anfdrlieffe, und bann auf cinige Tage in bent Ecfjatten geffellt, um Die ß̧cwulgclung mef̧r ju forbectn; was aber etwa anfángt zu fránfelln und

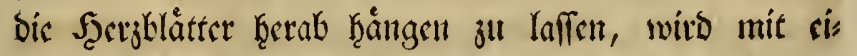

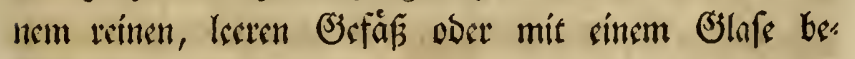
Decft.

Mas Das Serferzen ber alten Etodefe betrifft, to nimmt man benfilben juvordentf bie alten, vertrodine" 
ten Slátter ab uns rénigt lie von allem stmanigen Unratf, fteflt fodann ben Topf umgefetret in bie linft,

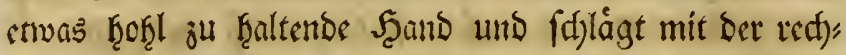
ten auf ben Boden Des Gefáfäes, worauf Der Stod mit Der feft jufammengeballen Eroe, in to fern bies

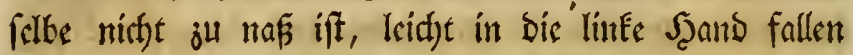
wirb. Sft bie Eros ju feudte, fo barf eine Derfez" jung nidjt vorgenommen werben, Denn vermoge if̧rer Edfwere mutro life aus sinander unts ju Sboben fallen, bie mun von Erde entblófen WOurjeln aber Daburdf leiben und Der Gtock tweit fofwerer jut SWiederfefts wuirgelung ju bringen fenn. Die àuß̧ern, ben ß̉allen

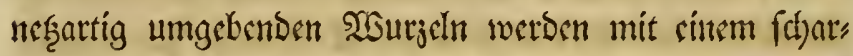
fen Mlefer bon allen Geiten akgeffunitten, alsbann

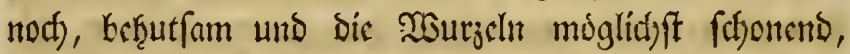
fo viel Erde abgebrócfelt, Daßj Der Ballen bie Etárte

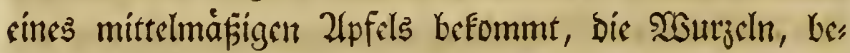

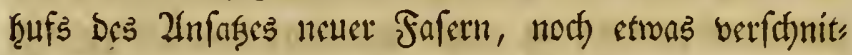
ten und fodam in cinen, feiner Jirófe angemeffenen

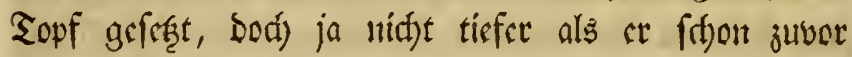
ftand. 2lus ben fabon angegebenen Sruinden fouttet man um bie șurzeln herum zroar frifd grmiffate, bod) abgetrocknete Eros und bewieft Durd) Silopfan

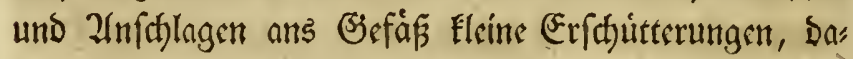
mit bie Erobe alle Riaume ausfülle, Demnaidfif aber verfåh̨rt man mit (Sup uno Gtandort nad) Der (d)on oben crtheilten 2Inleitung.

Die erft bom Suni an blif̧enben Siswåd)fe, mits

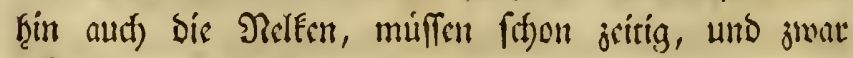
fpáteftens ím Zlpril verfef̧t werben, Dagegen Diejenigen, Deren Shlif̨jeit fruffer sintritt, erft Hach) becnoigter 
Tlor, bis fpateftens jur Mitte Des Eeptember ju vet:

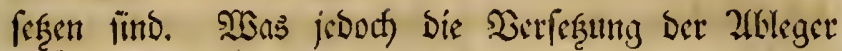
uno Erfunttlinge ober Gtopfer anblangt, fo mur bies

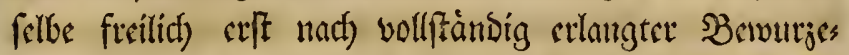
lung, unis jwar immer fo bewirft werbent, daf fie vor Dem Zusgange Des SEtober beenter fen, Die 2lnt

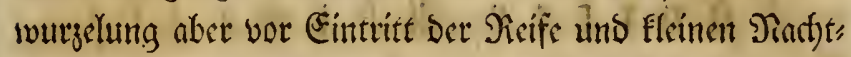
froffe Statt gefunden ḩabe, weil mit Demfollen bie Eirfulation Det Sáfte vermindert und ber Rukceftand Der Pfanjen herbei gefuhtet wirb. Llebrigens (d)aben Denfelben bic fleinen Froffe Ecineswegs, fie werben im Bezgentheil alogeţátet unt weniger cmpfindlid) für bie

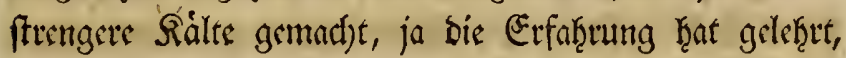

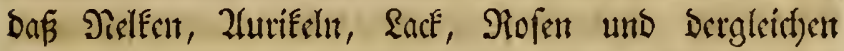
(Jewád)fe Keffer uns leid)ter bluf̧en, wenn fie juvor

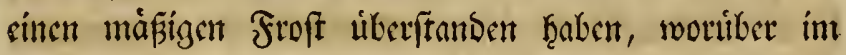

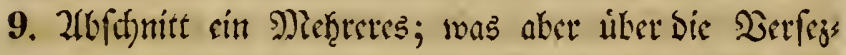
jung nod) weiter ju figen ift, wiro ber 7. unts 8 . Ibfornitt entḩalten. 


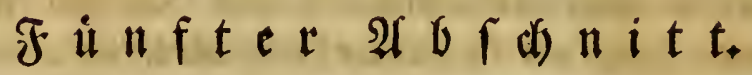

\section{Das Giécen der Yflanzen betreffend.}

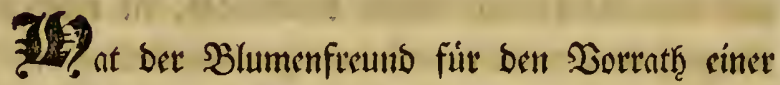

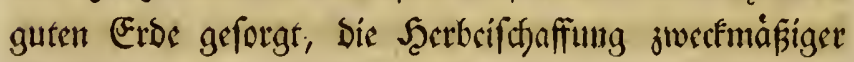
₹üpfe fidd) angelegen fenn laffen, bie Sçanbgriffe siner

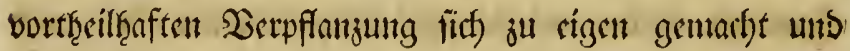
cinen Etandoot fuir feine Topfyflanzen ausgemittelt,

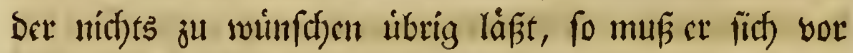
allen Dingen nod) mit Len Erforderlitb) feiten simes

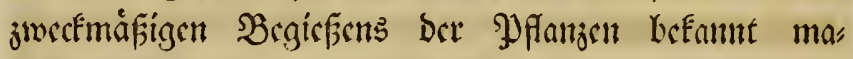

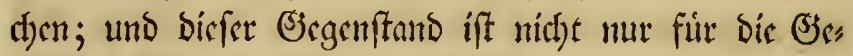

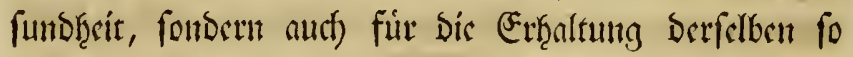

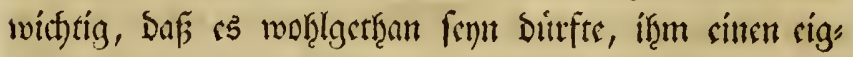
nen 2 lofit)nitt ju wisment.

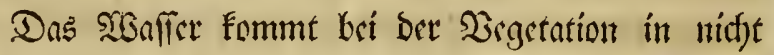

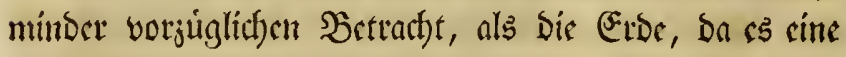

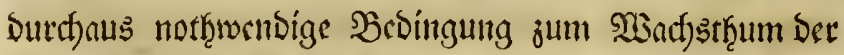

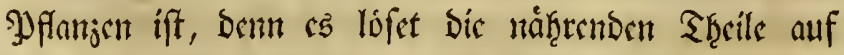

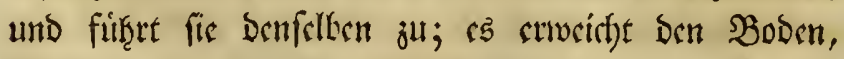

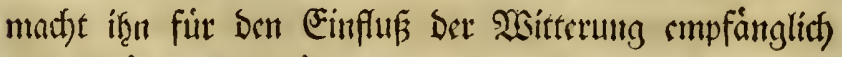

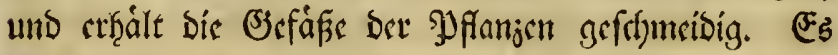

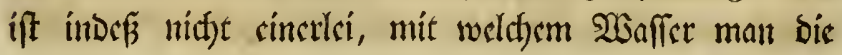




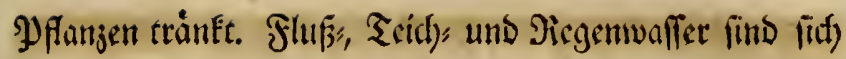

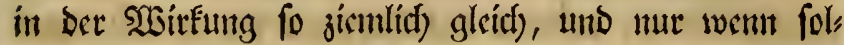

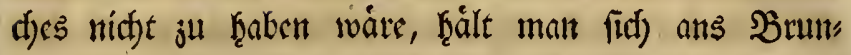
nemwaffer, es muz baffelle jebod) 24 Stunden vorther

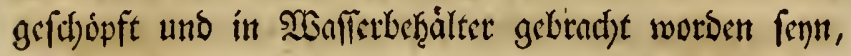
Damit is voillig uilerffanden uno feine Salfetterile ver: Dumftet Fabe, von fuft uno Sonne aber Durdjwàtme uns millser gemad)t worben fen. Sim Winter ift nod-

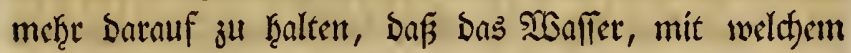
man giesect, sine móglicllft gelinde Temperatur babe, uns follte fold)es erft frifth hecrbei gef̧olt worben fenn,

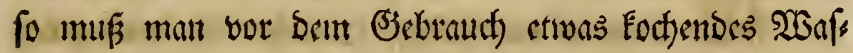
fer zugiefent ober, not) beffer, mit sittem gluhents ges mad)ten Eifon ss absunften. Zus gant matirlict)en

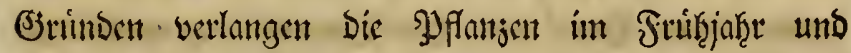

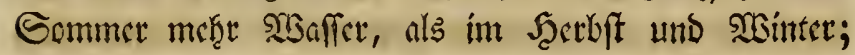

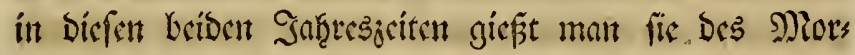
gents DDer Des Dormittngs, itt Den erffern beiden aber

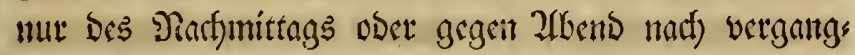

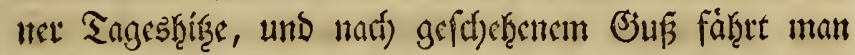

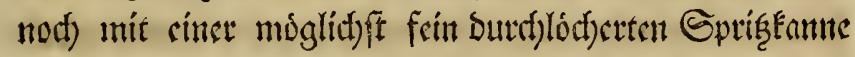
liber fie her, um auff bas Sirnt ju crfrifd)en und ju

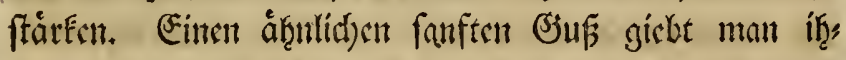
nen in Sen hecisen, Die 2lusbsinftung ju feţr forbents ben Gommetmonaten aud) Des Nlorgens, bevor bie Goune inte Gtrafilen auf fic werfen Eam, Kefonders

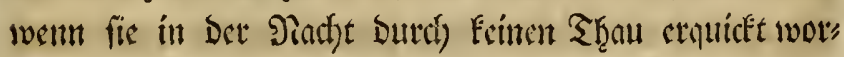
Den wáren ober unter ciner Bobacf)ung geftanden háts

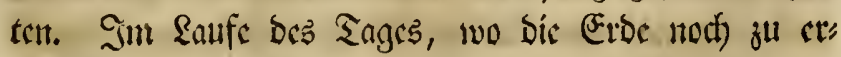

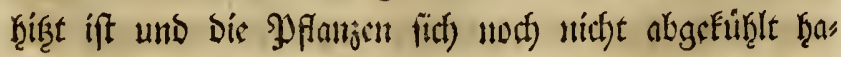
ben Esmen, ift jobes Begiefien ju untethaffen; ss würbe 
Diš cinte Gtuckung Der Sefäẩe jut Folge ḩaben, und

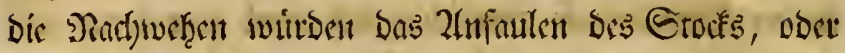
cit Şrand: und Bobligwerden Deffeltent utto Das Dioften

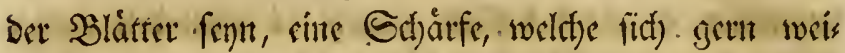

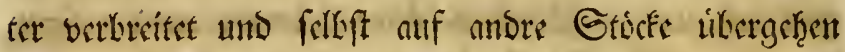

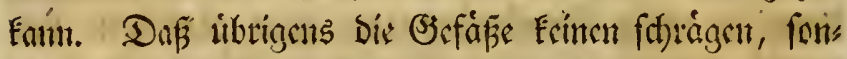

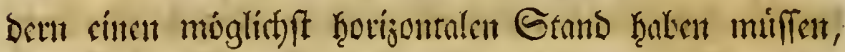
Damit bie Erope von allen Esiten gleid)ntáfig Durd)jos gen, von. Den . SnJurgeln aber mifft abgefpilt werben

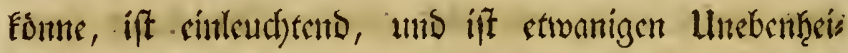

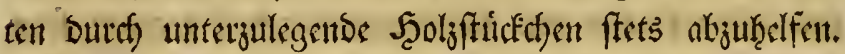

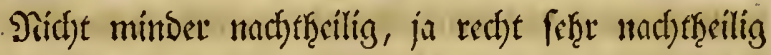

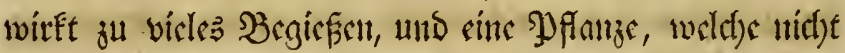

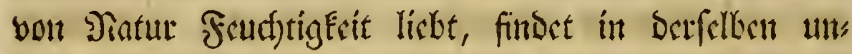

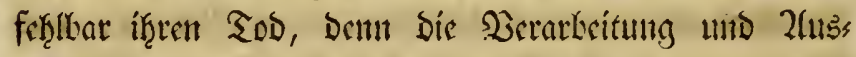
Dimftung ber úberfúffigen Feuctigfscit faum unmòglidf)

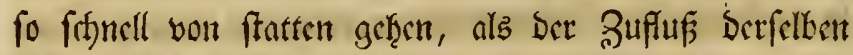

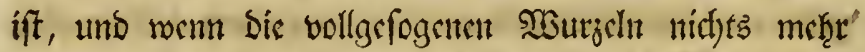

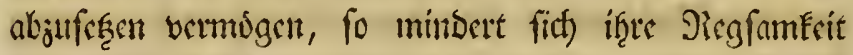
uns fie fangen ant ju faulent, weldses fich nut bem

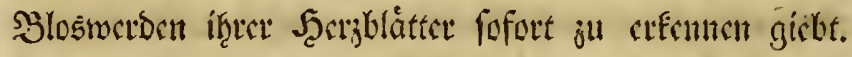

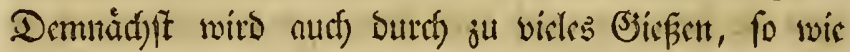
bei sunem lange anthaltenden ober oft wedertef̧renden frarken Pirgen bie Eroc ju feft uno binoeno, bie 2fus"

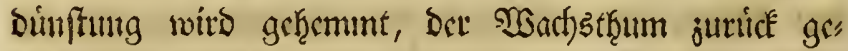

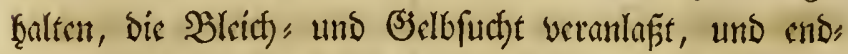

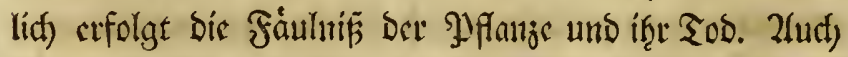
bas Zfuflocfern ber Eve wurbe manig ober gar nichts

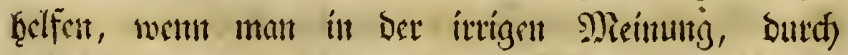

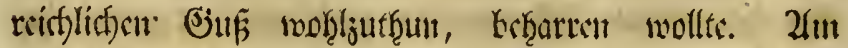

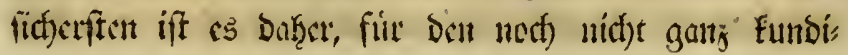


gen Blumenfreund, Dus Begieß̧en ber Setwåchfe nithe frither vorzunthmen, als bis biefelben Durft zeigen, Das, hecift, wenn bic Blatter anfangen fid) melf hectab

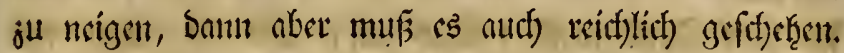

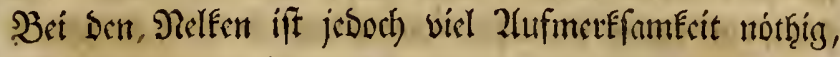
indem fie faton tiberals trocken feyn muifen, bevor fie bie Şläter fentent, und hier ift es fidfurer, bie Erbe

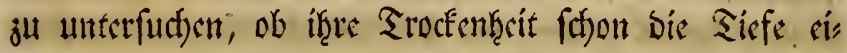

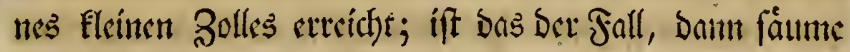
man nicht, fie ju tränten. Sint ber Regel füb̨ut Das

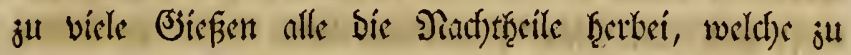

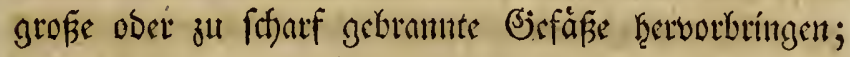
wenn lite aber, im guinftigften Foll, aud nidfe etfran: fen unt abfterben! fo ift bod) immer cine 2lusartung

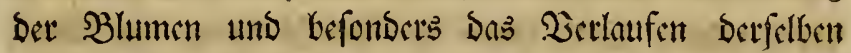
zu beforgen, woju bie mit violett gejsictuncten weífgrunt: Digen, beşgleityen bie mit 2furor, afif)grau und price ge: jeicfuncten gelfgrumbigen unt bie fupferforb mit ponesau

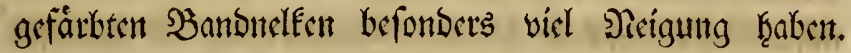
Dem Serfaffer biefer Ectrift ift, bei anfänglityer lln

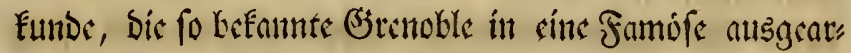
tet, unto unter andern audf feu cendreux sine blo

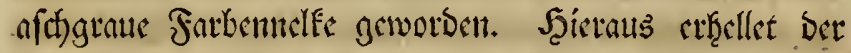

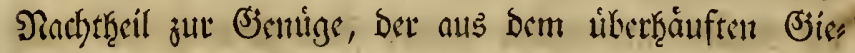
fict etfolgt, ein Fefter, in weld)en man um fo ether berfallen mirb, went man ben Pffanjen cine zul lef̧mige

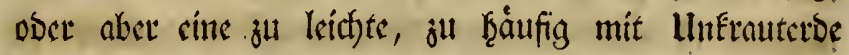
bermift)te Erbe gegeben ḩat. 2luf ber andetn Geite

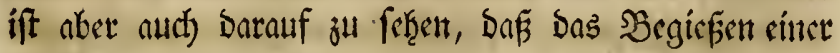
ober Der andern PJfanje nicf)t zu libermáfig lange aus gefegt merde, benn es mürbe foldes ebenfalla von bett 
nact)theiligften Folgen begleitet fenn, ittoem bas innete

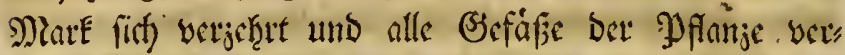

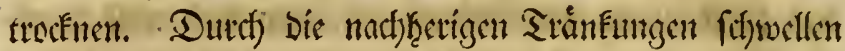

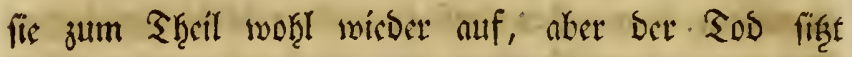

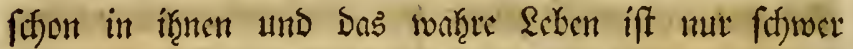
mécber zurick ju bringen, befonders metnt Diefe Wer, făumniffe bei ftrenger Siálte bcs Trointers Gtntt ge" funden haten follten, wo bie Dyfanjen meiftetts umetts bar verloren geţen. Sindef mulf man boct) níd)e un,

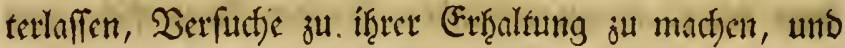

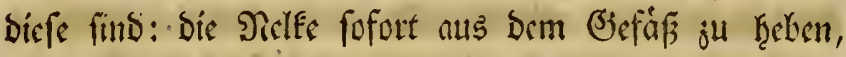
Die Erbe bis auf cinct Fleiten, Den Tsurizeln zu belaf,

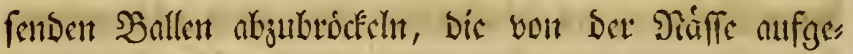

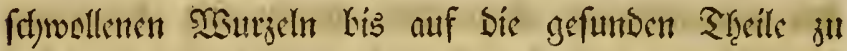

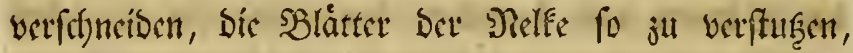

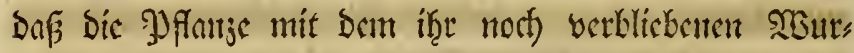

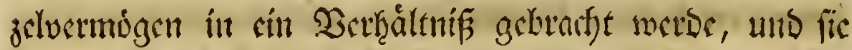
fobam in neue, fraeftige, jebod) mit Sant wof̧l vets

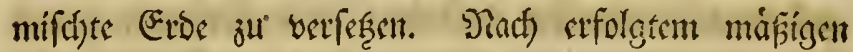

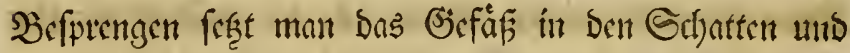
fobald bie Blátter you Der Dáffe nbgetrecfnet, nuth

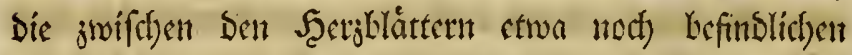
Waffertropfan weggeblafen worden fints, bebecft mant Die Siranfe mit cinem (J)lafe, ftellt fie mad) unt mad) immer weiter in bie fruihfonne vor, 1 mo watet cs

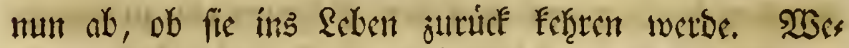

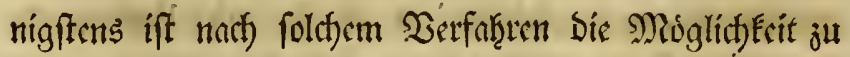
errichen, baf ber Gtamm neue Tricbe auswirft, went auch ber Scerjftengel abgefdyntten werben mifite, uns ift bie פicles felten uns fadon, fo bat man bann bod 
immer genug getwonten. Sie im Whinter ju trocken laffen, bringe meiffens Derluft.

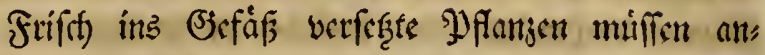
fánglief) mur máfíg begoffen werben, bamit bie jungen Wurjeln fich erft geţitrig mit ben Evbtheilen verbin. ben fónnen, libertraupt aber barf bas গ̧aller aus ber

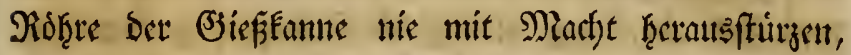

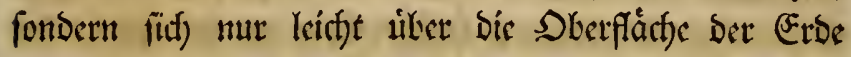

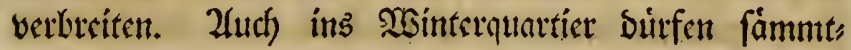
licbe Pfanjen nur máfíg feuct)t gebract)e werben, uns

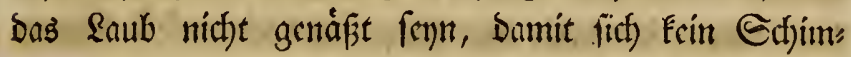

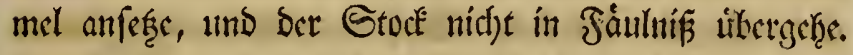
Ulm biefes autf) bei bem sointerguß zu vermeiben, tḩut man woḩl, bie Erbe nach Dem Gtamm Der Moffantje

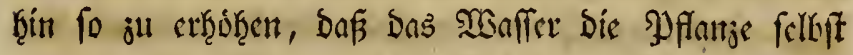
midjt beruffeten Fonne, fondert in ber zwifden ber Ers

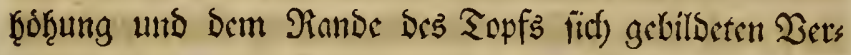
tefung verbleiben milfe. Sitanfe Sofanjen Kediufen nod) weniger fettd)tigfeit, man folone fie baher mit

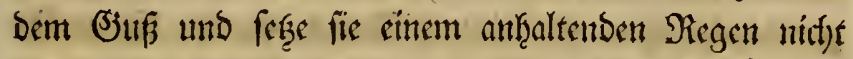

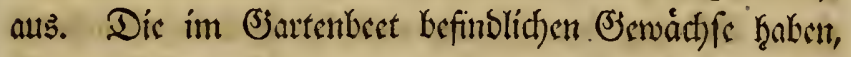
wenn fie cinmal angetwitrolt fitto, auser bei lange ans

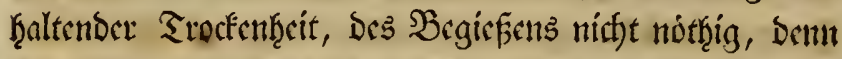
thre

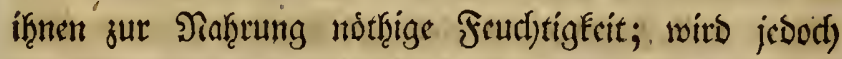
gegoffen, fo mur es aud reichlict) gefdectent, bunit bie Diâfe wenigftens auf $3-4$ 3oll tief cinbringen Eónne.

Dakj gut gefiulte Nelfen nicht im Stande find,

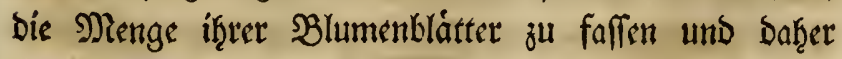

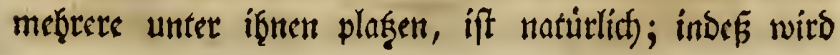




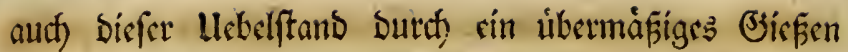
wernigftens fef̧r vermeţut, und Menge vorḩanden, um baffelte ju vetmeíben. Der grume moosartige $2 \mathfrak{n}$ fare, ber fict) in Sen zu vicle feuch),

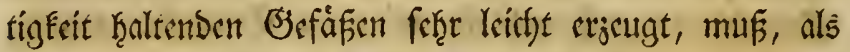

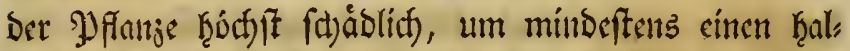
ben Boll tief, whne jebon bie Murjcln ju verlę̧en, akgef̧oben uns bagegen friffae Eroe an bie Etrlle Der alten gebract)t werben, in fo fern nidjet ein antores Befáf erforberlich wuirbs. Ulckrigens ift es nicht zu verfäumen, bie nach uns nach lid) body zu feft feçende

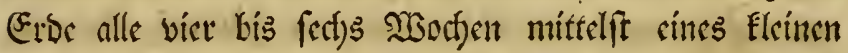
sifernen Echaufeldaens aufjulocken, um nidjt fowoht

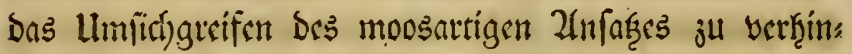
Detn, fondern aud) um bie Eroe firr bie willigete 2 nt

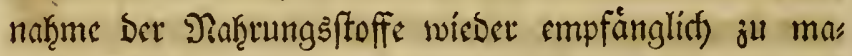
(f)en und bas beffere Eindríngen ber Suft unb ber

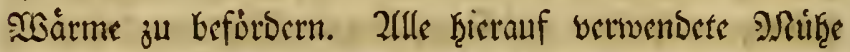

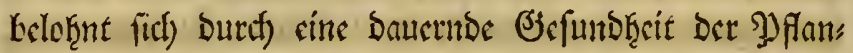

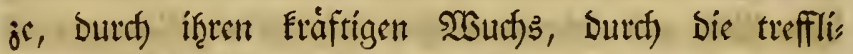
d)ere Bilbung Der Blume und buref) Den vermetriten

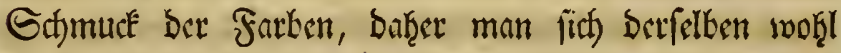
gerne untergictht.

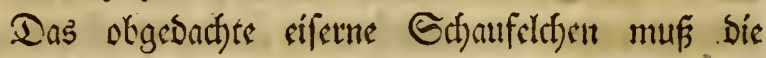

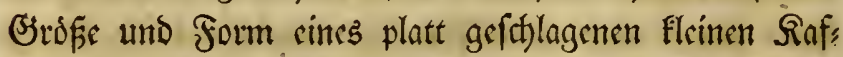
fecloffels ḩaten uns mit cinęm ḩóljernen Scanogriff vet" feţen fenn. Ein bergleídjen gróferes, um Das junge Lut fraut nus Den Beeten ţeraus วu hecben, ift ebenfalls feţr oul empfrh̨len. 


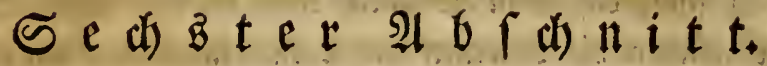

Bebandrang Der Nelen yor uno waths reno Der fror.

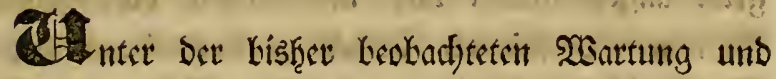
Yflege Der Pielfen ḩaben wír uns bem Beitpunfte ge" naţet, wo biefelten anfangen ju fpindeln, Sinvipen ju treiten und fobanm unfe Mathe mit cinev fiertlidjen

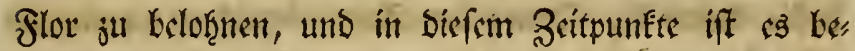

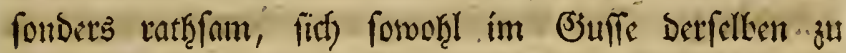
máfigen, als fie auch yor anţaltenden Dirgenguffifen ober

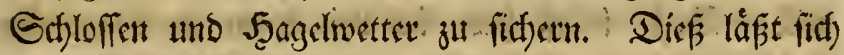
butef) Uleterb̨ängung ciner bid)ten, mit Scl geträuften Drillify)leimmand, weld)e an bas in voraus faton ange: brachte Dachgeftelle Durch 2(nbinden leidft befeftigt uni wieber abgenommen werben Eanth, an fifferften ertet,

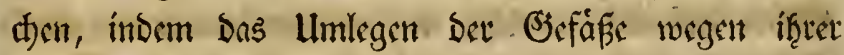

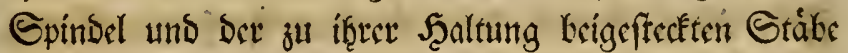

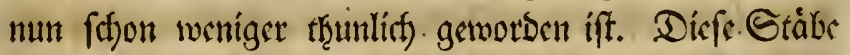

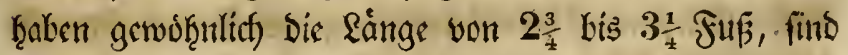

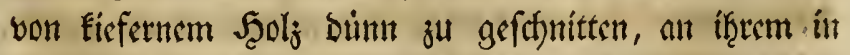
Die Erbe Eommentoen Theil fifjarf jugefpifet unt antge"

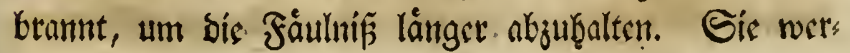




\section{6}

Den, um Die Wurjeln fo wemig als moglich fu befit)a

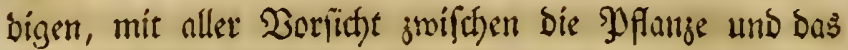

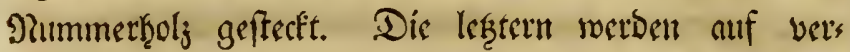

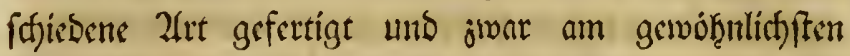

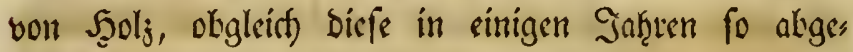

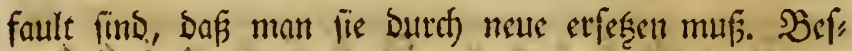
fer wüben bie Gleictenen mit batin eíngefoblagenten uno

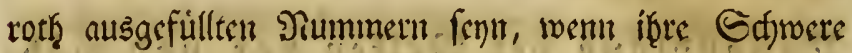
fie nid)t oft fo tief in bie Eroe fenfte, Daj fie faft umiid)thar werben. Zlm heften (d)einen bie aus Bine" tafelı gefdnittenen, mit Firmif perlfarben ober Klap,s grün angeftrichenell und mit rothen ober fdumargen Dummern-verfehenen Seitfen ju fenlt, often fid cine Nienge in Der Bzreite sines. W̧alben Bolles und $7-8$ Boll lang aus einer Safdl idnneiben lafien. Die Roften eirct Sinttafel fino nicf)t bebeutent, uno mait wird Dafür Durd) Die Dauer Der פummetjeid)en hinneid)eno entfithábigt. Zur Befeftigung Des Bllumenftengels an

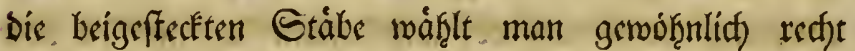
milben $\mathfrak{B}$ aft, inder

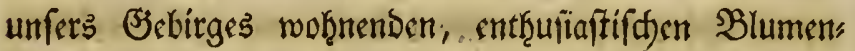
freunte, Der eime bebeutente, aus lauter vorzuglid)en Mataboren befteţende Nelfenfammlung befifet, wie id) fie nod) nie in to trefflid)er Ilusmaf̧l beifammen fath, Etábe gefunden, weld)e, in Bwifdentaumen son 4-5 Boll, Ringe batten, Deren Umfang grof genug war, um bie Rnofpen ber Nelfen bequem fininourd) ju fdies ben. Dies mag die Befeftigung der Neleen fetre för Dern, allein follten, ba bie Ringe aus ciner harten,

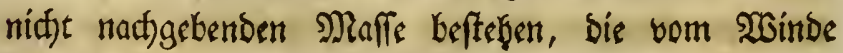
immer fin und ber beroegten Nelfenftengsl nidht burd) 
Spindel abfotheiben, fonbern lis auch licher ins Emto fef̧en, Damit fir bort fraftiger roctoent und ftátfere Triebe gemimnen. Tiad)t minbel treiben bié von aus"

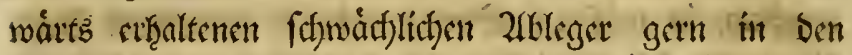

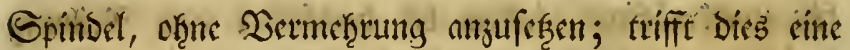

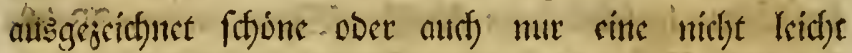

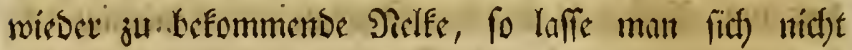

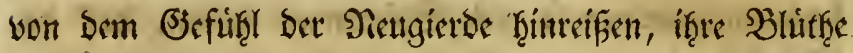

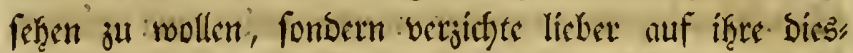

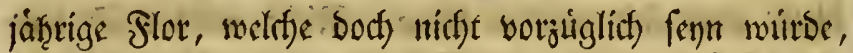
und faneide ben Gpindel ab, um mo móglid) ableger ju befommen, bod muz sin foldser Stock ber Eonne

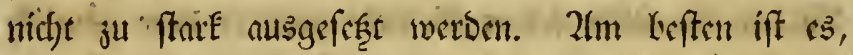

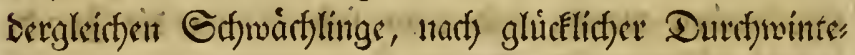
rung fofort in Sopfe ju verfesen, weld)e im Wer

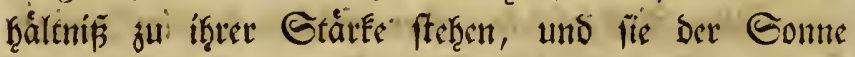
weniger als bie úbrigen ausjufef̧en; Dng Gpindeln wirb alsbann wobhl unterbleiben, fie werben meḩr in (iid) felbft erftarken uns bas folgende Sakge cine um to

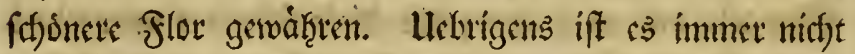
woh̨l gethan, Dergleit)en Gefwåchlinge, nuf mold)e

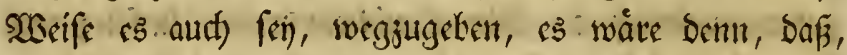

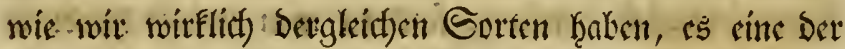

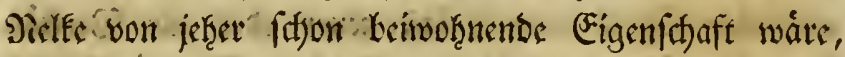
mur fotwant)e Genter zu treiben.

Eino bie Epintidn ju ciner Şdhe gelnngt, in weldere bie Entmidfelung Der Rnofpen beginnt, fo nimmt

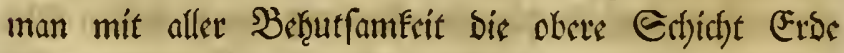
weg, giebt bangegen frifite hin und lockert ben Sopf

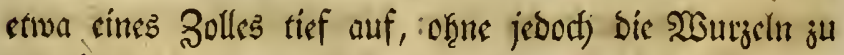
befcjábigen, wesb̨alb man fich lieber mef̧r am Ranbc 
ftens Diejenigen aus, die ber Şauptblume fu naţe ftethen.

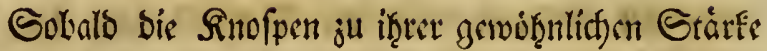

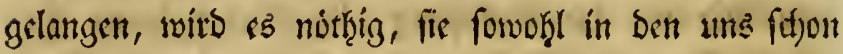
an unto für firth to áuFerft moḩl zufagenton Fruif̨ftun Den als aud) gegen $2($ beno burd)jugethen, um bie SBlatt, láufe, weldje fidh um biefe Seit befonders nuf bie Rnofpen, besgleityen zmifdyen ben Эeelfenblattern fo gerne anferecn, aufaufuct)en und zu tobten. Dirs muß bie grojfte Sorgfalt Des Befirzers Der Deleenfammlung fenn, uns man barf nicht glauben, Daf́ cin frür und abends ftattfindendez Befprengen mit Der Gprif̧fanne jene

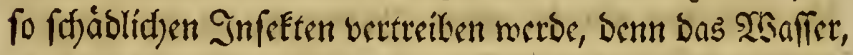
es fei fauer, fúf, ober bitter, rolle tiber fie hecrab unt

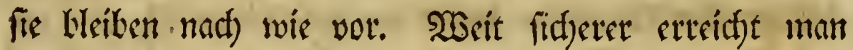
biefen Zwesf burd) einen rect)t luftigen Standort unb

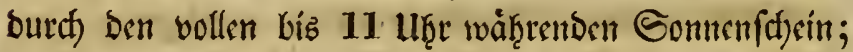
Denn es wirb Esinem Dislentiften entgeţen, Daf in their Ben Gommern biefes llngejiefer weit meniger als in ben regnigten fich grigt. Sints beren north wentige, to fann man lie ferge leid)t vertilgen, wenn man ein in

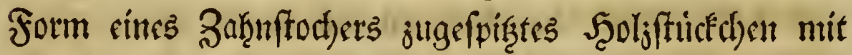
Epeichel batręt, fie mit biefem vom Blatte abjterift und tóbtet, auf ben Sinofpen aber, soo man fie fintet,

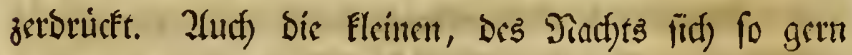

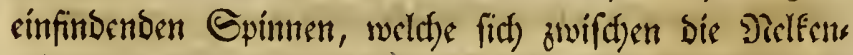

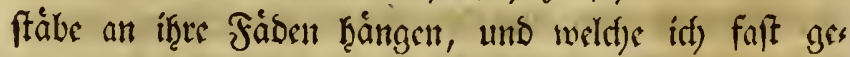
neigt wåre, für bie Erżcuger Der fatalen B̉lattlåuf ju balten, muß man unn bisfe Zrit auffangen unb vet"

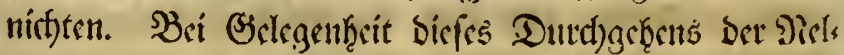

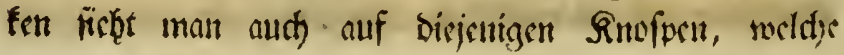




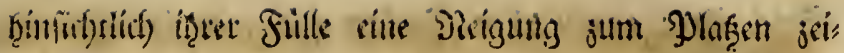
gen oder ben 2(nfang Daju fajon gemact) baben, um auth) Dí úbrigen naturtlitgen Spalten į̂rer åufern, bie Sinofpe formirenoen grinen Blátter, mit ber Epifze einer Eleinen feinen Gefecte weiter aufüfdyligen, bas mit bic Blume von allen Geiten in einer fojonen Runs Dung herwusbliţ̨; besglesid)en verftuget man die Gpizs jen Diefir Einfoffungsblätter ein wenig, um Daburds

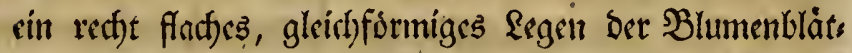
ter ju beswirfen. Sollte 'biefer Ianthhúlfe ungeact)tet Der Gpalt Demnod) his auf Den Boden ber Şứlfe hets abreipen, fo muz man nach bem vólligen 2 Iufblifgen

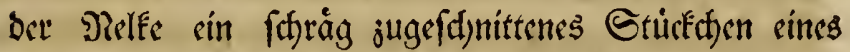
grin gefácbten Rartenblatts bef̧utfaun in bie Seffnung

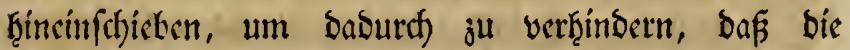

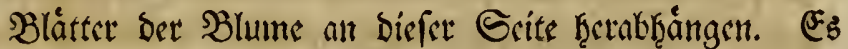

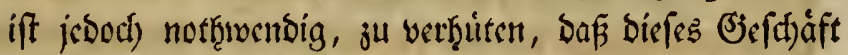
nicht mit feutften, ffybifenden Fingetn unternommen werbe, benn cs witbe ber Edyweif niedt mux ben

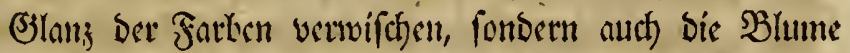

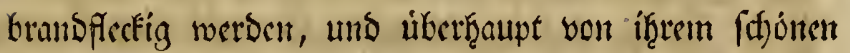
2fnfeţen untendliet) verlieren. Der námlidben Folgen wegen gicht man audf niffet gern ju, bafi befudfende Delfenfrumbe an bie Blume risthen, bemn bie leifefte

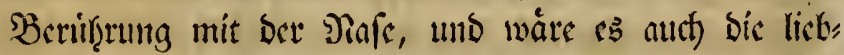
lichfte, wutrbe, bei ber im Gommer aud) zur Fuif̧lifen Scit erfolgenden Grtweifansbumfung, ber Blume an

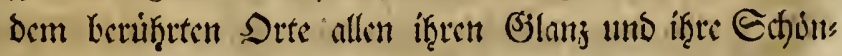

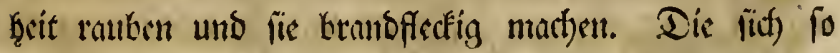

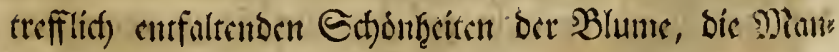

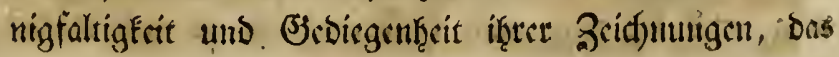


Epiel î̧ere prarthtwollen Farben foll man Kerwundern,

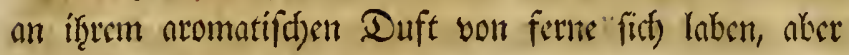

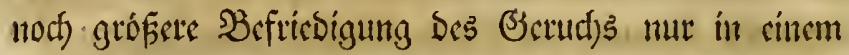
Dargercithten, unter ben fidmuckbolleffen Farben heck

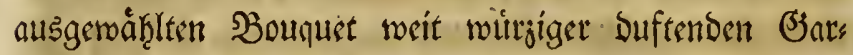
tennelfen finden. Es verbient bei Diefer Bjelegentereit

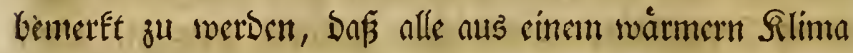

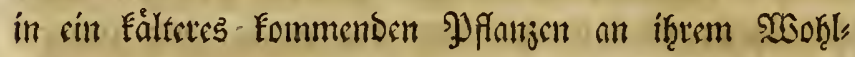
getud) zu verlieten pflegen, wie benn aud) Kefanntlid)

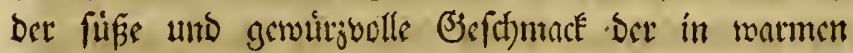
Begenden einfeimifechen fruid)te Denjenigen mangelt, weld)e in umfern Boden verfeçt und bufelbft gejogen morben find.

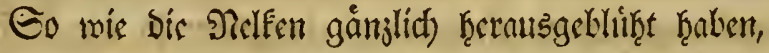
bringt man lie auf ben sigenobs fir fie aufgeftellten;

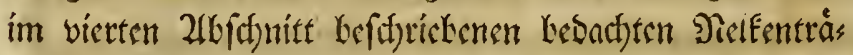
ger und oronet biefelten am keffen in form cinter fanft

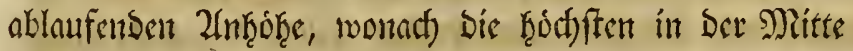
Der Etellage, an beiben Geiten aber bie nicorigam

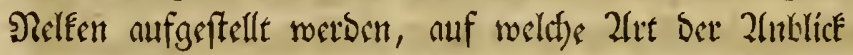
auş Der Ferne in cine angenergm likertafthende Epan:

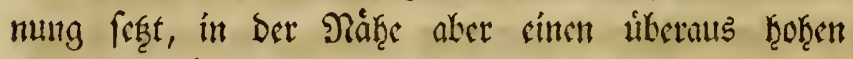

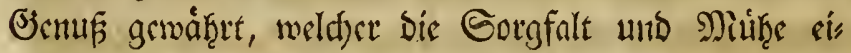

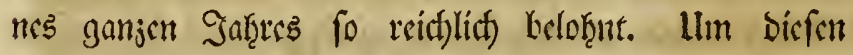

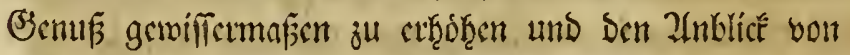

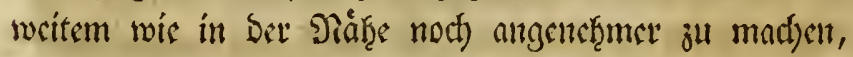

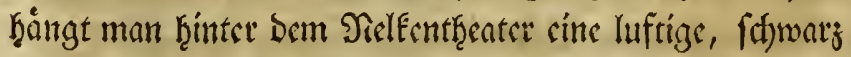
ober bunfelgruin gefärbte Reinnons auf, weldye unten mittelfit cinte Stange beftswert uns fo befeftigt wirs;

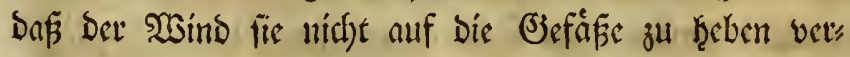

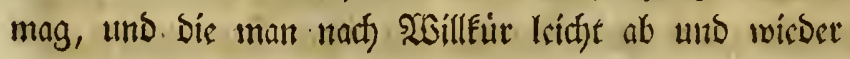


sinen fo bedeutenten Finfup nuf bie Bridjung Der

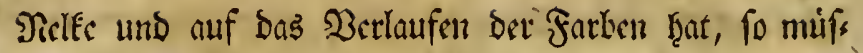
fen wir in truben und naffen. Sominern baf̧in fethen, Den Nangel ber Eonnenftraf̧len Duted) cinen máfigigern Sup unto burd) betmehreten \&uftjugang ju erfę̧en.

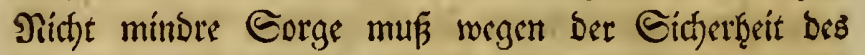
Thenters, allf welchem bie Dielfen ifre Bierbe jeigen, getrngen werben, Denn jur Beit ber Flor finten bie Shrwuirmer unto 2lmeifen fich gar ju gुern cin, um Die, Suifigferiten im Rilth ber Relfe zu Eoften. Dic erftern begnugen fid aber bamit nid)t, fondern jernis gen bie SBlumenkläter ganj nafe am Frutfytfitoten fo

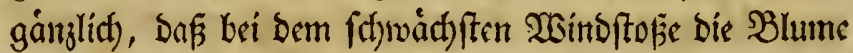

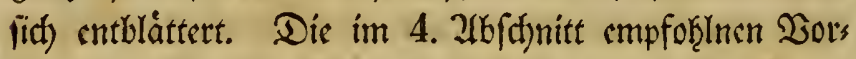
rid)tungen an Den $\mathfrak{B l u m e n t r a ́ g e r n ~ m e r b e n ~ w o h ̧ l ~ K ̧ i n r e i ́ ~}$ deno feyn, bie Eried)enden Jnfekten abjukalten; menu

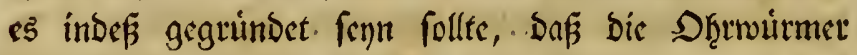
mit Flugeln berfetren find, uns alfo bie angernthenen

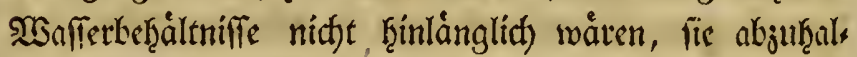
ten, fo muf man ouf ifiten Fang bedadjt fenn, uno

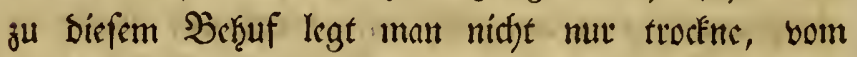

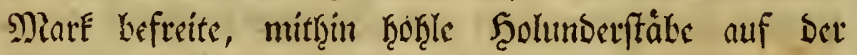

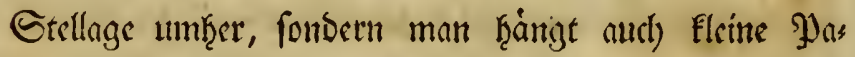
pierduten ober bie von Grjopfenfüizen aligenommenen

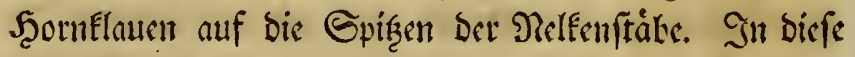

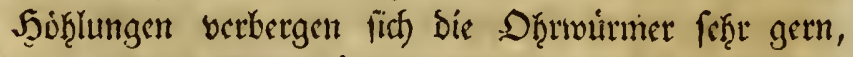
man fucht fie bann táglidy in ben erften Mlorigenftuns

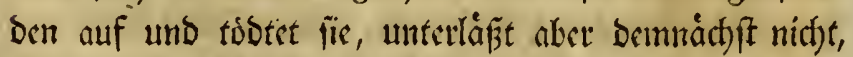

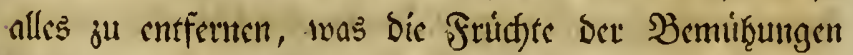
rincs ganjen Sak̨ris verbetben uno unt un bie ge" byoffen Frtuben bringen Fautr. 
ten Daum cinngt uno sin. Zftifenthalt verfit)iconenet Jinféten wirb, nie vernad)láfigt werben.

TSeldfe Dollfommentrecten man voit cincr פecles, bie fefoun genamet werben foll; verlangt, iff juar fafon

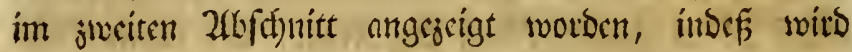

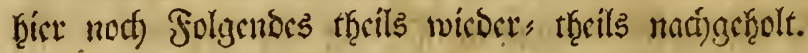

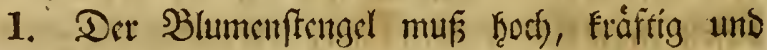

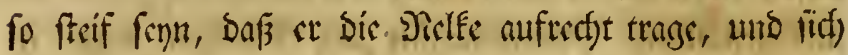
Diefelbe nur to tief meige, als, nothig ift; fire yoll ins Zluge ju forfert.

2. Dak bie Rnofpe zilinderförmig, faft cimer

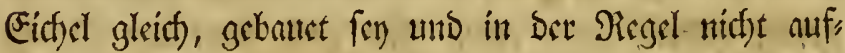
plaze, fombern ben Ed)aft jufammentralte; am alletwe" nigften aker barf fie futr und bicf̧̧ullig, ober, juar lang, aker babri baudjig und fpis julanfent fonn, indom Dergleichen פelfent faft immer plazen uns nur felten Durd) untergelegte Rartenblätter ju cincr geregelten Siunbung uns B̉látterlegung ju bringen fint.

3. Die Blátter Der SBlume múffen lang, of̧ne ju flattern, breit uno ftcif, in fid) felbit villig gleich

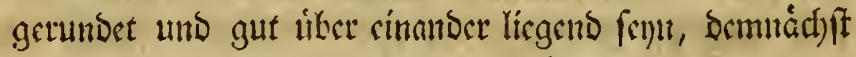

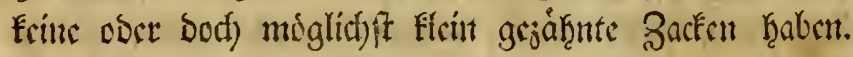

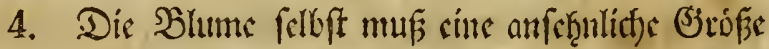
von $2 \frac{1}{2}$ bis 3 3oll in Durtymeffer, ober 8 bis 9 Soll

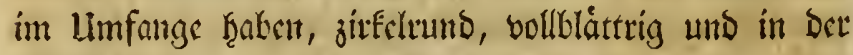
Mitte methe gewoilbt als flach gebaut fey)t.

5. Se feinet unb fojärfer bie 3ridonung bet Scnarfiridunden uns je breiter bie Der Bandoftreifnelfen

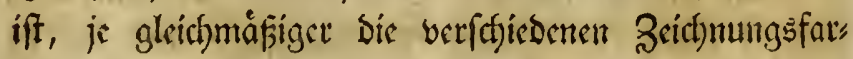
ben vertheilt find und je ticfer fie fid), befomocts bei

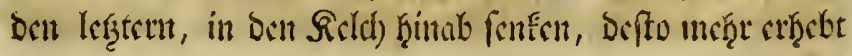




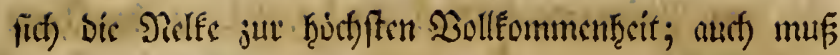

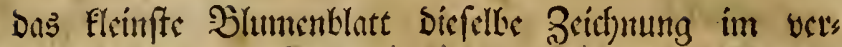

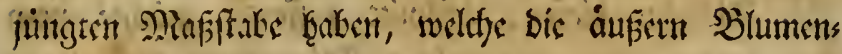
blátter aufjsigen.

6. Die Fatuen ketreffend, beten Mifoungen unis Hebergänge ins Unenslict) gethen; fo milfen bis

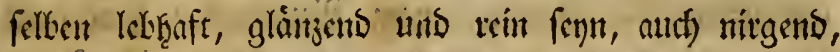
aufer bei Den Sufdnelfen, in cinander fliefen.

7. Die Stunbfarte mus auch níct)t im mindes

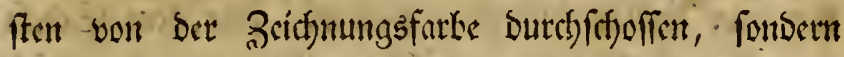
gånjlid) rein fenn und sben fo menig Durch Jjunfte entftellt wetben.

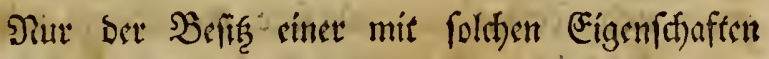

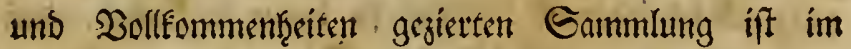
Stanbe, bie vicle Mưf̧e ju vergelten, weldje man cin ganzes Jahte lang auf fie: ju vetwenden b̨at. Tur cine folche Gammlung exfreut im vollften Maje uns wito uns nod) cinmal fo reifecns, wenn sin mit unfert ఇeis

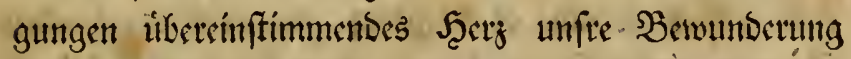
theilt. Ulno nod) einmal fo licklict) Duffet fie, went ber 2lbent beginmt, auf bie Fluren fietab ju fefwes ben, bie Sonne mit millberen Gtrufflen uns leuthtet, Siufe fich) úber bie Sintur ergiefft uns taufend Relife

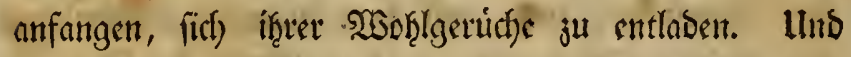

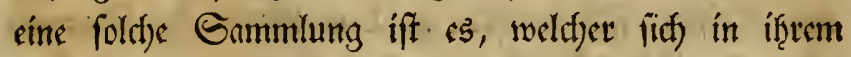
ganjen vollen limfange ber in bem argenwartigen 2 (b)

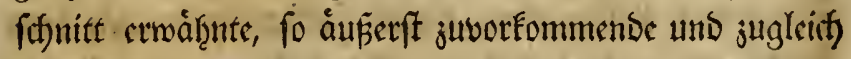

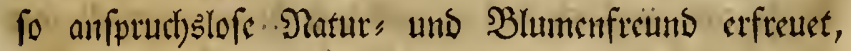

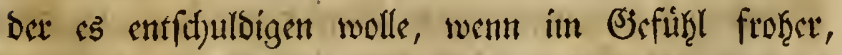

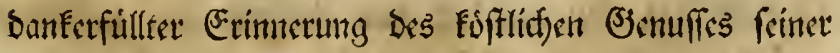

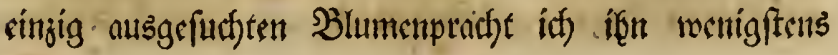




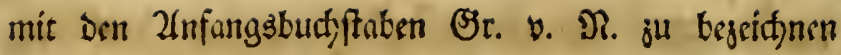
mir ertaube.

Z(ls fur biefen 2(b/annite paffent, modf)te nod) bet Inlage siner aufgeflebten Slátterfarte fiurjlich) ju erwáh̨nen fenn.. Das ju Derfelben ju wáf̨lende, als

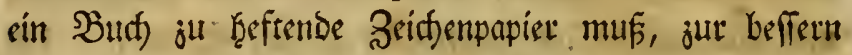

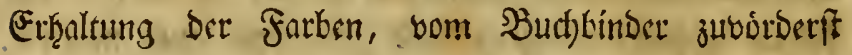
bogenmeife butif) sin WOaffer, in world)em eine Suan, titåt Golpeter jerlaffen roorben ift, Surágejogen unb vor Dem Sceften getrocénet rerben. 2lus Dem Echaft ber jum Zuffeleben gewáblten. Blumenblätter wirb juborocrift der Gaft mit Den Fingern bef̧utfam ausges

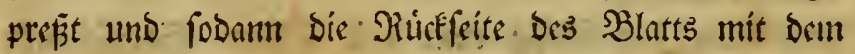

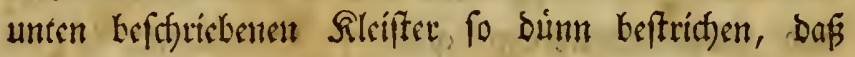

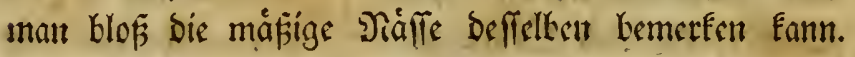
Dach sincr millfuirlichen Sromung wirb biefes Blatt auf bas. Blatt bes B̧ucts in Der gernoeften Ricts tung uno mit Dermeibung alles Faltenturfs aufges flebt, uns fobald es geţorig nusgebreitet worben ift, mit sinem feinen Druck" ober Rofdypapicr Kedecft uns mittclif ber flarfen Şans auf Daffelbe gestuicft; offne es jeboch in oder aus sinander. ju fodicben ober

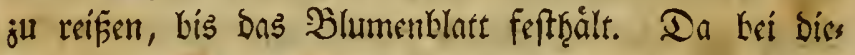
(em 2(noricken, aud) nad) Eem Dunnften mit Silsifter, fid) Derfelbe nn Dem Rande Des ß̉lumens blatts Dennoch Fecrausbricft, fo muf mit ciner trocfinen Stelle des Sofdjpapiers biefes fanfte 2lufbruicéen forts

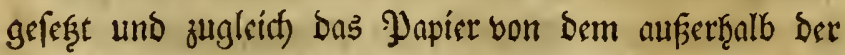
Blume lidf) hetausgepreften Rleifter gercinigt merben. Gobals Das Blumentlatt mur einigermafen in feiner angeflebten lage verbleibt, wito cín Gtüc trocfnes 
Druct" ober Eoffppapier über baffelbe gelege, bas Buth) finnell jugroruickt uno fobann unter sime Suuchbinders preffe gelegt, Deren beibe Besttftucte - wenigftens bie

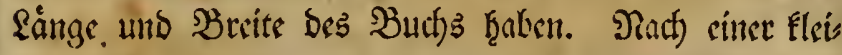
แen falken Sicttelftunde lúftet man bie Sुleffe stwas, und nach) Serlauf eines gleid)en Scitraums twirs man

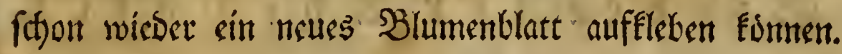
Uleber, unter oder ucben bem SBlumenblatt Eommt bie Diummer ber Nelfe, auf bie andere, "weíf ju laffende Geite bes $\mathfrak{B u d} 5$ s aber fommt nach Der Reifiefolge ber aufgeflebten Slátter, - auß̧er ber Nummer, aur ber Name Der Delke. Damit ber Silcifter nitht ftockig wirb und bas Blatt flectig mad)t, muF burd) fortges fę̧tes \&uften für Das mógliduft balbige Trodfuen bef: felben geforgt werben. Sur Bereitung Des Sleifters wirb etwa cine Mefferfpize voll feines Weifectumeţl in eimen reinen; ja nicf)t fettigen blechernen Loffel gefthut: tet, etwa 2 bis 3 Raffecloffel boll Waffer baju ges

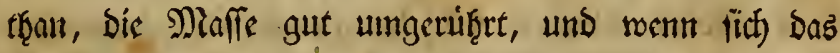

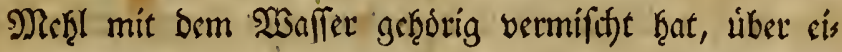

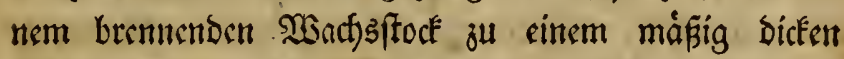
Brei cingefort)t; ift Diefer abgetuffelt, fo fann er fdyon gebraud)t merben. Da ber Sleifter leid)t fauer und bann unbraudjbar mirb; fo mußs berfelbe táglict) frifós abgeffoct)t, ja an heipen Tagen jweimal frifa) bereitet werben. Das Zluffleben mit Rleiffer ift meţe zu empfef̧len als bas mit Suummi, nur muß er móglichfit bün auf bas গRelfenblatt geftricten roerden, bamit feime braunen folecfe entifteren und bas B̉latt aud) um fo leidfer und rafaner antrodfne. 


\section{Sicbenter $\mathfrak{A} \mathfrak{b} \mathfrak{d}) \mathfrak{i t}$.}

Die Zermelitung Der Telén Durdy ab: reger uno Edinttlinge.

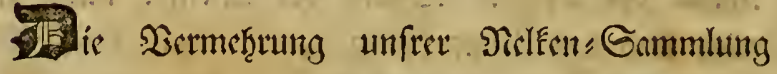

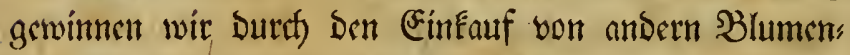

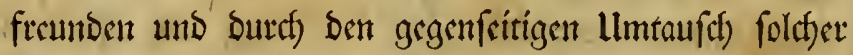

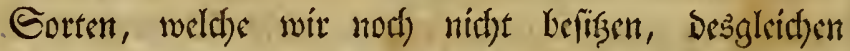

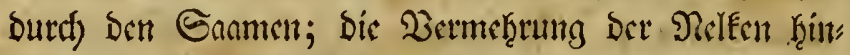

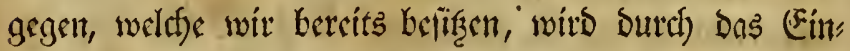

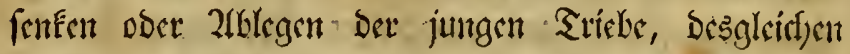

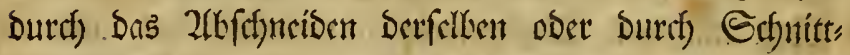
linge berwirft, weldse unter (Blas getbradtet unt am ges

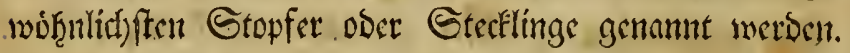

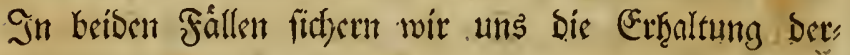
jenigen Gorten, weldse wir bercits befif̧en, uns da je

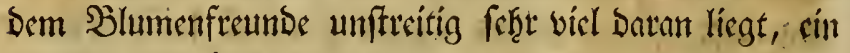

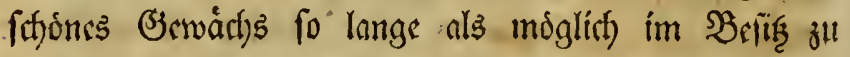

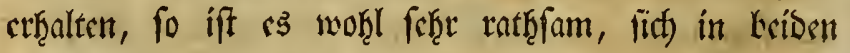

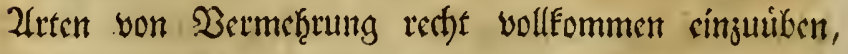

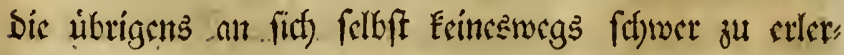

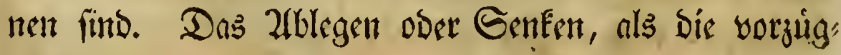

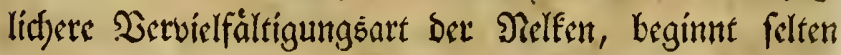


und ginge Durfelte nicht in ben Epindel, fo muf mant

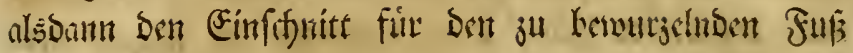

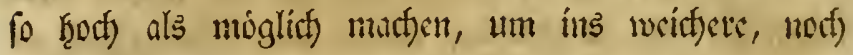
wutjelfähige Scols ju Evommen. Die crft maty bem Esptember, mithin fryon ju fpà gefertigten Eenter

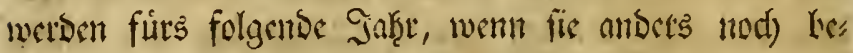

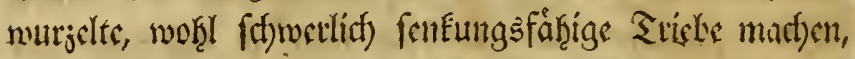

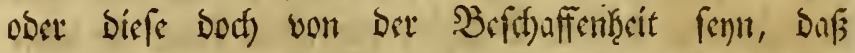
man fie wirserum exft im Gpátommer ablegen fanm;

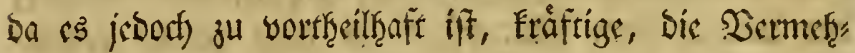
rung fitfernde 2fGleger und in Folge beffen cinte volle Eommmere Flor ju geminmen, fo ifir cs nothíg, lith

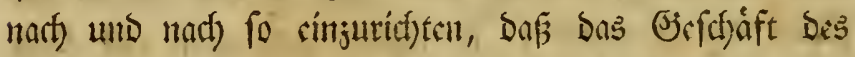

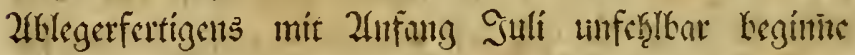

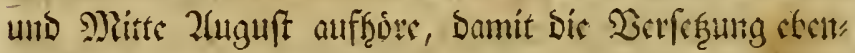

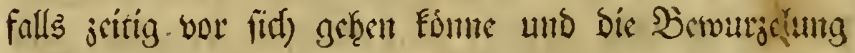

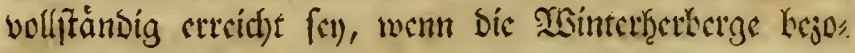
gen wirb. Es Foun ja aud) weber bom belifect Der. Pelfenfammilung toch benjenigen, mit weldfen $\mathfrak{c r}$ in

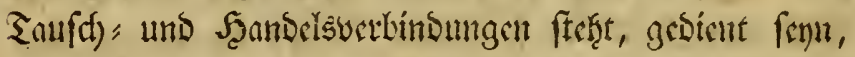
(d)mat)e, wenig. Kerwurjelte 2(blegel ju haken, weld)e

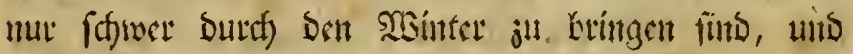
grlánge bics ja, entweder nidjt floriten ober bod) int

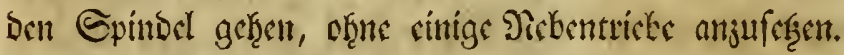
Mit Dem Monat Dftoker beginnt bie Brifentoung, untD

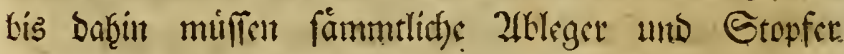
(d)on cin vollfommen gutes 2 Surjelvermógen crlangt f̧aken, vf̧ne weld)es bie Gensung feine Freube macht. গur bicjenigen Sticke, weld)e ju hod frethen, um abgefentet werben ju fónnen, werben, Dis beffern Noarfjs"

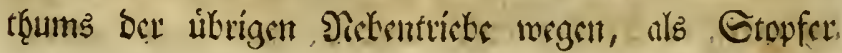


unter Slaz gebrad)t, ber jüngere Natfywuths aker, ber fowoḩ zum Geneen als zum Stopfen zu fitwach ift, bleibt am Mutterftock, um entweder im folgenten Jaḩt auf bem Eartenberte ju prangen ober um bie erften uns fruiheften 2fbleger ober Gtopfer aus if̧m ju mo

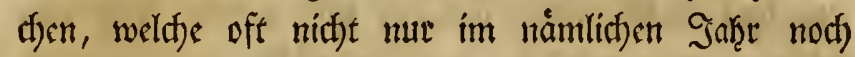

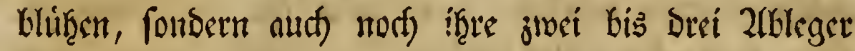
liefern. Scat man nur erft cinige Ulekung im Genfen erlangt, fo geht Daffelbe fafnell von ftatten, benn $\mathfrak{s}$ fommt vorzuglid) barauf an, baf man bas fo heor) als

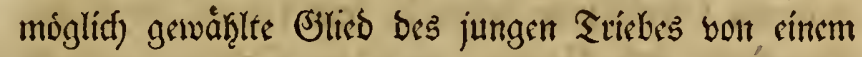
Sinoten bis zum andern mit einem fot)arfen febermefs fer ber länge nach genau in Der Scálfte fpaltet, uno

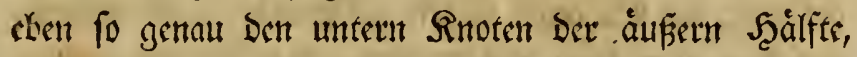
welkfer ben zu berwurgelnden fü bes Genters billoen

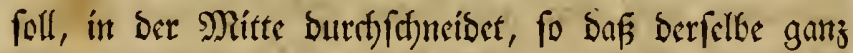

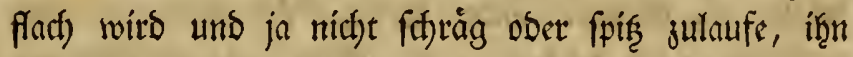
fosann fanft binakbricft uns, oḩne if̧n vom Stamme losjuriticen, in bie Erde himabbeugt, bis zum britten Sinoten cimbrict, ofene bie Eroe ju feft an simander zu ballen, unt mittelft cintes Scakens von birknen Siu then befeftiget. Die jweite, Der Sảnge nact) Durchforals tone Scalfte blcibt am Mutterftamme feft uns führte

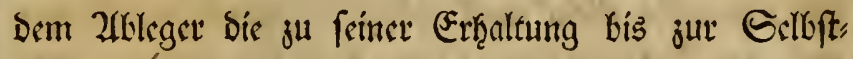

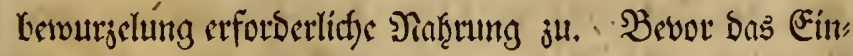
fenfen Der Triebe unternommen wirb, reinigt man tidft mut ben alten Stock von allen trocknen unt liketflif, figen Blättern, fonbern verftuf̧t nud) Dic Epifen bes

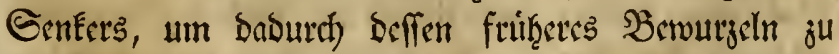
veranlaffen, fo wie aus bemfelben Girutbe bas jum

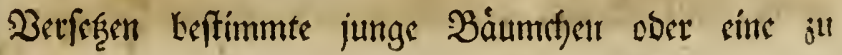




\section{4}

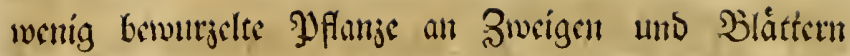

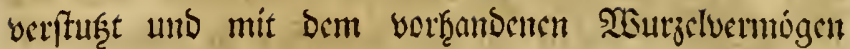

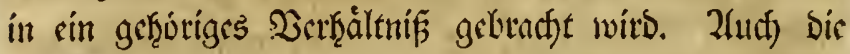
obere alte Erofdhid)t wird yor bem Genfen aus Dem (Sefáa genommen und burd) neue Erbe erfę̧t, indem

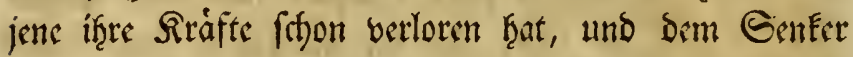

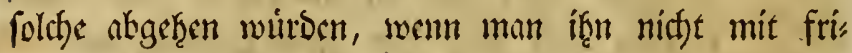
fider Eraftwoller Eroe verforgte.

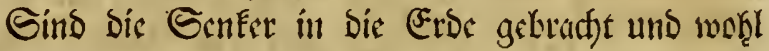
befeftigt, fo werben bie Befáfe mit einer fein surtfs locherten Eprigéanne befprengt und fobann auf bie mir

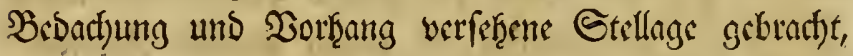
um in ben erffen fedfs his adft Sagen, vor ber Somme

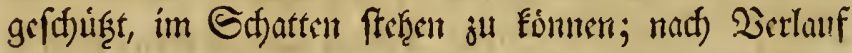

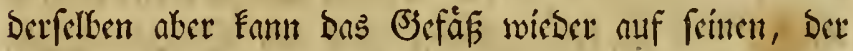

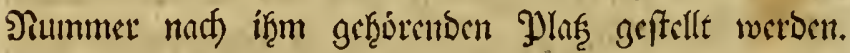

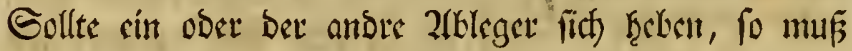

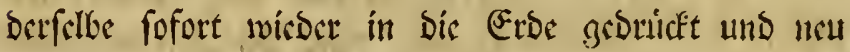

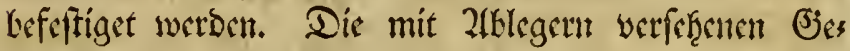

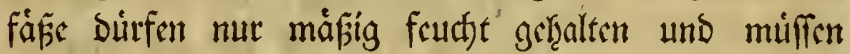

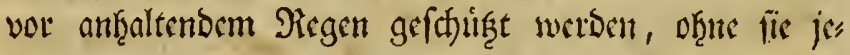
Dod aud ju troden ju halten, indem bie bewurrsclung

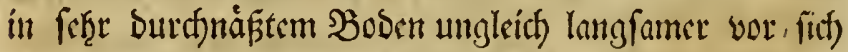
gețt, ja nicht alleín woh̨l gånglich) unterbleibt, fontocut auth) Der Fall cinturten Eann, baß cinjelne und jwar

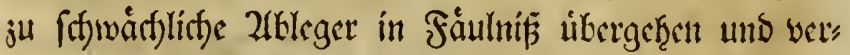

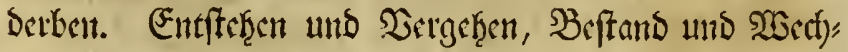
fel, geboren werben uns fterben ift mun freilid) Das Soos alles Deflen, was irbifich ift, uns ungewiés beim Zntbruch bes Tnges, ob as unts noch vergonnt fenn

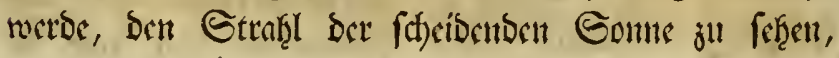


jweifelno am ateno, ab wir nod) cinen nenen Tag

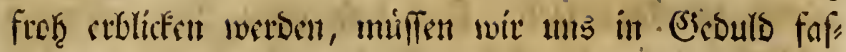

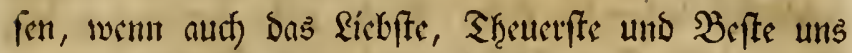

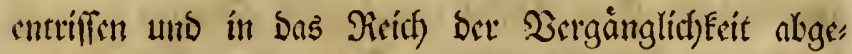
rufan wirt. Dem Burtufte Der SielemfenEer uno

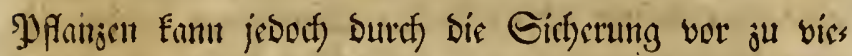

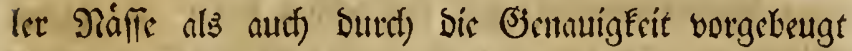

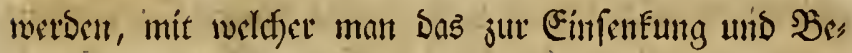

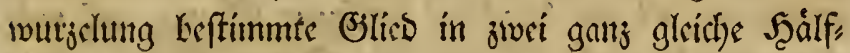

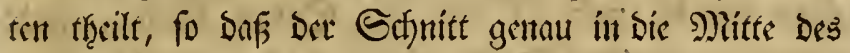

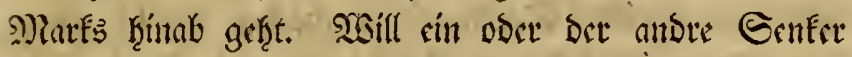

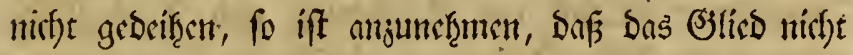
geunu in ber Dritte gefpaltet uns ber am Mitterftece

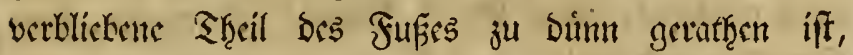

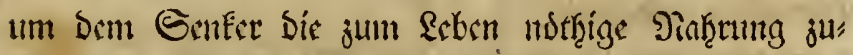

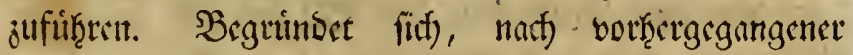
lluterfucfung, Diefer ju befurthtenoe Fall, oder ift ber

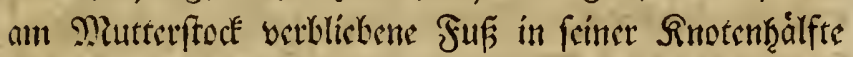

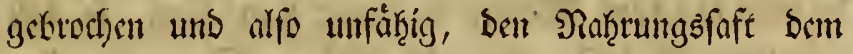

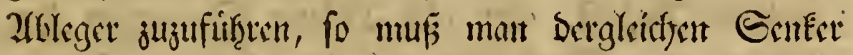

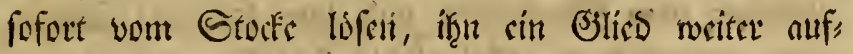
wáts falten uns als Gtopfer unter BSlas bringen,

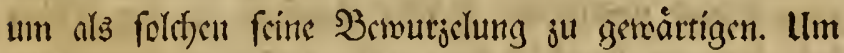

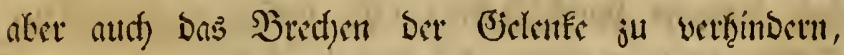
'muf Das Sifáfís ctroas trocfint gef̧altell, aud) Das Gon Fent nidft wow, fondert mad)mittugs birgmommen wers

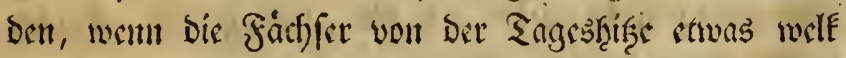
gewvorben fints.

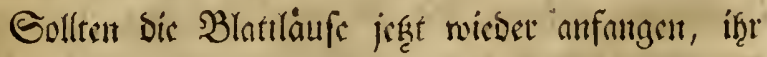
Woefen treiben ju wollen, fo muf man batuuf bedat)t fente, fie nidyt nuffommet gll lallen, Denn fonft wit: 
Den lie aus Dem mit 2lblegern angefitllten Topf mur fd)rer zu tilgen fern. Der keforglid) B̈lumenfremo

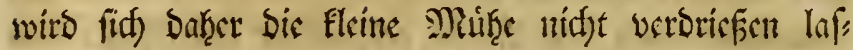

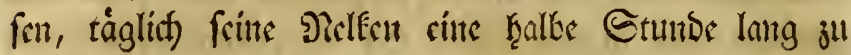

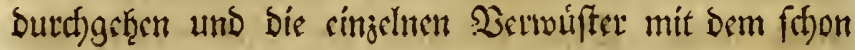

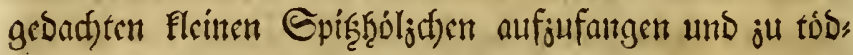
ten; indef miedertrole ich), baf nichts leffer ift, biefes fid) unglaublid fannell vermeţeende Ulngejicfer entfernt

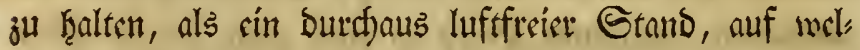

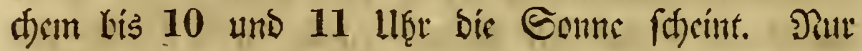
naffe, regentridge Eommarjafere madjen ḩicrin sinige

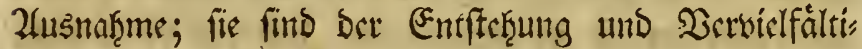

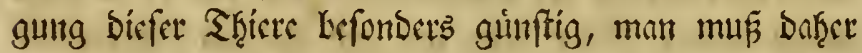
it brrgleidson, jum Słlick foltenen Sommern frine Gorgfalt ucrouppeln.

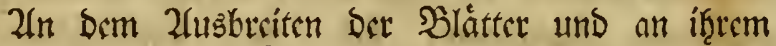
Urkergange in cin frifthes, lebendigrs Bruin crkemt man bie Keginnende Bemurgelung, weld)e in ber Pirgel in vier bis fünf $200 d$ en vollendet fenn Eam, fo Daf mit Enbe 2luguft, ober mit 2unfang Eeptember ifre

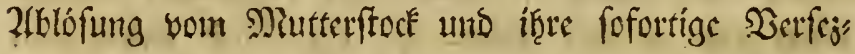

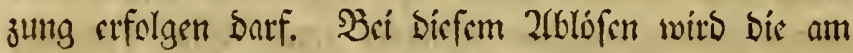
alten Gteck verblickene Scálfte chenfallis in Der Mitte Des Sinotens Durchffthitten uns Deffen nad)tráglid)er

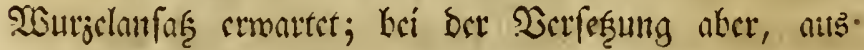

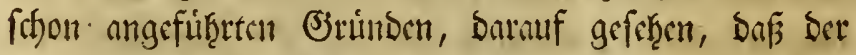
2(kleger ja nidje ticfer ails bís zum brittin Snoten

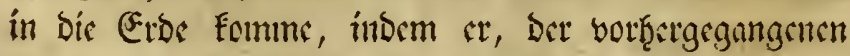

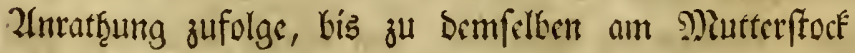

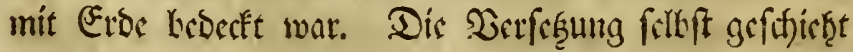
unter Brifígung Dir Dlummer vom alten Stock in 
cillit juar guten, boa) stwas weniges meţe als gewishn

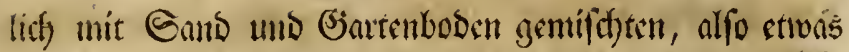

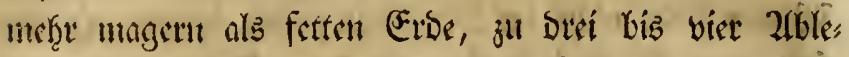
get in cill Befáf;, uno mut Gortiti, auf welche man

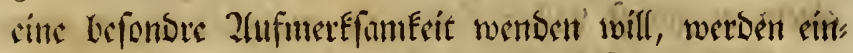

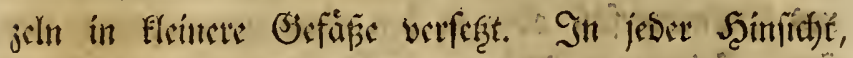
befonbirs aber un Paum ju gewinnèt, ift es rathfou

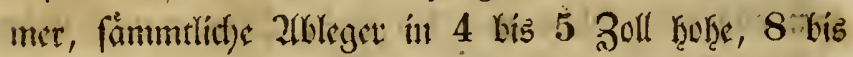
9 Soll britte, uns 2 bis $2 \frac{1}{2}$ Tuß lange Ráftuen von

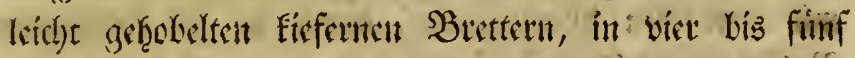

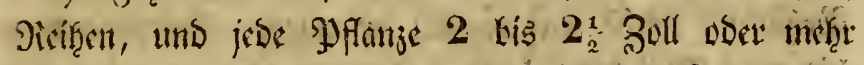

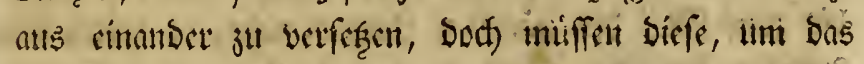

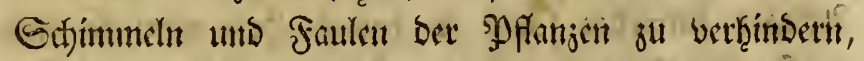

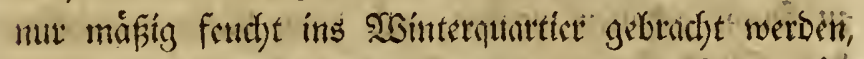
beut je grófert Der Scaufen Eroe iff, je lánger hált

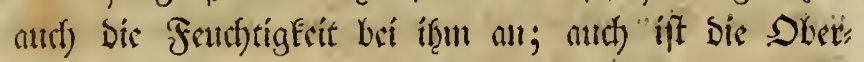

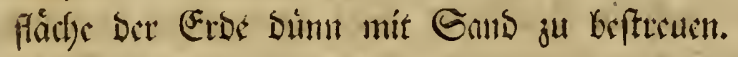

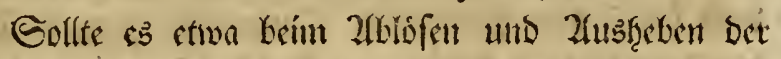

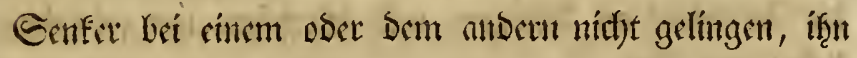

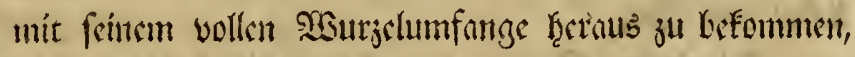

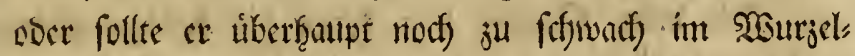
anfage verthlecten foyn, fo bringt man cinen folden ?hleger in cinen fleinen Topf unt bedectet ifgn fodani

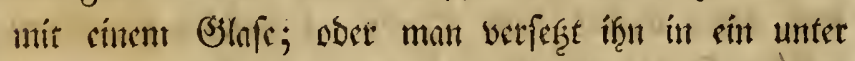

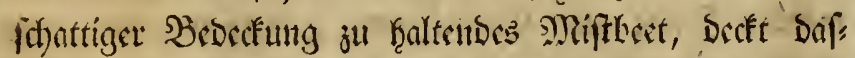

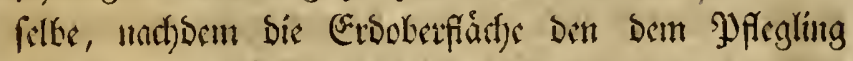

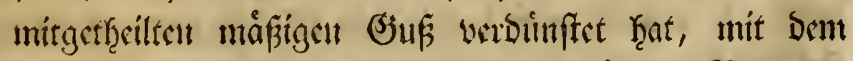
Finfter ju uns enwatet beffent vollftändige Biwurjes

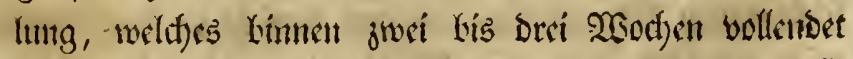

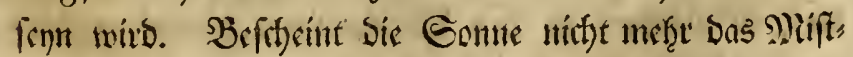
hert, fo with bie Edfatten getente Doortidytung wies 
ber weggenommen, auth jumeilen, befonders bes ’and)ts, bas fenfer geluftet. Gollen Derglciden 2lbleger Den

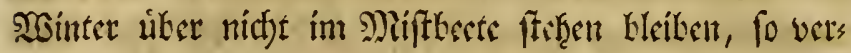
feçt man fie nach) gant vollendeter beswurgelung mit cinem moglieffif vollen Erbfallen entweber in cin trbes nes. Şlumengefáf ober in ben oben angegebenen $\Re_{a}$

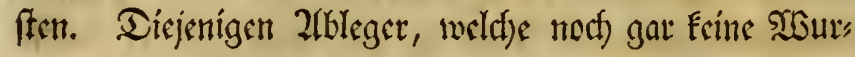

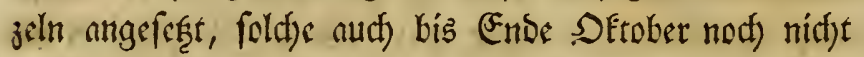
crilangt ḩakent, muf man am Miutterftocfe laffen und

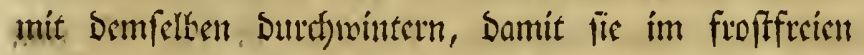

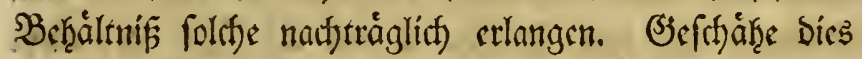

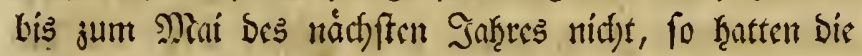
2ableger entweber fach ju ţartes $\mathrm{Jgll}_{3}$ ober fie limb ju feucte gethalten morben, und bann bleitet bas befte, ben Grock fammt ben 2lblegent ţeraus ju frelien und ins Gartenkert ju verpinnjen. Eollton liit) bic 2CKleger auth in Demfelben nid)t berwutzeln, fo wirb bod) Durdf Den vermetreten פiad)mutbs junger Stiche

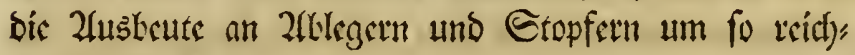
licher ausfallen.

Die alten Etófe, yon benen bie Zlkleger alyges nommen worben fins, ferenen mitunter, noth in ber Swifancmscit, wo bie 2ableger am Gtocke befindlit) fino, f(d)on wieber neue Triebe an, weldhe zum foms

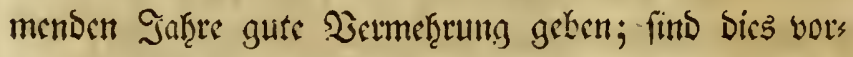

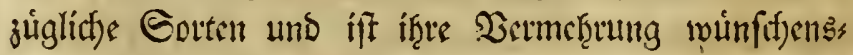

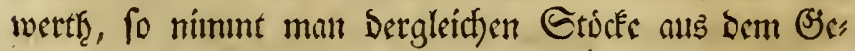

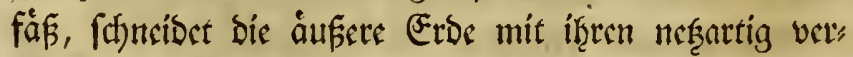

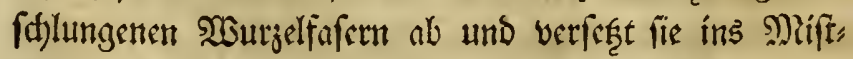
bert, in meldyem fie ben 2 sinter diber verbleiben fón

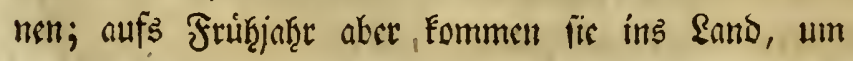




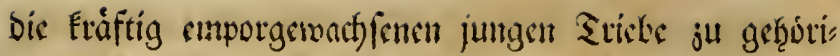
ger Seit jut frmfent ober als Gtopfer ju Kemufen, nadf) bem bas Eine ober bas 2lutore am tḩunlichften iff. Ju Ermangelung cines Differects bient, boct) minder gut, Die Durd)winterung in cinem frofffecten Sicnolles.

Mlitunter giebt

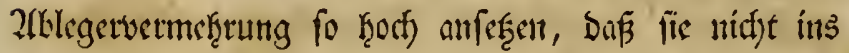

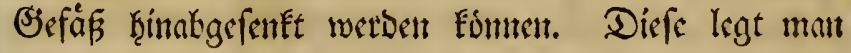

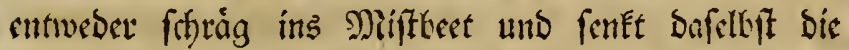
ZWleger cin, ober man fdulägt cinem alten, paffeno gro"

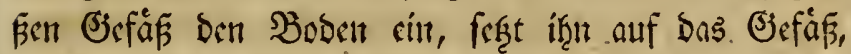

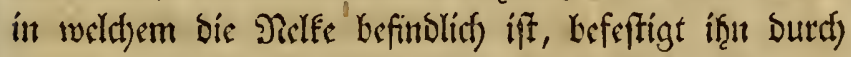
intuen unb aufen beigeffectete fleine Etáke, fúllt if̧it mit Eroe, und fenft nun in biefelbe bie 2lGleger cin.

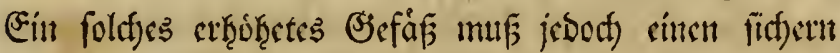
und feften Gtondort halen, Damit es nicht buted its

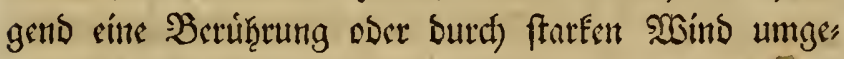
worfen werten Eann.

Die jweite Servielfältígungsont ber פellen Durt) Scfnittlinge, ober Das Gtupfen, ift, ant fid) betradfet, leichter uns mentiger múf̨uoll als bas Genten, allein bie Bewurgelung ift unfichere, aud) ift bas llnningenetrme

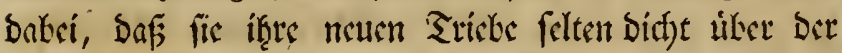

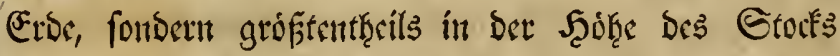
anref̧en uno Daf̧er ben Belifect nótḩigen, entweder wieder Etopfer von triten ju mathen, oder cins ser

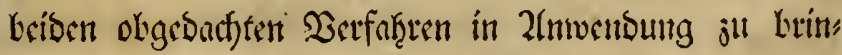
gen, weld)es auff rethfamer ift, benn of̧ue kefontore Эoth und Şcranlaffung mad)t man midjt gern Etcp" fer. So wie bei ber Błlumenjutht nírgetto Rúnftelciit gut thun, fo taugent fie aud) bei ber 2anfertiguntg ber 


\section{0}

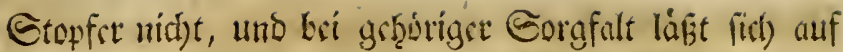

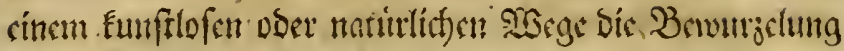
derfelten chen fo gut curtid)en, als auf nod) fo getuinn

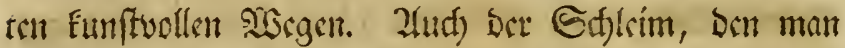

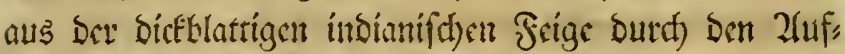

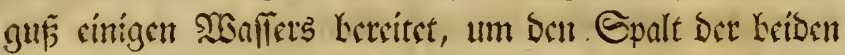

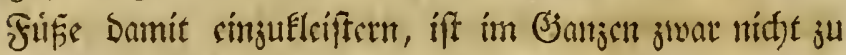

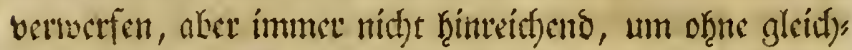
joritige Immentung Der nutthigan Eorgfalt Den Etopfer

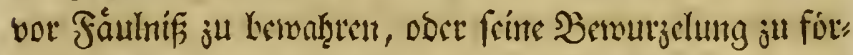

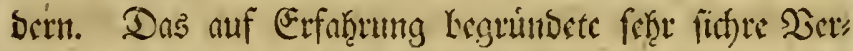

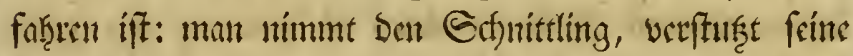

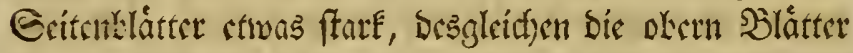

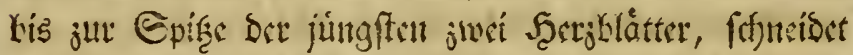

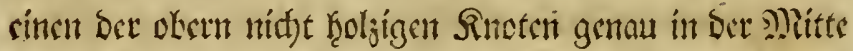

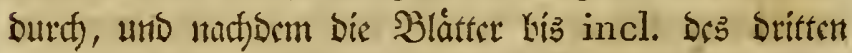
Sinotens bidft am Gduft algeffunitten worben firto,

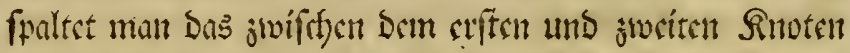

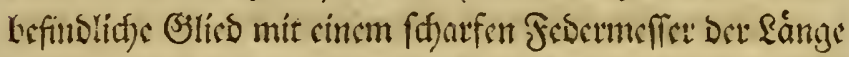

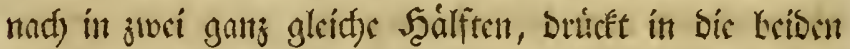

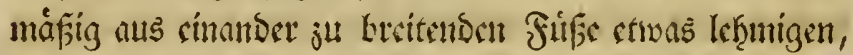

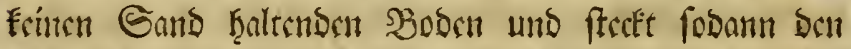
Edunttling bis incl. Des britten Rnotens in bas zu fai:

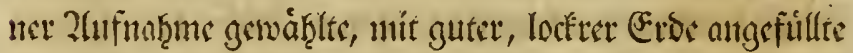

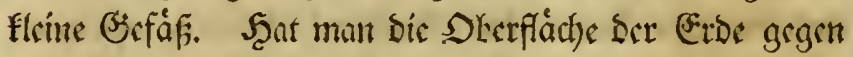

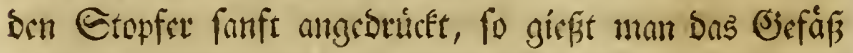

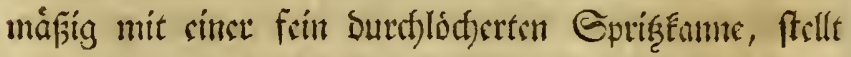
baffelte unter sine Suft julafiento Bebad)ung in Den

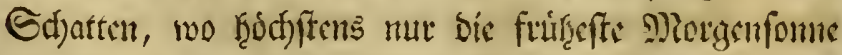
cine balle Etunde lang himtriffen Fant, unb läft Den

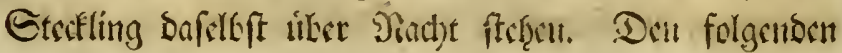




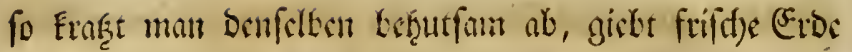
uno loctitt alsonm ben Topf auf, um bie Feuthtigs feit leffer ausbditiften ju mat)en. Dicfer grume lles berjug verbirgt aud) jumbillen Den trocknen Suftant

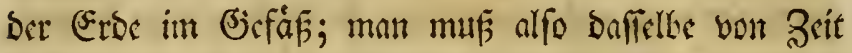

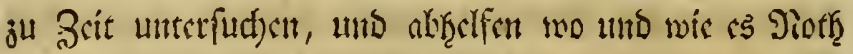
thut. Gtopfer bolt ju f(tywad)en, nid)t geţórig auss

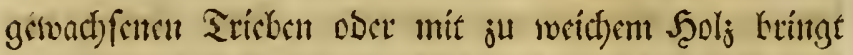

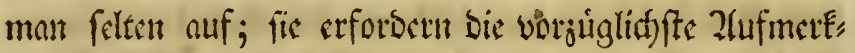
famksit, um nidjt ju betfaulen. Fantran Itad) ctwa

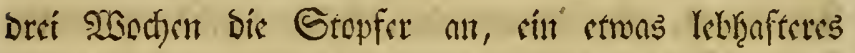
Griut anzumetrmen uns fich Exciten ju wollen, fo beat

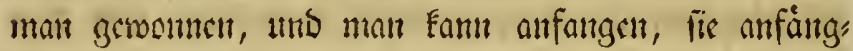

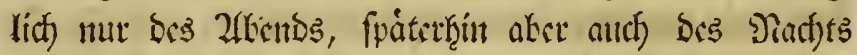

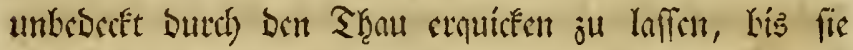

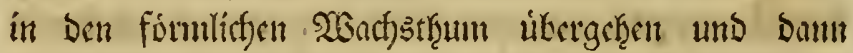

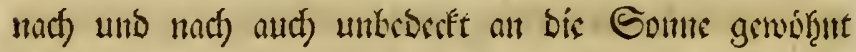
werdett Fonmett.

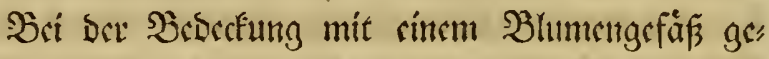
Hen bie Gtopfer cint; weil if̧uten Das Rifft mantgelt,

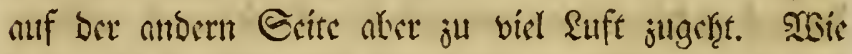

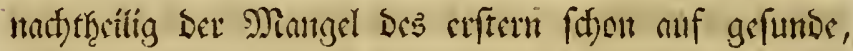

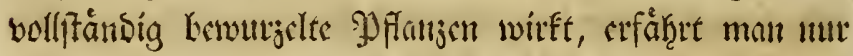

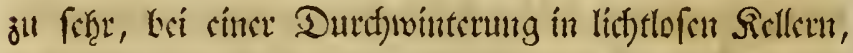

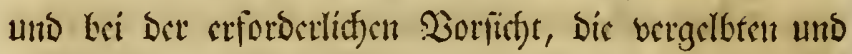

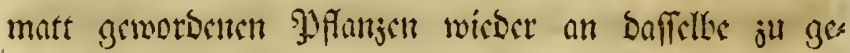

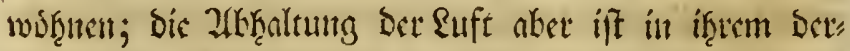

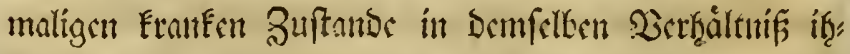

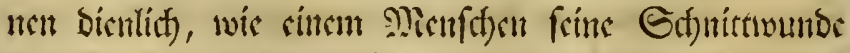

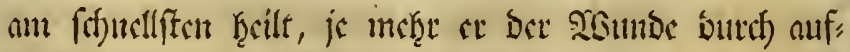

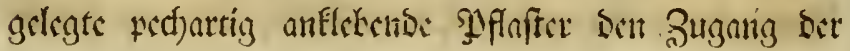




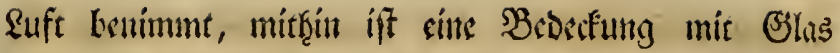
jeber andert volö山jictęen.

Dirs unn iff bis gantge Berf̧andlung Der Gtopfer, mit beten 2uffetigung mut fdyon im Mai uno Juni beginnen Fant. Es Inffen firf) Derfelben aud) Mefrete

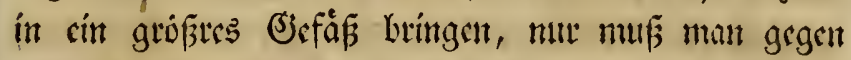

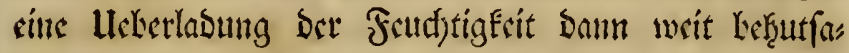

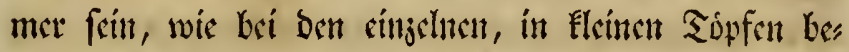
findlitien Etopfert. Da jeboct) cin Stopfer fich fius

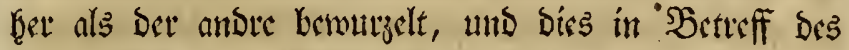

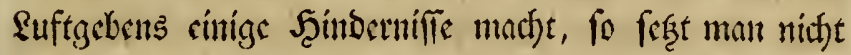

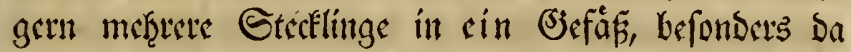

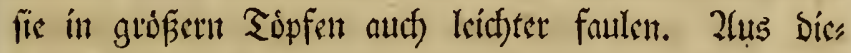

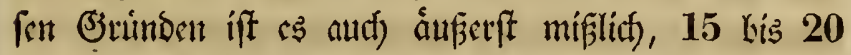

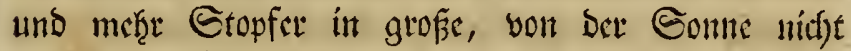
leifft ju Surtefwármenbe Topfe ju bríngen, ober gav in Sáften anjufertigen; man witrbe fict)er, wo nicfte alle, fo boch bei meitem bie meiften verfieren. Hebris

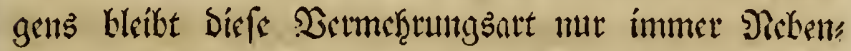
fad)e, weldfe eswa bet an einem Stode befindlidye lles berfup an Trieben uns beten notḩwensige Ruffung, obcr andere פebcmumftảnde gebieten, um bie Echnitts linge Dodf nicfit ganj nuflos verberben ju laffen. So

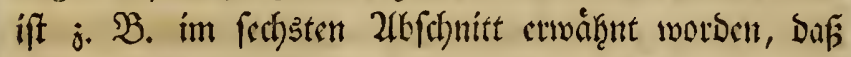

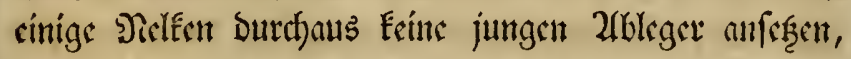
fondent lebiglict) in ben Epindel treiber. Sró̈ten

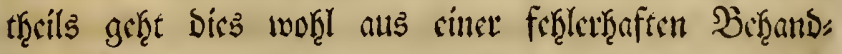
lung, aus cinct nicf)t ganj tougbaren Eros, befonderis aber alts sinem ju fpat begonnenen Genfen fietvor:,

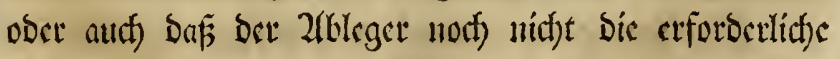
Rrife hatte, als man į̂n fenfte; fint inder bergleidyen 


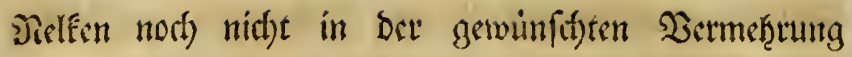
vorf̧nnoen uns if̧er Safonkęeit uns Ealtenţeit megen

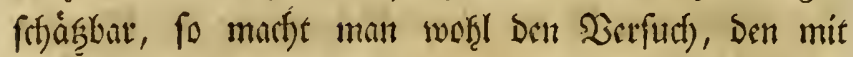

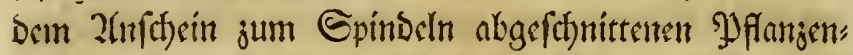
thecil als Eropfer unter Șlas ju brintgen. Zllerbings

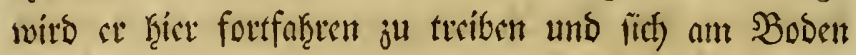
bes Bilafes hectum bis auf bie im Befáf befindlidje

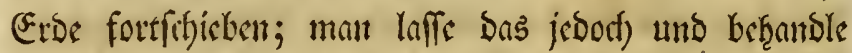
if̨n mit ber ofen nutgerathenen Sorfid)t, Kefonders yor

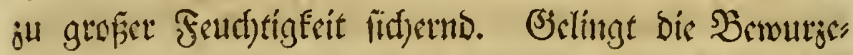
lung, fo fdyncibe man bent Epindel fo tief $a b$, Da

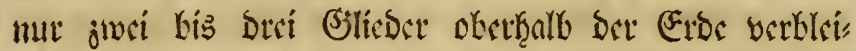
Een, unt jwar bieftet lifer Dem jweiten, allenfolls aut) ulber Dem Dritten Sitoten. Derglcitfan Gtopfer ferzen ge" wóf̨nlicí) sin bis zomei junge Tricke nu, weld)e bann

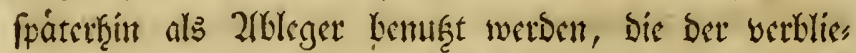
Eene Gtumpf bes Mlutterfoct's onjufescen woht aud) nidft faumen mirs, in fo fern nicft fojon cine Sirane"

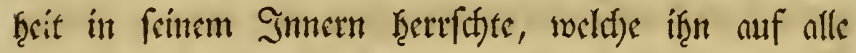
Fälle getobtet riaken wirbe. (Einen fold)en franten Etoce ins Miftbert ober allenfalls aud ins Sand ju fę̧en, bleibt nody immer bas Tiatḩfamfte, mur muf man benfeltert, in fo fern bas Sbiefen crforberlid) wird,

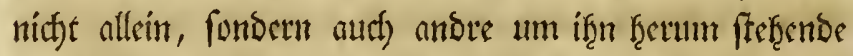
YYfanjen zugleid) Legisfen, weil fonft bie Regenmuirmet

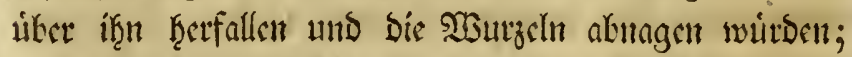

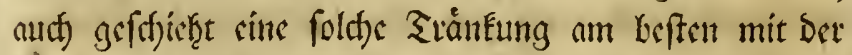

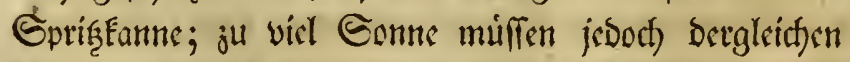
franfe Etocfe aud im Sande niche befommen.

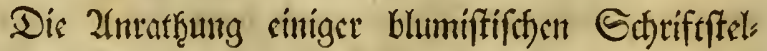
ler: bie Gefynittlinge erft meb̨rere Etunden liegen uno 


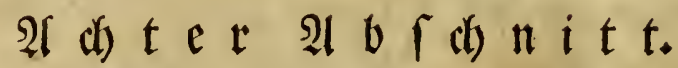

Heber Die Erzichung deb Sameng und Die Dermelrung Durd Denferben.

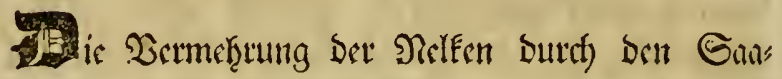
men hat unter andern bas Worjliglicte und unts fo.

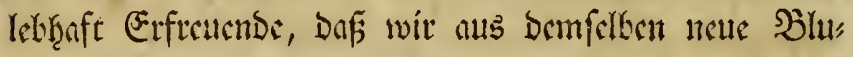
men mit ganj andern Farken uns Seichnungen gewwin nen, als wir borf̧er befaß̧en, und cine sinjige berferl Een, bie alle ben Forberungen entfpritit, auf wold)e man bei cince vorzuglici ju nennenden Blume fichte, macft, daßj mant fifon im voraus des Dergnuigents geniefit, mit wold)em man feine blumiftifd)en frrumbe Durd) Hekerfenoung berfelten liberrafot uns getn uns

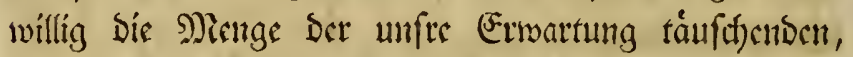
cinfarbig uno unregelinápig gejcicfneten ober finfblatt"

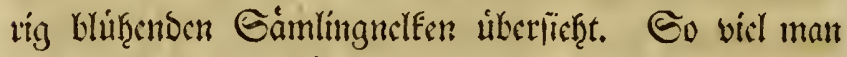
aber aud Gorge trágt, fidh in ben Şefif guter Gan menmutter ju ferch, fo ift es bod nichte fo ganj leicht, Gaamen von Topfinclean ju jichen, benn ftate gefuillte פelfen bringen fiton feinen Ganmen, Die minoer gefüll, ten aber fesecn bei ben wentigen Sinofpen, weldfe man mur

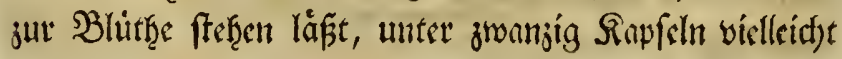




\section{8}

vier unb jwanjig Gtunden fo jufamunen, als wairen fie vertudlft. B̉et ftark gefullten Dirlfen vermogen jes Dod) bie Befruchtungstwerffeuge, wegen S)lenge Der

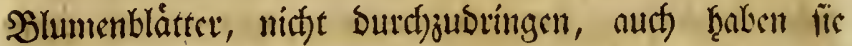
nur felten vollfommene Etuukfáben. Demmád)ft ges langen fie in Der Regel fruiḩer jur Reife als bie weib"

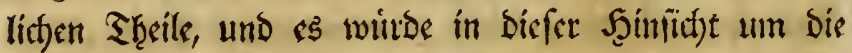

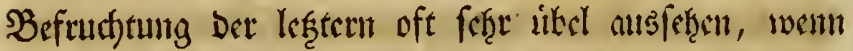

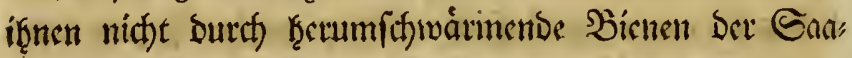
menftaub von andern Neleen jugefuihtet wuirbe.

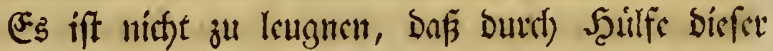

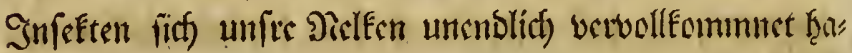

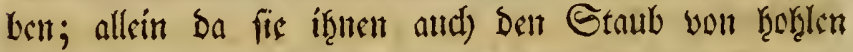

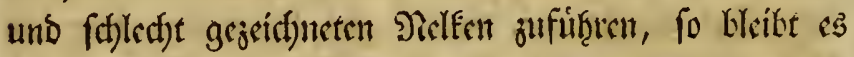
immer nut Dem Bufall untertworfen, went aus $\delta \mathrm{cm}$

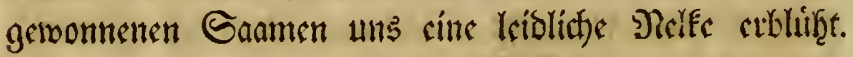

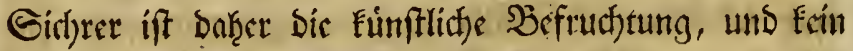

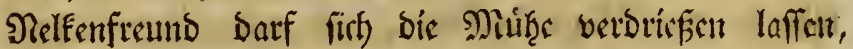

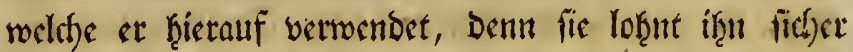
mit Dem beften Erfolge. Das Serfnhtern hicethei ift:

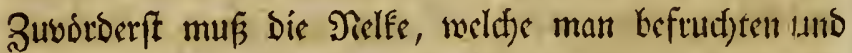

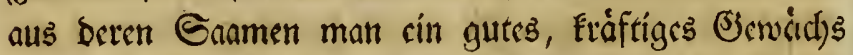
ergíftęen will, aufer ben móglictyft ftumpf abgerumbeten Blumenblattetn, vofllig gefund und in jeder: Scimlitat gut gebaut fenn, fo wie biejenige, yon weldfer man

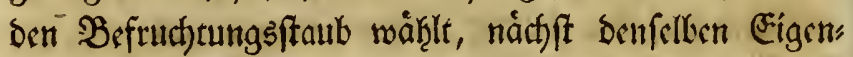
(c) aften auch eine Dured)ous reine Strundfarbe, sine

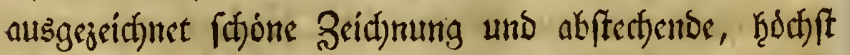
lebendige Farben kqaben muf; Denn nur als ben vorzlig" lichften, am isgelmáfigften gejeid)neten B̉lumen laffen

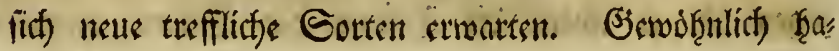


ben bie Todternelfen bie Strufe uns Den Bెau Der Mitter, Dagegen Beifonung uno Farbe Des Datets, und in biefem Betrad)t laffen jid) wok̨l zu ben erftern,

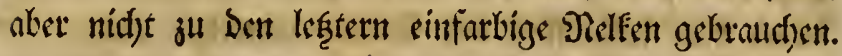

Llim jeber amberweiten Befrud)tung ju begegnen, entfernt man. bic ju begattende Dielfe nictet allein von ben úbrigen auf eine vor ber brennenden \$) Xittags[onne gelitterten, gegen Mlorgen und Zlkend Derfellen aber offuen, jeboch bebadyten Etellage, beren Jǘfe mit ivaf

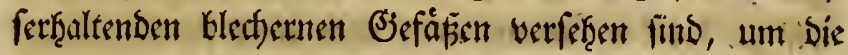

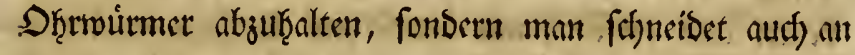
berfelken bie auf ben Gtaubfáben befindlid)en : Rolben ab, bevor jiti nod) Der Strub entwickeln und bie Gtrmpel befructen fann. Nun brobactutet man bis"

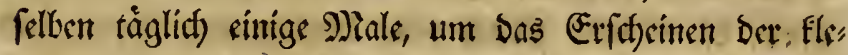
brigen Etgweiftrofpfd)en und mit îtuen Das Strimmen

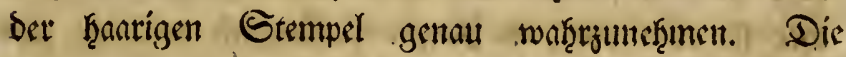

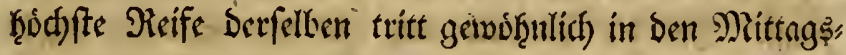
frunton jwifd)en 10 bis 3 llkr sin, uns bann ftetern bie haarigen Epif̧en ber. Etempel voll foldter Eleinen runben Tropfen. Gobals man bies bemerfet, frolt man

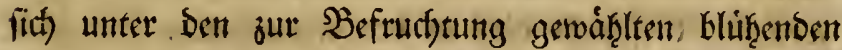
Datlfen biejenige, auf beren månnlicben S̉lutţentheilen, ben Solben oder. Gtaubbeuteln, Der reiffe gelbliche Staub vortianden ift, und ftellt fie neben die an, bes frudstende Blume. Die Beftudftung mus, wo , nur

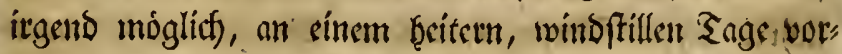
genommen werben und bie ßlume meber voun Sbaut

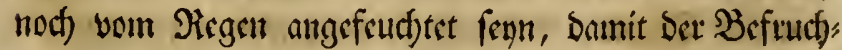

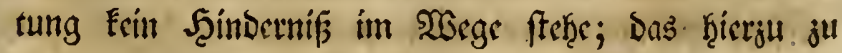
gebrauchende, tauglirffite Inftrument ift cin abgeftumpf 


\section{0}

ter, gut jufammenfifliefender Birtel. Dlit bicfem ex"

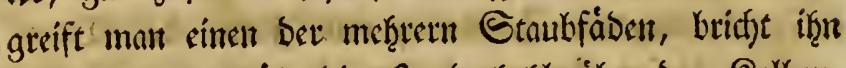
bef̧utfam los, ḩâlt bie Scand ḩof̧l uiber Den Solben,

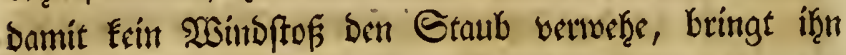

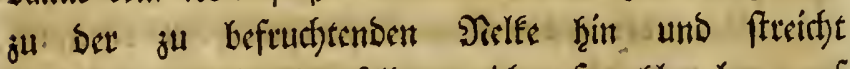
uno tupft mit Demfelben nitht fowofhl oben auf ben Siftillen; fondern aud) längs berrfelben von allen Griten fo fanft herab, . Daf ber Staub an ben fafti gen गुunften feángen bleibt." Llm ber ß̧eftudytung ge" wif ju werben, nimmt unan nod) eincu jweiten Etauk beutel unt verfáf̨rt mit bemielben cbenfalls in ber an" gegebenen 2lrt, fidfert fobann bie Mutternele vor jes

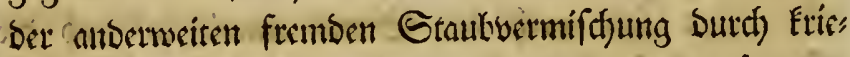
d) sines, bie Blume jeboch nicht beruhterenten flor:s, unb

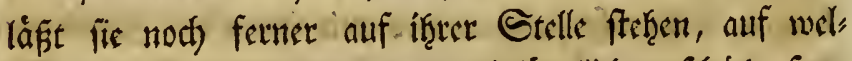

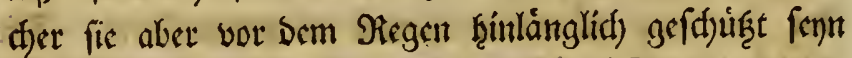
muf.. Sift bie Bెefructrunt gut von Etatten gegan"

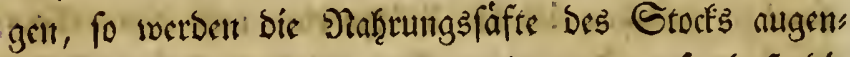
blicflich nuf ben Frudtetnoten bingejogen, , fo Daf bie Blumenblatter binmen viar und jwanjig Gtunben ver"

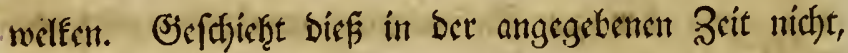
10 "if bie Sperntion nichte gelungen, bie vollige Reife bes citten ober. Des anbern Beftucjtungsivetfienges

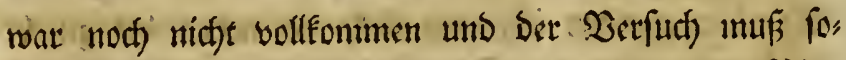
fort 'nicberhiglt merben. Sollte fic aber vor ber Mlóg" licféteit biefes Derfucts, wegen Mangel an Saamen,

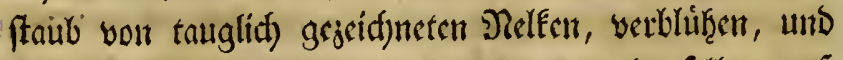
bennoch Gramen kringen, fo hebe man benfilten auf,

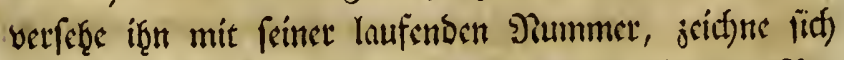
in feinem Befrudftungs" und Gaamentude bas $\mathfrak{R}$ 
tionale Dez Ganmenz mit allen Ertignifien und Reten, umnfánben auf, unto adfte auf ben Erfolg Der Eànt linge, weldye aus. bamiellen erjílt wordent fints. Eiin

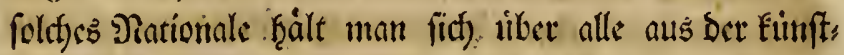

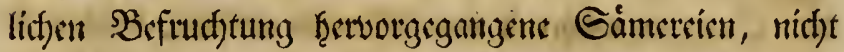
allein, unt bie beften Gannenmitter fennen ju lemen, fonosen vorgitglid) um nad) 2(nlstitutg ber 2fbesmm:

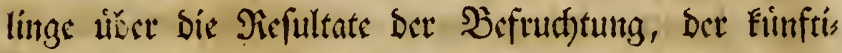
gen Fatbenwaf̧l und Dergleid)ent int Picine ju fommen uns auf biefe Ifrt getwiffermafent in bie Piefultnte ber,

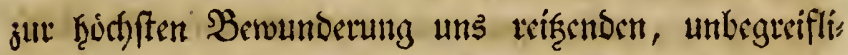

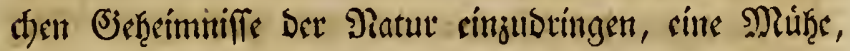
wold in in îren Erfolgen fid unenolid) belof̧nt.

So wie. Die Blume zufammengetvelft ift, nimme man ben Llmb̨ang wieber ab unb ftellt Das Şrfáz allf

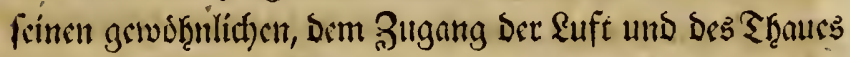

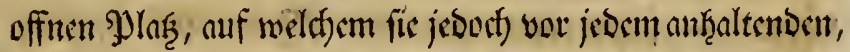

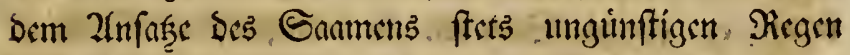
uns vor ben bie Gnamenfapjal getn Durctjfeffenden

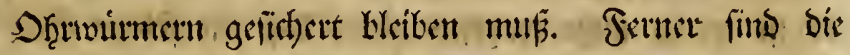
Blumenblatter, fobals fie vertrocfinct, und f̧ate finto, nebft ber bie SBlumenfapfal umgebenden åufern Scille

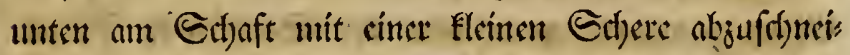
ben, Damit fid). Eeine ఇâffe in Denfelben auff̧alten uno Den Ganmen burd) fáulnís verderben foume. Eotrold Die Rapfeln cine braungdlblit)e Farte befommen uno oben fid) offunen, zrigan fie Die Reife bes Ganmens ait, unto. Daun ift es Brit lie abjuncḩmen, Damit bir

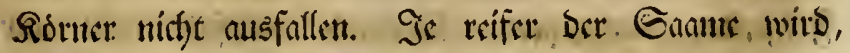
oefto fejonere Syflanjen etwarbfen aus demfellen; ss

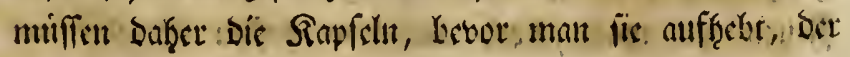


volligen Tadfureife vegen, nod) luftig aufgethangen uno rect)t troctén gethalten werben, Dannit Der Eaame nicht

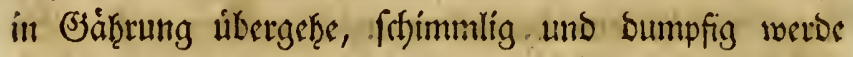

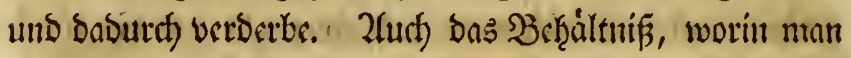

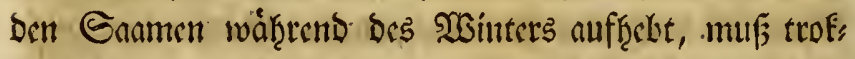

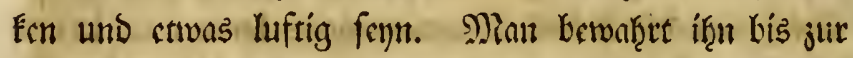
Itusfant in ben Sapfeln, in weld)en jeder Eane am beften bauert, bringt if̧n in Fleine Yapierbtiten mit

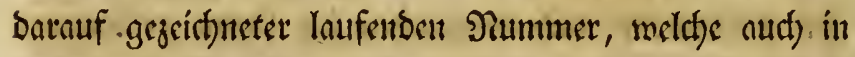

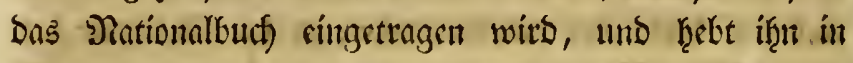
Beuteln von locker gewebter Scinmants auf. Zluf bicfe

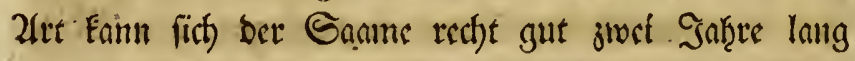

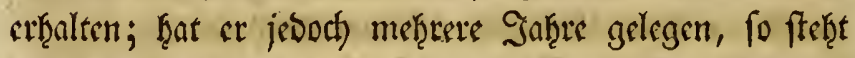

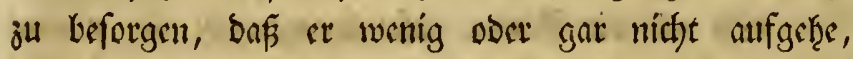

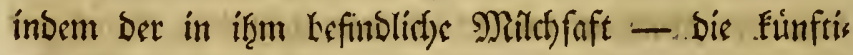
gen Snamenlappen, weld)e bie frimenden Pflänzchen náḩıen - faton vettrocfnet ift. 3war foll berfelle, wonn, ar eintige Etunden in aufgeloften Enlmiat, ornbirte Rod)faljăaure 2c. gelegt wirb, nod) aufgehen;

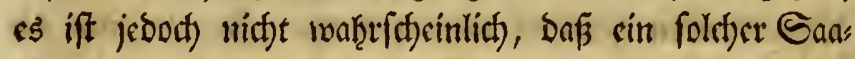

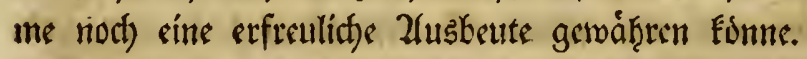

Sin wie fern bie fatten an 2(bmect)slung unt Blany gerwinnen, wenn man ben Ganenen in Brannt"

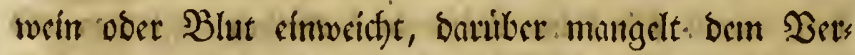

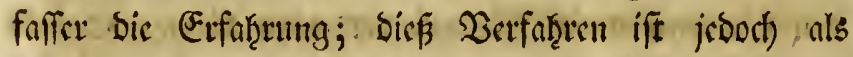

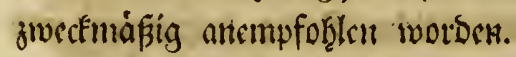

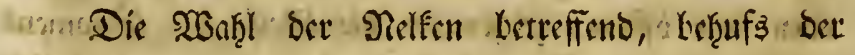

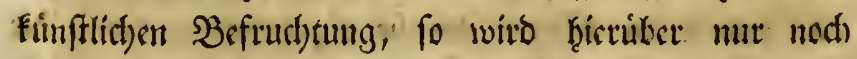
Folgentes nact)gebolt: 23otmals ampfaf̧l man nur

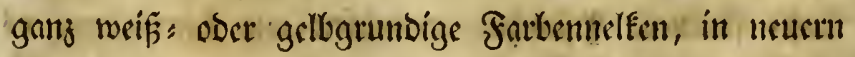
Seiten hat man jebod) mit bem beften Erfolge mu 


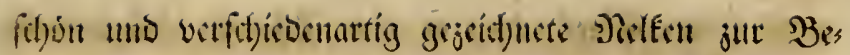
frut)tullig gewåf̨lt uns cben Daburd) sine Dannigfals stgfeit ber Zeid)nungsanten und Fartenabwertfelungen

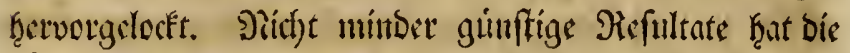
sisurfl Dunfter Farbenulfen, mit Dim Eamenftaube

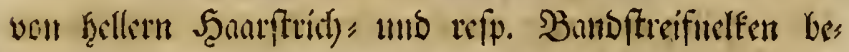

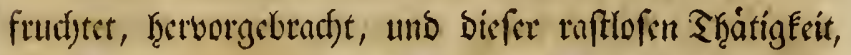

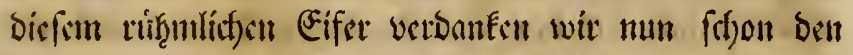

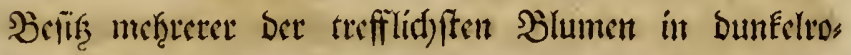
there, hedltother, fupforfarbner, afd)grauer, violetter

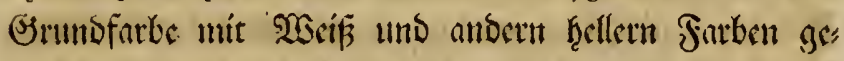

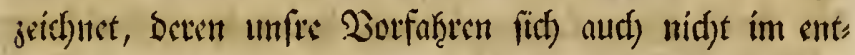

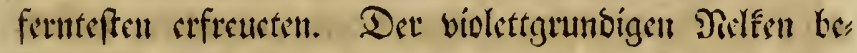

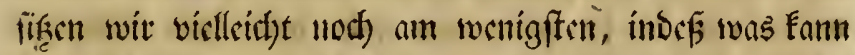

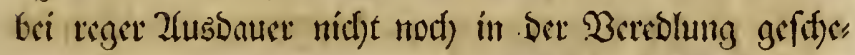
fecll, was von ber gitígen शatur uns nicf)e nech alles gefdjenft werben. Es ift jwar nidjt ju leugnen, bap

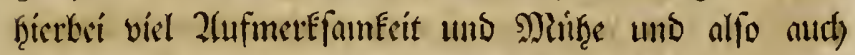

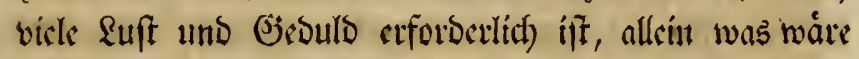
Denn in biefer Şolt nity)t mit cimiger Zlufopferung

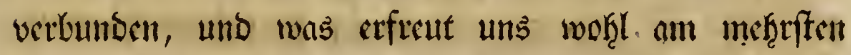
als Das, was in Folge unjers Simment, Stribelns und

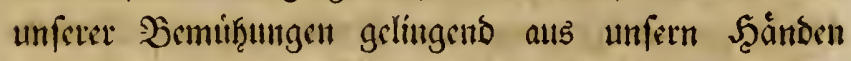

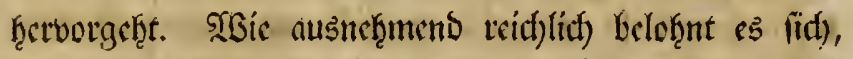
wemi man aud) nut sine einjige terfit cole ßblume aus Dem sigen gejogenen Enamen gewiumt, uns wie keeiltmant fit), andern Blumenliebfrabern, mit benen man

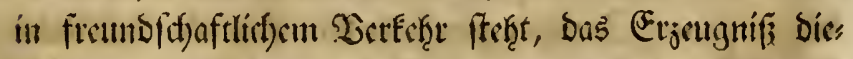
fes unfers unermudeten Jileifis mitjutterilen, fokello is

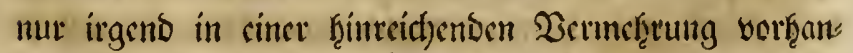
oen ift; Denn fo sigemunigeig, felbftrudytig uno farg ift 
wof̨l felten Einer, Daf cr cine Planje blef Deshralb

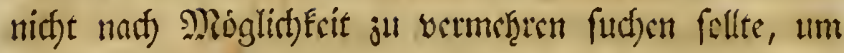

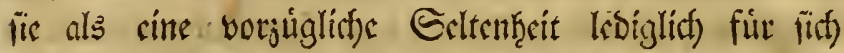

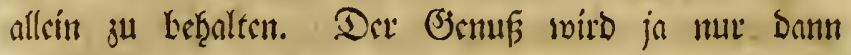

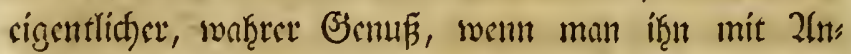

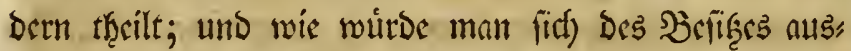
gescrifneter Edjontheiten etfreuen formen, went jeber Şlumift nut fuir Den Ealkftgenus und nifft aud) fur ben Inowe arteiten, sinen gemonnenen Gämling von ausgegeid)neter, feltner Edjonfecit nid)t aud) foinet Freunoen mittheilen wollte; ja es gicbt Deren cintige,

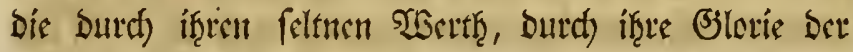
ganzen, Kefreundeten Sllumenmelt angeţoden follen, wenigftens in fo forn man fict von ben Eimjelnen liberscugt halten barf, Daßj fie biefelben nicht offentlich jum Derffauf bringen, fondern als sin unveráuperlis

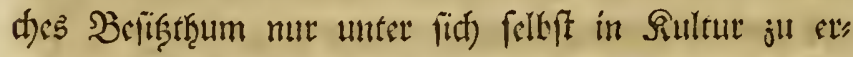

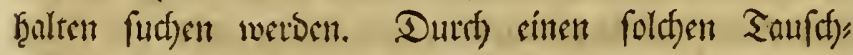

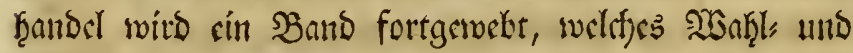
Seffirglsuermandtfyaft tectoorbrad)te uns um fo fefter ju halten ift, als cs nur cinjig ju crfereten vermag. Die Vermeţrung biefer Frruben beruḩt Klof auf Der fúmftlicten Befructutung Der Delfern, Deren Eamen, mitter man fo viel als moglich unter ben farten" nelfen von trefflitisem $\mathfrak{B}_{\text {nu }}$ uns glanjoollen, leutgten ben Farken ju wák̨len ţat, als weldje chedocm ganj unterbitet blicken. Mlan forge mur fit bie Bicwin, nung fdooner Bcidnungsndlen uno für Dic Errhaltung

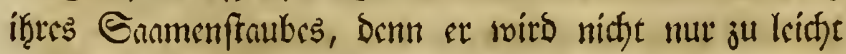

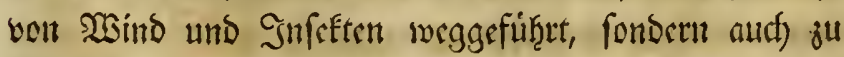
foncll gersift, befonders menn man ben Gtock an ju 


\section{6}

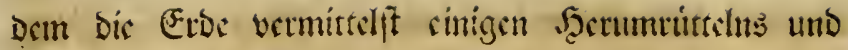

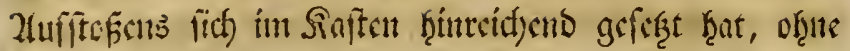
iid) jut feft auf cimanbir ju lagetn, jichte mant in bit

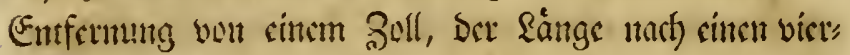

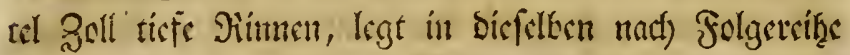

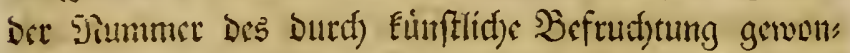
nenell Eamens, stwa $\frac{1}{8}$ bis $\frac{1}{t}$ Boll von cintander, bie Ganmenforner sinjeln hint, ffecft beim erfen wie bcim lifeten Eaamenforn bor cinjshnon Gorten Das

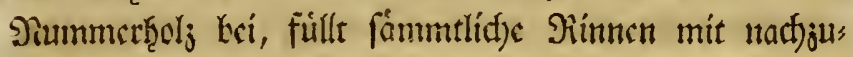
fouttentor Eros aus, Kefprengt fobann biefelle noths Dirfrig mit ber Eprifetanme, Damit fie fid), vermoge

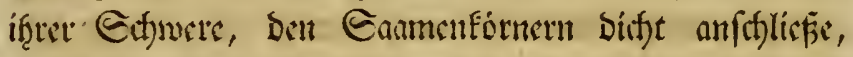

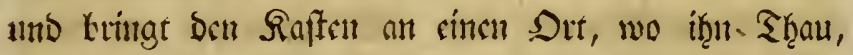
Rigen, \&uft und Morganfonnte teffen fornent. Dic

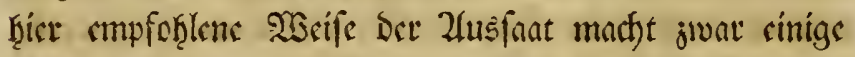
Mhifie und nimmt ctwos mef̧r Raum cin, fo Daf man

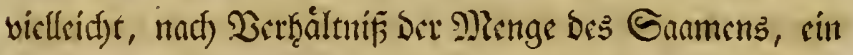

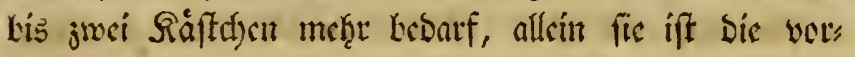

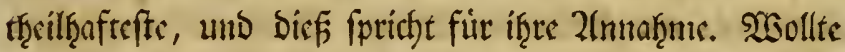
man aber bie Sioner nidft fo cintgeln in bie Eroe brin gett, fo milifen fic boch fo sumn als mogliat in bie gejegenen Piimen gelegt merben, Domit bie aufgrgan:

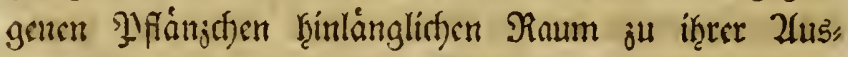
freitung beţalten, Suft und Sonme aber fie hinneid)eno

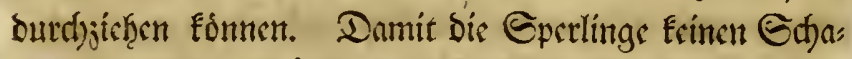
ben antrichten, foblęgt man nuf beibe Geiten bet Sạ

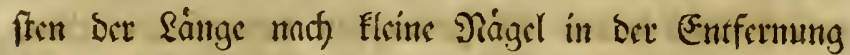
bori 1 kis 2 3oll cin uno kefeftigt an benfelten ubers

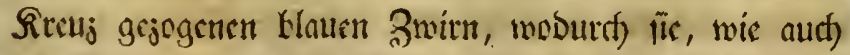

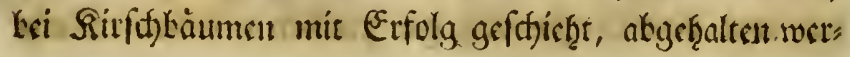




\section{8}

mit. Der alten Eror aus ben Pelfentspfen ober in más figigen Quantitaten mit ber aus ben MRifteeten ents. mommenten, gánglít) vertotteten (Erbes. Ulm afer in bar

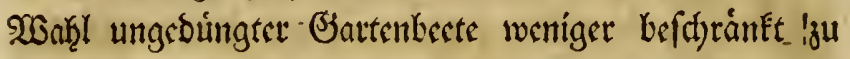
fenn, ift es forter gut, Den Şarten in brei Quarticre cinjuttecilen, von bicfen jåḩrlict) nur cincs ju bintgen,

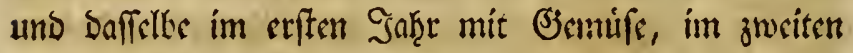
aber mit Dielenfämlingen ju bepflanjen, weldhe man in

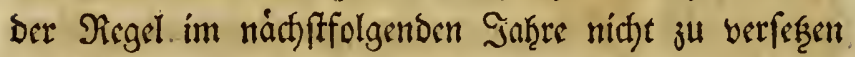

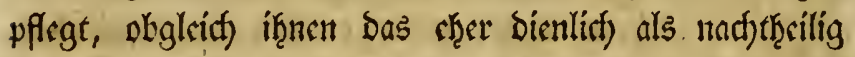
fenn muirbe; Dann bringt man fie auf sin Bert bezz britten Suatticts.

Das jut Wetpflanjung gewåf̨lte Bect mirb zu ciner Scit, wo oer Booben von Ecinem Regen fdumie" rig ift, in geţoriger Ticfe uns unter fotmalen Etis d)en umgrgraben uns bie Erbffiollen gut jerfoflagen, Damít Die Eroe móglidffit mild und locker werde, Eeine.

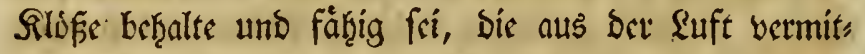

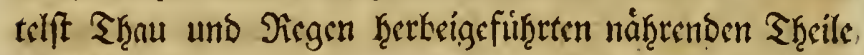
leicjt cinjufaugen, bie zarten $\mathfrak{W}$ urgeln aber leicht bins abjubringen uns fidf nujgubreiten vermógen. Dâ̧. ein folctes Bect folon im vorigen Scerkft umgeworfen: werbe, ift mit aller Sorgfalt zu beobachten, nidjet fos woḩl Damit Das Lnfraut berfaule, fondern aurf), Dafa. Der Boben redjt gut burdffriere und vom froft mitrbe gemacft werbe. Finden fich bei ber Subereitung in Suni aber noch. UnE Eautwourjeln, fo muiffen biefelten, gleid) Den Gteinen uno anderm Ilnraţe, forgfältig ber: ausgefuct)t und bei Seite gebrad)t vertoen.

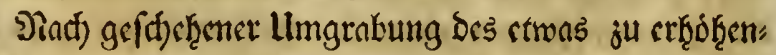
Den Beets miro Daffelle unit Dem Rechen (aud) Sarfe ges 


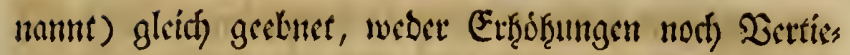
fungen geduldst, in gevisf̧nlid)er Brcite abgetteten und barauf vier bis fünf gleidy weit bon sinanber abftes

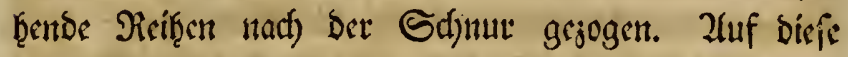

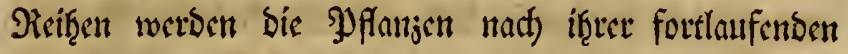

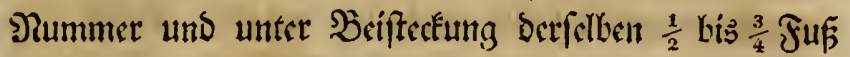

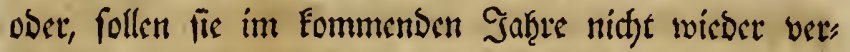

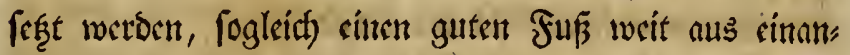
Der, jebod) nífft tiefer verpffanzt, als fie frutherer ges fransen baben, fo baf ber Thecil, an welldem bie Saar menlappen franden, ouf jeben Sall úber ber Skerfiádje Der Erde berbleibt. Eic werboen fofort begoffen, jeboct)

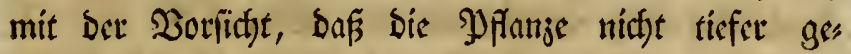
fenet, nod) weniger aber umgetnictet und bie Fiffe ber Şerbblatter nidfe mit Erve gefuillt werbe, in weldyem

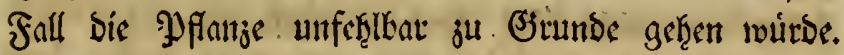

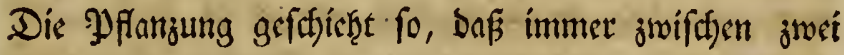

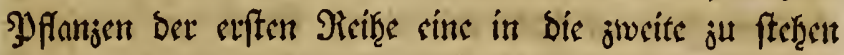

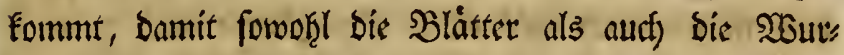

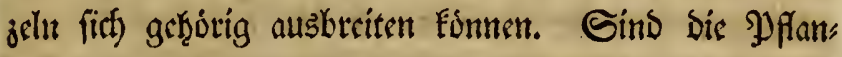

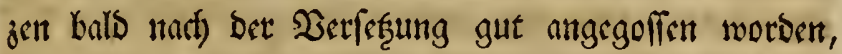

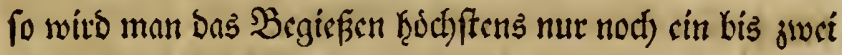
Mal, in fo fert es in ber zawiffyenssit nidjt tegnete, wiesertrolen burtesn, befonders wenn ber Boden etwa's fdiwer fenn follte. Das offece Begießsen taugt úbers baupt nid)t, Dern wemn bie PYfantjen nur intmer in

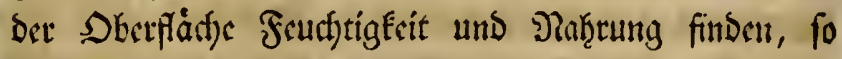
wurtseln fie niffet ticf genug und Keiden, wemn bas $\mathfrak{S}_{\mathbb{E}}$

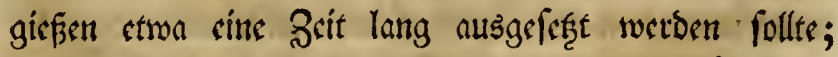

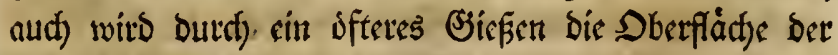

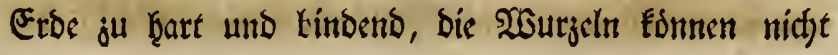


tief genug cintringen, wodurd) bie गु fonjen im 23udf)

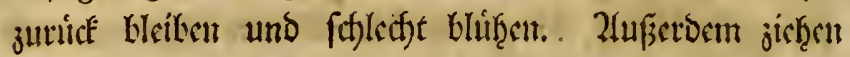
firf) alud) bie Regentwuirmer altf bie naffen Stellen hïn,

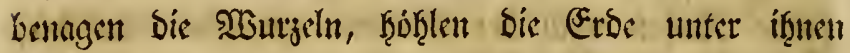

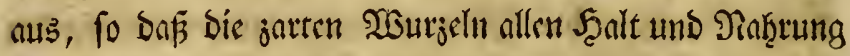
verlieren, uno folgliff) verberben miffen. SJiefst man

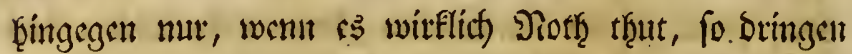

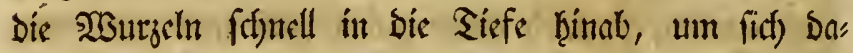

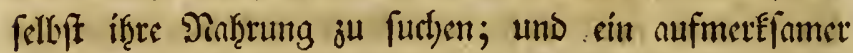

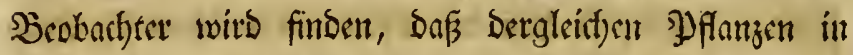
Den heipien Sagen, wo bie Sberfiádfe Der Erbe vor

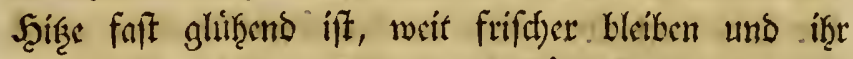
Saub falt fuib̨l anjufuifelen ift, máh̨rend bic unter cí

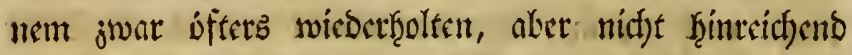

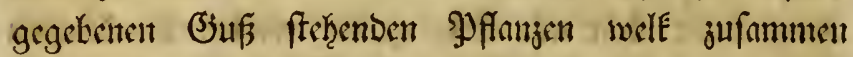

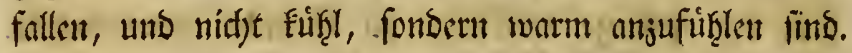

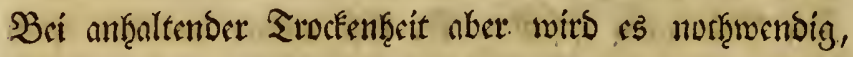

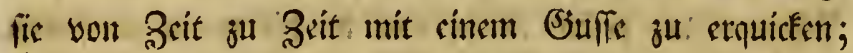
Dícs. muf jebor) mit émer Eprififanne uns jwar fo gefthetren, Dẩ bie Erde bavon bis auf eine Biertels Elle tief burd)bunigen weroe, bent mur in biefem fall

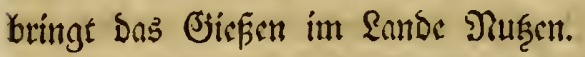

Da bie (Erbe nad) uns nady bidst und feft wits, fo ift bas Y)fanjenbect von 3eit ju 3eit burct) $\mathfrak{B}_{\mathfrak{e}}$

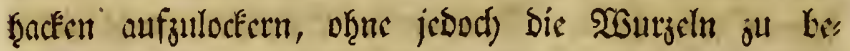

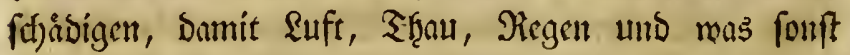

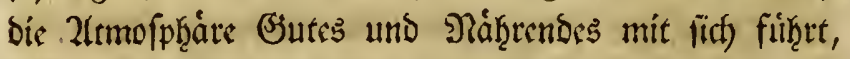
beffer sinzubringen bermógen, aud) jugleit) Das Un,

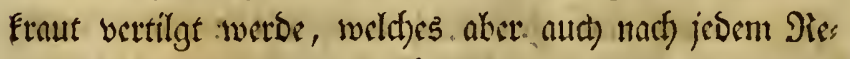
gen aub̧uheben, nie verfåumt werben Darf. Einer

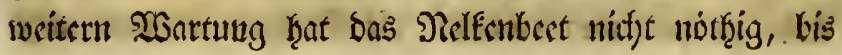




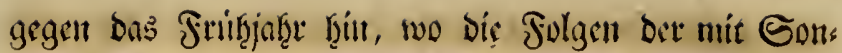

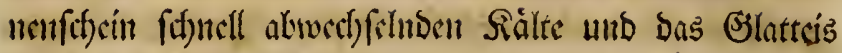

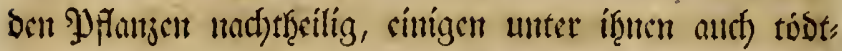
lich weroen Eunt, uns wo es ththfam wits, jie gegen

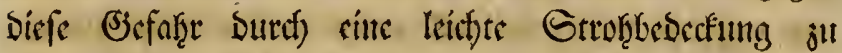

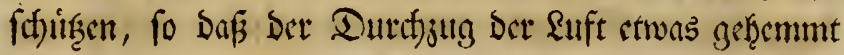

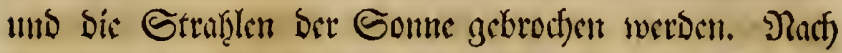
jrbem singetretenen Shaumetter brickt malt bíe yom

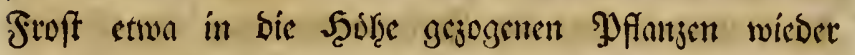
finunter, bedecft erforberlid)en Falls bie von Erbe ent:

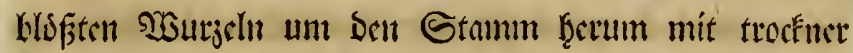

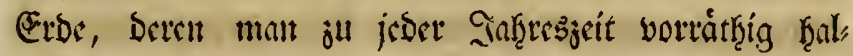

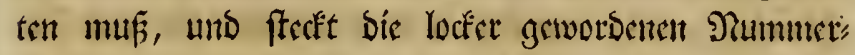
bolyce wirber feft. SBei weiterm Dorricfen Des Jruiţ,

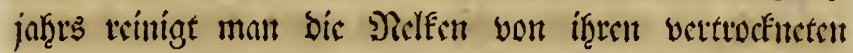

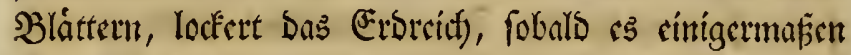
liberttodfitet ift, wicber auf uns forgt mit ber grófiten Zlufmerffamfeit für bie Sertilgung brs bertvorfément ben Llnftauts. Sçntte man beabfirftigt, Dic Pflanjen in Fommenten Frtigjaţr wieder ju verferen, fo wirs Das Bert hierza im Márz bearbeitet unb bals Darauf,

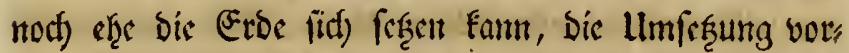
genommen, bie YJfanzen gut angrgoffen, Dann aber

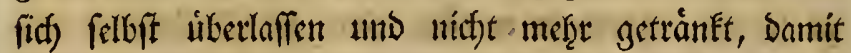
Dem Wertaufent ber Blumen nict) Diaf̧rung gegeben werbe. Sangen fie benn enblich an ju fininseln, fo

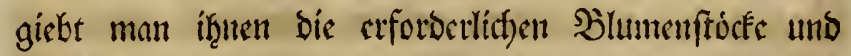

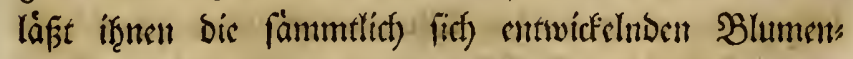
Entofper. Sinben fich unter if̧nen fiir ben Topf mit: bige Sorten, fo Eann man jwar biefelben in Berte

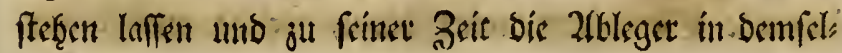


Len anfertigen, Doth) ift sa ratḩfamer, fie bei meţr trocfinem als feutftem Suftante Der Eroe beţutfam mit

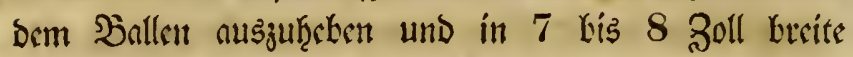

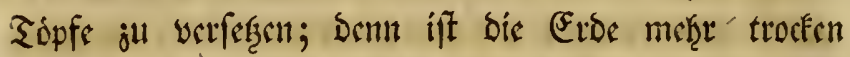

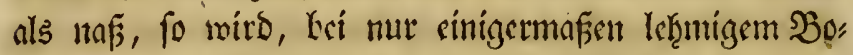

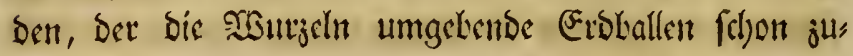
fommentralten, fo baf fie, of̧me irgents sinen bedeuten, Den Echaden ju erleiben, in das Gefáf geturacht reck

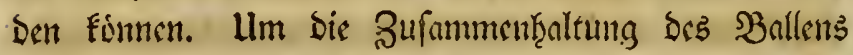

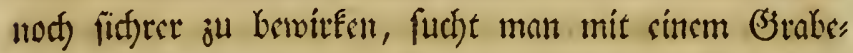

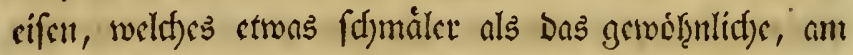
Leften ganj won gefdemicoctem Eifen gefertigt unt mit

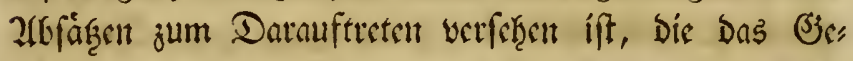
wád)s umgetende Erbe von allen Geiten fo tief nls móglich ju trennen, mit bem leşten Etich) aber es

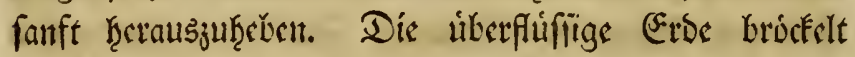

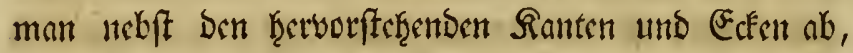

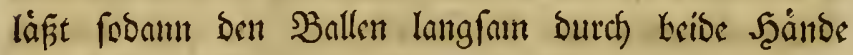

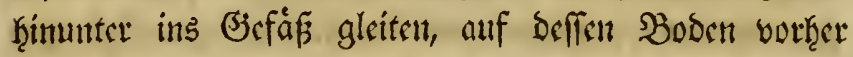
(d)on etwas gute (Erbe gebracht fenn mus, uno fatuts tet fodanit trockne Evibe nady, Damit alle Smiffycutáu, me vollfommen ausgefillt werben. Scált Der SBoben jebod) nitht gut jufammen, weld)es gefdichtert, wenn $\mathrm{ev}$

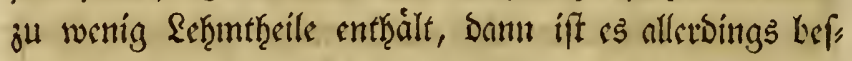
fer, bie Stocfe im Sande ju loffen uno ihre laufende Gámlingsnummer, welche von der Ganmenmummer unterfofícben und anbers geformt fenn mu位, 低ucu bort beijuftecéen ober an ben SBlumenftock oben ju befeftis getr. Dem ins Gefáf grbrad)ten blikentoen. Stoct ftecft matt ebenforls mebjt ber Gaamenmummer aud) bie laufende Sámlingsnummer binju, welde man beiber: 
feits Dem Stock und feinen 2(blegern fo lange läjt,

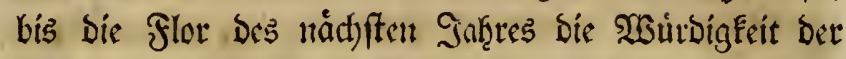
Blume in bie Topffammlung befunbet unto man bas f(t)on bei ber fJlor bes vorigen Janteres fortgeferęte, mit Dent nothigen Şemerfungen bereiduerte Piationale voll

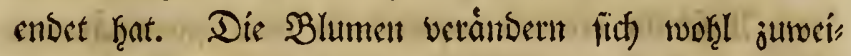

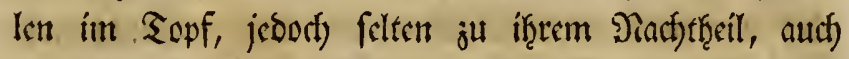
werben fie in Demfellen ber Miggel nach grófect uns lebentíger an Farben, indem fie aus sinem, magern Boben in sime gute, forgfáltig prápariute Erbe foms

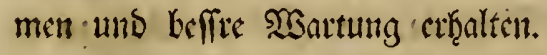

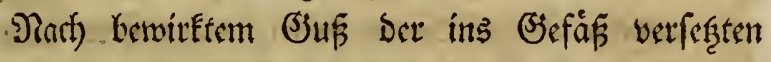
פielfe wirb Diefelbe in ben Gantten geftellt uns bleibt Dofelbft fo lange ftehen, bis bas Jecben und bie Etei

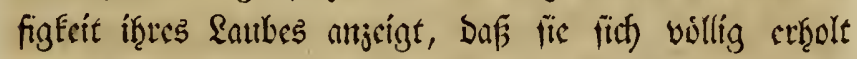
teabe; jebod) witro fie immer nur nach uns thad) in

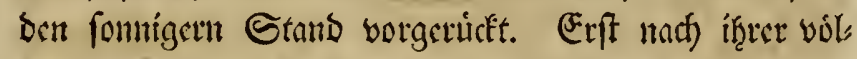
ligen Ertholung mad)t man Die $2(6)$ leger, weil fie Dann weit ficferer Kewurgeln, als went man biefelken gleich nad) Der Ulmfę̧ung allfertigent wollte; cs wáre Denn,

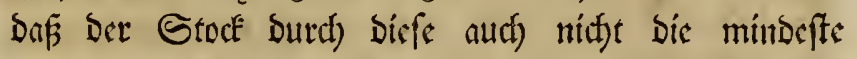
Gtórung ctḩalten obcr bie Umfę̧ung fpat im Jah̨r cine Der jullef̧t, etwa erft im DFtober bluif̨enton Dicls fen getroffen háatte; in biefem fall fertigt man jes

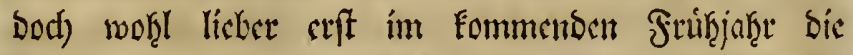

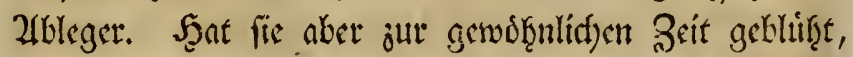
fo Eann man von Den ju!n. Genfen ju ḩod) ftef̧enden Detentrichen gleid) nad) volljogener llmfertung Stop" fer madsen. Gámmtlid)e ableger, befonders aber von Den in SBeet belaffenen Tielfen, fentet man am jwects" mápigftent arft gegen 2(bend, wenn dis YYFanjen mod) 


\section{4}

welf fints und iţe Bruitgigfeit toeniger zu beforgen ift, lockert nber vorber bie Erose um ben Gtamm hece um ouf uns foututet gute Sortatḩserbe nach. Die anderweitige Suerferzung Der 2(bleger und was fonft nod) Darauf Şigug bat, ift fowohl im 4 ten als im 7ten 2(b/d)nitt crortert worben, in bem gegennártigen aber nur noth wiebertholentlich bie Zluffewahtung treff",

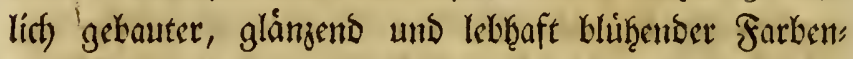
nelfen anjuemtpfeţlen. Şoţle und anbre fdled)t ge"

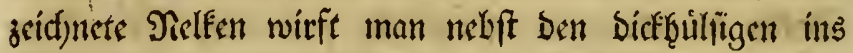
Eros uns llnftauts Mangajin, im Fall fie nidst ju cis

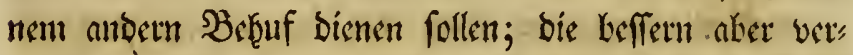

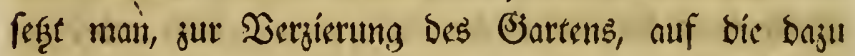
geriguten Rabatten. 


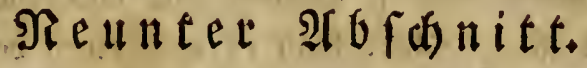

Bon Der Dardinterung ber Rellen.

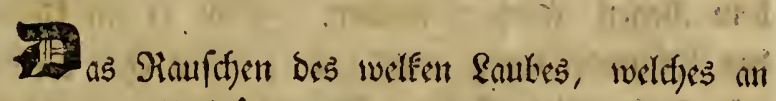

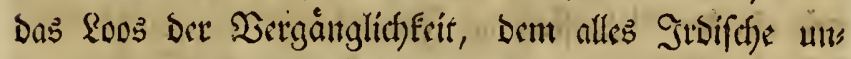

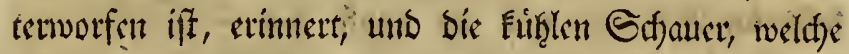
úber bie vergelbenosen fluren fterifat, laffen uns nun

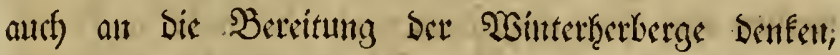
wellese bie Rieblinge, bie uns bent Sonuner Gínsurd) to ḩod) erfreuten, nummef̧r bebsitfen werben. Sie gereinigt in Daffelbe zu bringen, if bas erfte Erfor"

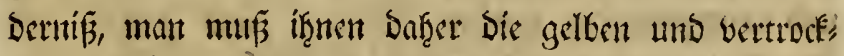

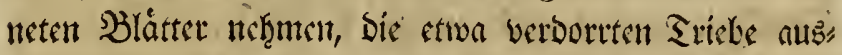

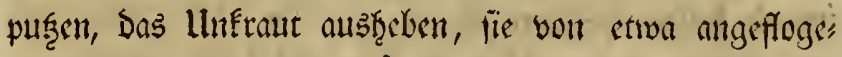
nen Spinmweben, B̉lattläufen und Der von if̧nen viels

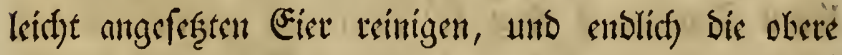

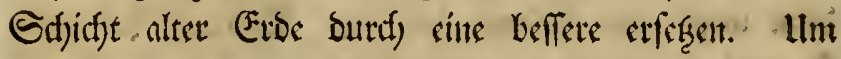

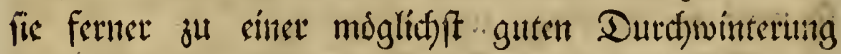

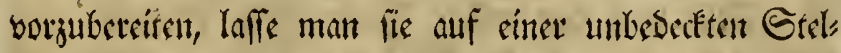

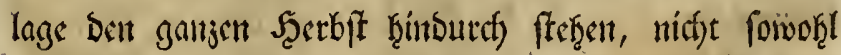

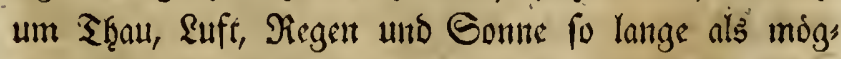

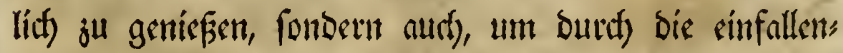

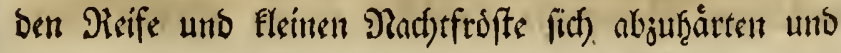




\section{6}

an bic Rálte zu gewwįhten. Diefe ift zwar im Sopf weit angreifender, als im Lande, Fann if̧nen jebod) in

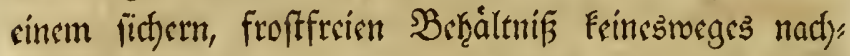
theilig werden, wenn fie tridjt vorfecr fdyon in einge foblofiencu, luftlofen Sten vergártclt uno Erane ge" mad)t murben, bem je gefunder und ausgetildeter sin

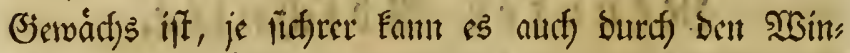
ter gebracijt werbent. Eo wie dic Sálte zunimmt,

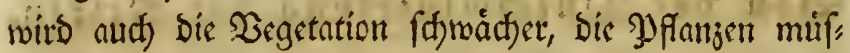
fen bafere um fo fparfamer gegoffen uns vor anf̧alten bem Regen gefictert metben. Eoll ja cin Uebel in

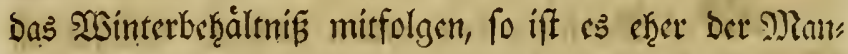
gell, als Der lleberfúp an Feudtigksit, ber woḩl allen falls im Truikjahre und im Saufe bes Gommers, wo Die Sanále Der Pflanjen vont Der Wảme ausgebstrnt werben, von if̧net eingefegent wirb, aber nid)t im Scerbjt, mo bci junch̨menoer Rálte lich) bie Ranále jufammen, zisteren, Der Llmlauf der Gäfte vermindert wird, Diefel, ben alfo von ben IIflanjen nid)t wicber verfiucftigt

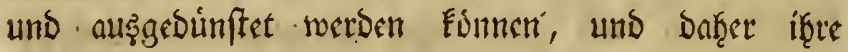
Sitanffecit crgengt wird, weld)e fie im Saufe cines mur irgent Ealten SิSinters if̧rem gewiffent Llntergange cut

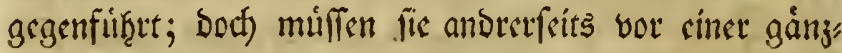

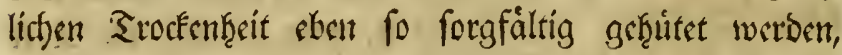

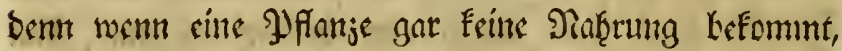
to muf fie allerbings aud) singeţen.

Fällt nach) Den crften. Sact)tfroften Єdunce, uno beginnt Der Froft in Die Bjeliaude ju Dringen, fo tringe man bis beffneiten, uns baburef) mit siner roarment Decfe verfebenen Sopfe ins swintetgemadt). Freilich verlangen fámmtlidje Topfpflanjen im Winter meţr 
Zufmerffanfeit, als wåh̨tend bes Gonumetz und Scetb: ftes; follte aber aud) cinige Sálte in bas Senwulbe cinbringen, in ben ftengern Sóntertagen fogar Der Froft bie Erobe hate gefrieten madyen, fo fen man bennod) unbeforgt, fobals man bie obgebacteten Sors

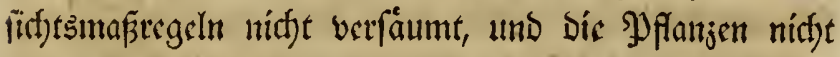

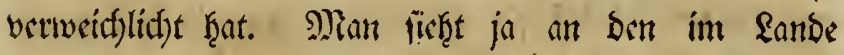
ftergenden, ber Rálte to gánjlid prés gegebenen Nels fett, was fie zu ettragen vermogen.

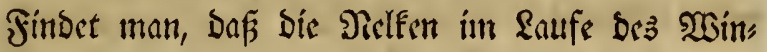

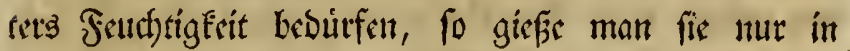
eincen nidst ţartgefrornen Suftande, wo moglid bci Thaumoctter ober fonft gelinder Şitterung, bei gedffs neten Fenftern, mit verfd)lagenem Şaffer, oder ffelle

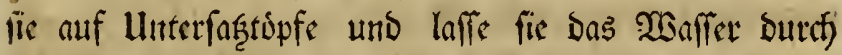

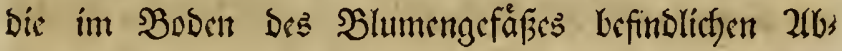
jugstórfer cinfaugen, woburd) fie zugleich vor Schim, mclumfar und Sảulnif berwahet werben; am allerbeften

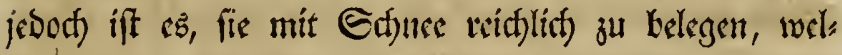

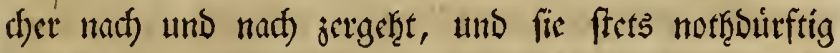

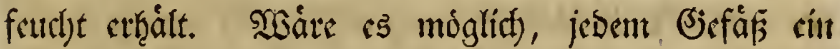
Unterfaf̧nápfden zu geben, unb bic Dfanzen von un:

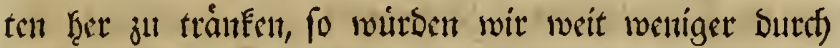

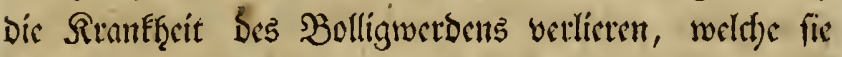
mur ju leidft Lefállt, wenn bals nact) crfolgtem Stuß sin ftarker Froft cintritt, Der bie YJflanje Didft uiber Der Suctfládje ber Evoe, fo weit, wie bas Muffict fie neste, am meḩriten angreift, und inte bafelbft bes

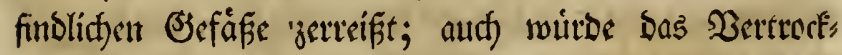

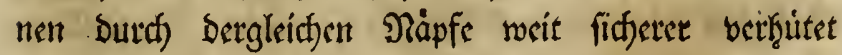
rerden Fonner. Se angemeffener ber Gtandort unb 
ie forgfamer bie Noartung ber Diclten ift, je fidfere

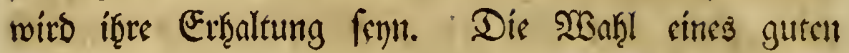
Standorts f̧at man jebod) nid)t immer in feiner Sor

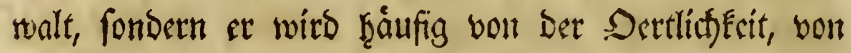
Dem Ulmfange unfers Belaftes unt ven andern Llm:

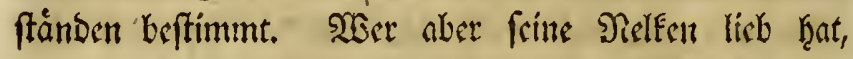
und fie vor Blattláufen berwahert wiffern will, Der Duret)s

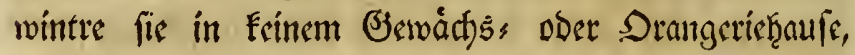
in welderm immer meţr ober weniger in und auslàn

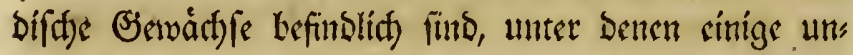
abwendbar mit SBlattláufen wie úbcrfáct fins, als

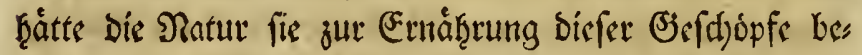

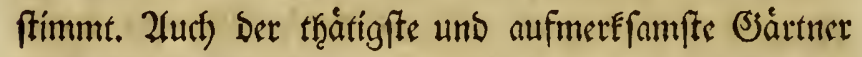
vermag es nisfot, fie gantz ju vertilgen, uno Derfalfer Diefes hat bie traurigften Erfahrtungen von biefer Durtsy

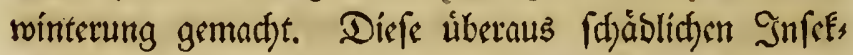
ten theilen fidh Den Nelfen gar bald mit, und vergifs. ten fie fo gewaltig, Dâj fie mur felten vom gánglidenen Serberben ju retten uno im ganjen Saufe bes Gom mers nur mit Der unetmíbetfen Gorgfalt zu vertreis ben fino. Lluto bies ift norf) nicht bas cinjige llebrl Des obgebactsten Durffwinterns, aud) Dic Dláufe, rocls

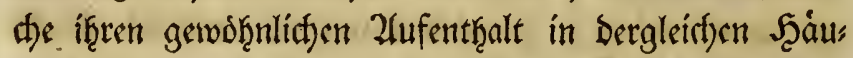

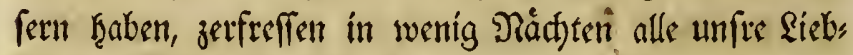
linge, und bie (a)wáchffen und jarteften babon bis auf bie Gohlle, fo baj fie auf immer verloren find. End

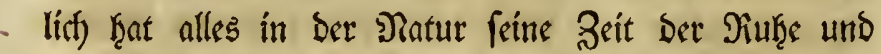
bes Gd)lafes, unb aut) bie YPflanzen haben cinen fols

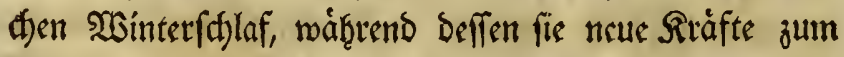

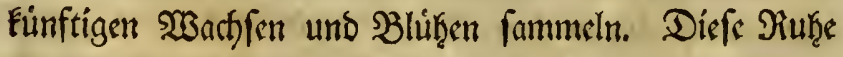

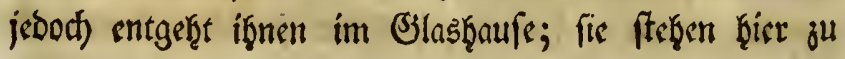




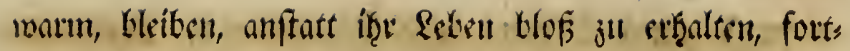

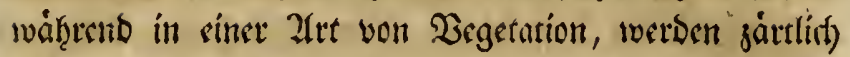

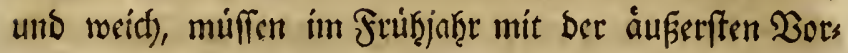

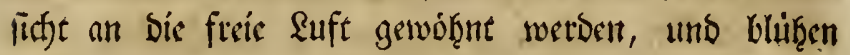

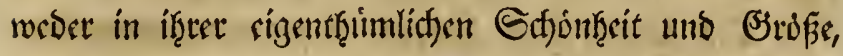

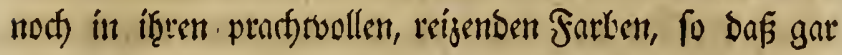
niffts für bicfe Durdfyinterung fpricftet.

Faft von Denf(clben פindftherilen begleitet, ja nod)

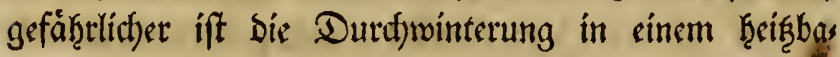

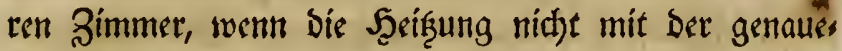
ften Sorficft borgenommen wirb, Denn in biffem ents

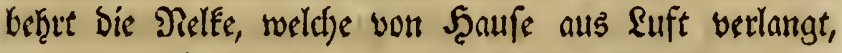
und als Sámling in Den fitengften Wointern ausjlls

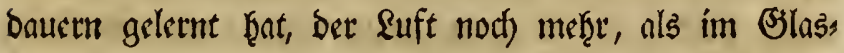
ḩaufe, wirts von Der Stubenmárme nod) W̧efriger ges

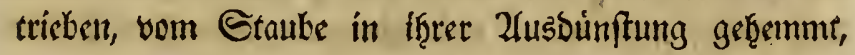
von sinem balds verfáumten, balb ju oft wiéberţols

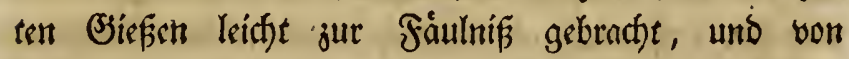

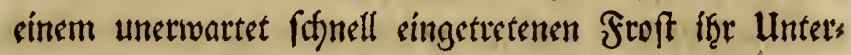

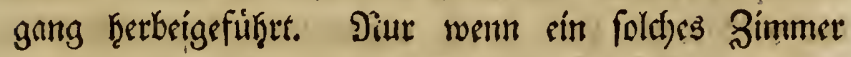
lebiglidi) zut Durffininterung beftimmt iff, uno bie

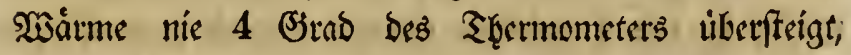
ùbrigens sine belle, fonnige Lage byat, bann ift, ç ę̧er ju smpfistilen.

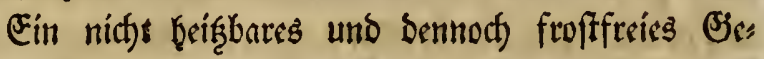
wollbe ift jeboch in jebem $\mathfrak{B e t r a c h t}$ Der befte Raum, in weldfem wir bie Nelfen burdf ben Wointer fu brins gen byaben, befonders wemn baffelte fo Velegen ift, baj

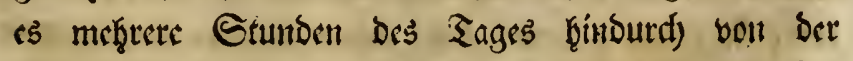
Some ertgellt wirto, uno burdf Deffnung Der Fenfter

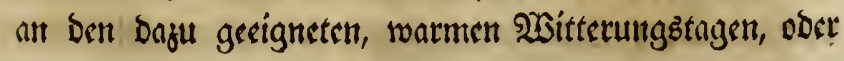


rváh̨tend cines Regens unt Tḩauvetters, ákerḩaupt aber, fobals bie Semperntur uiber Null ftef̧t, Suft $\mathfrak{c}$

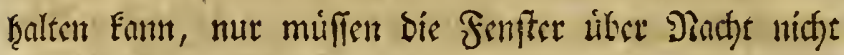
offen gelaffen wertoen.

Die Wonf̧l cincs Rellers ift weniger anjurathen, indem Derferte gewóf̨nlíd) ein Zufenthaltsout ber Diáufe ift, uns in ber Regel if̧m fíftet und \&uft abgetren, moburch bie DPfanzen vervecidflicht uns gelb werben,

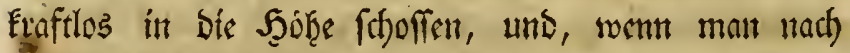

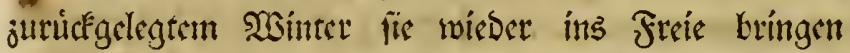

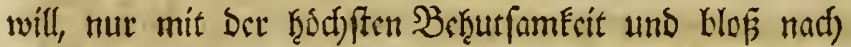

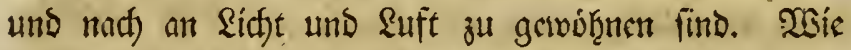

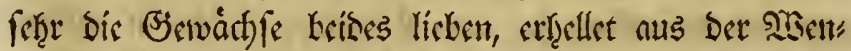
Dung, weldye bie Etubenpflanion fitets nat) bir Erite bes Jenfters ntketmen, man mag fie Steḩen und wen

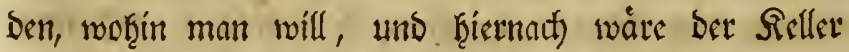
nur fuir Dent Notb̧fall uns unter Der S3esingung ant

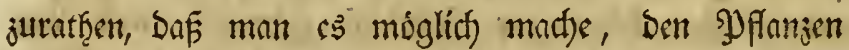
von Seit ju Scit Ruft ju geben, und ju kervirtern, Daß bie verborbene Ruft Durch angezundete fleine Gtrohs feuer verbeffert, und fein bes Infeuchtens bendthigtes

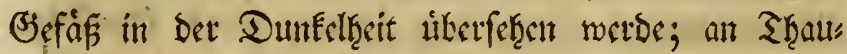
und Regentagen nber, ober audf) f(t)on, wemn bie Siálte nidjt zu Kedsuteno ift, milfen bie Rellerlod)er geoffinet unt fidft jugclaffen werber.

In Ermangclung cines Retlers uns fonft paffen Den Piaumes im Şaufe, verbunden mit bem fid meţ; renden 2(1nwuths ber Eammlung, if bic Durffyintes rung in cinem sigenbs baju angefertigten, zwar aud) Des liduts entherienden, Dod) sinem Reller faft nod) vorguzieţenten Erofenfen anjutathen, welcher folgenders 
marme, ober regnigte Tage eintreten, man eine ober

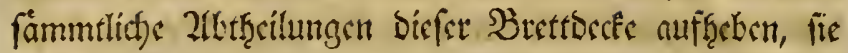
Durá) Etrif̧en in ber J̧ס nen uns Den Эy fianient ctras Luft geben Eómte. Şus

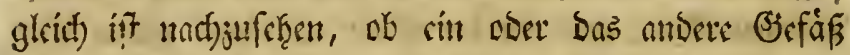

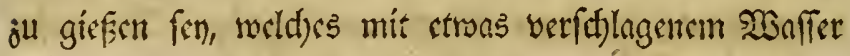

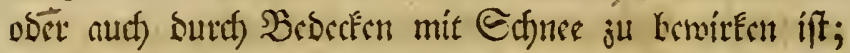
ferner, ob lid) irgentivo Safjimntel angefef̧t ḩake, uns finmeg ju pu(zen fen uno Derglcid)en meţu. Wor (Fin trítt Des Ifbends werden bie femfter wieder herabgelafs

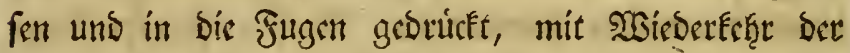
Sálte aber auts) bie Berttbecfe mieder ḩerargelaffen unto mit Mift Kelegt, mit welthem ber Raften aurf) ringshretum ju umgeben ift. Da man ber biefer

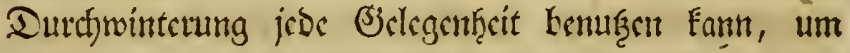
Den गffanjen Ridje uns Ruft jufommen ju laffen, fo

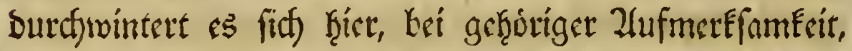
beffer, als in ben Dunteln luftlofen Retlem, cs müfte Dern Der Şinter jull lange wáḩren unb ju ftrenge fenn, in sweldyem fall aber audf woḩl bie beạteften, in

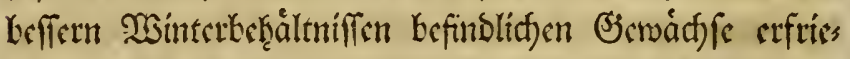
ren Foumen, wenn baffeltec nid)t Durd) Feuctung ju ct: wármen ift, uno Derfoffer biefes Fonn verfichern, Daf cr in bergleichen (Erbfaften nid)t mur Nelén und 2(u, rikeln, fonsern autg Golslack, Sebfonen, Scortenien, Rosa semper florens uno áf̧nlict)e (Serwád) fe fẹt gut Surd)wimtert ḩat.

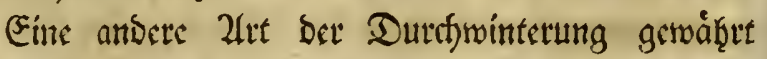
das N2iftheet; es roctoen in baffelte jeborf mur bie

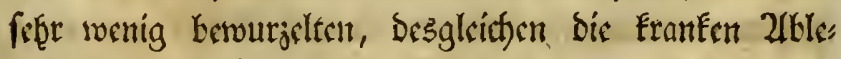
ger uto semnáchif bie alten Etóce verferet, weldje 
Dof es bei elfolgendem Thaurvetter ober mact) einem anţaltenden Sirgen von ber ablaufenden ?áfie nicht iberiftwemmt werben Eann. Der Eonne Darf Das Bect Darum nidft ausgefef̧t fenn, weil Das fdonclle

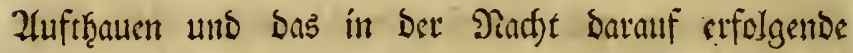

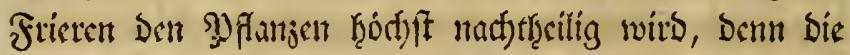

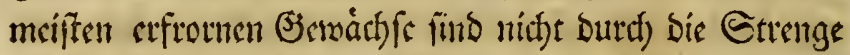

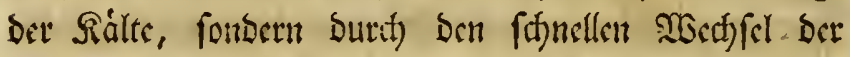

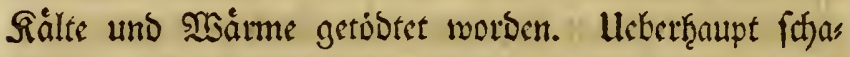
bet cine Falte, trockne Srinterluft unenolich weniger, als

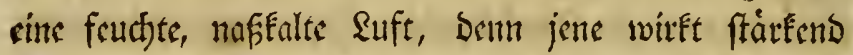

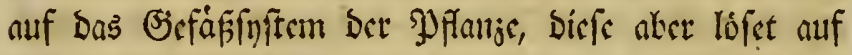
uns mad)e faslaff, und nun barf nut ber mintofte Froft sintreten, fo verbickt ar bon Eaft plofilitif, bringt Gtockungen herbor, bic Sicfäje jerfpringen und bie. I) fanje wirs kollig und ftirbt ab. Scicraus crfecllet

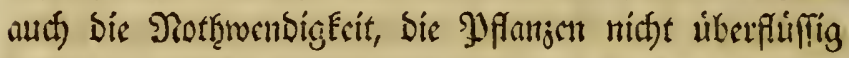
feud)t ins şinteripuarticr ju kringen, benn in cincm cingefdrànten, luftlofen Tiaume unb bei ber ftillfes hemoen Wegetation verarbeitet Die SPFanje biefan Heber

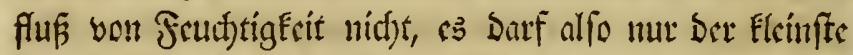

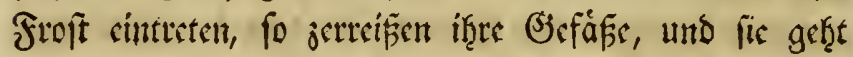

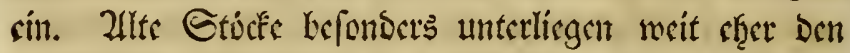

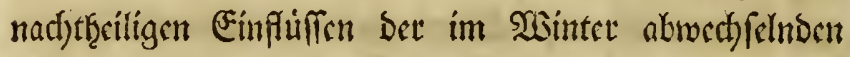
23itterung, als junge Etdofe und 2(bleger, Daher nod)

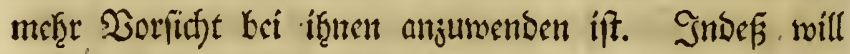
id), ber angrgetenct Debenereignifie wegen, boch nidfe rathen, bie vorguglidgen uns feltenen Gorten, uns

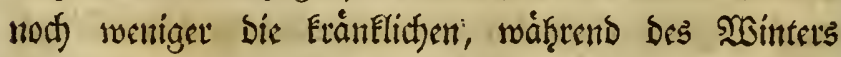
Dem Sartenbeet anjuvertrauen, benn wirben fic Durch

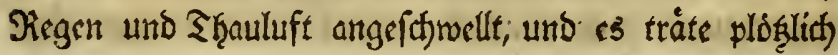


guten Edjuecbebectung fitjon manches unfrer järtlis

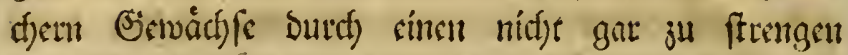
wsinter uns in sinem nicjt gar ju offen belegenen

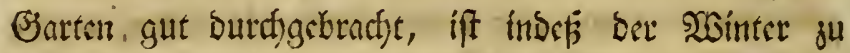
nes, fo fälle bas Saub ju fef̧r jufamment, unto bie

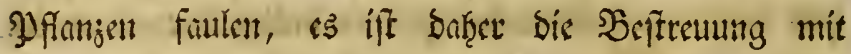

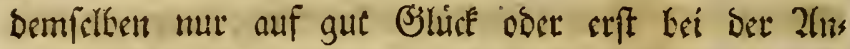

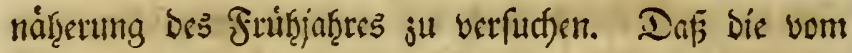
Froft aus ber: Erbe gejogenen Yy fanjen kalb, und bes

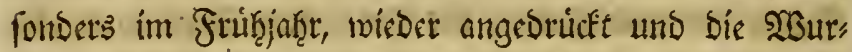
jeln mit ertbe bebecft werben miffen, twirb bei biefer Beligenticit micserţolt.

SSil Fommen nun auf bie leste, yom Berfaffer

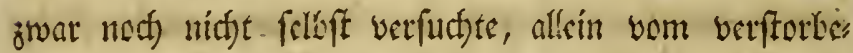

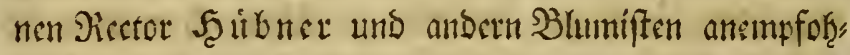
lene 2fet von Durtfointerung, weldfe jebod), meines

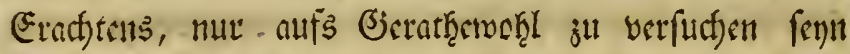

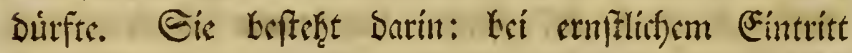

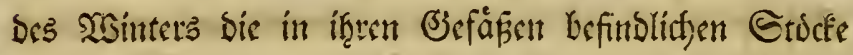

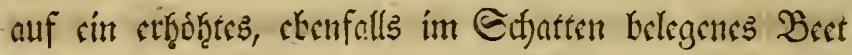
in sine vorįer mit Dem Sirabcrifen aufgemorfene Mínne, sinen Sopf neben bem andern auf bie Rante ju les

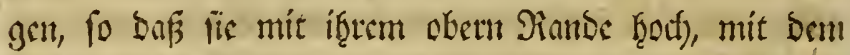
Boben bes Jefääes aber in ber Rimme ju liegen Eam: men. Scierauf fojuttet man jwifd)en die Definungent

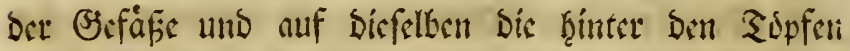

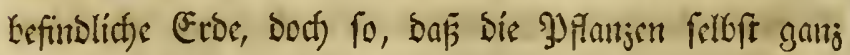
untedecft Kleiten. 2lu bie Etelle Der rerggenommes

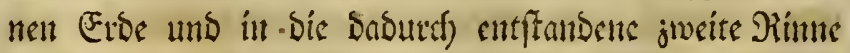

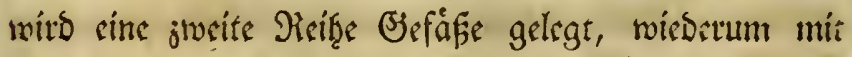

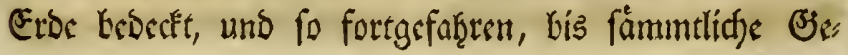




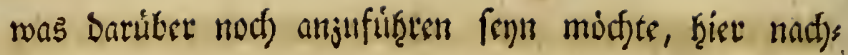
trolen.

Won tect)t3megen, foll jeber Dielfennbleger, er mag bur(f) Taufd) ober burch Rauf in unfere Şäande ges langen, ober von unt sit andere Blumenfirunde bers fendet werben, in cinem bollfommen ausgerwad) ferten, gut ferwulgelen uns villig grfunden Suftende fenn,

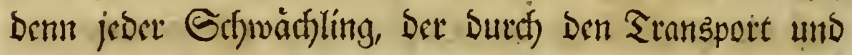
surd) Eintrúllunng in trocfines, ober auth zu feucftes

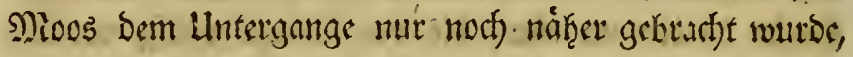

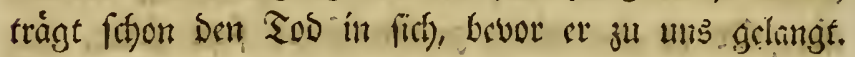

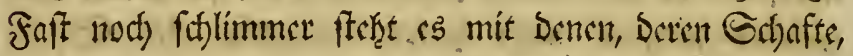

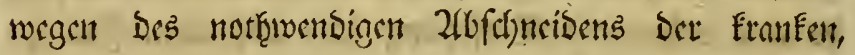

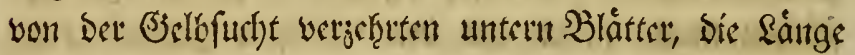
von meţr ober roniget nls cinç Fingers ḩaben, unb

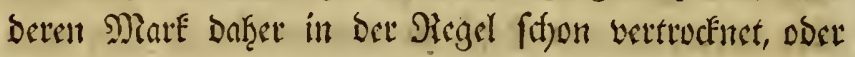

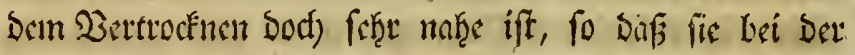

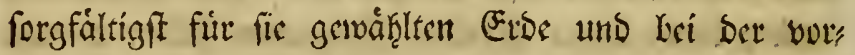

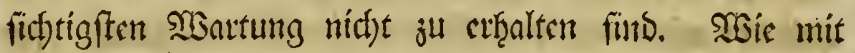
foldyen Derlen allenfalls noch) ju verfahien ift, Davon

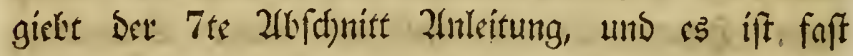

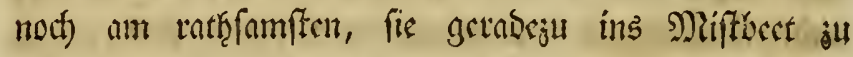
verfefen. Eolle man fie míber Bermuthen Durét) Den

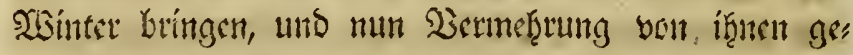
wimnen wollen, fo Darf man foldye Pilfen, Da tie ges

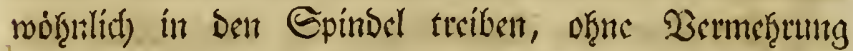

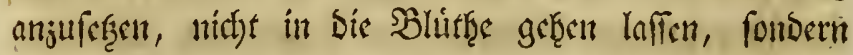
man muf den Spintol abfuneisen; Demn ift Die Gorte

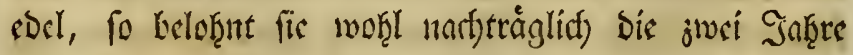
Sintouth mit if̨r gethabte Gorgfalt uns Dathęe, ift fie es aber nict)t, fo smpfinost man num freilidy bie 


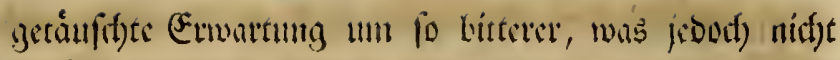
ju äubern fteţt. Doch) wie gifagt, Dergleitifen langs fisdffige 2frleger loffen lith mut felten fortbringen.

Die Sifte oder Edfatjtel jobes anfommenden

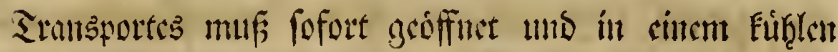

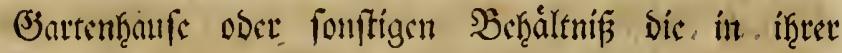

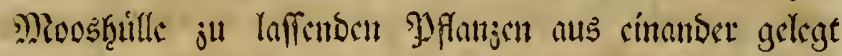
werben. Godann beforgt man fich auf bein 2libcitz;

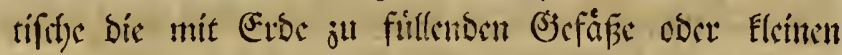

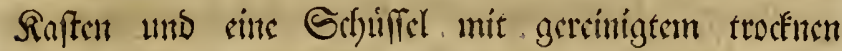

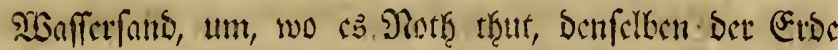

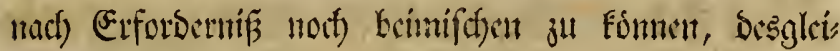

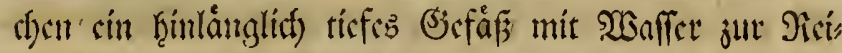
niguntg ber Yyfanjen, went biefete nothig werben

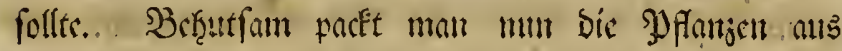

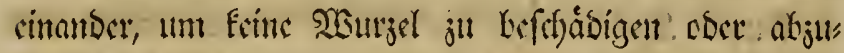

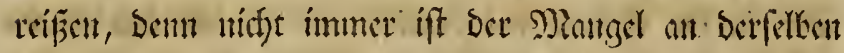

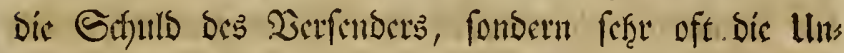

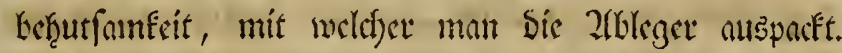

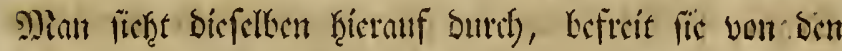

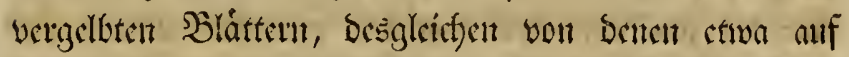
ifruen kefindlicl)en B̉lattlåufen unb von ben fofort ju

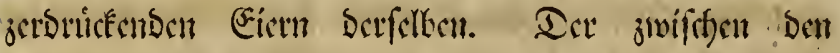

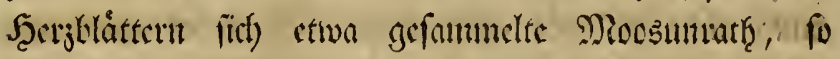

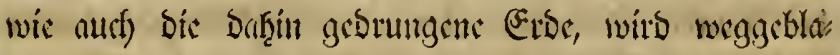

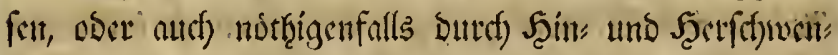

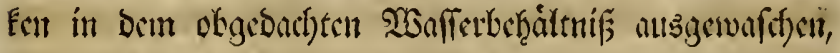

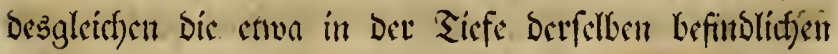

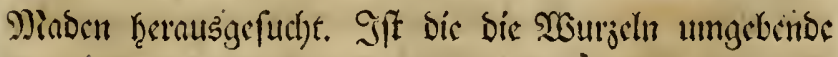

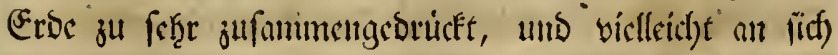

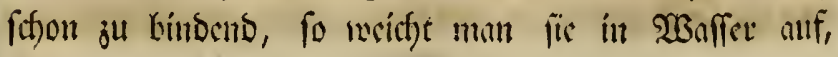




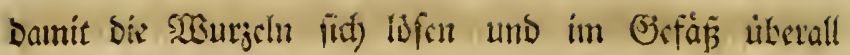

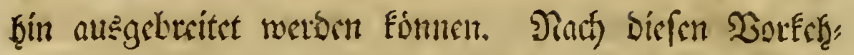
rungen verfef̧t man bic PYfonjen, befprengt fie máp̈ig und ftellt fie auf cinige ₹ane in sin Eliţles, másig

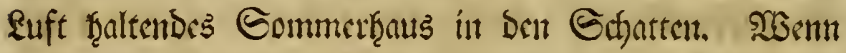

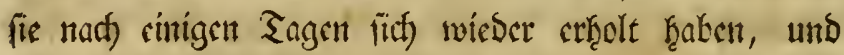
anfangan, tḩre Blátter fteif jut tragan, fo bringt man fie ins Treie, jebort) nod immer in Den Echatten.

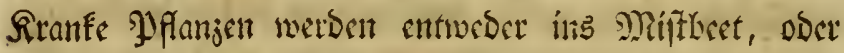

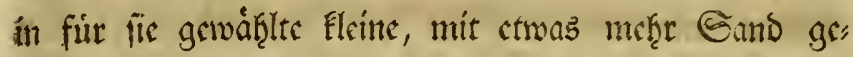
mifdfe Erdoe berfertet, uno, wemt bic vom Befperngent

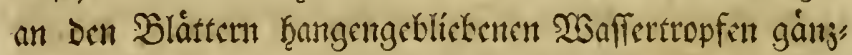
(ic) veroumftet fint, und bie Sberfiactye ber (Erbe fid) bollig eingezogen hat, mit einem Silafe bebeckt, $2 m$ o

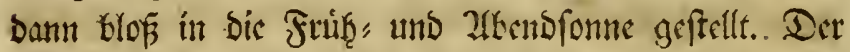

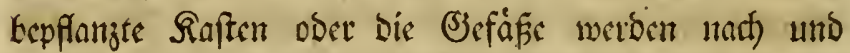
nach in bie Eome vorgeruiff, unt fo wie bas Orrun Der Sranken siniges felten uno Sarte geminnt, rúcft man fie mef̧r in bie Gorme vor. Fállt sin fanfter

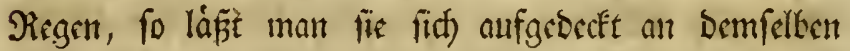
cine tís jroci Stunden erquicfen, gemolf̨nt lie nad) unt nach an Suft und Eonne, und verfáhrut Dann weiter nach Den fdon gegebenen Inleitungen. Sft Die Een bung uid)t ju ffát ringegangen, fo ift $\mathrm{s} s$ tḩunlid)er, Die Eranfen, fdywad)en, ober ju wenig WWurjel habenden

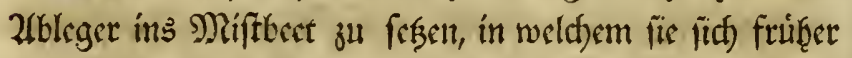
betwurgeln, und ftátfer und fráfriger werben, als es im

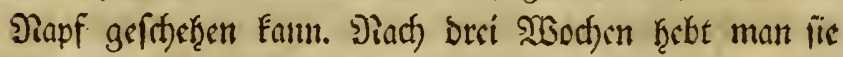
mit sinem guten SBallen aus, uno verfefet fie in ben Topf ober in Den Eleinen im 7 ten 2 Lbfef)nitt etwåḩnten IPfanjenfapten. 


\section{Zefuter $\mathfrak{A} \mathfrak{b}$ id nit.}

Bon Der abwartung nad Der volroge nen Durbwillterung.

207 von if̧ren millben Grahlen beleud)et, anfangen, neties

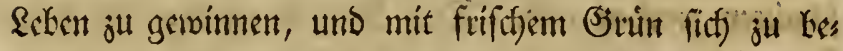
Elctoen, fo wurbe es untect), uns unfern Ricklingsblus men, ben Delest, nact)theilig fenn, wemn wii fie nod) lánger in singefolofofenten Tiaumen aufbervafiect rooll ten; und fo Eam man vom IInfang bis Mlitte 2lpril

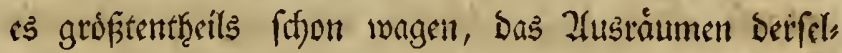

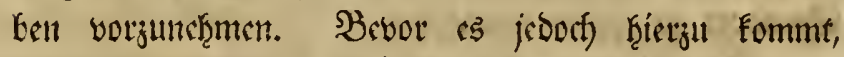
mur man chen fo forgfáltig lie baju vorbereitet haben, als man im Syerbfte Lemingt war, fie fuir-bie Durcl)s

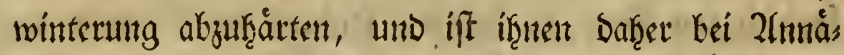

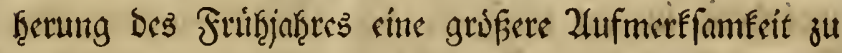

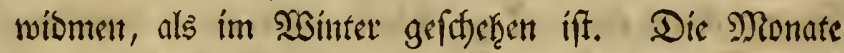

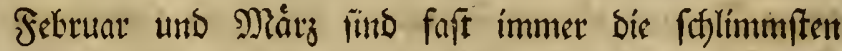
für fie, ittoem fich) bann enft bie Folgen ju úberḩáufs ter Seuteftigéeit, ober bie ju lange Dauer Der Trockens

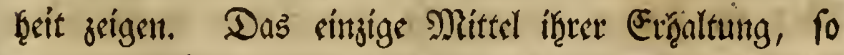
wie zut Rráftigung ber librigen, ift, ignen fo oft, als 


\subsection{2}

es mui irgento bic 2 itterung geftattet, frifd) Euft ju

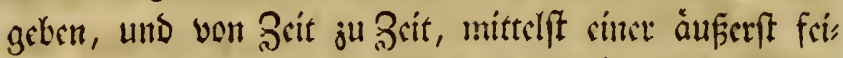

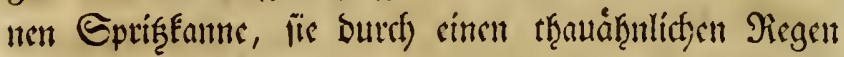

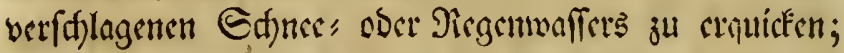

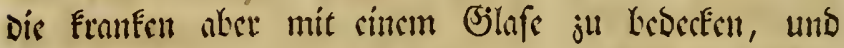
náb̨er ins Eounculicht ju bringen, jebod) Lei gesffnes tem Fenfter, um fo visl ols mog!tít) burt) fonft sim

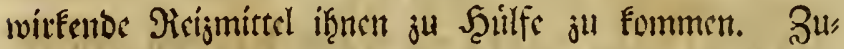
glcid) ift es gut für fie, if̧ec Blátter jul verftuscen; ja es Enun, Kefonders bei ben ju feuct)t geftandencn,

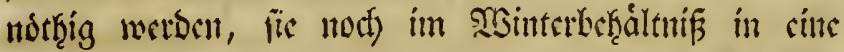

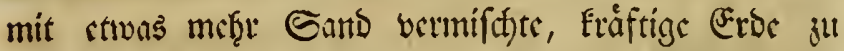

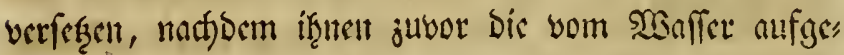

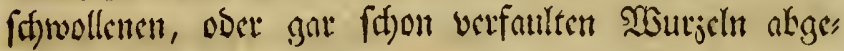
f(d)mitten worben fints. Des Parfjts merben bic Fen, ffer wieber gefdbloffen, und bie franten SPflanjen bidjt

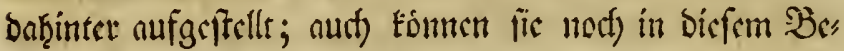

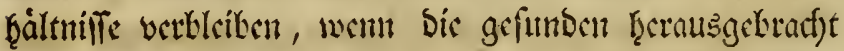

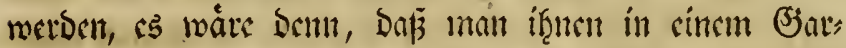
tentraufe cinten nod) leidftetn unt, jugleidi wåtmetn Gtambort ju betren vermódjts.

So viel man aber aud die Fenfter groffinet ḩa fen mag, fo finto bie Durdfwinterten Dellen bod) nidft fogleid) ins Freie ju ftellen, fonbern man bringt fie juvorberft in rin luftiges, ber Gounc jugánglidjes Commethraus, cinige Sage fpàter unter cinen bebecteten, gegen Slorgen offenen Edyuppen ober foult fojicflid)en

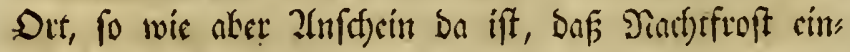
treten will, weroen fie ins B̈artenţaus jurtice getwad)t.

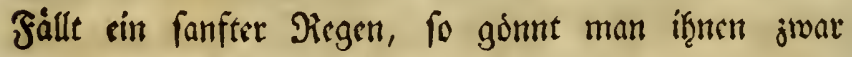
benfelken, abse mur sin bis jmei Stunben lang, Damit 
ïe bes Buttent nicht jul bicl nuf cinmal tefommen. Sint lie bei biefer forgfältigen B̉iţandlung baḩin ges

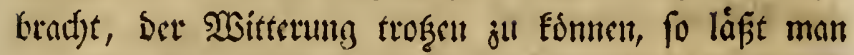
lie unter ber unbedad)ten Etellage Tag uns Pad)t of: fen fteţen, bis lie Eráfrig gemug getworben lins, um

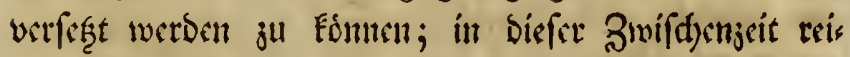
nigt man fie von if̨ern vertrodfneten Bláttetn, uno locfert aud) Dit Eroe ctwas auf.

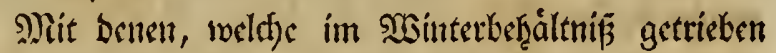

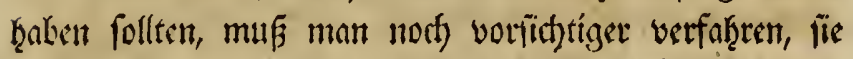
mur bei twatmen Sagen ins Freie ftellen, uno jwar blop in ber erften Miorgenfoume, vor (Finbrud) Der

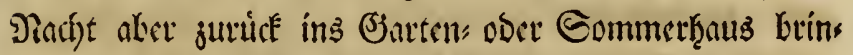
gen, if̧e Erbe fruher als bie ber übrigen nuflecfern,

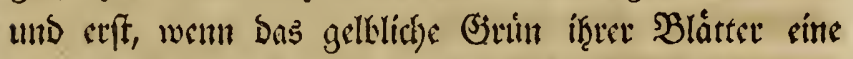
Dunflere farbe nngenommen ḩat, Duirfen lie ber \&uft und Goune auf cincm frestu Etandonte ausgefert werben.

Drn Eränflitif gewefenen, unb bereits ins Freic

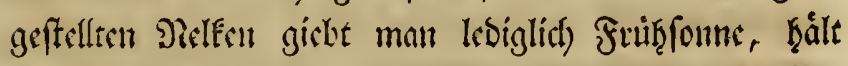
fie aud) nod) unter ber Blnstedoctung, bis fie there

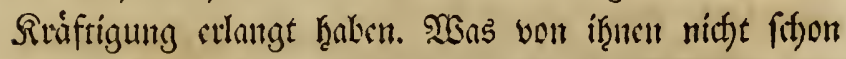
berfegt ift, wirb, unter Dem angegrigten Werfaheen, jef̧t tod) verfeft, uns allenfalls nod) auf ben Boben bes Gefápes ctwa cincu Bull ḩod) groker 20 afferfand ans

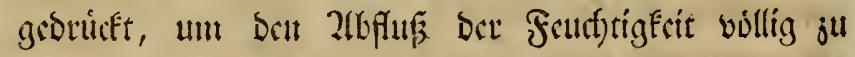

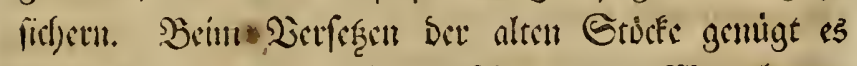

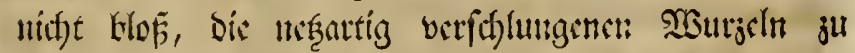

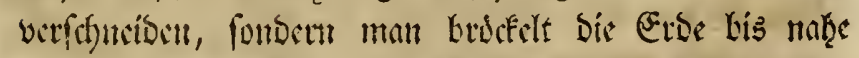

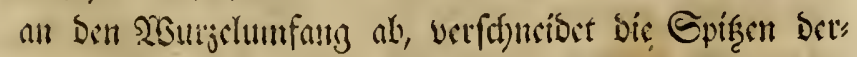

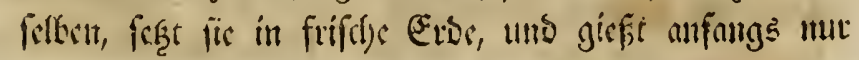


máfig, fo wie aber bie Degctution meţu Foligang ges winnt, wirb aud) Der (Suź, je nad) Dem SBedurfnif

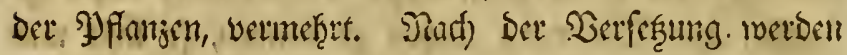
bie Mfanjen nod) cinige Tage im Gd)atten gertalten, und arft nad) volliger Evthgolung auf bert firten Gtands

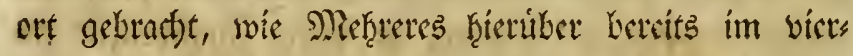
ten 2(bffthitt gelehert worben ift. Llebung uns 2luf" merefamfeit merben Den Znfánger in ber B̉lumenjud)t

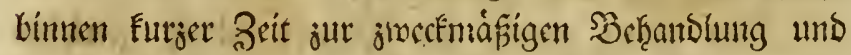
albroartung Det Sielfe führen, und follte bie vorlie" gende In nlettung bies etcid)tem, to if Des Derfaffers

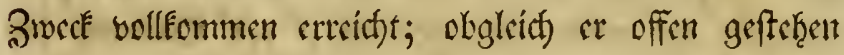

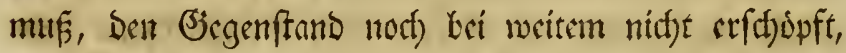

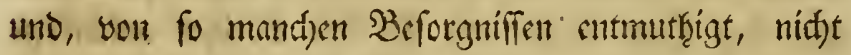

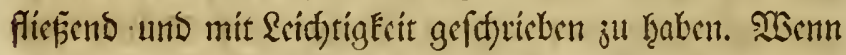

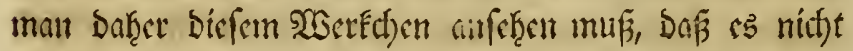
unter bem Einfluffe cines freien, harmlofen Geiftes, oịne Den miduts vellfommen Gdjones gedeigen fann, entworfen morben ift: fo if bie Bitte um eine ge"

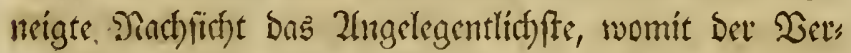
faffer Diefen a(bfounte fiblieft.

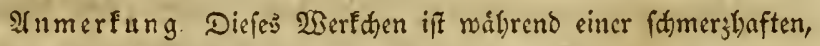
mebrere g)ionate anbaltenden firanflyeit einer gelicbten Towter, unter ben bangfen Empfindungen, gejdrieben worben. 


\section{(E) iffed $\mathfrak{A} b$ fdithit.}

\section{lleber die Sranebeiten Der Relfe.}

Ii Delle untcrliegt methetn Rranthciten, Die

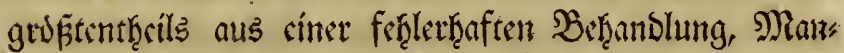
gel an Ruft, tiberḩäuftem ઉjię̧en, ju fettem Boben,

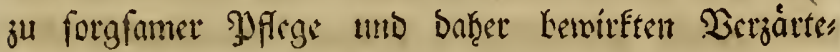
lung entfethen; Deşgleityen ment bie Sriebe nod) zu jung, ju meníg ausgetwachfen gefrnft, ober als Gtops fer unter ङJlas gebrad)t merben, obgleid) im lefetern Fall wohl Die wenigften fortfommen, fondern bals ans fangen jul faulen. Die bedeutentoften, ḩáufig mit bem Derluft Des Gtecks vertumbenen Siranffereiten find:

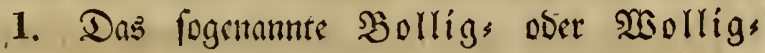

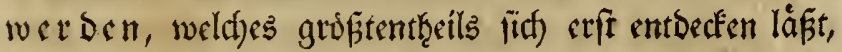
wenn Die SPflanje Eaum meţe ju retten ift. Didjt liter ber Drerflád)e ber Erbe entrwickelt Das Mark Des Stammes cine braungelblit) Farbe, uns lofer fid nad) unb unaf in eime braune meñlige Eubftanj auf,

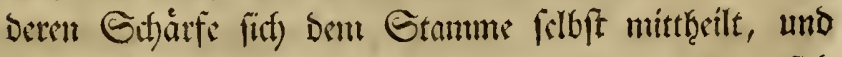

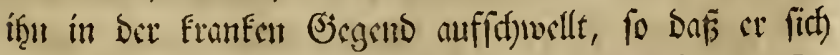

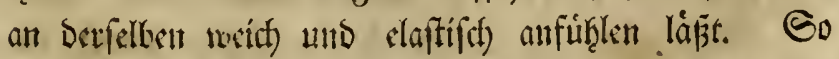
Iange Dus Seolj nod) ciniges Seben that, ftrigen bie 


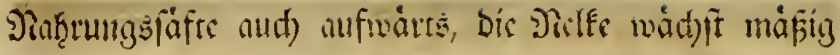

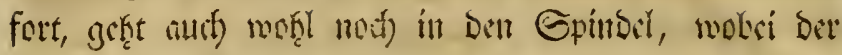

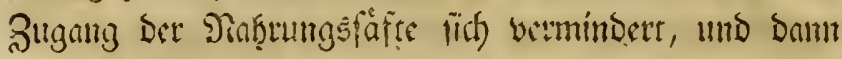
Der 2 sad)stf̧un nad) und nad) langfanner wird, Das

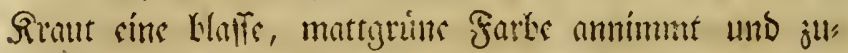

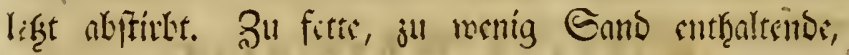

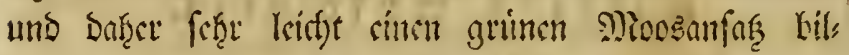

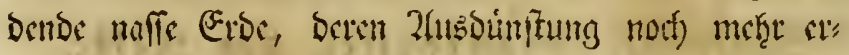

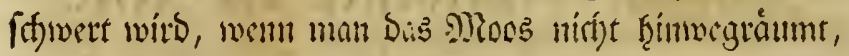

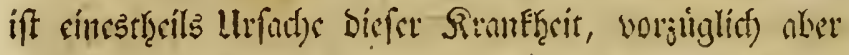

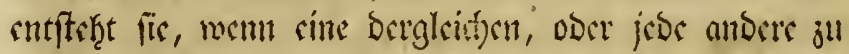

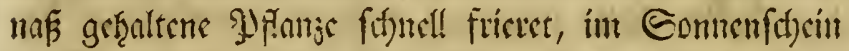
ftehento wisber aufthauct, unb bie פant)t Darauf abers mals von sittem fitungan frofte angrgriffin unto ges

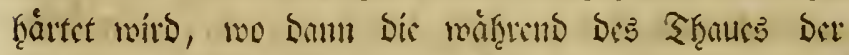

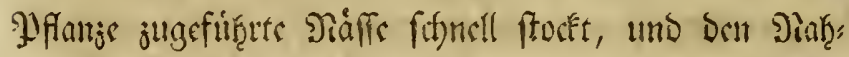
rungsfaft (Den bit boun Froft nod) nidfe ergriffenen

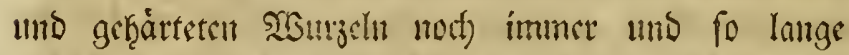

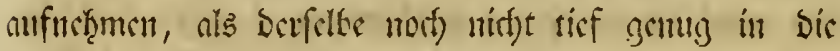

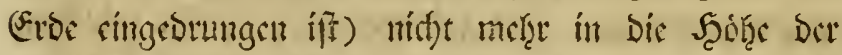

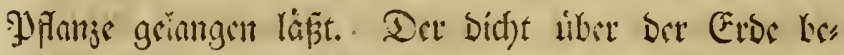

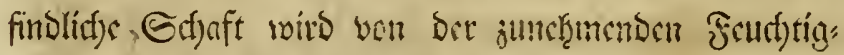
Esit gedrångt, gemaltfam aufgefitumellt, his bie aud)

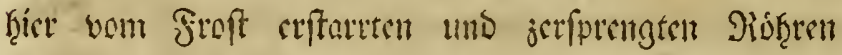

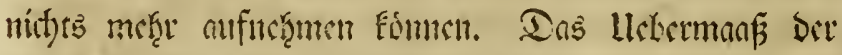

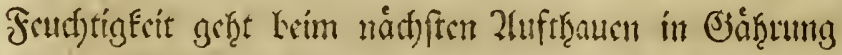

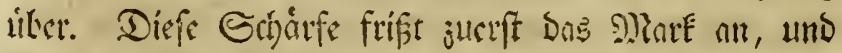

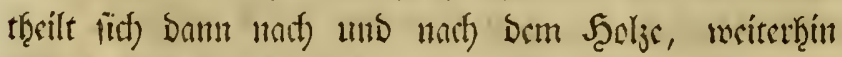
aber aut) Der Py fange bís okenhin mit.

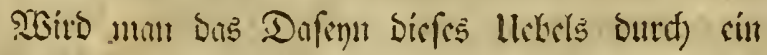

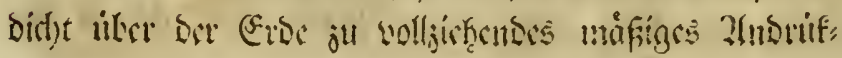




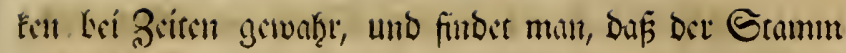

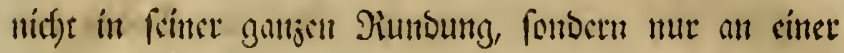
Geite bavon angegriffen ift, fo fdjutbe man biefen Elumfen Theil mit cinem fiharfen Federmefier bis auf Dell gefuntorn nus, táume bas branbige Nate we'g,

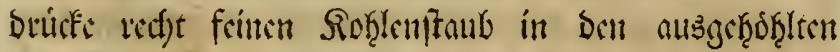

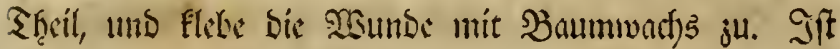

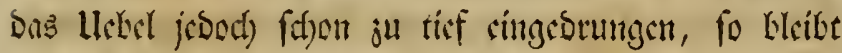
jur Erthaltung Der Gorte mur tods) Der singige Dets

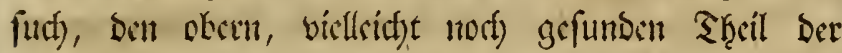

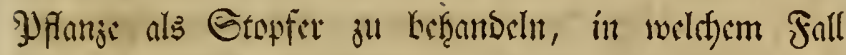

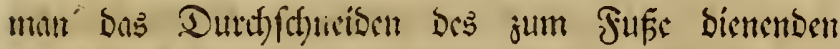
Sinoretis fo hect) als móglich verfutden muß ; ţat aber Das Slataf auth fiton an biefen Bilicbe sine braune Farbe, fo wits fid) mu folten ber Etopfer erfialten.

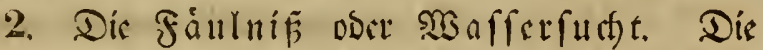

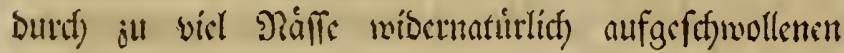

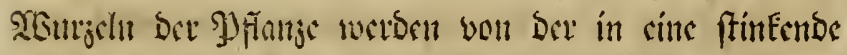

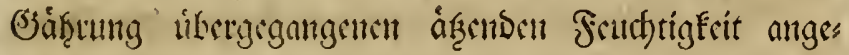

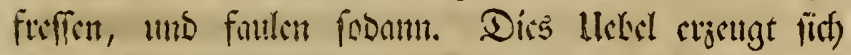

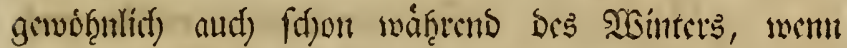

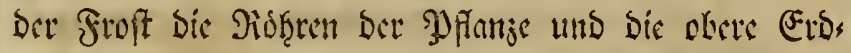

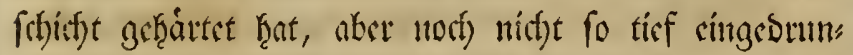

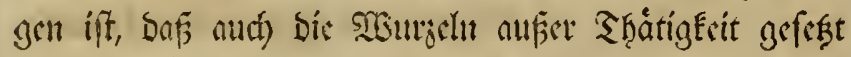

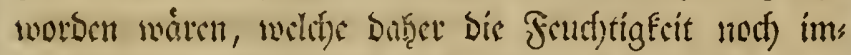
met sinfaugen, fir aber nisft uterge in bie jugefromen

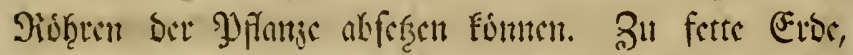

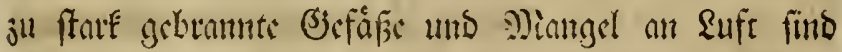

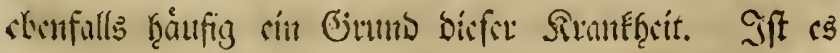

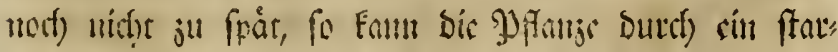

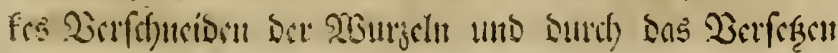




\section{8}

in sine friftae, mit chras mef̧r Gand vermifd)te Eroe vielleifft norf) gerettet werden. Zluf ben Boben bes Befáfes wirb $\frac{1}{2}$ bís 1 3oll grober, gereinigter Thaf, ferfanto gefdjuttet.

3. Der $\mathfrak{B r a n b}$. Unvorlitftiges abreífen Der vergelbern ober vertrocenten Blátter, auffatt fie hart am Stanme abjufdunciben, B̧entagen Der Mlåufe im Durctwintcrungşgcmad), uns Befdeábigungen burch Snfeften verurfad)en Diefe Sirantfecit, welefe auth wohl

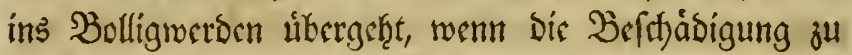
ftare war. Ein 2lusffinciben bes Enotpligen ober fos

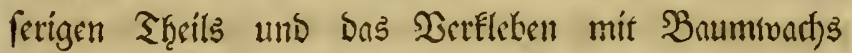

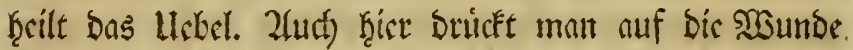
ctwas Sob̨lenftaul cín.

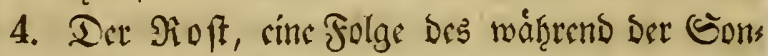

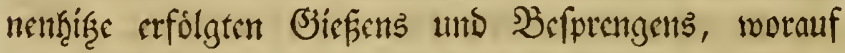
Die Feuchtigfeit von ben welken PDFlanjen jwar begies rig singefaugt, aber ber Lleberfuf Derfolken nicht eben

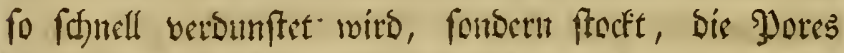
ber Blätter an meţretn Gtellen jetreifit, uno bant als sine verbicfte braune Diaffe hecrvorquillt, weldt)e mad) unto nach) froubig wits. Slan Fonnte bicke Siranffecit

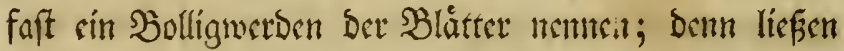

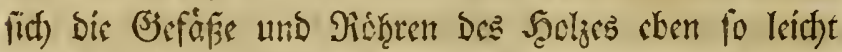
anfbrángen, wie bie ber Şlatter, fo muirbe biefelbe Erfderimung aud) Lore vorínmmen. Dir bom Rofte angeftecften Sלläter merden fofort algeffonitten, uno

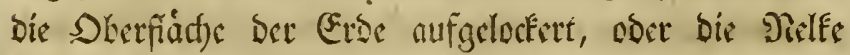

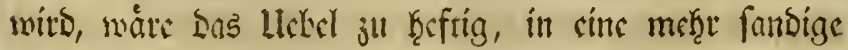
Erise verfegt.

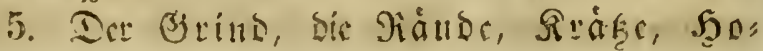




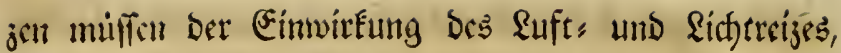
kefonders in Fruhjaḩr, nut máfíg ausgefę̧t, uno vor

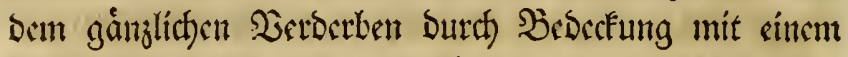

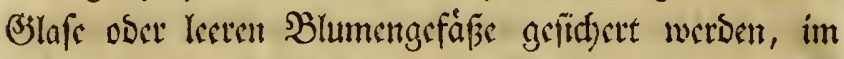

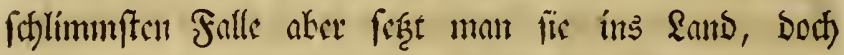
anfänglitit) aud) nur unter cincr Besccfung. Sins

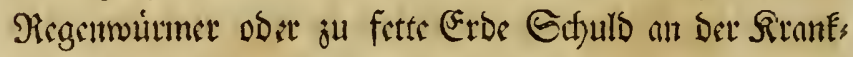

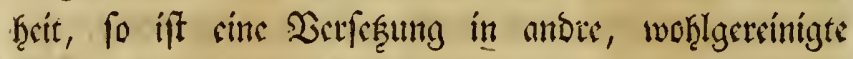
Eroe nothigig.

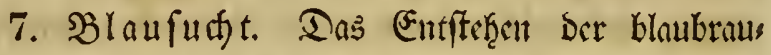

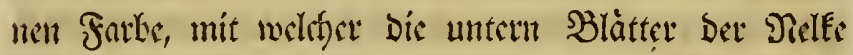
Liberzogen werden, ift sime, grífitentheils nur Den a/d)s grauct, Den rotḩgrundigent uns fupferfatbenen \$elfen

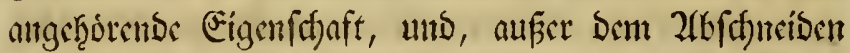
Der Dayon ju ftart angegriffence Blátter ober bod) Des

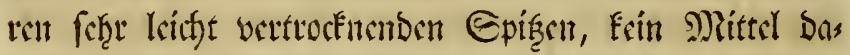

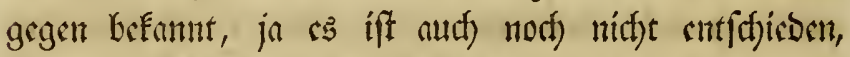
ob cs witelitf) chte Rranffecit for.

8. Siclbfud)t. Sie gehte bem Werttodenen Der

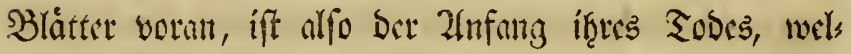
ffom Der Dev ganjen SDfanje nad)folgt, wenn sine Det

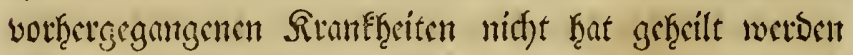
Eonnen, ober bie Jyfanje fonft vernachláffigt morden ift. Biswóf̨nlich folgt Derfelten:

9. Dic 2lusjeftung. Dir unter cince ju vot"

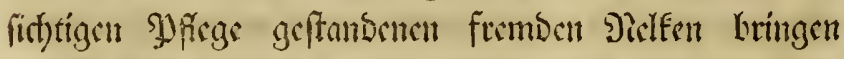
jutweilen bie 2fnlage ju ciller Doer ber altbern ber vors genumenten Rrunfficiten fityon mit, Kefonbers bicjenigen

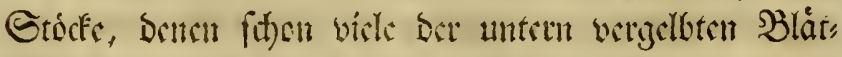

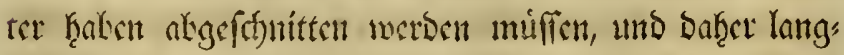

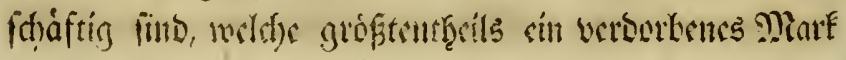




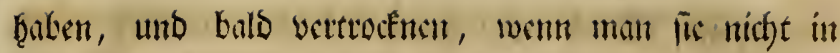

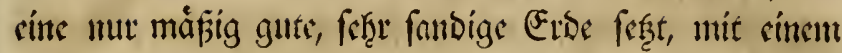
Slafe broceft und fouft vorfict)tig pflegt. Dicfer 2lus;

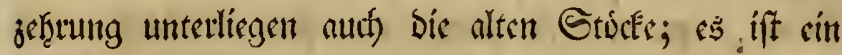
langfames 2 Gbfterten, weldfes mu baburd) hínjuthalten ift, Daf man bem Gtocfe moglict,ft magre, mit vielem

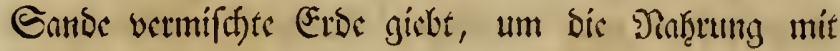

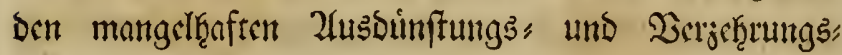
Eräften in Ulebereinttimmung jul kringen. Dic Sticke

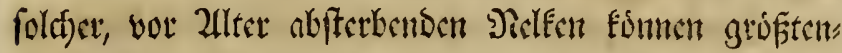
treils mur noch als Stopfer benuşt werton, in fo fern

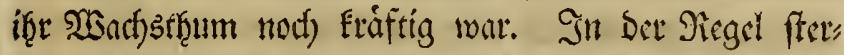
ben alle biejenigen 2fGleger an Der 2fusjek̨tung, Deren jum fun beftimmtes Slies, nicht Surd)aus in ber Mitte gefpalfent wurbe. Sift ber jur Beswurgelung bes

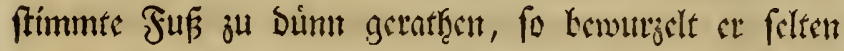

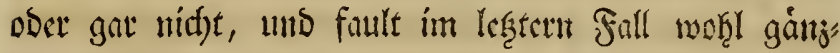
lic) ab; ift bagegen ber am Miutterftock geblicbenc Suf

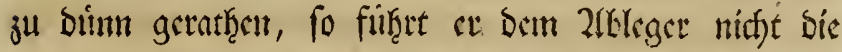

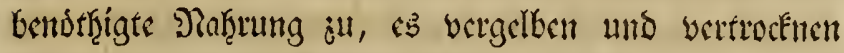

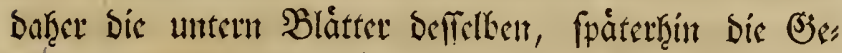

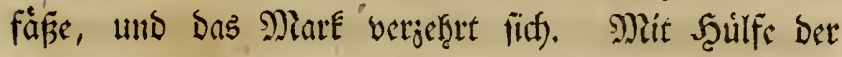

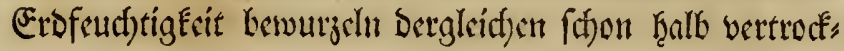

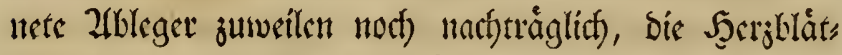

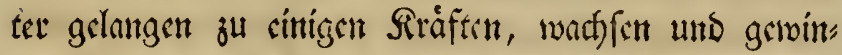

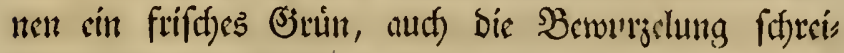
tet weiter wor, aber beffen ungeadfet fertet bas rigents

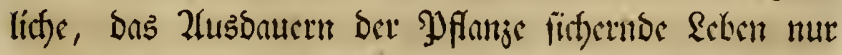
felten, befonders aber bann nicht wicder, wenn Dergleis

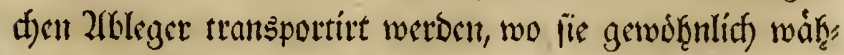

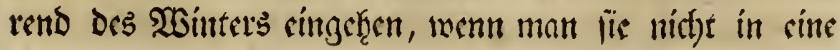




\section{2}

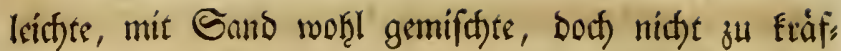
tige Erob verfeft, uno fonft mit åuferfter Worlicht

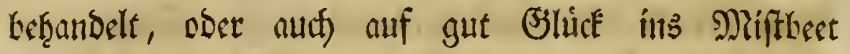
bringt, boll wo fie jebod) vor bem Einfrieren mit Dem Erobrallen herausgenomment uno ins S̈efáf vers

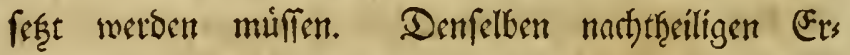
folg ḩaben aud) biejenigen 2(bleger, beren Gpalt jwar in Der Mitte Des BJliedes gemadjt morben ift,

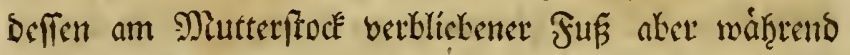
Des Genfens zerbrad), und mur nori) an sintigen Fas fent mit if̧m Jufammentiangen Klieh. Das Mark ift vor Der, gemóţnlich nur máffigen, Ṡewurgelung ber, trocknet, uno fommt níd)t wieder ju siner, 2fusbauer getwäh̨renton, Sirnft. 


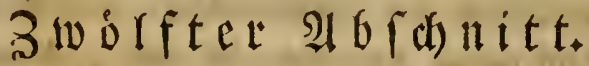

Don Den Feinden der Relen,

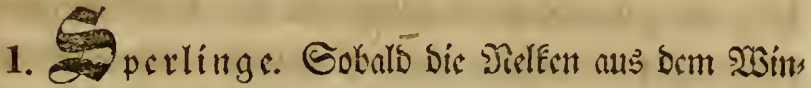
tergemach ins Freic geftelle werben, find bio Eperlinge

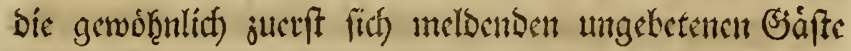
Derfelben. Das frifare Griut uns bie Bartfecit Der

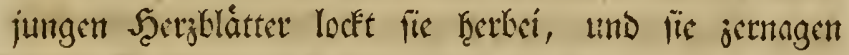
nidjet mur bicfe, fonbern risien aud) bie neuen Triebe aus, unb fondoen alfo ben Gtockent oft fo ferge, als

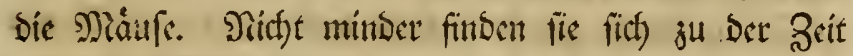
auf ben Gtellagen ein, wenn bie פielfen ju Entospen anfangen; fie jernagen biefalben, Druident bie zatten Şlumenblattchen hervor, um fie zu verzeţren, jerbes d)en mitunter bie SBlumenfpindeln, unb beíngen uns

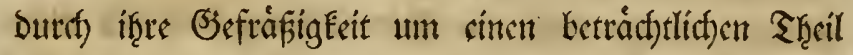
ber fodonften Flor. Sie abjukgalten, if Daher bie erlte Sorge, unb-bas jwectmápigigfte Mittel kicegu ift, wo niffy in jeben, fo bod) in ben zweiten Sopf Der vor" Dern und eben fo in ben Der lef̧ten ober himtern Rethęe

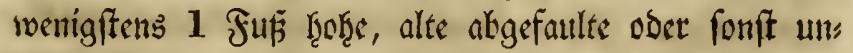

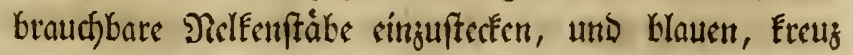

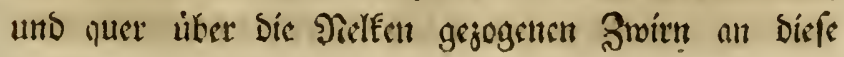




\section{4}

Gtäbe ju befeftigen. Eokalb bie Malfen indor anfans

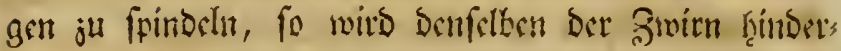

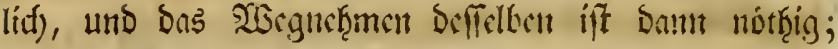
ftatt befien bient folgendes, allenfalls aucl) gleich) an:

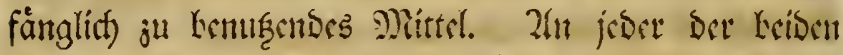
fabmalen Eeiten brs Şlumentrágers incrón in gleíl)

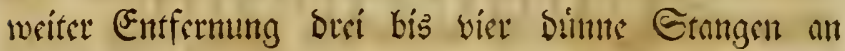
das Ende ber Satten angenagelt, von situer jul andern

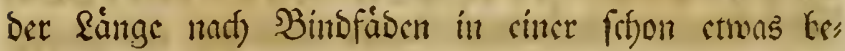

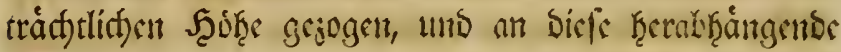
Edfnuren in ber Entfernung von $1 \frac{1}{2}$ bis 2 Ellen bes feftigt. 2In Dns Ende bicfer Ecínurent merdent in jider

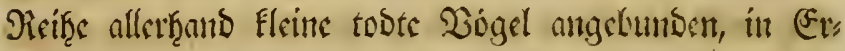

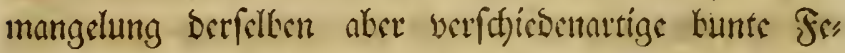

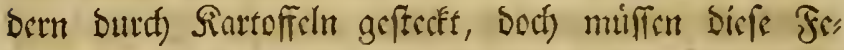
bern fdont stwas lang fernt, uns burct) bic ganje Sat" toffel gef̧en, weil fie fomf vom sivinte verwerht we\% Den, fobals bic Sartoffel trocken wirs. Dermittelft

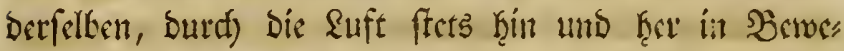

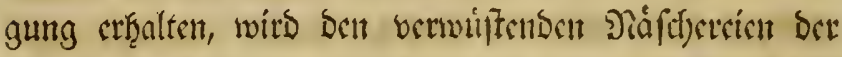
Eperlinge Einthalt gethan, mu muificn mit bem all

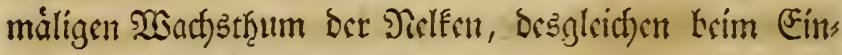

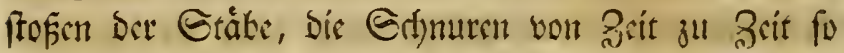
verkurgt werden, Da

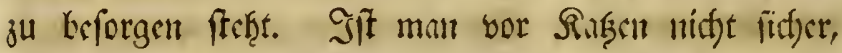

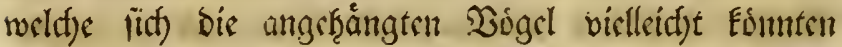

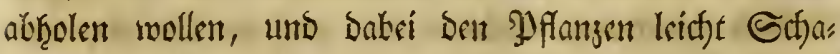
oen zufügen murben, fo fints פiefge liker bie Etellagen ausjubreiten. Nod) tidferer doer menigitens, mínder meitläufig werden bie Eperlinge nicht fowof̨t von ben Tielentôfen als auth von ben Bartenteeten abgerfalten, 


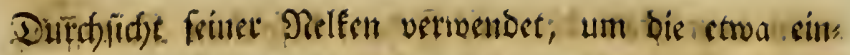

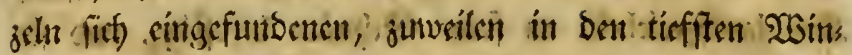
feln Der :Slátter fidt betbergentosn Infeftcit gleíty. bei if̧rem Entftehen ju: verberben, ber wirb um Esine feiner frohen Seoffinungen betrogen werben. Froft und

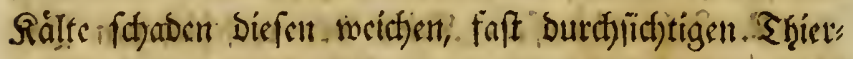

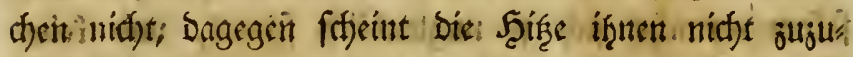

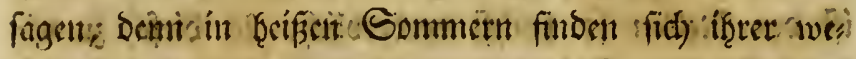
nige; imbent fie meiftens erft, gegen ben Scetbft gum

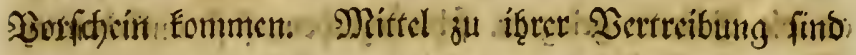

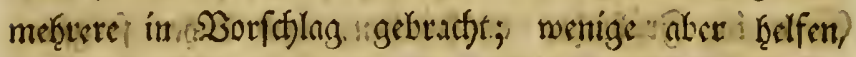

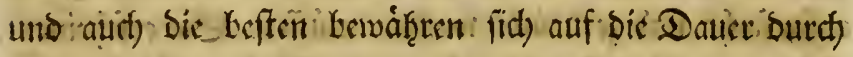

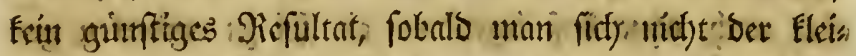

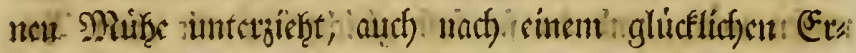

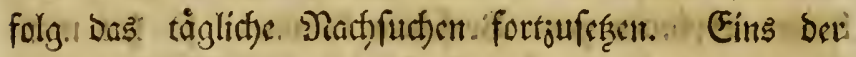

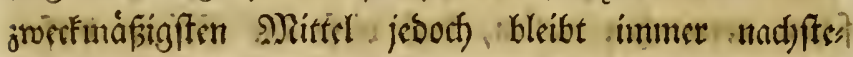
fiendo:

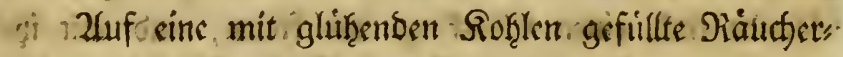
pfonnc, î sinem Elcinen. nicorigen Raum. ober Berţált nifi aufgeftellt, wo bent Misimor wie ber Zugluft jeber:

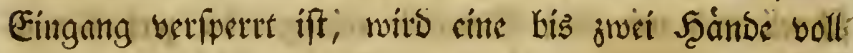
orbinairer. Raudftaback unto. etwas geftofiener Stjwe" fel gefduittet, bas von Blattláufon angeftecte Sefáp.

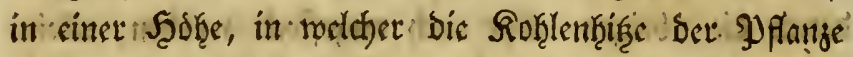

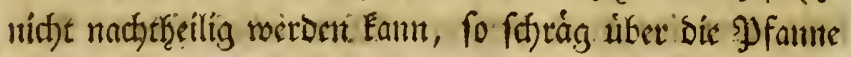

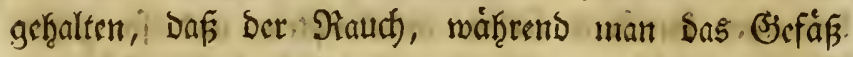

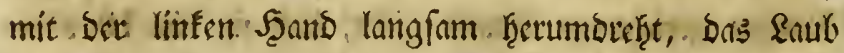

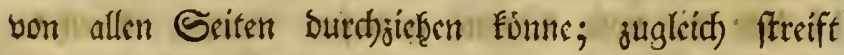
mant mit Dent auisgebreiteten Fingen Der, redfeten Scand

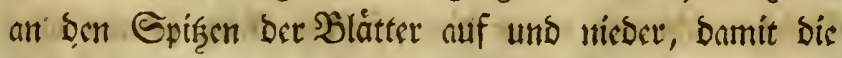
vom Dampf crmatteten Blattláufe hecrabfallen uno ver: 
brennen. Die cinjeln juritcfgetlichenen Blattläufe wets ben forgfam abgefuctit, wegen ber stiva nidje aufgefulls benen Thiertfen nber, bie obern und untetn Esiten

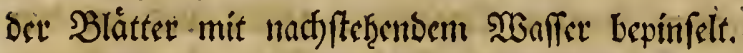

Llnter 4 bis 5 Thęile Esifenfpiritus meroen 2

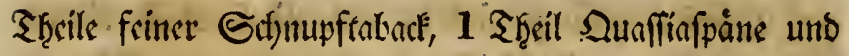
1 Theil fobmarge Seife cinige ₹age in Der Somme

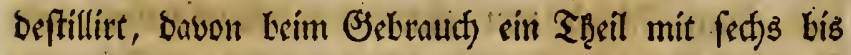
acjt Theilen Regemvaffer gemifat, uns naty bolljos

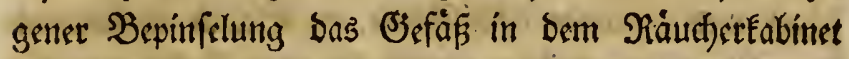
nody sime bis zrosi Gtunden bingeftellt, nact) beren כerlnuf Doffelbe ins freis genomiment, mit siner Oprif̧s

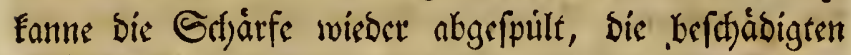
Blätter abgctnommen, und bie alte (Erbe burn) sine

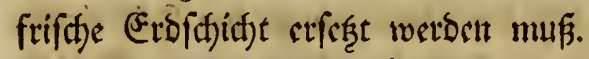

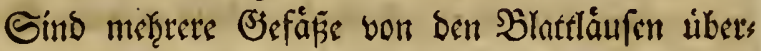
fallen, fo legt mant bicfalben um Den Rand sines pals fend grofen Tifetes fo, Dof bas \&aub úber bemfellben

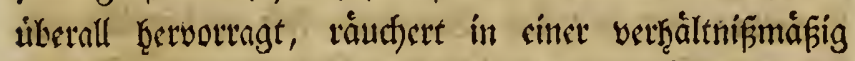

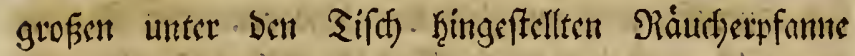

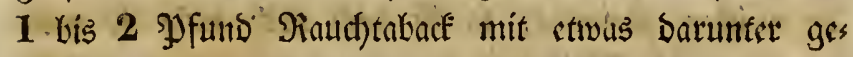
mifidtem Safrosfl ab, verfallicfit bas Rabinet, unb beginnt nach siti bis juei Stundent das abftreifen ber

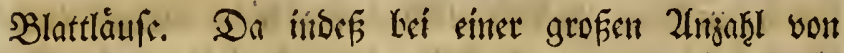

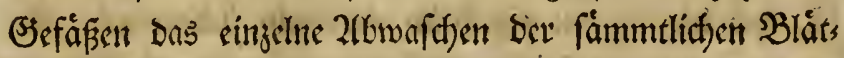
ter ju zeitrnubeno fenn witbe, fo tautft man lieber,

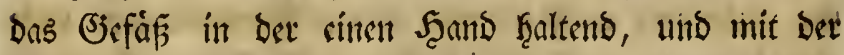

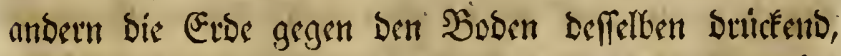

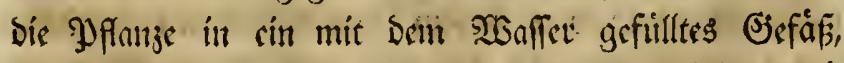
in bemerlben fín unto f̧er faţrens, uno reinigt nad) 
cinigar Beit bie Etscte nutb der oben angegebenen 2lutleitung.

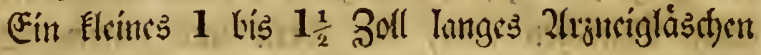
mit cintigen Tropfen Suscefillber gefuilt und an ben

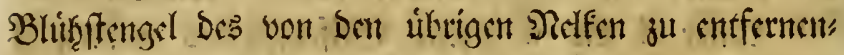

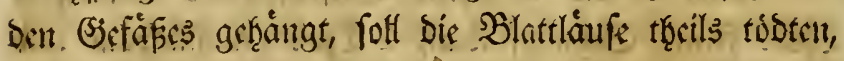
theils entfernen, besgleithen wenn man bic Jyfanjen

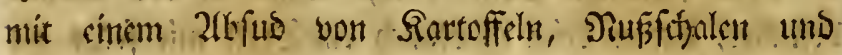
(t) warjer Ecife benteft uno alsbalb mit frincm Extmupf:

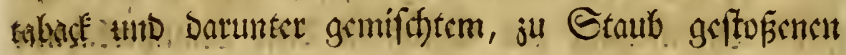
J)eteriilienfamen Kefteut; aut) foll bas beftectuen mit,

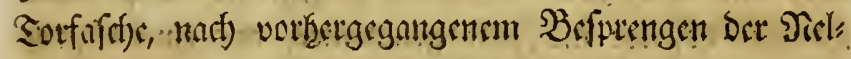
fen, tit tobten.

3. Spinnen. Es gisbet sine Zlit gan!l flemer

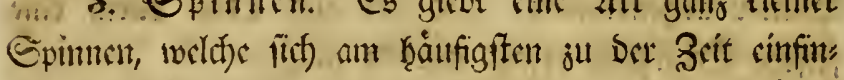

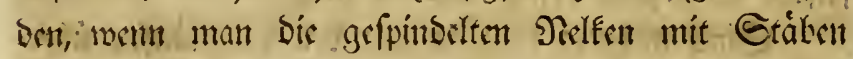
veriicht, unt meldfe Dann aud bis Ende der flor,

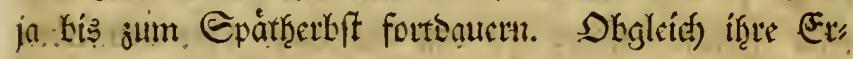
fof cinung mit, bev ber Blattlaus foft glcit)kitig ous

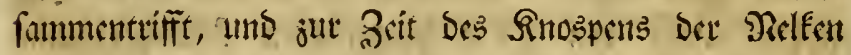
am meifent junimmt, fo ift boch nod hidft fo ganj unkebingt bic Nlicinung berjenigen ju threilen, tweld)e biefe Fleinen Epinnen fur sie Mlitter ber Blattlåure. fralten wollen, okgleid "nod) lantge nidft allsgemittelt

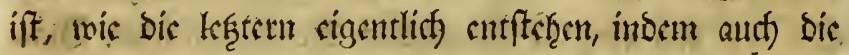

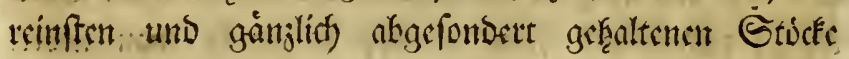
und befonders aud mathe andere Plfanjenaten, vol: juglid) wern man fir in nid)t ganz freiem Euftuge

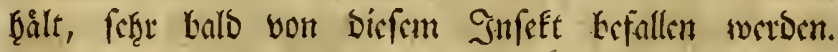
Uletrigens ift es wathl, Daf auch Dicfe Elcinen Epinnen

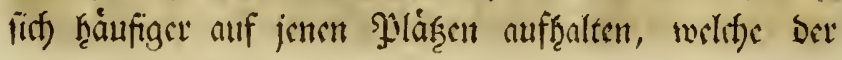




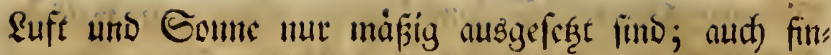
bst man bei sinct vollftáibig roin geţaltenen Gamms

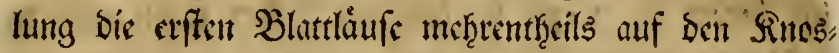

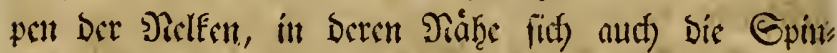
nen meţt als iu Sorafe Derfatben aufhalten. Wie Dem ıun aut) fen, fo fingen jwar bie Epinnen bev Wisles feinen lefondern Gednden ju, aber fie umweben bod

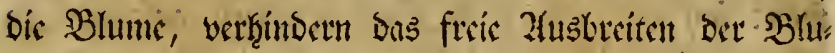

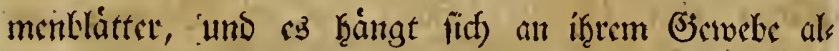

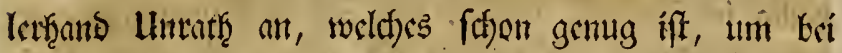

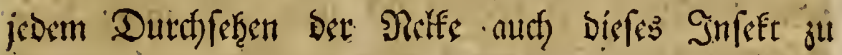
vertilgetr.

4. Det Shrwurm. Srof ift bic Dertwiftung, wélebe bie Bllattlaufe an bem Palfengrafe antriftent metm man fie tiberţans neţmen läft; aber woḩl cben fo grap ift ber Sdfuden, ben bie Shrtwuitmet vertts

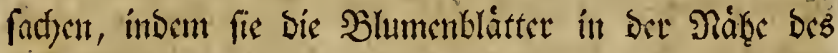
Frudtetnotens fo abnagen, Safj bic Dellee beim leifes ften Şeruf̧ern cntblättert aus cinanber fållt, uns $\mathfrak{c}$ um alle 2lugenmetise fo wie um bie Steminntung volt Samen gefdethen ift. Llm fie von bem bluhhenden Dielfentheater abjuhalten, ift níd)ts jurefmáfiger, als

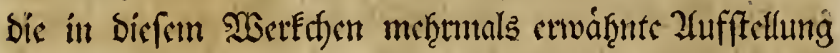

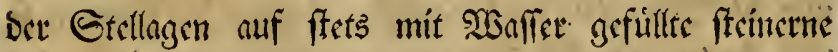
ober blecrune Gefuffeln, ober bie Befeftigung cincs,

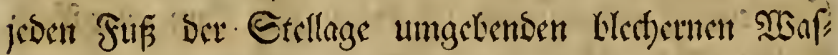

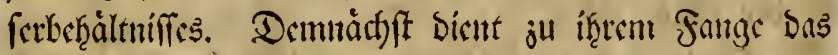

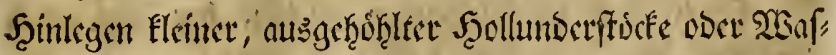

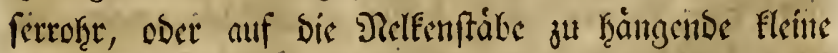

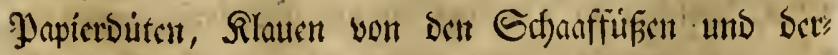

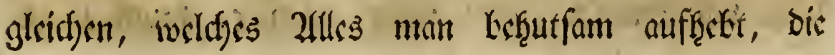


Tourmer frerusbláat, und fofort tóbtet, ju weldyem

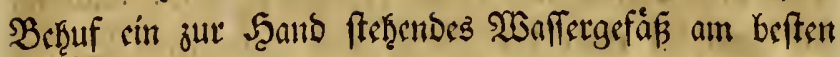
ift, indem fie, wenn fie auf ben Boben fallen, fid zu gefdywind verlaufen.

5. Der NelEenflok; cin Eleiner gefligelter,

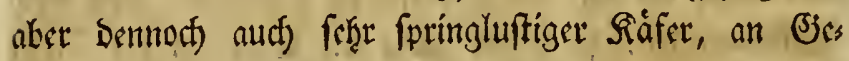

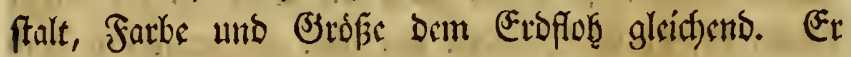
findet. jift sin, fohald bie DelfenEnofpen anfangen ju plasen, ober fich zu dffnen; find bie B̉lumen aber yollig im flor, to treiben fids auf uno imerţalb ciner jeden berfellen oft 15 bis 20 und noth mefre biefer InicEten hecum. Bervegt man die SBlumenblatter mit sinem Eleinen Sholghten, fo eilen fie aus bem Sinnetn

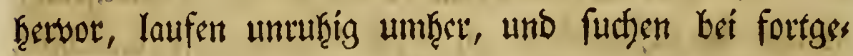

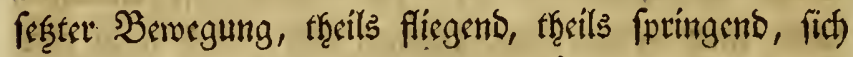
ju entfernen. Durd) Die Baumblátter Der geplaşten Эeleen bohren fie fid) bis jum Frudtetenoten Durd, nagen an ben Blättern, faugen bie Stifigfriten cin, uno verberben auf biefe 2trt vicle Blumen, Dod fino fie. bei weitem nicht fo fdádich, als bie Shrmirmet. Ulebrigens ift noch Esin Dittel befannt, fie abjutgalten, ober wegaufangen, uns es bleibt weiter nichts úbrig,

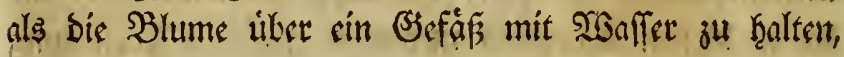
uno bie Ráfertien aus berfalten treraus zu ftobern, fo Dnf fie ins Woffer fpringen, welkfes Dam in weiter (Entfernung ausjugiefen ift, went Fein fluf ober ßad) in ber ఇáthe wáre.

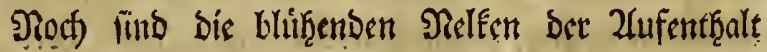
sines ganj Eleinen, nidft vơllig ciner finie langen Sons fefts, weldyes fo fein uns suinn ift, Daf, wenn es nicfst yout bunfler fartbe wáre, man cs Enum wuiros 


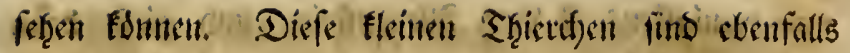

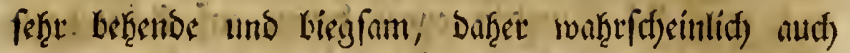

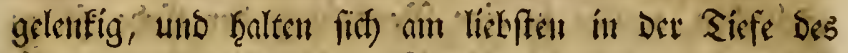
Reld)es auf, von no fie hictouslaufent, wo went man nach)

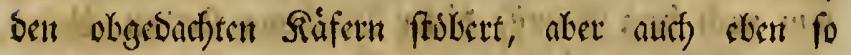

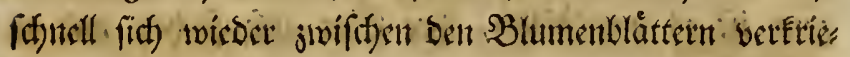

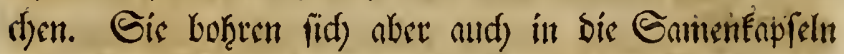

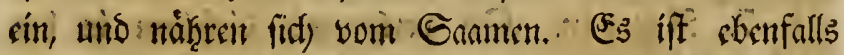

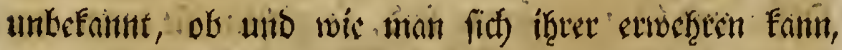

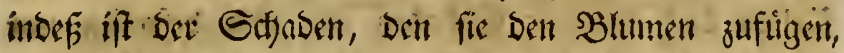
aud)" nicjét bebeutento. Sb bie gants flénén bunflen

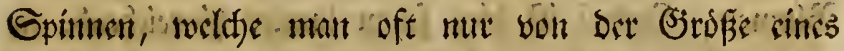

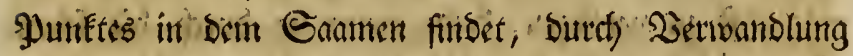

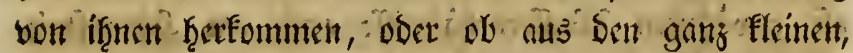

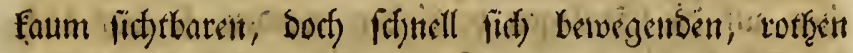

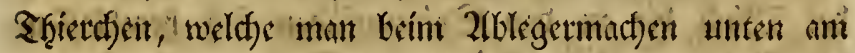

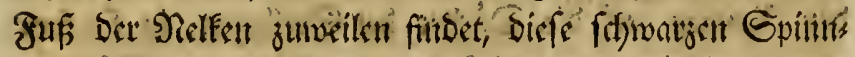

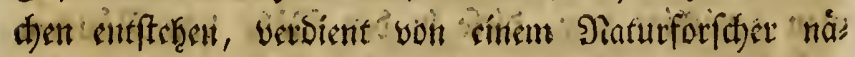

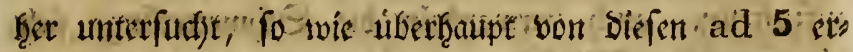

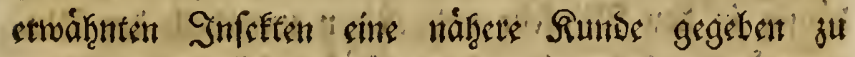
werber:

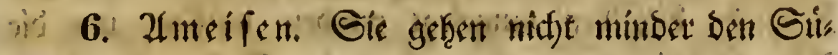

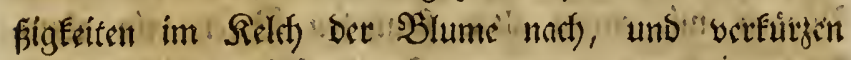

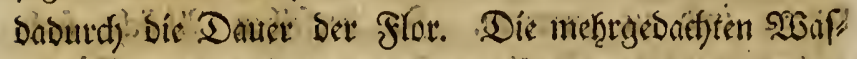

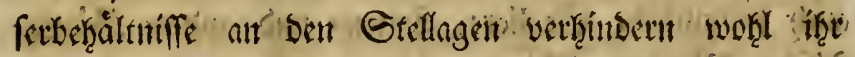

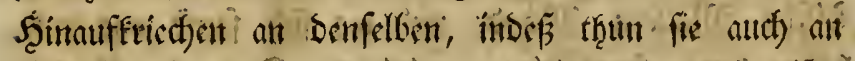

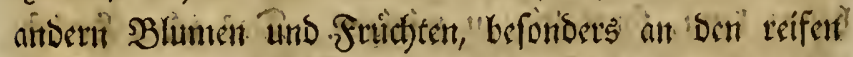

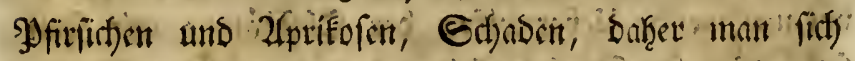

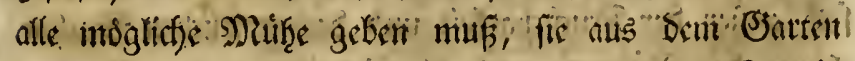

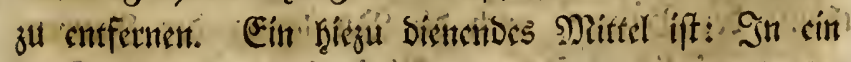
Suart Biegenwaffer miffite mait 5 bis 6 botf sucter 
unb wenigfteng 2 goth fliegenftein, unt gief̧t Dann

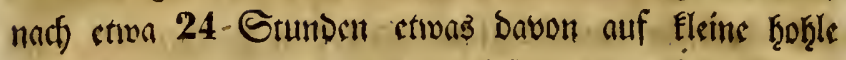
Scherben, weldye in eine Wertiefung Der Erobe fo ju

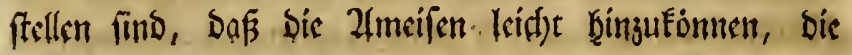

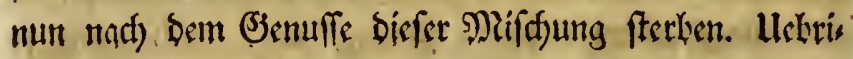

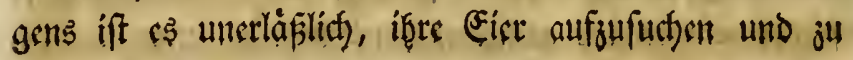
jerbricfert.

7. Raupen. So vetheerents biefelben in ben Sbft: uns Bemufegärten find, fo, ridfen fie unter Den Diclen bod) veniger Gdjaden an, uno befreffen mur fpáterhin bas laub berfelben, feltener bie Blätter ber

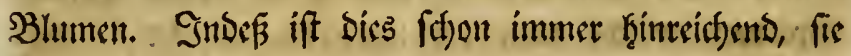
moglichfit ju vertilgen, benn wenn fie burch die fifon

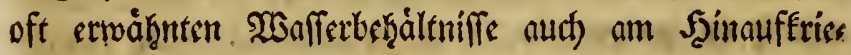
den auf bie Gtellagen verhininert werden, fo jagt Dods)

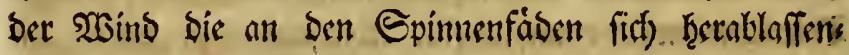
Den Raupen auf bie Dácher Der Stellagen, in fo fern

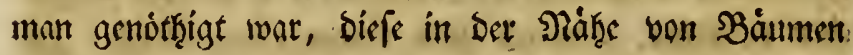
aufauftellen, aud) verwandeln bie Gdjmetterlinge fich.

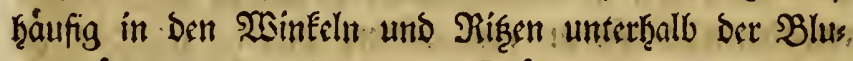
mentråger, bab̧cr in jebem Epätḩerbft uno jeitigen:

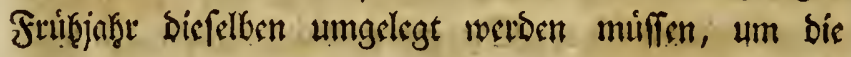
Duppen mit sinem alten ftumpfen $\mathfrak{B}$ ejen rein abzus

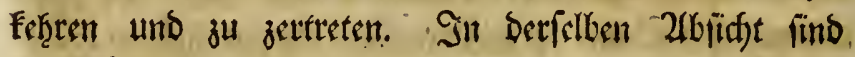
nucf) fåmuntlid)s Spaliere, Satten" und andere Bänfe,

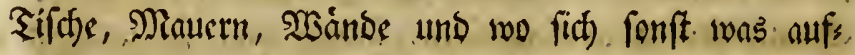
ḩalten fann, forgfáltig ju reinigen. Das jeden Seerbjt vorzuneţmende Ueberwesisen Der Sbftbáume mit Rale.

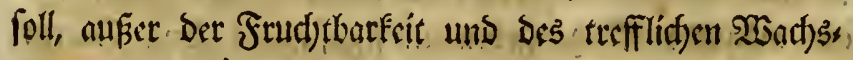
trums ber Báume, aut) bíe Dertilgung ber Piaupen. gans vorguglich beforbetn, Simfteteraut aber, in Seis 


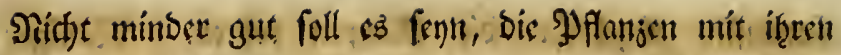

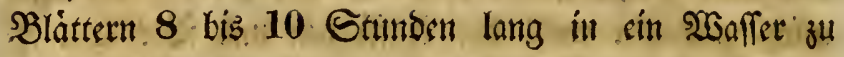

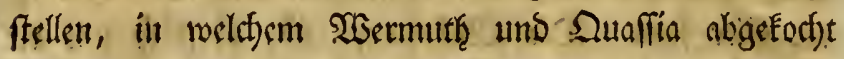

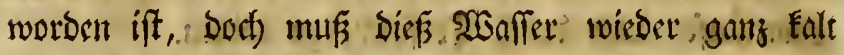

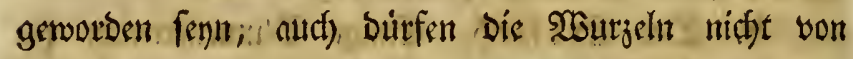
Demfalben naf merben. Die, ziemling laitge nntaaltende

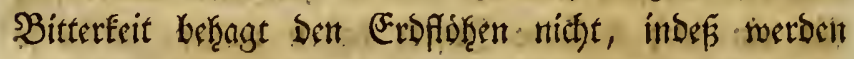

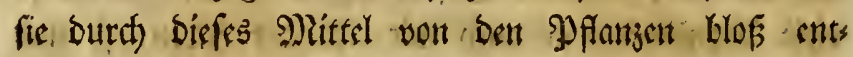

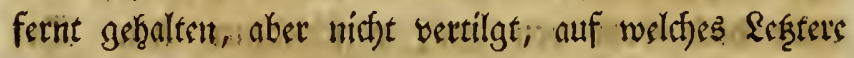
bod) Die, vorguglicffe Gorgfalt zu xidjtent ift:

9. Die Eleins gruine 2elEenmade uno not) andere 2(rten Dergleichen glatten uns beţaarten Unge:

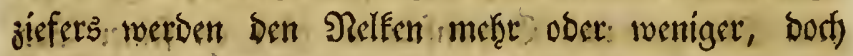

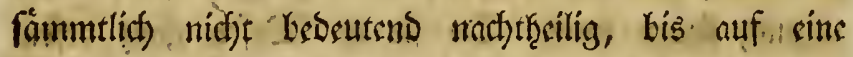

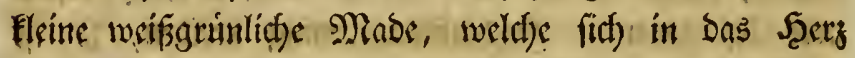

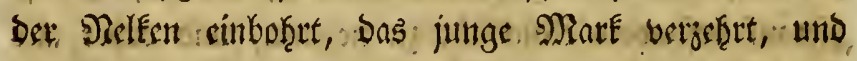

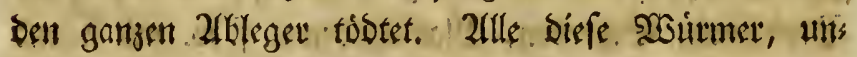
ter weld) auch bie fleine grüne, auf Siefero, fpanis

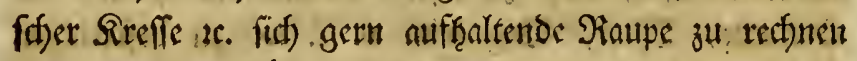
if ; muifen forgfáltig oufgefud)t uno getobtet meroen,

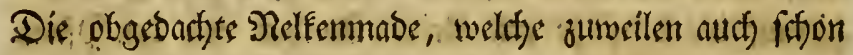

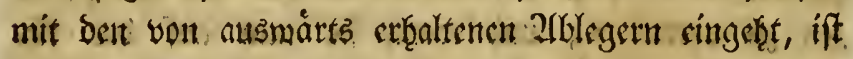

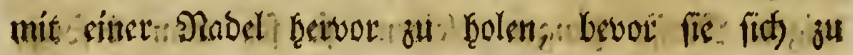
tief in Die Mflanze cinfreffen fann.

10. Maulwurfe thm diefs bislen Stjaben onrictetenden Shiere von ben DielEenbeeten abjuţalten, múfer diefelben zwar nur äußserft felten; um Die Sis? genwuirmer nicht beran ju loffen, bami aber aud) fo.

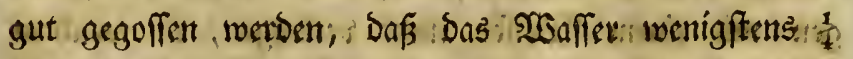
Elle ticf eimbringt; Kefonders find bic DJfintzen nidet.

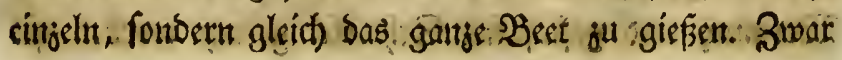


fernt lis unfef̧lbat bon benjenigen Besten, bie ivit vorjiglid) gejidsert wiflen wollen; nud ges f(d) wht bies, - wenn man cin lober oud) mef̧rere Elcine Fàjecten in bie Erbe cingrálbt, in ber Mitte Des obern, mit ber Socrfàdye bes Bartenbobens

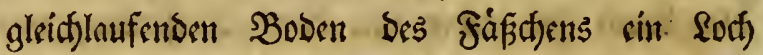
bohert, Dutch Daffelbe cine etwos ḩohe Etange ftecft, und oben an Detfolben sine WSimbFlappers muffele befeftigt, Durth beten in Der Eros ber

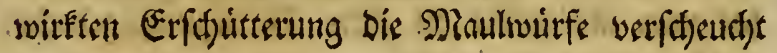
werben.

11. Die Maulwurfsgrille, 2dferwetre, Raits wurm, Eroferts; wirb .Duref) biefelben Mittel vers fifeut)t ober getobtet, weldbe jur Wertreibung bes Maulwurfs cmpfoḩlen rootben find.

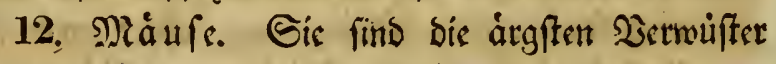
ber : Telest in ben SWinterbergàltniffen, wie fie aud)

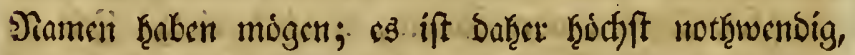

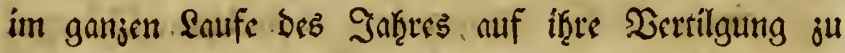
Senfen. Da bies nidyt immer burd) idas Zuffetellen

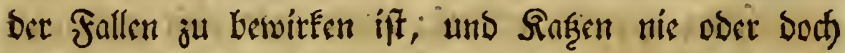
mut felten in biefe Besţalttniffe jugelaffen werben, fo muF man fich Durch Dergiftungen, weld)e jesodi mit

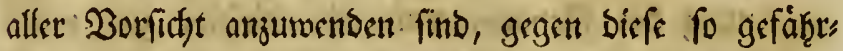

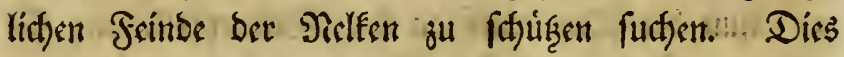

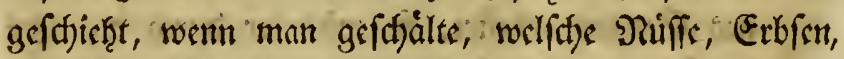

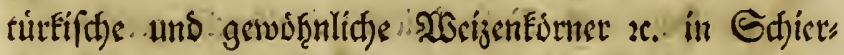

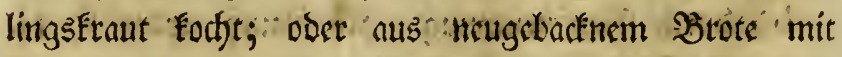
Fett und: Datunter gemifatem 2lvenie Dillen madjt

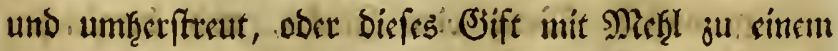

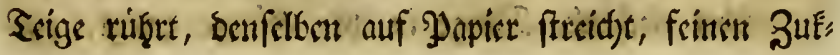




\section{Aactiag.}

3. Erft im शovember 1826, alfo faft sin- Jahn nad) Bertibigung Des bon miv pntworfenten Gnfterns

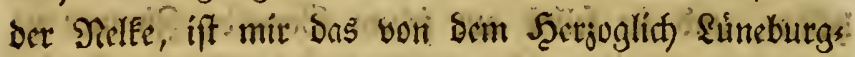

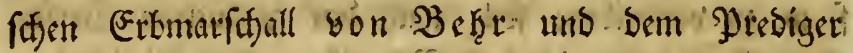

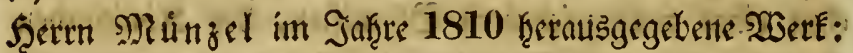

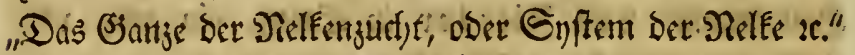

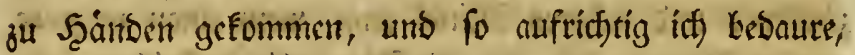

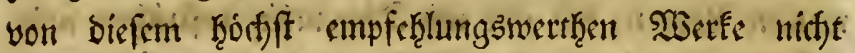

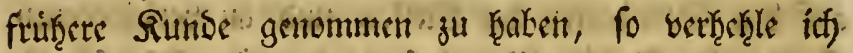

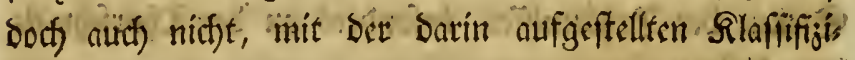
rung uns Luterorsmung (Dibenfpiclaten) Der. Nelfen

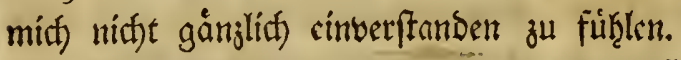

Şanj aus meinet Serle genommen ift bie War,

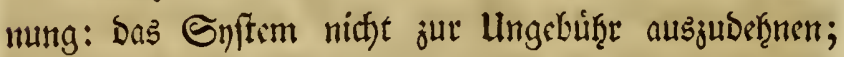

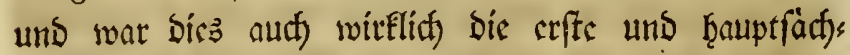

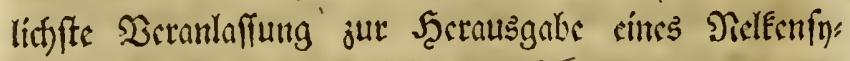
frems, an welctes id mid) jwar ffton lange balte, fs

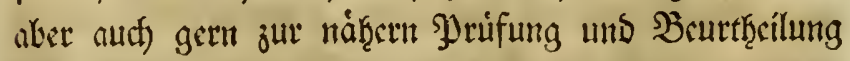

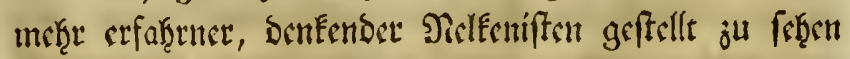
winfthte. 


\section{0}

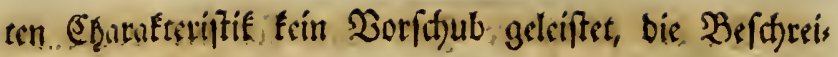

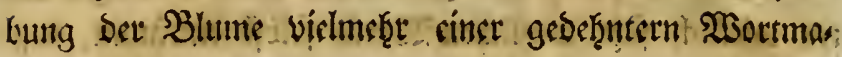
lerei beburfen roctos.

Dir im Rupfer Tr. 7. Dargelegte britte Deben:

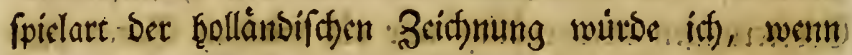

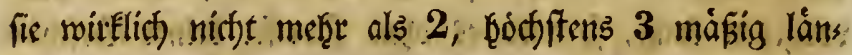

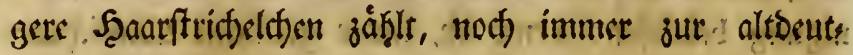
fefen Bciffulung rectinen, ba, ftreng genommen, nur bodfft felten sine Seidjnung Duthous rsin und regels. máf̧ig ift; hăatte fie aber bergleiden weiter gegen ben Ridl) Kerablaufende Etriffe, Dann mütoe fie mit: Rect)

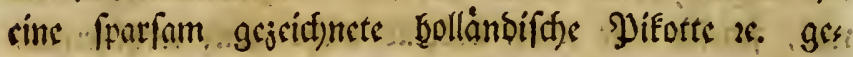

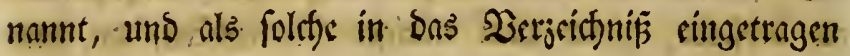
werben miffen.

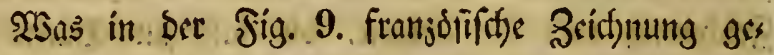
numut wird, babe iff in bem vorliegenden Trerte bes

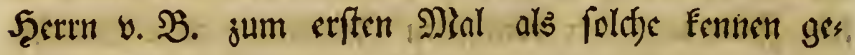

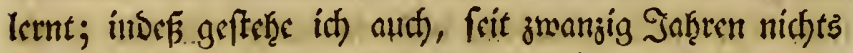
Liber bie DielfenEultur uns dos biesfállige Eyftem ges Iefen ju haken, nls mur vor $1 \frac{1}{2}$ Sab̨ren bas Wortét)en bes Sectrn $x$. Lerifa und cines Zlugsburgifften Dels feniften. Die von andern Blumenfieunoen indép ès

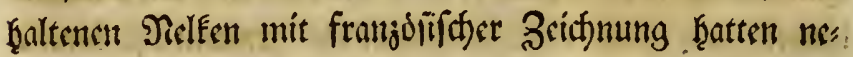
fen ber Pyramioe nod) immer sin pan Scenterl, und es miffe bies Klof Sufall gewefen fenn, wenn bie ob:

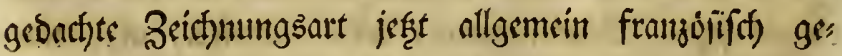

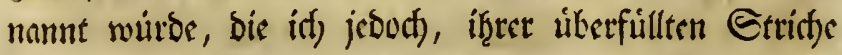
megen, of̧ne alle waf̧re Bcidgnung, nidgt gutheilïen

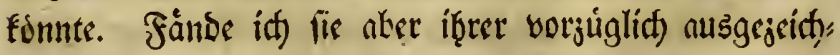
neten Diekencigenfhaften wegen Leibeŗaltungșmerth, fo whifte id) freilith nidse, unter weld)em Sunftnamen 


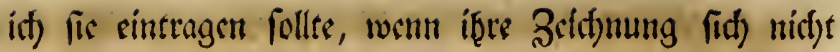

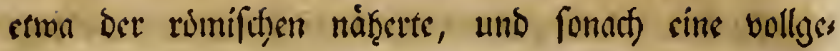

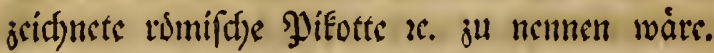

Woenn id) es, nach bem 23orthergefagten, für ges ratben eract)te, bie mit 1 paar Scenfel gejsidfuncten Diel

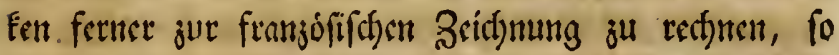
fit)sint si mir gants folgetect)t, jur (panifden Bcid)s

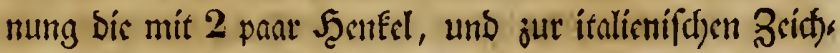

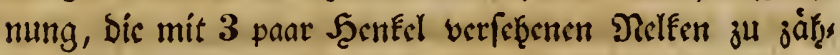
len, fo menig autf) ju lätgnen ift, Dof bie Datur uns biefe Briffunungen in voller Ricinigfeit uns Enms metrie bis jeşt nod) feţr felten finenfift. Sic folgt unfern mit Dem Pinfel Dargelegten 2 uimfat)en nid)e,

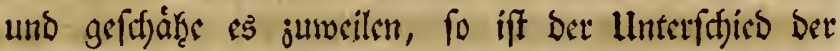

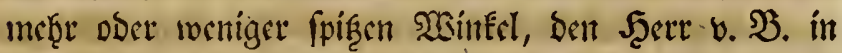
Den Figuren 11. uns 14. jwifhen Der fpanifden und italienif(t)en Serichmung aufgeftellt hৃat, visl zu unfid)er,

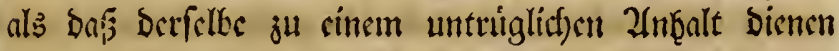
Émte. Daf mant bie ad Fig. 13. gejsichnete, von

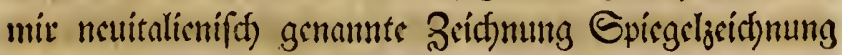
nemt, fdjeint allgemeinet wetben zu wollen, unb betw tet wenigftens an, Daf Der Bridjunng bie Jyntamide mangelt. 2(ngemefiener ţalte id) jesod), bie Fig. 2.

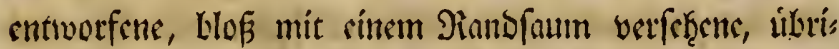

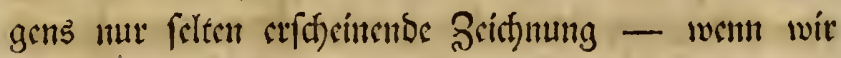

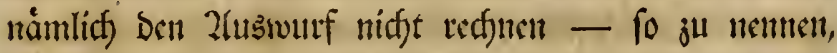
indem bicfer Rambfaum gleichfan Den Riaf̧men for" mirt, Den bic fogenanten Seand" ober Rerifefpiegel ḩas ben. Siene Beifunung aber jue Deutf(t)en ju tect)uen, tnoslt Şart v. SB. mit vollem Sird)t.

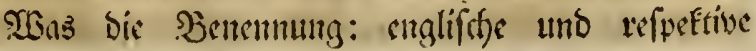




\section{2}

Deutfitge Bantoftreifuclfen betrifit, fo vernag ith nitht, ber Mcinung Des igerţuten Jcerrn 3 erfoffers unbebingt

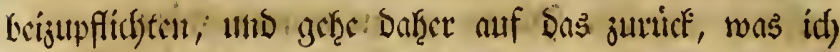

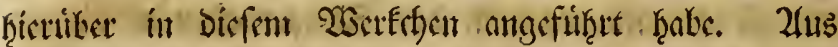

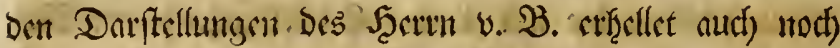

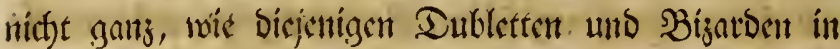
ben Wergerifyinffert Eentetlid) gemaity werben follen, wet,

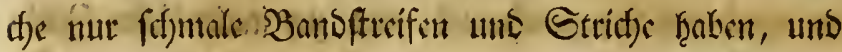

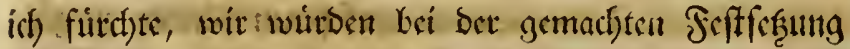

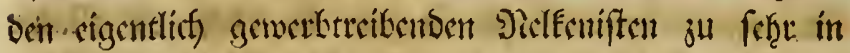
bie Saánde falleti, und unter ber ßenenenung "englifathe Baansftreifnelfet", jwar Blumen mit methr ober weni"

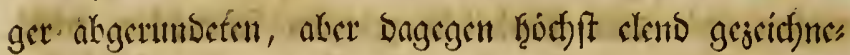
ten Sláttern erthaltent. Diefent lieşe fict) mun jwar bas bitrt) vorbengen, wocum allgemein - iff) fage: allges incill antgenomment ober émgeffirgert muitbe, fid ber moreflityen Mialerei alfo zu bedicnen: breit gefterifte

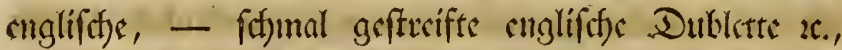
burit geftreifte beutfitse, - febmal geftreifte beutfde SBijarbe; ift es jebod) niffet rocit folgeret)ter, wentr bie Erfenmungstworte Diefer פelfen clen fo von ber

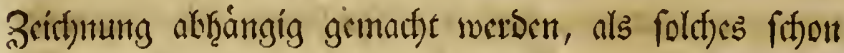

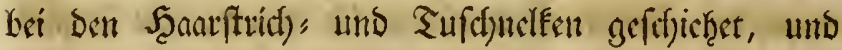
Dafi bei jenen, wie bri biefen, bie form bes Blument

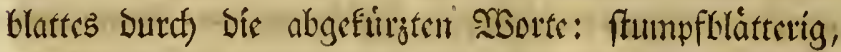
gejåf̨nt, flcin gejáh̨ut, foft ftumpf, angegeben werbe.

Zllerbings findent wir uns oft in Derlegentheit,

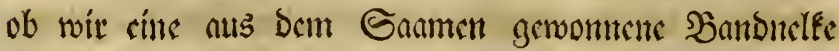

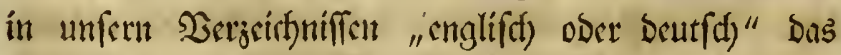
freifist: breit oder febmal gejeiffinct, sintragen follen; tat fie indef viel ober merhe bucite als fofmale Etrci: 


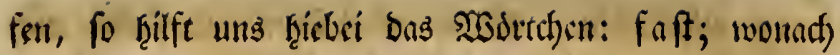
id) Dergleidfen Delen folgendermafen cintrags: beuts

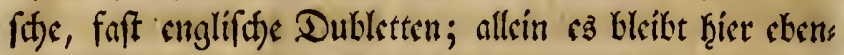

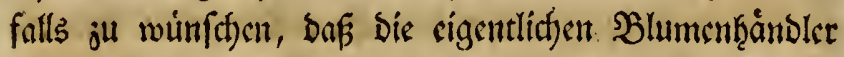
(iid) Diefe Mletḩobe auth ancignen modften.

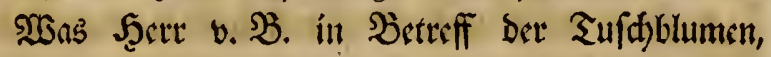

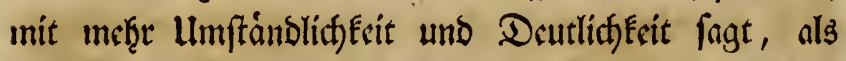

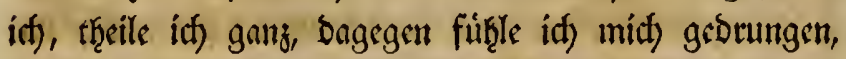
bie Farbemelfen, in fo fern fie fief) Dured) Bau, Farte,

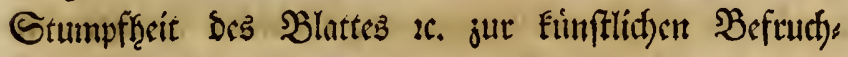
tung rignen, in Srtus ju ncḩmen. Şwar giebt uns ber Sufall, wie bie Siumft, ţauptfä́d)lích von ben voes jüglít) fajón uns regelmáäig gejcidjueten Delfen, treffo

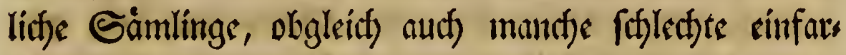
bige Deles; inder ift es fidfer, ban wir bie meiften

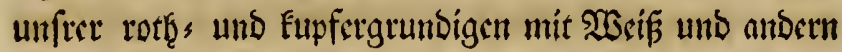

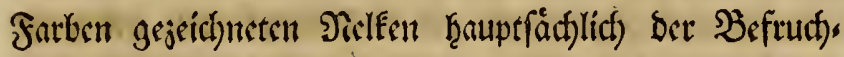
tung folduer cinfarbigen B̉lumen-ju berbanken haben,

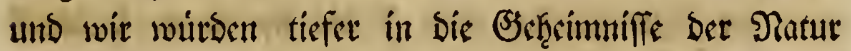
cinjubringen vermógen, wenn wir uns jebergeit bemis ben wollen, wenigitens itt Dergleid)en Seftud)tung verfud)en sin Nationale ju fralten, Den Davon gewoun nenen Gaamen unter befonbere ঐummnet allein ju fáen

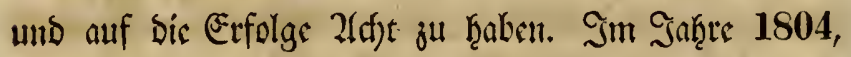
wo id), auser (Jirenolle, nod) nidft im Befif von

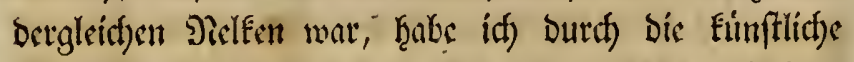
Befrudtung ciner cinfarbigen rotḩen Nelfi nut bem

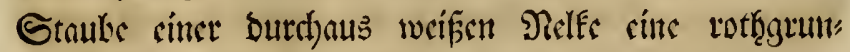
bige fodon gefterifte Dublette mit breiten weifen Strei fen getwommen, uns im bisfjáf̨rigen Gommer ift mír

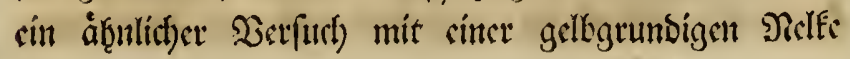




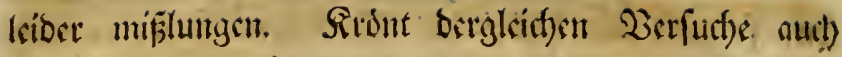

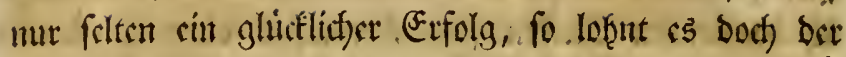

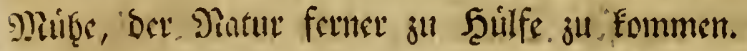

Die Ertor, weld) Der Shetr Werfaffer für bie Didfen Leftimmt, ift, mit meníg Worten, folgente:

1. Ş̧cil wof̧l werrotteten uns, gut Dutdgrartsiteten

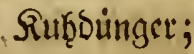

$\therefore \frac{1}{2}$ Thail Eroe aus ben Delfentipfen, bie jeboct) wes nigftens 1 Jah̨t gerub̨t hृat; unઠ

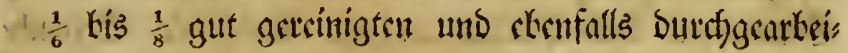
teten Fluffanto.

Solle jeboch bicfe (erbe nicht etwois ju fett, ju lok" fer unt ju leitht feyn, unt ss ben Pelfen nicht meţr

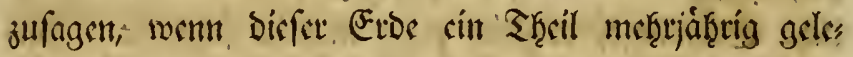

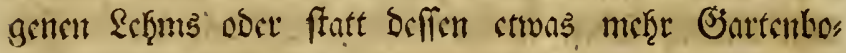
ben Keigemificht witroc?

- Fernet fosint mir cin Delfentopf von ber pag. 71 befdricbench Srojfe, námlict) 6 kis 7 3oll hod), uns im Durctumeffer oben 7 his 8, unten 5 bis 6

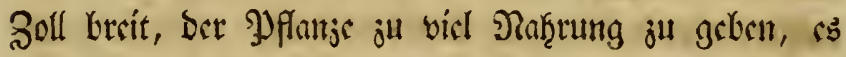
muiffte bern sin im vorigen Sahtere uidft geblúf̧ter

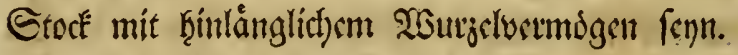

v. Sir. 


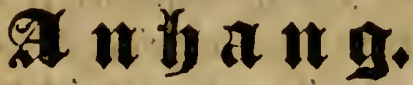

\section{2on der sultur ciniget andern sieb: ringäbrumen.}

\section{$\mathfrak{A} \mathfrak{u} \mathfrak{x} \mathfrak{i} \mathfrak{e} \mathfrak{e} \mathfrak{l}$.}

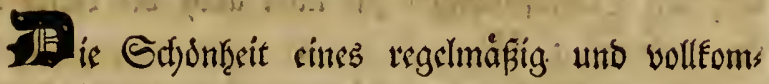
ment ausgebuilbeten 2lurifels, bas unenolid)e Farbenfpicl

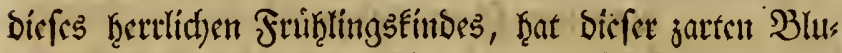

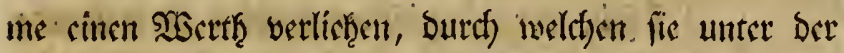

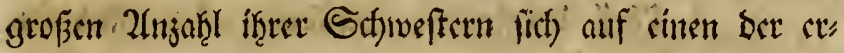

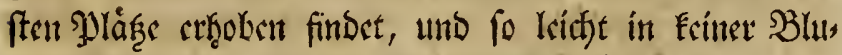
menfanmlung fidf) nusgefd)loffen ficţet. 2(ud) fie trat

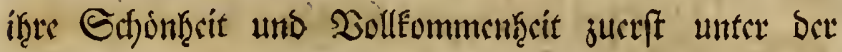
pfifgenton Scant ber Scolländer und Einglänber ents wickelt, wirs jesct aber aud) bon unfern cinfecimifa)en Błlumiften in nid)t minterer Etjontect und Dirgclma:

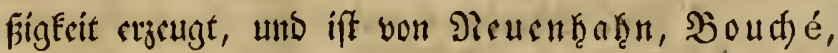

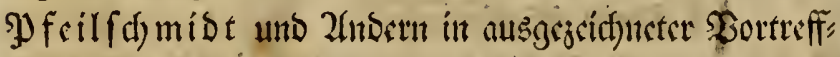
liffecit geliefert worben. Gie will indef; forwotgl in

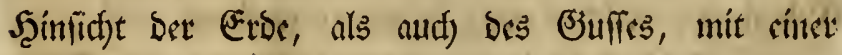

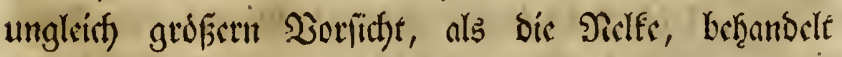

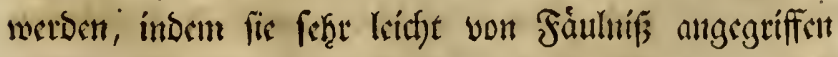
witb, uns dant nut fatwer ju tetten iff.' Şat mant 


\section{6}

jebod) hierin bie nothige Senntnip lich verfajafft, bie if̧nen am Eeften zufagende Er ausgennittelt, und fie vor allem mit cínem, fie tibermáfig trébenden, if̧re Wुutzeln verberennenton, Die ganje Dyfanje EranE uno wrict) madjenden Dinngev verfdfont, fo lokgnt fie uns

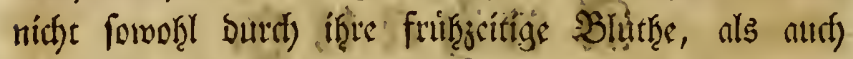

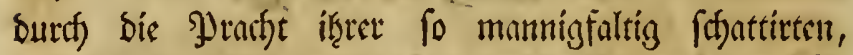
fammetglánjendoen; mitunter recfet feltenen, zumi Sbeil bepuberten Farten. Sie verlangt. Ecine gar ju leidfte, Dod) audf) nieftes rouiger als fofwere (Erbe, weldfe

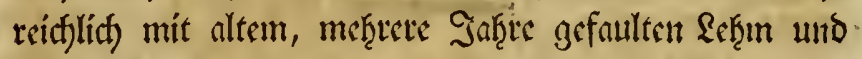
mit getrinigtem, 20afferfande gemifdt ift. Der anger rathenen Eromiffungen beat man aud bri biefer Blus me meţrete, o. $\mathfrak{B}$.

1) 2 Tḩrile gut gedungten, loctern unt Durdige worfenen Sartentoden,

2 Shcile ber gånjlich verrotteten Unfrauterbe,

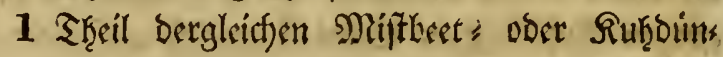
gererioe,

$\frac{1}{2}$ Thcil Sef̧m unt

$1 \frac{3}{2}$ Theil gereinigter Gand;

ober 2) 3 Thrile Gantenerde,

5 bis 6 Thęile llnEtauterde, unter weldhet

- Subzounger bereits gemifot ift,

1 SGreil Sefrmboden uno

2 Shcile พ̂afferfans;

ober enolich 3) 7 bis 8 Thęcile vollftänbig gemifthte Delfeneroe, weld)er noch beigefugt werben:

1 kís 2 Theile gut burtjgentbriteter, von wino und Woetter mirtbe gemact)ter Sef̧mloden bou alten Şåuferu, 
2 bis 3 Trgecile Gaño unto

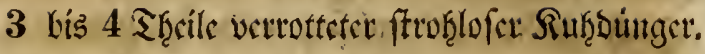

Diefe Zlngaken merben ungefáhr. jut Zlitkitunt

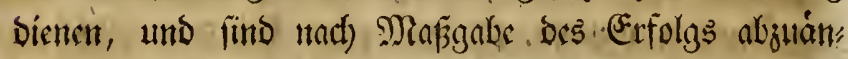

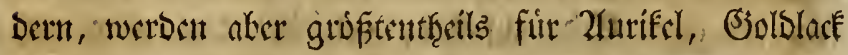

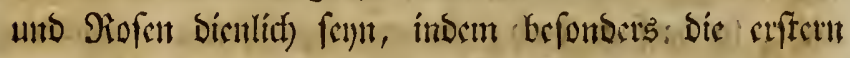

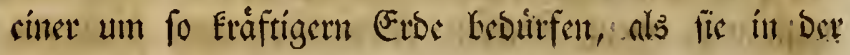

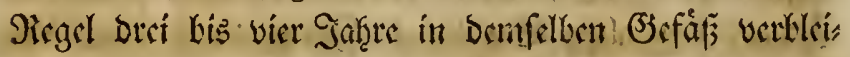
ben inuifien, un bolleomenen ausgerondffene, fratfes unto

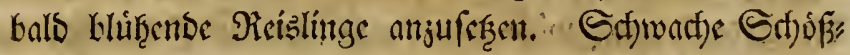

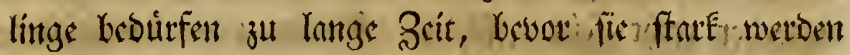

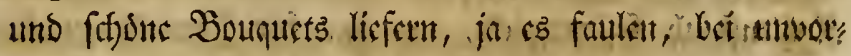

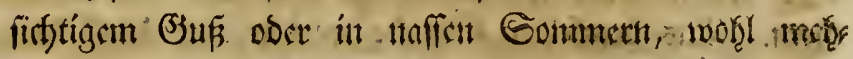

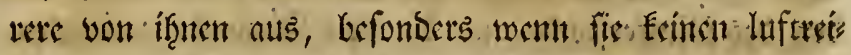

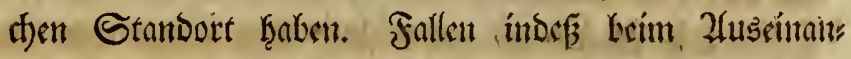
Derneţmen Des alten Etocks, madjosen Derfelle mit als

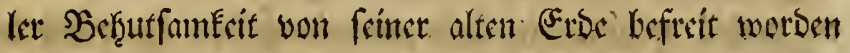

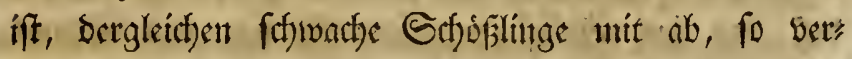

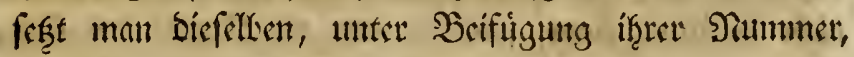

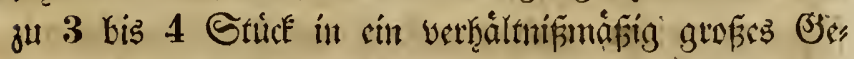

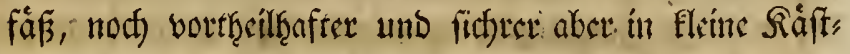

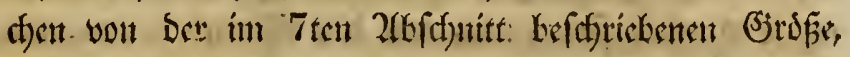
bie ber beffern Dauer megen ant- Dat bier Ecesen mít

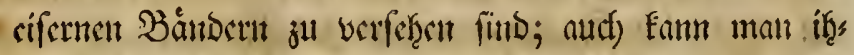

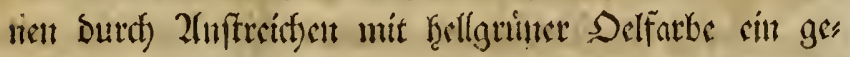

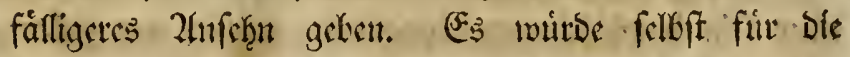

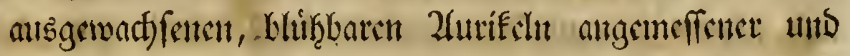

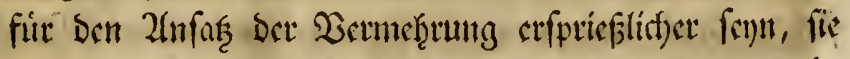

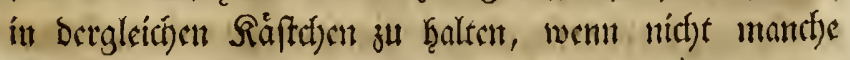

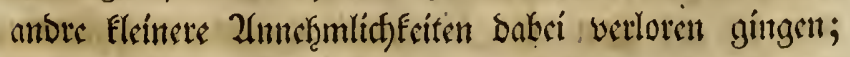
bent vor allen Dittgen muirben lie hier weniger ber 


\section{8}

Fáulnifi, als in ben Tupfen, ausgefertet fenn, lich uns

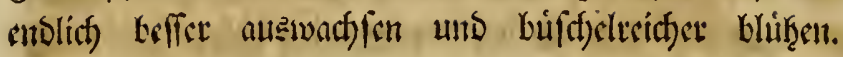
(Eigentlic) foll fertin Gabofling von frinem Mutterfock

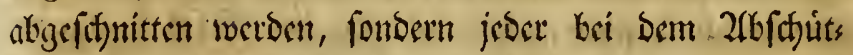

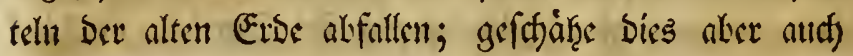
nifft, to Darf at Doif) Ecincswerges abgeriffen, fondern

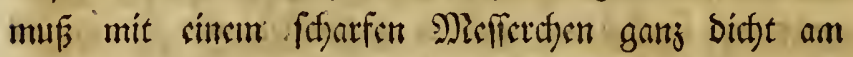

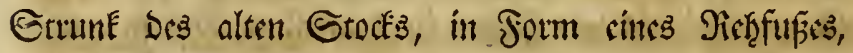
abgefdnitten werbert. Sevor matt ben Gefjofling it

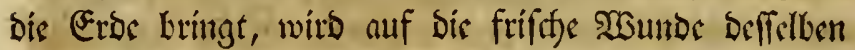
entweder red)t fein gefd)abte Seribe ober Dergleidjen

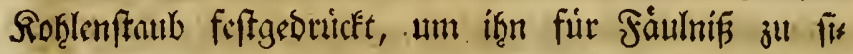

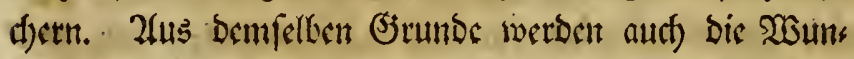
ben Des Mlutterffocks utto Die von Fáulnif gereinigten, bis ins gefunde Fleifi) ausgefduittenen Etellen Damit

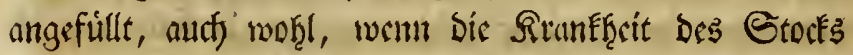
es nothíg mad)t, bie Evos um Denfeltoen fo erthofhet,

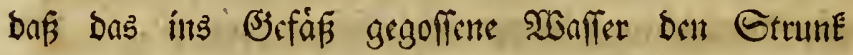

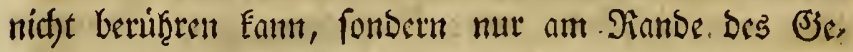

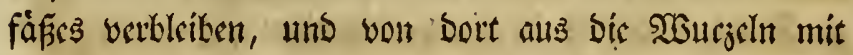
ber notţigen Seudtigfeit verfeţen muß̧; ju noch grosßş rer Sidjerh̨eit ftretut man um Den StrunE ḩctum sine Quantità reinen, ausgewafajenen Eano, besgleidyen um bie faulen Gtellen innerţalb ber Eros.

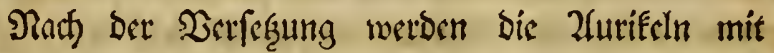
siner fein burchlócherten Gprif̧Eanne måfig angegoffen; uno foonn kis jur 2lntwurgelung in Den Schatten ge" ftellt. Diant und narb giebt mant ifnen etwas Mioes genfonnc, fo wie fic aber vollig ffarte geworden, bringt man fie auf iņten für bie 2lurifelfamnnlung beftimm ten Stand, weldacr wo moglid, fo geridftet fenn 
muF, baß ar bis 7 Doer 8 ltḩe bie Mlorgen", uns

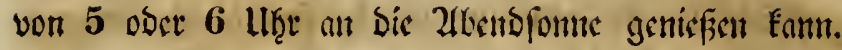
Sor allen Dingen muf Demfellen von allen Geiten

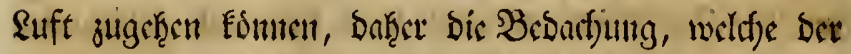
Zurifeltráger jum Gifur ber snglifonen, gepuberten

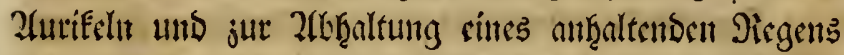

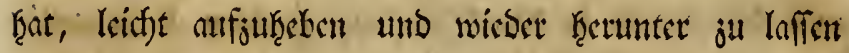

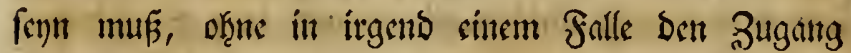

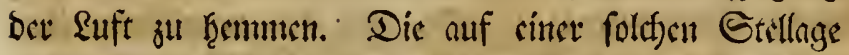

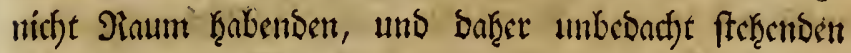
Euickers?lurifelu múffen bei sincm foldfen anf̧altenden Diegen alf bie Gsite gelegt vertort, um fie vor jü

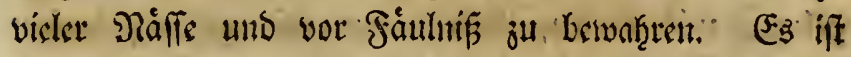

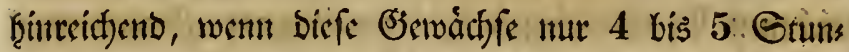
Den Des Tages der Soume ausgefef̧t ftetren; von Mitte Septembers alt bis jut Eintáumung ins Wointerbes

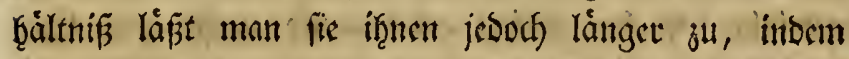

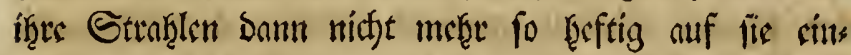
wirken.

Sollte man 2lurifelm: Sefojflinge aus כerfetren

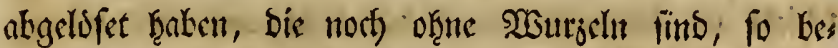
frantsclt ntant fis wie bis Nelfenftopfer, ḩâlt fie meţr trocken als feudft, und bringt fie mur nad) und nad) in bie Gonne, of̧ne if̧nen jebod) biefelbe gànjlict) ju entzichenen, weil if̧e Berwurzelung fonft weit langfannev yor fidf) geţen mutrbe.

Die von andern Blumenfreunden zugeffuidfen

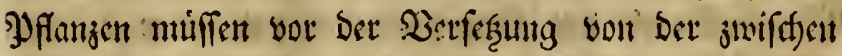
bie Blatter cingebrungenent Evbe und fonfigent lln:

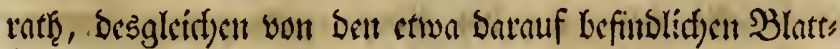
låufan uns beren Eietn forgfáltig gereinigt, und) bert 


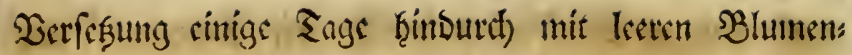

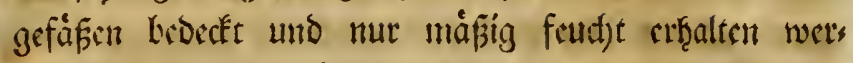

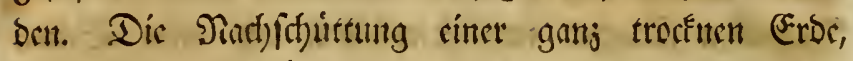

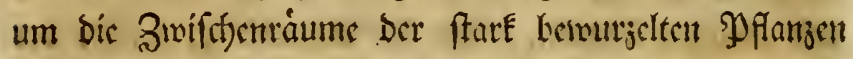

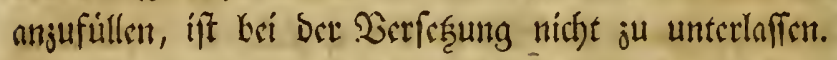

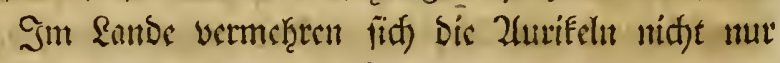

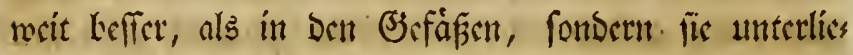

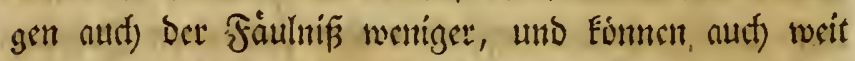

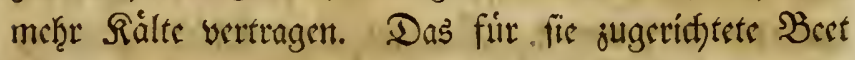

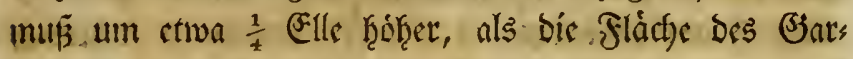
tents ift, in éner lufffrecen, nur Der Mlorgens oder Dse

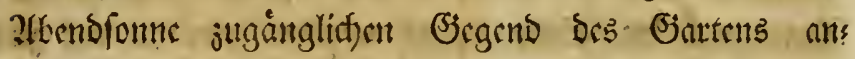
gelegt, mít Ratten, Feficr aber mit gechiorig krriten

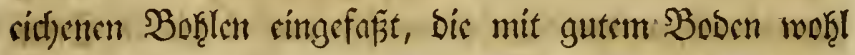

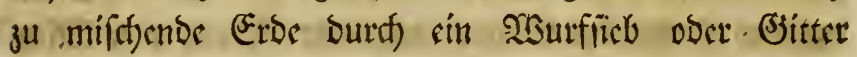

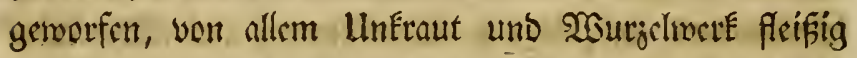

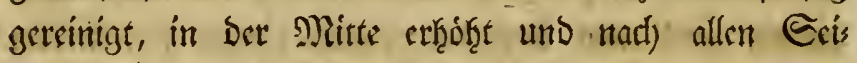
ten, forrág abfallens gentad)t werben, bamít jie nie

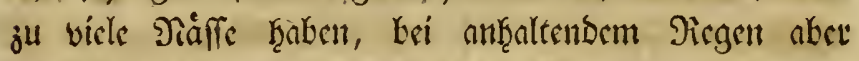

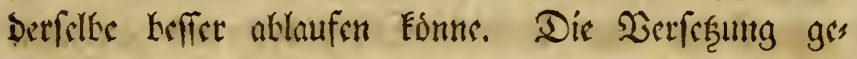

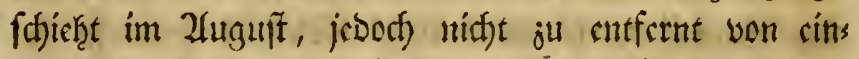

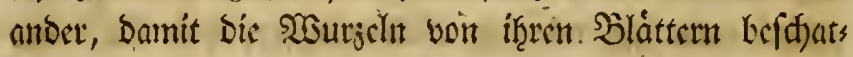
tet werben fónnen; englifafe ober gepuberte 2furifélı

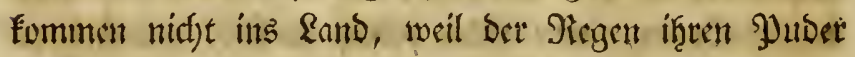
megfpúlen, und fie unanfshrnlict) matsen muirbs. Eollte

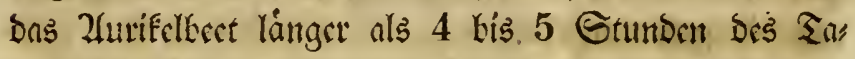

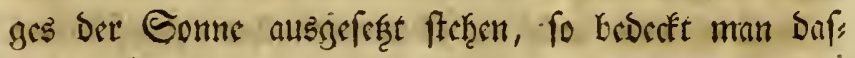

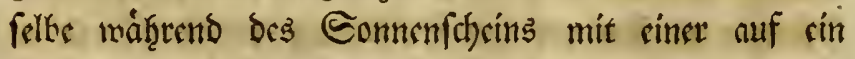
vorgeridfetes. Geftell ju befeftigenden Reímuandoecfe,

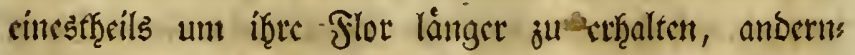

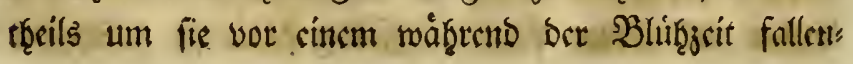




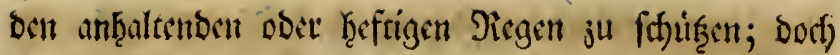
imuf bubiurf) bet Ruffiug fo wertig als moglity ges

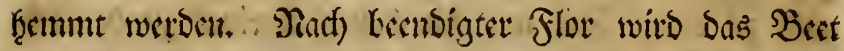
rinigemale Des Saţres mit ber Eleinen Şattenḩacfe aufs getockert, vom llitfraut aber ftets rein ju erf̧alten ge" fuct)t, besgleidfen von ben vertrockincten Blätern forgs

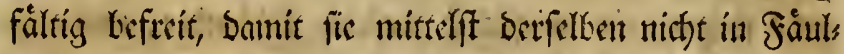

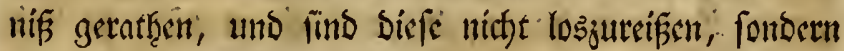
mit ber. Schecte abzuffunciben.

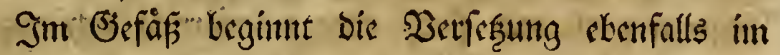

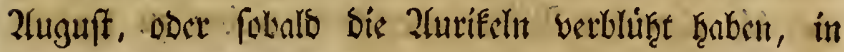
fo fert man nidgt ben etwa noch unteifen Snamen yon ifnen abriatten wollte, autf nimint man zugleits bes nèn, weldje nitfet verfegt werben, bie obere Erbe auf 1 bis $1 \frac{1}{2}$. Soll tief weg, um fie mit neuev Erbe ju

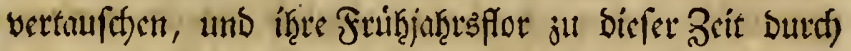
nicfts ju ftoren, fiefrt aber genau barnuf, Daf Feitte

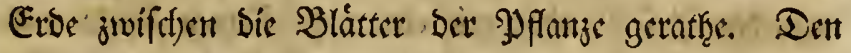
SuF betteffeno, fo Datf berfalbe ebenfalls erft in Der IlbenbFifich uns am licherften nur bann crfolgen, wemn

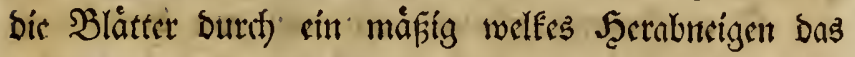

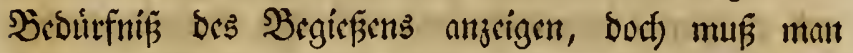

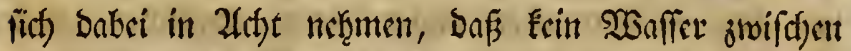

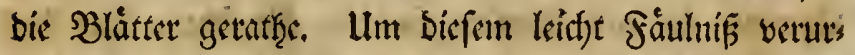
factanden Ulebel ju begegnen, find bie Zurifellt audf) nur äuferft felten, uno jwar an beffen in Den erften Mlorgenftunben mit ciner, jeboch foḩ frinen Epriş fante von bem auf ifituen befindlid)en Staube ju reis nigen, in fo fert bies feit geraumer Bcit Durd) Feinen - Tiegen gefdhehen máre; fis burch biefen erquicken ju

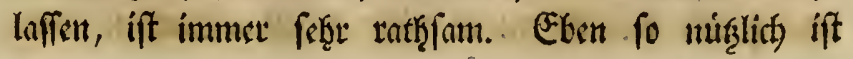




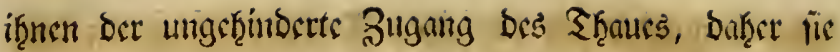
aufer Der florjeit ffets unberbud)t fteţen milfen, uns. aud) ju biefer Brit mur für ben fall cines ju Kefürf) tenoen Regens ju bebccken find.

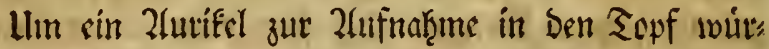
Dig ju finson, muf ber \$llühftenget beffellen ftrif auf:

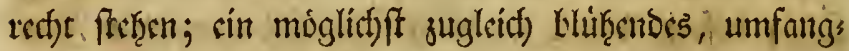
reid)es ßouruct trager; Die mit sinem uidft jut flei nen Zluge, aker mit befto grofierm Etem verfethenen

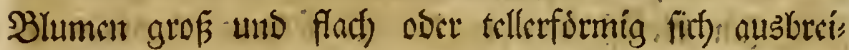

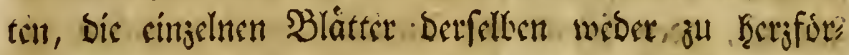
mig ausgefchnitten, noch weit weniger gejacft ober ju

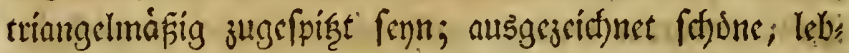

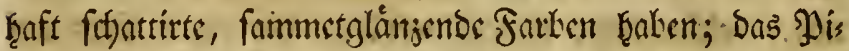
Itill tief im Sicld) Der Şlume bleiben, uno von ben Gtaukfáden ober Zntheren gánglief) bedecfet werben. Eine B̉lume mit cinem liber die Staubfáden herrbors ragenden Pliftill, ober mit cinem ju flénen Zlugs uno Gtern, wutroc bei aller fomftigen Ectornhcit und Ries

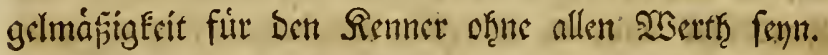

Den Gaamen nimmt man: mur yon ben beftent und edelfen fammetglángenden Eorten, beforibers abpe bou ben rackten ober ungepuderten engliffien, 2 uns

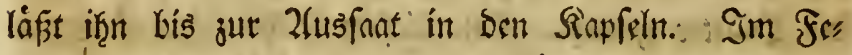

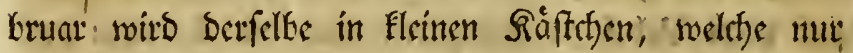
sinige Boll ticf sine jwar gute, Dod) múnder fráftige - Eroe, als bie fúr bie Zlurifelln im Topf Leftimmte, ḩa ben, blof oben aufgeffreut; man láfit fie Dann, an sus 11em vor ben Plorowinden geflifferten Drte Lefancien,

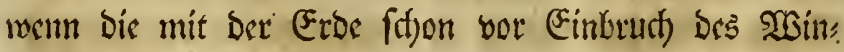

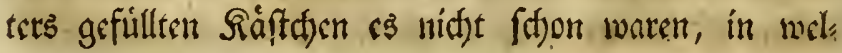


d)em Fall man Den Gaamen auf Den Gefnee frecuet. Begen bie Eperlinge ficfert, man fie butth uker cin

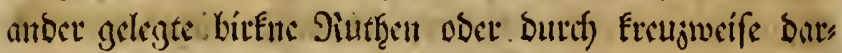

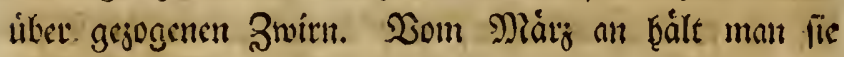
nur notḩburftíg feud)t, wo bann . Dic Pyflanjent im

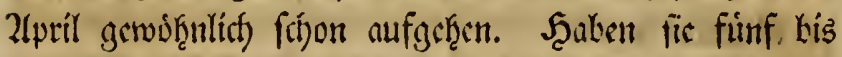
fect) B Blätter crlangt, fo merben fie jueci Boll weit aus cimanber in anore Sáftchen, bas folgende Sab̨r aber itts Bect verpflanjt, weldjes nicfte twur von Bcit

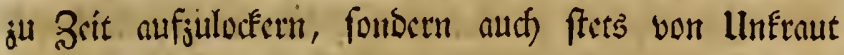
rein ju balten ift. Die Şlutręen gelangen erft im oritten, autf) moḩl im vierten Sahtr jut Dollemments freit, wo man bann bie fobonften fü ben Topf aus"

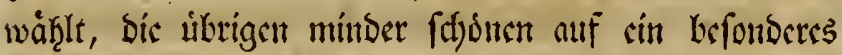
Bect verpfianjt, bie fojlecteten aber, ober ganj orbinats tan, nifft weiter im Soatten buldet, went es niffet bloz wáte, um Denfelten bunt ju sthalten.

Im Rande werben bie 2lurifieln von ben Gefjne" Fen, in ben Toppen abei von ben Şlattláufen oft

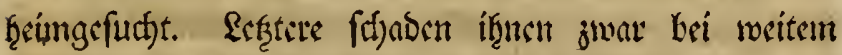
in bem Sirabe nicft, wie ben Siclen, faugen fie ater

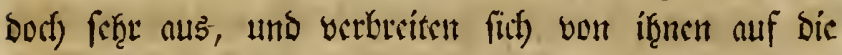

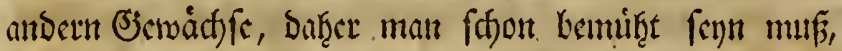
iie nicft auffommen ju laffen. Díc Sctunecten fängł Inan buect) dikerall fingelegte fofmale Brett" ober fats temptucke weg, alt beren untem Eciten fie firt) gegent Morgen lagen, und wirft fic fodann Den Enten vor.

Dir Durctuminterung ift Der ber Diclfen gleidl),

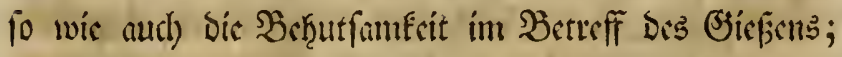
Der Sålte unterliegen fic aber meniger, als jenc, mut

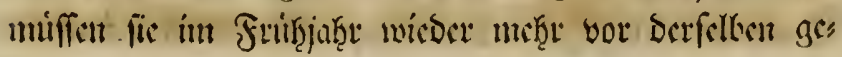


fiif)ert und entweber nid)t ju jeitig ins freie geftellt,

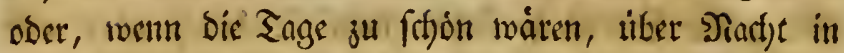
Eid)erticit gebradje werden, intoem lie nid)t allein zeis

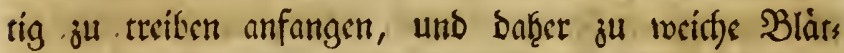
ter beaben, fondern ez würben auth bie B̉lutthenofpen ju Brunde geţer.

llm bic Spriemeln reff)t fofjon ju f̧aben, Keţans belt mant jee fowof̧l im Sefáf als im Lanoe mit ber námlidan Eorgfalt, wie bas Zfurifel.

Eo ratḩam es bei allen Pflangen ift, tie burch Uluterfernåpfe, wenigftens von Beit ju Seit, von un ten ther ju tráufen, fo mpfeb̨lensiverth ift bies befons bers bei ben Zurifeln.

\section{SEolds Docr Rolbenlace.}

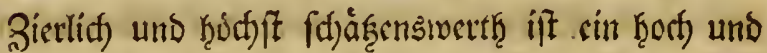
wokelgeroat)fener, groß̈Folbiger, feine Shlumen enge an (iid) Baltenoer, Dunfelbraun uno gelb fhattitter Bolds obcr Siolbenlack, und, jwar moniger folbenreich, aber

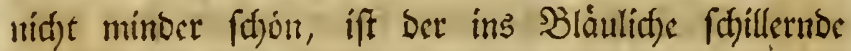
Dunfeltraungelb gefárbte Sacf; follen jebod) lecibe zur geţdrigen 2ollfommentreit gelangen, fo Eann bies nur Durd) cine juecfmáfige Sultur crticht werben. Diefe

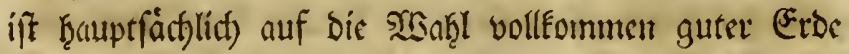
regrimbet, und biefe finter liff in ber vortgin angeges

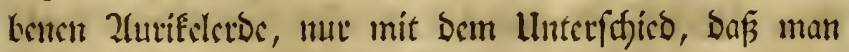

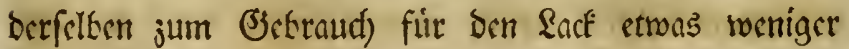

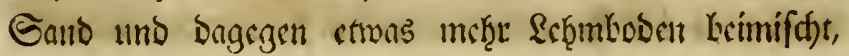


Dannit bie (Etde nidf)t ju leid)t inerbe. Der Sact will

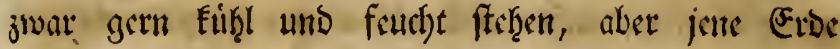

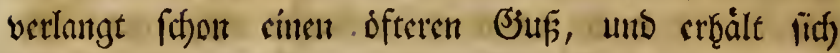

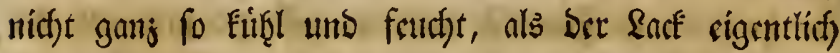
vertangt.

In cine foldhe Erbe fef̧t man bie zum Stopfer

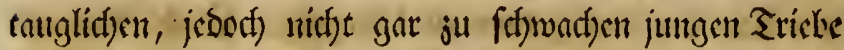

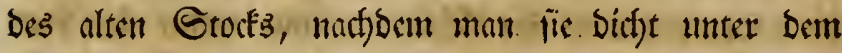

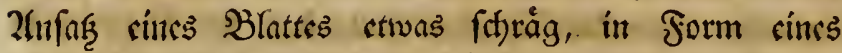

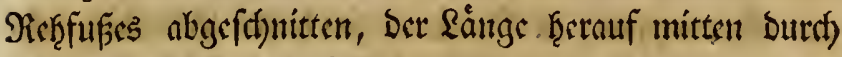
bas Mate bis jum nád)ften S̉lattanfaf̧e in jwoi glcíd)e

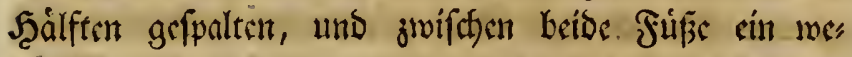

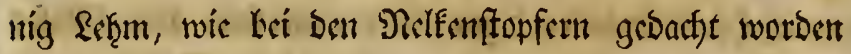

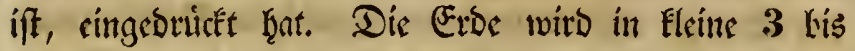
$3 \frac{1}{2}$ Boll im Duttumeffer fraltento und an 4 尺oll bुohec

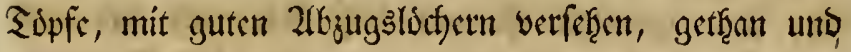
Det Eifynittling bis in. Die Jirgent, wo Das oritte Blatt geffantoen ḩat, fanft eingebrickt. Sift biefe in

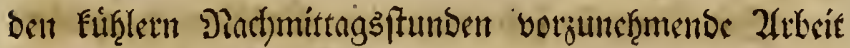
vollogen, fo kefperngt man ben Gtopfer mit simer

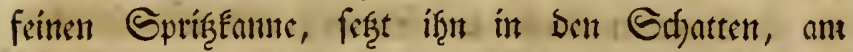
folgenton Mlorgen aker, bís roohin bas an ben Slàts

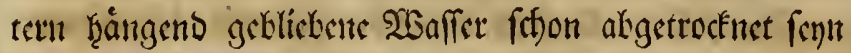

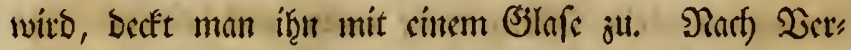
lauf von 6 bis 8 Sagen ftellt man bic Befáfac auf sime, uno naft abermaligen 8 Sagen ouf 2 Stumben

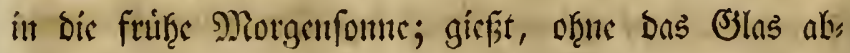
juthecten, fo of als bie Trockentirit ber zwiffthen berm Blafe und Dem Sinnde Des Sapfes befindlicten Eroc bie Nothrwendigfeit bayon andeutet; wito fie afer ant)

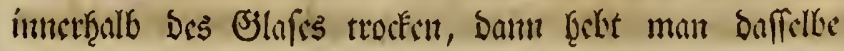


ab, und giente, in to fern nidst sin Regen fällt, Dns ganje (jefáf, weld)es erft wicber am folgenton Nlors

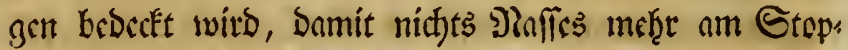

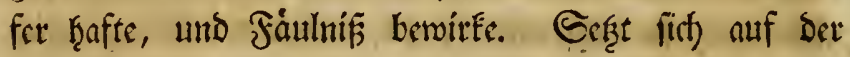
Dberfád)e Der Erbe cin griner Uleberjug an, fo wirb berfclbe beţutfaim abgefrnfet, um fsine. Stockungen in Der Zusbuinftung berbor ju bringen. Eirḩt man an bem Emporftreben Der Blåtter, uno wem biefelben anfangen, fich Dutét ju fátben, bapis Der Etopfer in

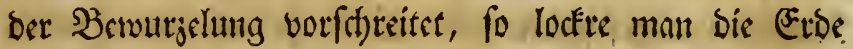
etwas nuf, befprenge lie alsbann, uno becfe ben fols

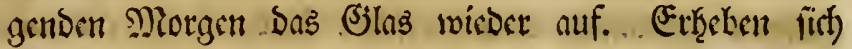

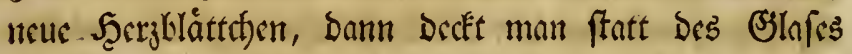
ben Gtopfer mit cinem lecren Lobenlofen Brfápe, nod)

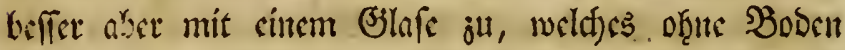

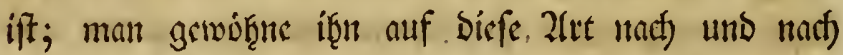

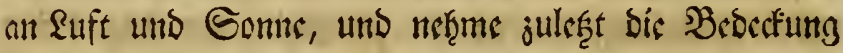
gånjlicf) meg.

Im Iuguft fef̧t man bie Gtopfer in gróscte Beffáfie, giebt if̧nen cine, yom Eeptember an aber 2 bis 3 Gtunton långer dic Gonne, und hált fir ftets nur máfig feudte. Die becrborkeimenoen jungen Trieke intilfen fofort algeftreift merben, Damit ber Scaupts ftamm of̧ne alle Nebenjweige bleífe und sine Eráfrige Solbe anfę̧e. Şat er im folgenden Jaḩr verblihht, fo fonneibet man ben Erengel ah, berte ben Etocf

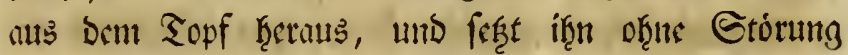
Der Tourjelli in cin Gattentect, wo er bis 9 Dorr

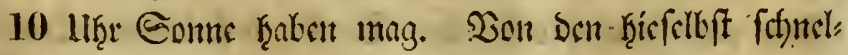

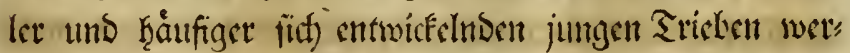

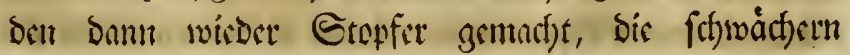
aler 
aber bis nufs Fommentos Safgr an Stocke gelaffen, zи weldyem B̉cḩuf man im Rnufe Des. Geptembers ben, felben mit Dem vollen. Eroballen aushecbt, und swieder

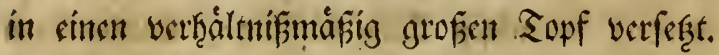

Bur Durdfwinterung geffett man bie Rackftocfe ju

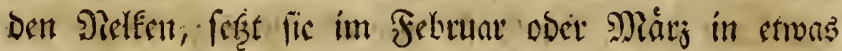
grópere Sopfe, mit guter Elbe, , ftefft fofort bie no, thigen Stake bei, unt bringt fie glcichscitig mit ben Zurifecln, unb untei berfelben Sorficht, ins Freie, in fo fern mat berst nicht sinige ins Deppelfenfter zum

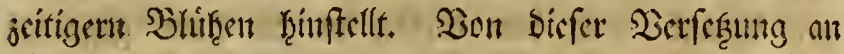

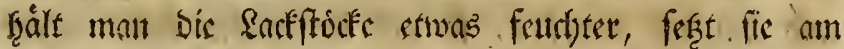

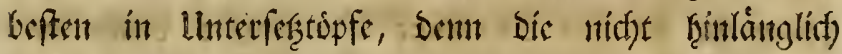

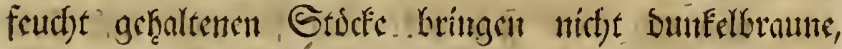
fonbern gelbe ઝ̉lumen, bic wentiger belicbt find. Stellt

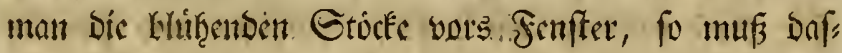

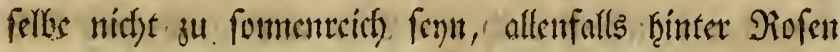

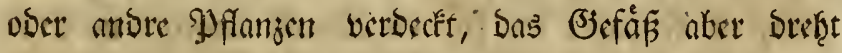
man tóglich, - Damit ber Gtock, ber feine Dictutung ftets nad) bet. Ricteffeite nimmt, sinen ganj geraben พิ)

\section{I d $f$ e $n$.}

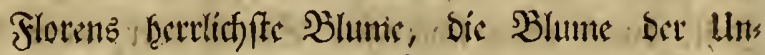
fould unt ber Freube, bic Siofe, beren Reld) Die fus

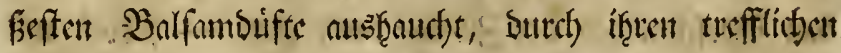

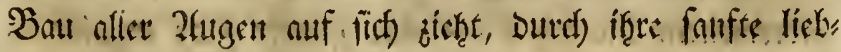

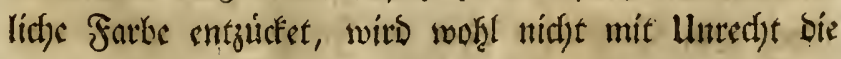
Róniginn Des B̉lumenteid jo genant; unt verbient unm 


\section{8}

fo mehre geftháf̨t ju werben, als fie füt), bei ciner

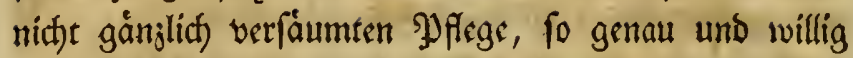
erjistzen láft.; Um fie yor bem femfter blúţend zu haben, werben biejenigen Zusfchoflinge, weld)e man von ben im Sanbe befindlicten Steckent abgelóft und verpflanjt fatte, fobals fie inur cine májige Rrone for

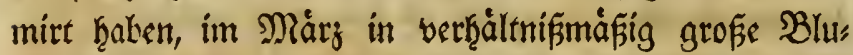

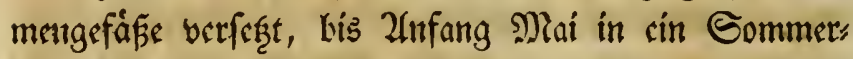
haus bid)t ans fenftex jum 2(nnourjeln geftellt, bann aker im Starten auf sinen mef̧r fofattigen als fonmis gen Stand, mit bem Siefáa in bie Eroe gegraben und Dafelbft kegoffen, fo oft fie trodfen find. Seier berourgeln fie fid his Ende Eeptembers yollfommen gut, und um bicke Zcit ḩebt man lie auझ, und ftellt fie auf einen blof ber Mittagşonne zugánigigen Plof̧. Dic Rofe verlangt eint locfres, fandiges und jiemliat,

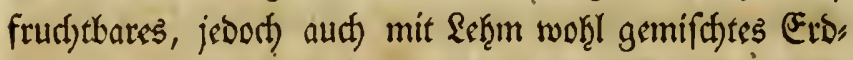
reíf), es ift baf̨er bie fü bie Zlutifel angegebene Erobe gans paffent fur fie, wenn man berfellen nur nod etwas meniger verweften Ruţbunger keimifht. Den Wointer úber loringt man fie in bas Befráltníp Der Nelfen, nachodem fis erft eirige leichte frofte nusges

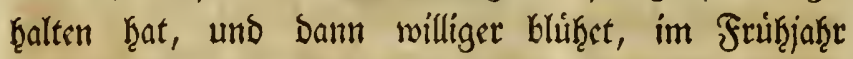
aber, wenn feite Nacfffrófte mef̧r ju leforgen find,

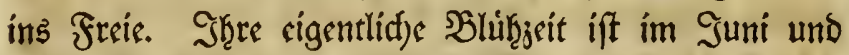
Juli, ouret) einen fanttigen Gtand aber, ober Durch

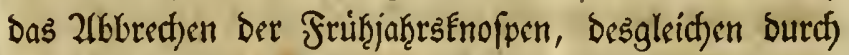
das Serfdumiden ber Zweige fann man - jedod) mit anderweitem Nachtheil - eine fpàtere f̧lor erzningen. Nach) Dem Serblüfen oder im Fruif̨herbfite lichtet man ben Btock etwos burd) 2lusfd)nerben ber trockinen, obet 
ju alten Zwesige, Danir ar neue Edjoffe treitbt, als

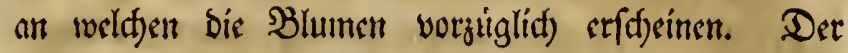

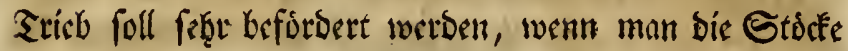

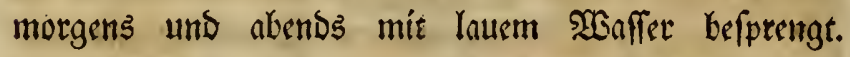

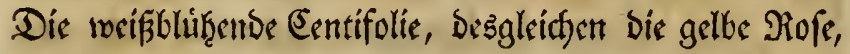
verbienen nidft minder in Tispfen gezogen ju werben;

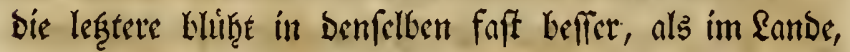
wo fid), befonders bri anthaltendem Regen, feţre leidat Maben einfinben, weldife bie Rinofpen nod) yor bem

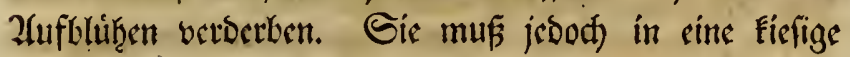
unt minder gute, ja faft magere Erbe verféft werden.

Sorżuglidjer zur Etubenflor eignet fidf) Die aus Ek̨ína uns Sapan ju uns getommene immerblúf̧ende Rofe, Rosa semper florens, ínbem fie autf Des WWinters, bidft ans Jenfter geffellt, bei 8 bis 12 Jarad

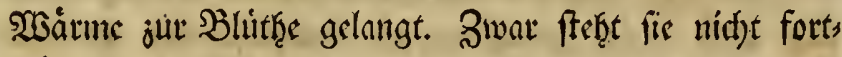

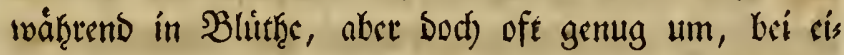
ner 2lnzaķl yon 5 bís 6 Gefáäen und cinem fonnens

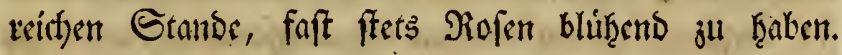
In gelinsen 20 intern, uns mit Baumlaub bedecft,

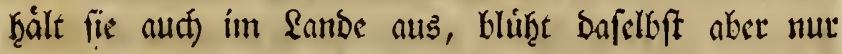

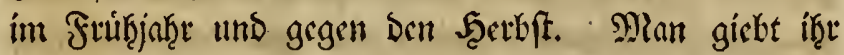
cine etwas fráftigere und leíd)tere Erode, als ber Eens

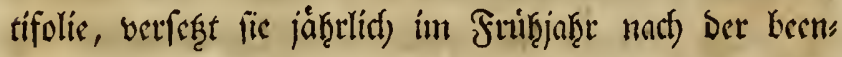

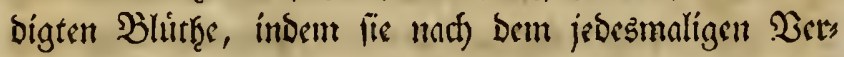

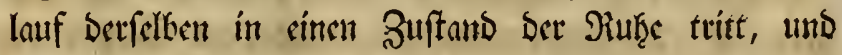
Daheret î̌r

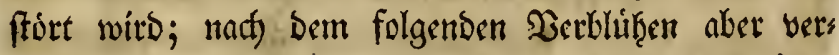

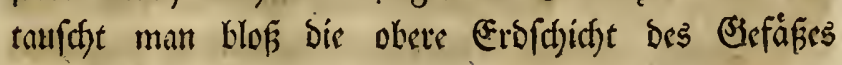
mit since friffent Erbse.

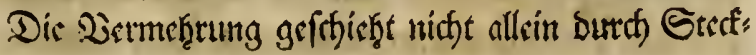


linge, fonbern -aud) Durd) Nebenfofoslinge, finown man

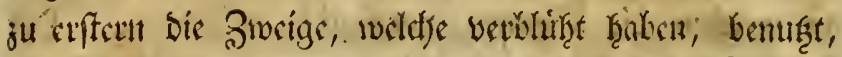

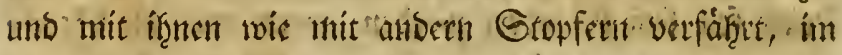

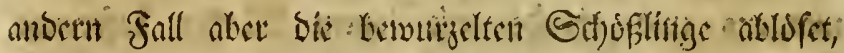

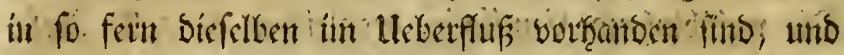

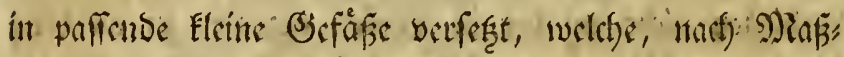

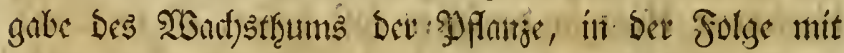
groferent vertaufcht wetberit. Die alter Etwefe werben

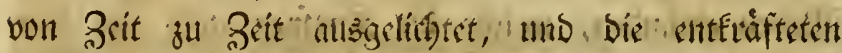
3rociage bis auf brit Zligen abgefduitten," wofern ber

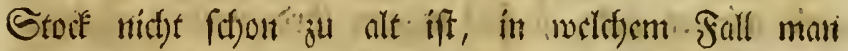

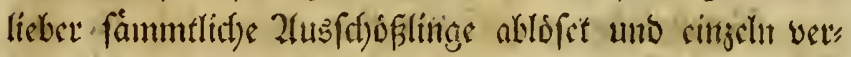

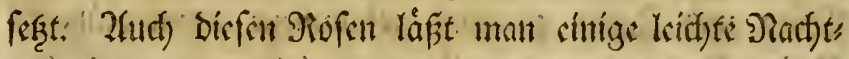
fisfte ju, bringt fie alsbann ins gemeinfane simter,

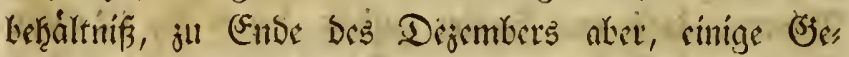

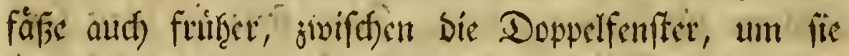
jumi Treiben ju nothigen, weshtalb Des शaat)ts Die in: nerii Fenfter za iffireit finto. "So wie alle in luftlos

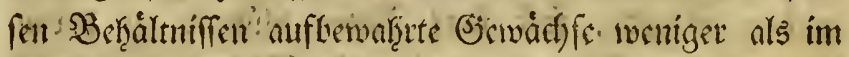

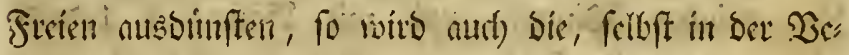

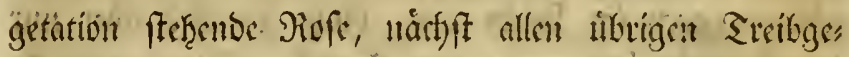

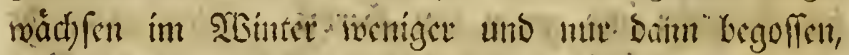
weint bie Erbe trocken ift.

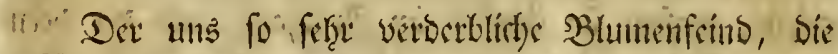

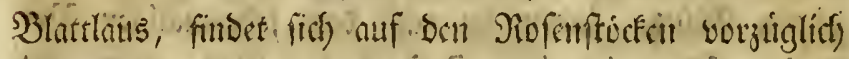

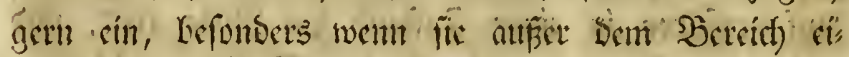

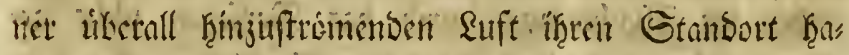

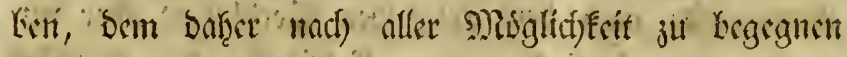
if. Einige stopfen Suecfillber in ein in Den Pios

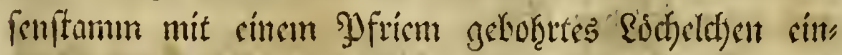

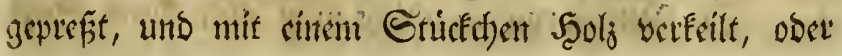




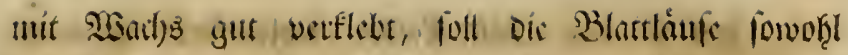
tobtat, als anth) abfratten.

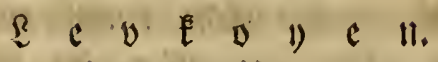

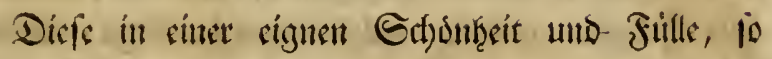
wic in Mamnigfaltigerit Der Farben prangende unto

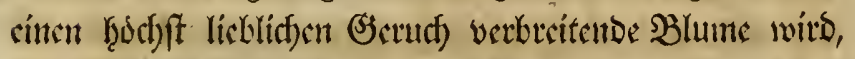

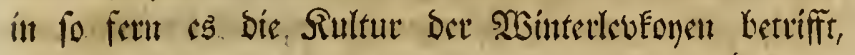

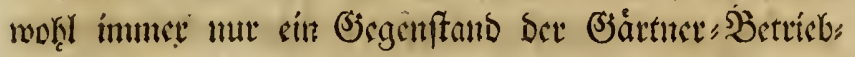

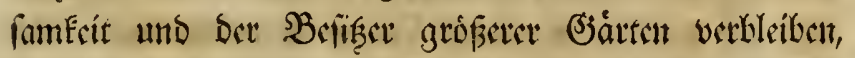

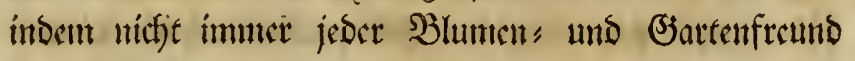
nact) B̉clieken tiber Raum uns Zait verfigen Eant. Die Esidftigferit kingegen, mit weld)er bie Gommes" levfonen ficf) anthauen lafien, mad)t fie Dem blopen

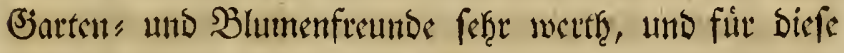

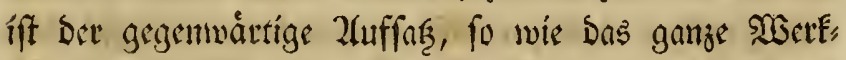
d)en, inu beftimmet.

Da biefe Blume alljährtig aus bem Eammen ges

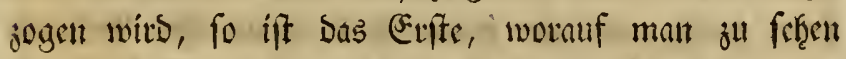

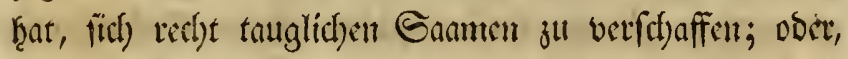

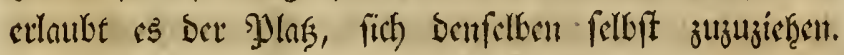

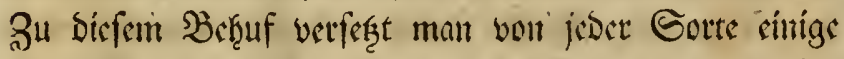
J)fanjen in Eleine, mit ciner guten aber ja wicflet fets

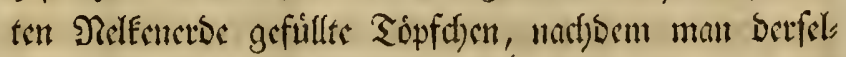

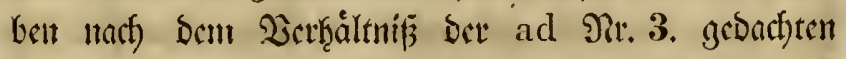

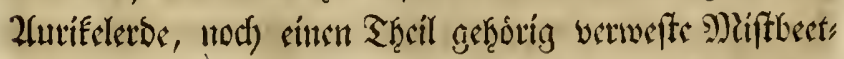
croe unt $\frac{1}{2}$ Thtril Gand krigemijetyt ḩat. Die Gaa menergieţung geh̨t wegen Dev metheren -2fufmettfam Ecit, bic man nuf fie vermentoen Eamm, in Den Jiefáfien 


\section{2}

beffer von ftutter, als im Eande, wofelbit Der Gaame yor Dem Wónter nifft jur Reife gelangt, obgleich) Der

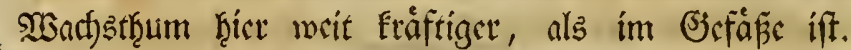

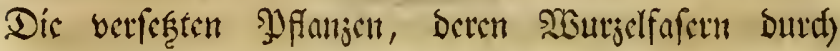
nactjuffouttende treckine Erbe liberall gut cinjuthullent find, werben máfig angegoflen, ins Shithle uns in ben Ecf)atten geftellt, fedfs. bis adf) Tage mit leeren Sopfen jugcoceft getralten, Dann aber in bic Frufterfomte

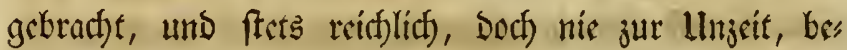
goffen. So wie bie Pffanjen hecrangerwady fen lind, uns allmálig fur ben crften Topf ju flein werben, verfeget mant fie mit if̧rem gantzen Ballen in geràunigere Şe

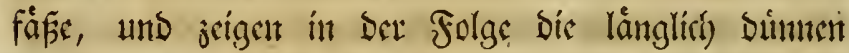

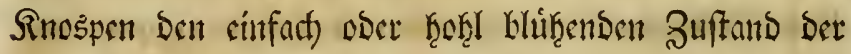

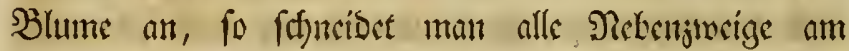

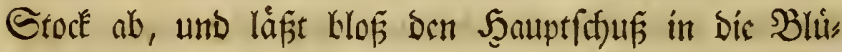
the gethen. 2(us Dem 3ufammenftellen fold)er Gtodfe mit gefullten Revfonent láft fict) ber von cinigen Shlus menfreunden geglaubte Bweck: cinten Eanmen ju ge" winnen, aus welfyem gefullte Şlumen ju erworten

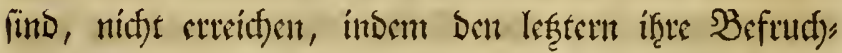

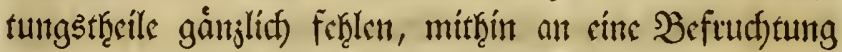
Durth Den gar nidft vorthantonen Eaamenftaub nidjt ju benfen ift. Diefer Bweck wirts ef̧er etreidte, wenn

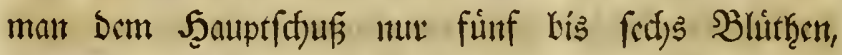

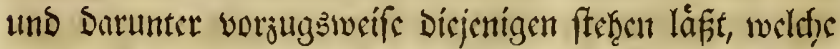

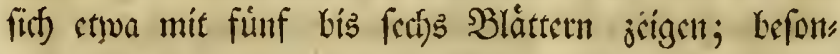
bers aker if sin guter Gaame von ben jwets uns

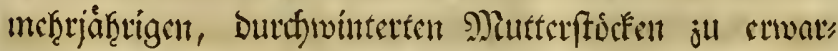

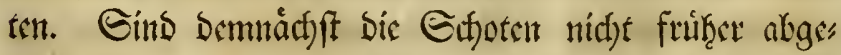
nounmen, als bis bir Eanume feine villige Bisife tzat, fo 
láp̈t man benfelben in ben Sdjoten an einem luftigen Doct) froftfrcien Sote bís jut Eant ḩängen, uno fáct

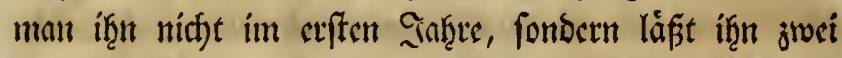
bis brei Jaķe liegen, fo wirb $\mathfrak{s}$, bei einer úbrigens guten Pflege bes Mutterjtodfs, an gefüllt blühenoen Sámlingen níf)t feţletr.

Dic 2lusfant beginnt im Februar uns Mairs

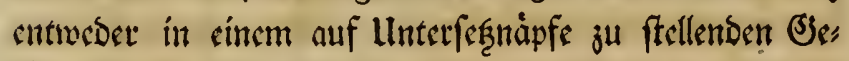
fáf, obcr in flcinen Ráftcten, weldte in einem Sabis

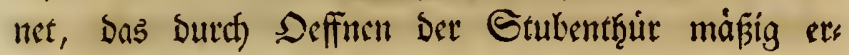
warmt werben Eann, ans founige Fenfter aufjuftellen fino; ober entlict) in cincm Fruif̧beet, welctes jur 2 (bs

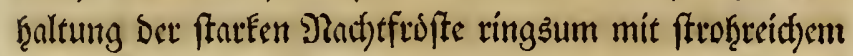
Mifit ju belegen, bes Эanthts aber oben mit Strohs

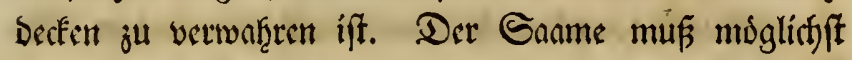
buin in bie Eros geveract)t, uno mur unter einem mäs figen (Sulfe gethalten werben; aut) Durfen bie PJfángs

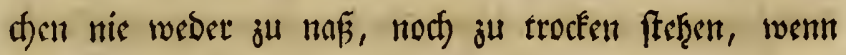
fie tícf)t faulen und umfallen follen; mant tḩut woḩl,

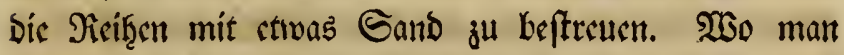

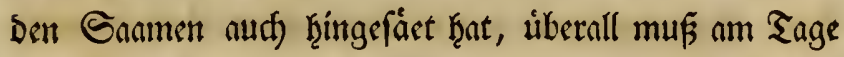

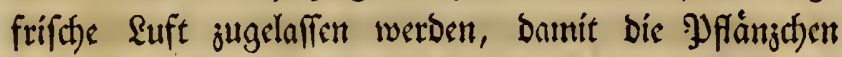
weber treiben, nod) ju weirf) uns järtlid werben, an Ealten Tagen aber uno uiber Nadte bleiben bie Fens ftet gefalolofen. Şaben bie Yyffanjen 4 bís 6 Blàats

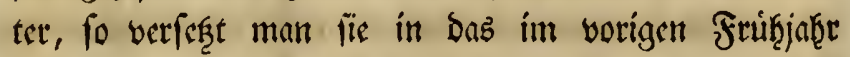
mit Surf̨mift gebuingte Siartenbect, cinen Eleinen frals ben Fuf aus eintander, um Feine ju gropen Lucfen ju mad)en, wenn man in ber Folge bíe cinfach) blüf̧enten

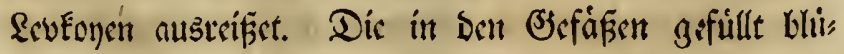

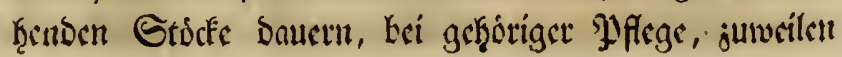




\section{4}

úber Şinter aus, wo man fie ilt cinem froftreien Beháltniffe, bei ju frartem Stopite aber in sinem $\Re_{a}$ binet auffecllt,... mo Duret) Daš Seffnen ber Gtuben:

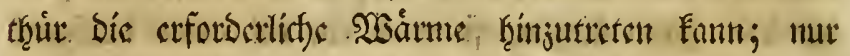
múfien lie im 20 inter . weníge, in Gommet Dngegen.

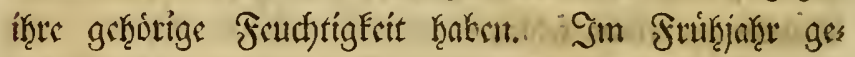
wodhnt man fie mur riach) uns nad) an frcic luft uno Sounte.

$$
\text { So d t }
$$

Diefes fofone aus. Sapait uns jugctommence, uns fidon feit methreten Santerent jut Slobeblume gewor"

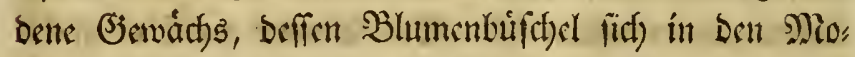

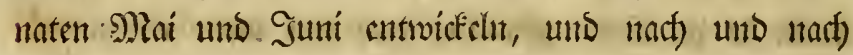

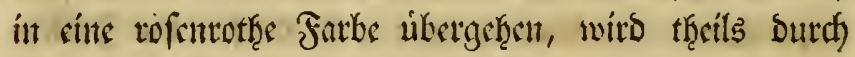

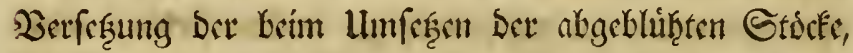

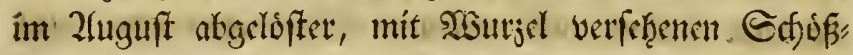

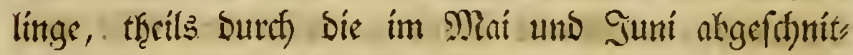
temen Stopfer, yon benen 2 bis 3 Grlente ill Dis Erbe Fommen, vermeţrt. Diefe werden in bie meţe

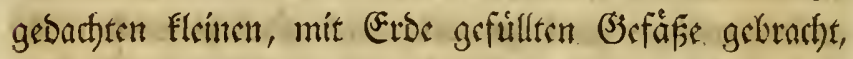
nach irfolgtem Socgiefen in Den Schatten geftellt, unt

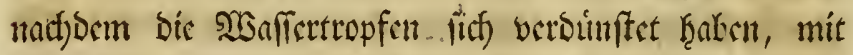

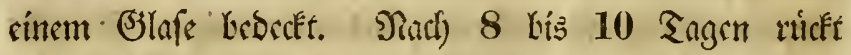

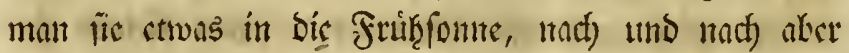
etwas weiter in bicfilbe, jebody fo vor, bafis fie nicht

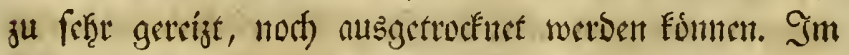

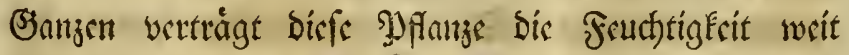
meţr, als jeose ondere SBlumemforte, ittoem fie in ins 


\section{6}

Denfelben aus Dem నjorratţรmagajine bei, Denn jie liebt benflben ganj vorzügling.

Damit bie feortenfien in einer blauen Farbe blits ben, foll man bie auf fumpfigen fauern SWiefen und in Den bortigen Bráken oft lifh vorfindende Eifenod)ers erbe nef̧men. Das Dafenn berfelben erfennt man an Den Dunkelgelblichen und eifenroftigen Etreifen auf Der

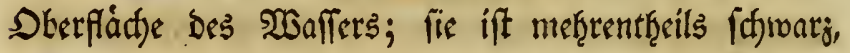
mitunter: aud) leḩmig, locker, mit Gand vetmifd)t uns

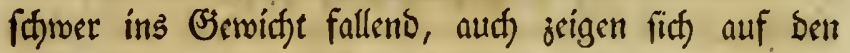
trocken gemorbenen Slumpen DunÉltoftartige 2Inflige. 3u jwei bis brei Theilen biefer Erbe wirb ein Theil

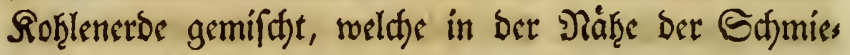
ben einige Boll tief gefunden wirb, Desgleid)en ein Tḩeil Seţm, wenn berfelbe in Der aufgefundenen Erobe nicft fdjon ober bod) nicht reidflid) gemug entrialten

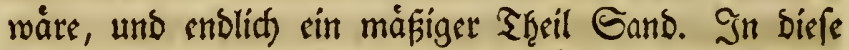
woţl unter cinander ju mifchende, bon if̧rem etwanis gen Ulntath gut ju teinigende Eroe wirb bie, sinen

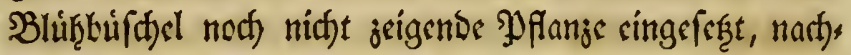
bem Derfelben bie alte Erbe mit sinem recht f(t)arfen Bartenmeffer, in Der Entfernung von $1 \frac{1}{2}$ bis 2 Soll, bom Etamme an abgefanteten worben ift, und fo

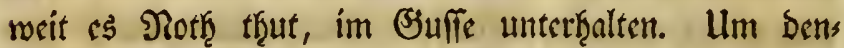
felben zu berciten, mirb cime Suantitàt ju Staub ges

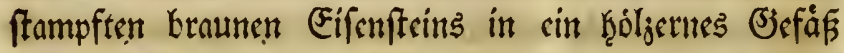
getf̧an, Desgleichen meḩrete Stúcfe alten vertofteten Eifens bazu, geworfen, Forfendes flufwaffer bar.uf gegoffen und bie Maffe moḩl umgeruihzrt.

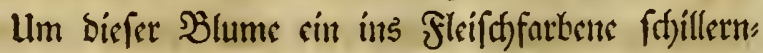
des 2lnfetren jul geben; foll man ber Erbe, auf jebes 


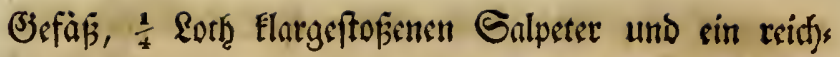

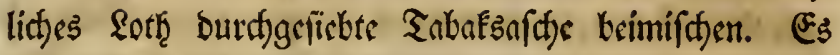
fragt firf, ob es nidft beffer getţan fenn follte, beibes

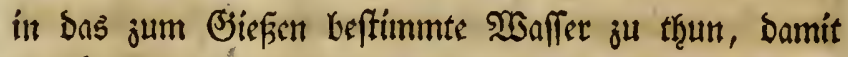

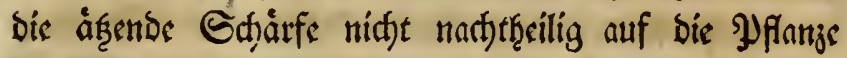
cinmintes.

\section{(5)}

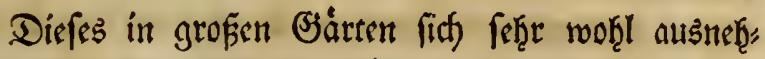

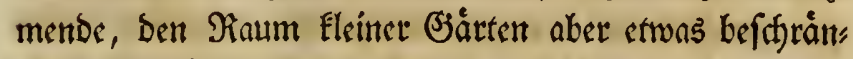

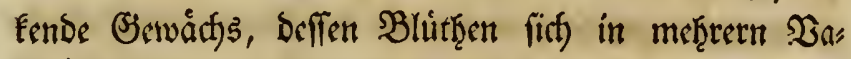
rietáten jeigen, und gefúllt befortbers geffadąt werben,

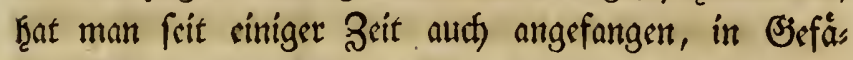
Een ju jirkţen, und bieffalls folgente Besţandlung smpfofglent.

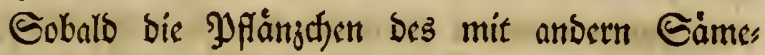

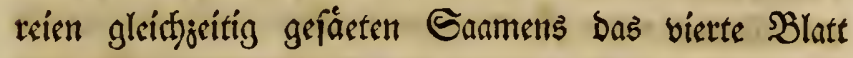
sercidfen, werben lie in Eleine, mit alter, gut verrots teter Mififbeterbe gefuiltte Tơpfden berfestet, angegof fen und fodann unters Miff feectfonfter geftellt, too fie,

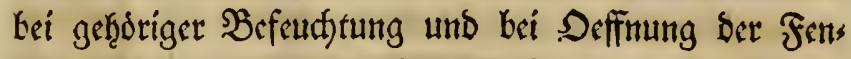
fter, fafmell wadfen; Niadfts jebodi merden bie fenffer twicber hereunter gellafen. Goball bie Yyfanjen anfangen,

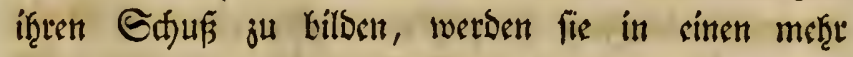

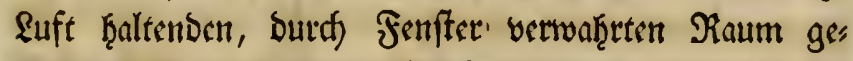

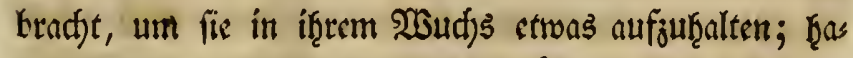
ben fie fint) bier aber etwas abgethärtet, fo verfestet man

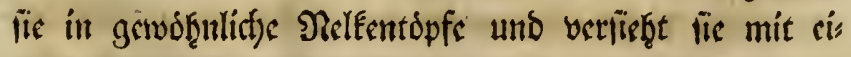

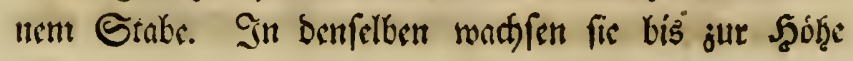


von Drei, vier Fuf, Doch muiffen Die Debenjmeige, fo wie fie entftetsen; abgenommen meroen, Damit alle Sitaft in Den. Şauptiftengel treibe. Die fidjonften beţålt man jur Durchivinterung, um fie fommendes Jahre ins ङjar;

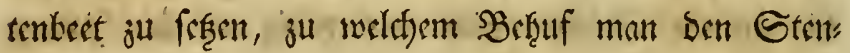
gel nach becubeter flor abfchncidet, unto bic. Tsurjarl

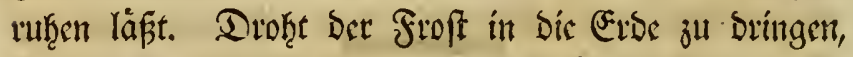

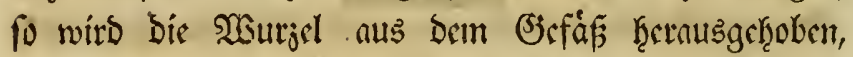
von aller Eros gefaubert, und an cinem froftfreien, trockiten Stte im Gande aufbemathet; is trockner, je

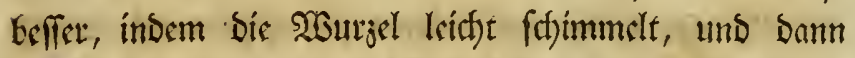
balb in Fáulnif libergeţt; fie merben Daţer nad) ab" gefornittenem Stengel aud) nute nod) nothblirftig feutfot gehalten.

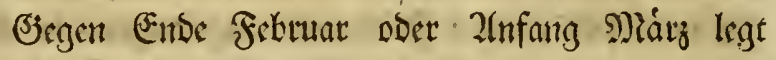
man Die im Raufe Deș TSinters jufammengetrock neten พSurzeln, etwa 12 bis 18 Etunden lang, ins Taf fer, ḩängt fic jum 2lftrocfincm auf, vertheilt fobann

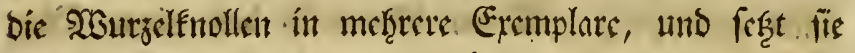

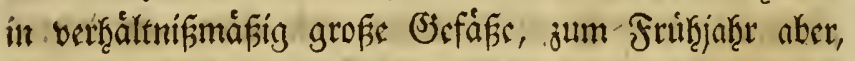

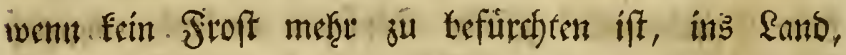

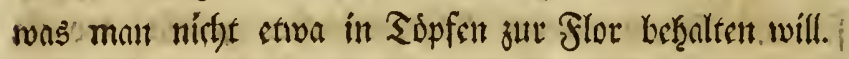

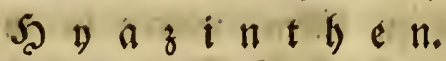

Um Die Scyajintḩen im. Sanuar und Fobruar bli: hend gu baben, fins sie Bwtekeln fityon im 2luguft ober bod) Infang Geptembers in befonbers baju ge fertigte Gefáfe ju legen; unb jwar miffen biefe oben 
Der Topfe, nact) 8 Sagen ben jreiten und fo fernet

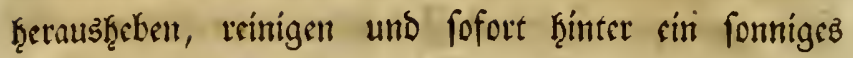
Doppelfonter jum Steiben ftellen Fann. Gollte Der Wointer jeitig cintreten, fo fef̧t man bie aus Dem fanbe

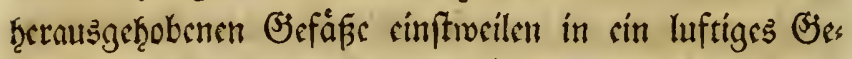
wojlbe, bís mait es fư gut haált, fie in bie Woárme ju bringen, welthe ftits cinc Scof̧e von 8 bis 12

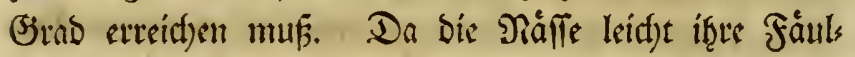

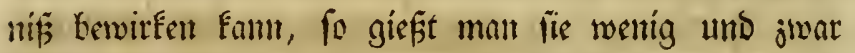
:muner แur am Ranoc, um bic Feuct)tigfecit notḩdurfs rig ju unterb̧alten, fängt aber Der Bluhfeftengel an zu reciben, fo lájt man fie bie feututigkeit von unten ber cinfaugen, uns ftellt fie zu bicfem Bef̧uf in lun terfaģnápfe, weltife gegent ben brittent ober vierten Sag mit frifthm, jrbod) úberftandenem Tืaffer gefiult wetbert.

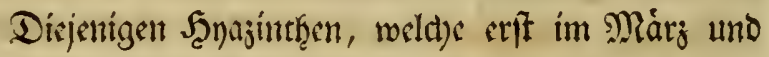

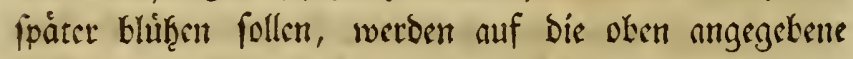

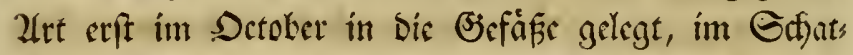
ten gethalten, und mit Fintritt Des Sroptes in ein teels les unb gegen brufelben gefithiftes Semólbe geftellt, bís man fie im Decemker ober Jamuar jum Treiben in Die Etube bringt.

3wiebeln fowoḩl als Sinollengewåd) fe vettugen nach Eensiger flor bie গạfle nid)t 'gut, befommen

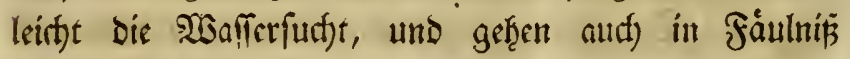

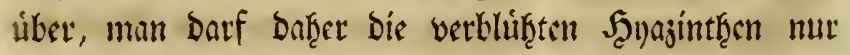
náf̧ig giefsen, Damit lie nad) uns nad) in bie Ruḩe

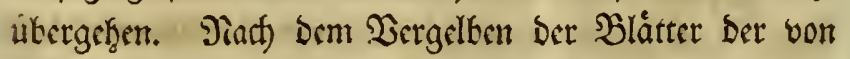
Beit ju Zeit immer wicber feutjet gefbaltenen Bwiebeln werben biefalten, fie migen in Lande ober in ben bies 


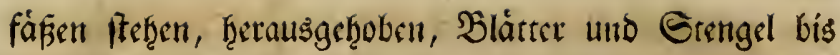
auf jwei Zoll abgefdunitten, im Gdjatten getrod'́net, in Sctober aber in bas mit Mififteeterbe und Sanb woḩl jugetid)tete Bartenbert ungefáh̨i fünf Boll tief gelegt, intom eine im Sopf getriebene Bwiebel im jueiten Jaţe nux nod) im Sande cine leiblid) SBluthe ţervorjubringen vermag, uno fưrs (jefáp fid) nid)t

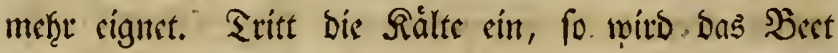
mit Şaumlaub, bei b̧arten Wintem aber ttod) jubei bis brei Boll tiod) mit Sierberloţe bedeckt; befonderts

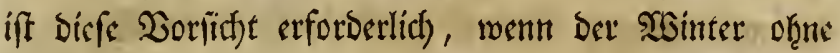

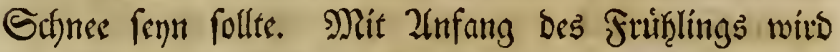

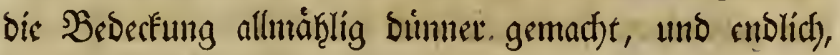

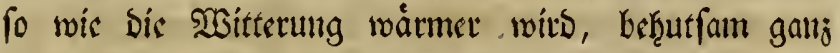
weggetåumt uns bas ßెeet eirt weníg aufgelockert. Ulm (iif) Der flor länger ju stfreuen, ift cs rathfam, ben

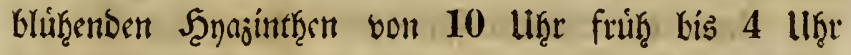
nadymittugs Sdyatten ju geben.

Die junge SBut nadjubietcen, if etwas lantg: wierig, imbef fann man fie in nidft ju fornige beets,

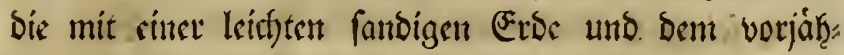

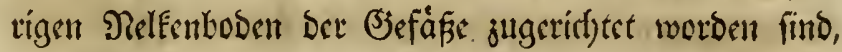

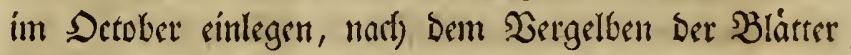

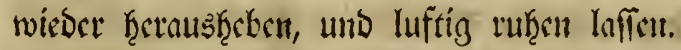

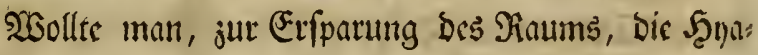
jinthen in eigens boju fot)on gefertigten Sláfern im Waffer treiben, fo muf baffelbe flüs, oder Scidjwaf: fer, uns vor Dem Zlufgiefien úberfturoen fenn. In das

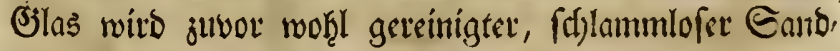
etra sines Solles hod), geffjuttet, bas alte Waffer am

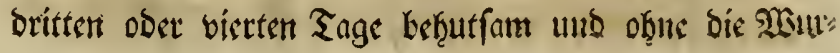


joth laus if̧rer $\mathfrak{E}$ ge ju bringen, abgegoffen, uno mit fuifthem, jebuch verfdllagenem 20 affer erfeft. Eind bie 3miebelt fur bent oberti Raum bes Ğlafes ju fleit, fo wirs bis Deffinung Suth wohl getrinigtes und ausges

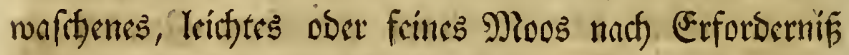
verengt.

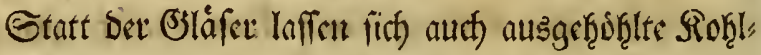
ruten, ober, not) angenthemet íns 2(uge fallent, rothe Ritben gebrauden, weld)e, an Sd)nuren ober famale Bánber befeftigt, an Fenfter immertialb ber Stube auf"

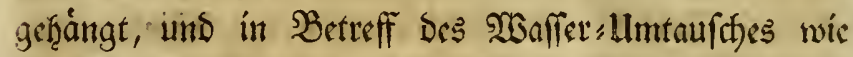

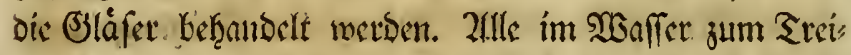
ben gebract)ten Blwicheln find jebod) fur jeden fernern (Sicbrauch) verloren, wenigitens wit's nur áuß̈erft felten

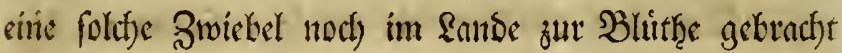
rertoen Eóntuen.

Unter Der bimmen Brwicbelbefletbung ţat fich) ju weilen fínon Gáiummel, ja mitunter auch fáulnís un

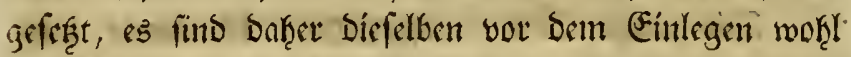

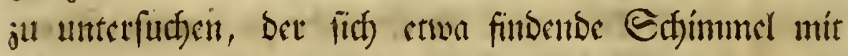
cinem feinen Such) bef̧utfam uns unter Wermeibung als Ier Reibungen abjumifd)en, bie angefaulten Theile aber

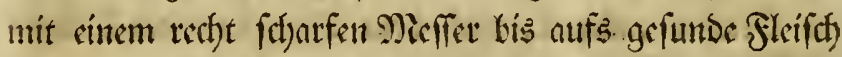

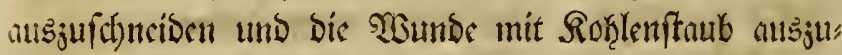
fiullen. Derglcidyen Bwiebcln rignen fitf nidt) fiur bon Sopf, fonoen fürs Lants, und finto aud) befonders mit Eans gut cinjuhtullen, werben aber felten cine fetoun

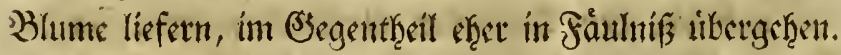

Bedruct bei Cart Triedrid) Amelang. 
Fim $\mathfrak{B}$ crlage ber Buchbandlung yon (5. F. It melang

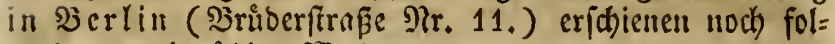

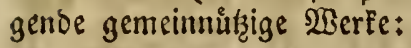

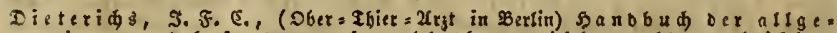
meinen uno befondern, fowobl tbeoretifien alo praftifden Urjencimittellebrefü 3 bierärte uno fanomirtbe. Doer: all=

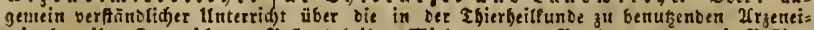
nittel, ibre fienneiden, Befianotbeile, W3irfungen und Beteitungsart; usit Beftius

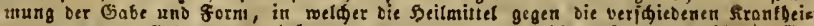
ren anjutwenten fins. gr. 8. gelleft.

ithit. 10 fgr. 08. 1 thit. 8 gङ̈r.

- - Ratedismu\& ber Pferbez

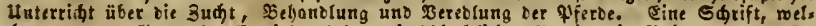

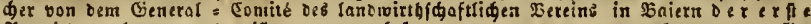
$\mathfrak{P}_{\mathrm{rei}}$ b fuerfannt morden ift. gr. 8. gebeftet.

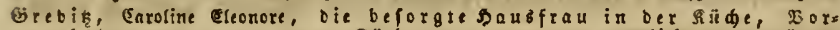

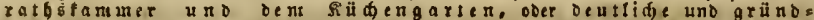

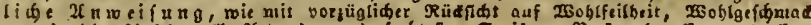

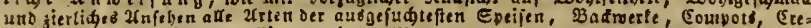
nes, Belees, Gefrornes, Cingemadtes, Narmelaben, Eaffe, mormer unt falter Bes tränfe uno giqueurs oud obne Borfenntnifie juberciten und anjuridgten fino, uno wis

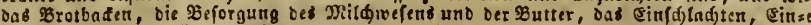
pöfeln, Räudern aller Fleifdorten, nebterer Gefitigel uno Fifde, bie 3ubereitung aller

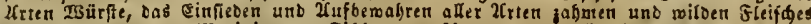

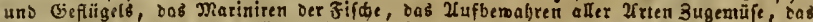

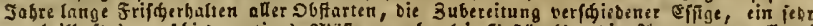
vortheibaftes berfbiedenartiges Jiäfen mebrerlet befiigers, die Jumendung afletle

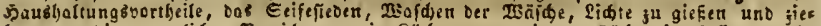

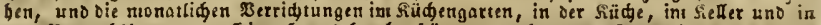
Der Borratblammex. Ein. Sand

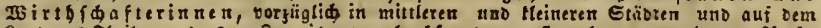
fande. 2 sheile, oro. 8. Jweite berbefferte n, fart oermebrte $\mathcal{U}$ uf = la ge. उufammen 75 Bogen.

He $r m b s t a ̈ d t$, Sig. Fr., (Königl. Preufs. Geheimer Rath und Ritter etc.). E] emente der theoretischen und praktischen Chemie; für Militair-Personen. Besonders für Ingenieur- und Artillerie-Officiere. Zum Gebrauche bet Varlesungen und zur Selbstbelehrung. 3 Theile. gr. 8vo. Mit 2 Kupfern in Quer-Tolio.

6 thIr. 10 sgr, od. 6 thIr. 8 gGr.

- - Bes chreibung and physikalisch-chemisclie $\mathrm{Z}$ erglieder ung der neu entdeckten Schwefel-, Ei en - u. muriatischen bitteralza uellen bei $D$ a b bera $n$ und am $H$ eiligend a m m im Grofsherzogthume MecklenburgSchwerin. Mlit einem Titelkupfer. gr. 8va. geheftet. 1 thlr.

- - B ull e $t$ in des Neuesten u. Wissenswürdigsten aus d. Naturwissenschaf, sa wie den Künsten, Manufacturen, technischen Gewerben, d. Landwirthschaft, u. d. bürgerlichen Haushaltung; für gebildete Lcser undLeserinneu aus allen Ständen. 15 Bände. gr. 8. Engl. Druckpap., mit $40 \mathrm{Kupf}$. und vielen Halzschnitten. 1809-13. à 2. 2/3 thir. complet

40 thir.

(Der Verleger hat sich entsclilossen, so weit der kleine Vourath reicht, dieses Werk um die $\mathrm{Hälfte}$ des bislıerigen Preises ader zu 20 thlr, baar abzulassen.)

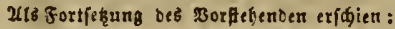

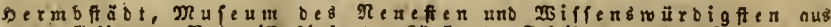
cem Bebiete Der Naturniffenfdojt, oer fitinfe, ber Fobrifen, ber Manufolturen, Der

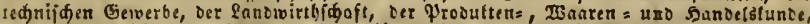

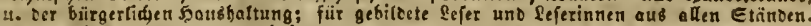

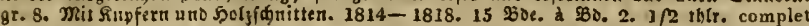

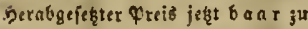

$37.1 / 2$ thit.

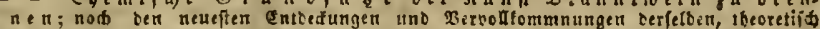

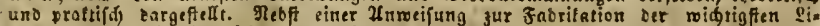
queute. $3 \mathrm{mei}$. El ite. 3 weite ourdaus berbefferte and bers

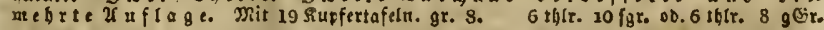

- - Ebentifde (j) runofäze oer Runf, Bier ju branen, noer

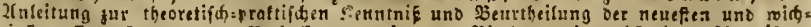

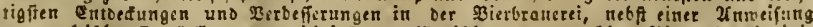

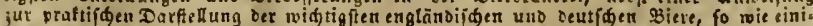
ger ganj neuen 2 rten oerfelten. Drit te neu bearbeitete u. bexmebrte $\mathcal{U} u$ is iage. 3 mei zbeile. Mit 3 illuntinten uno 3 fdrardensupfettas pelt in Elure Folio. Complet 


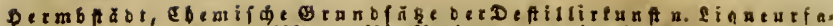

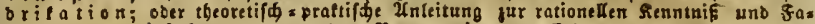
brifation eer einfad)en und boppelten Sranntweine, ber Ereme'z, Der Dele, ber É(ia rire, ser Ratafia's und Der übrigen feinen \&iqueure. gr. 8. TRit 4 Supfertafeln. 2 thtr.

20 igr. 00.2 thlt. $16 \mathrm{ger}$.

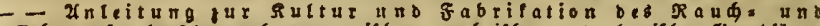

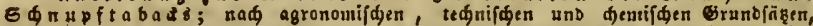
2c. 1c. gr. 8 .

2 thlt. 15 fgr. 0D. 2 thlt. 12 gisi.

- - Gemeinnithiges 5 a no bu

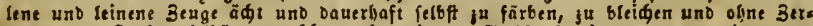
förung ber Farben felbft zu nafden: fo wie jur Eeloftubereitung ber gemeinen unb ber feinen Eeifexarten, ber Effige, Noutarben, fïnflidgen Weine, weins und bierartigen

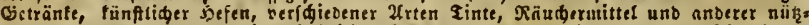

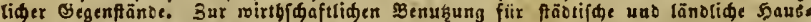
baitungen. 8. Sebeftet

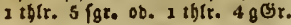

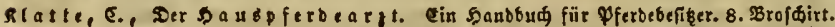
20 fgr. 0b. $16 \mathrm{gBr}$.

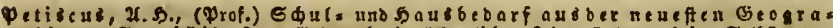
Dbic u. 'Etalifit. Sum Eebraudge in offentidgen qebranftalten, beint Selbfunter: ridte uab für Settungblefer bearbeitet. ar. 8 .

2 stgtr.

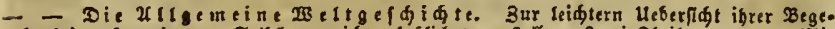

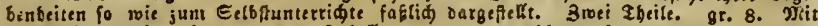
18 Supfern, 2 Sand darten und \& Sabellen 4 thit. 15 fgr. 0t. 4 thlt. 12 g Git.

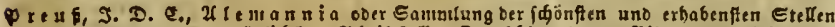

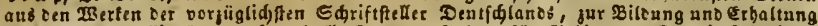

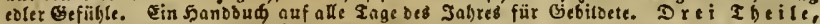
jeber Zlyeil mit eimem allegorifo, Zitelfupfer. 8. Sauber geljeftet a 1 zblt. compl.

3 thlt.

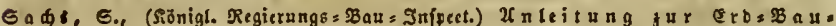

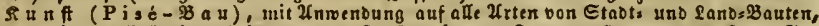

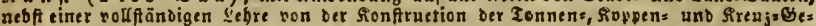

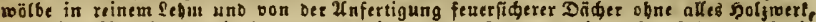

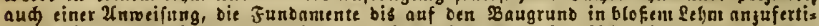

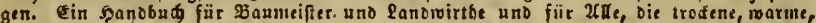

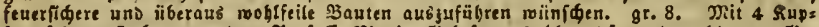

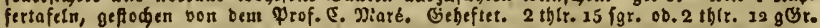

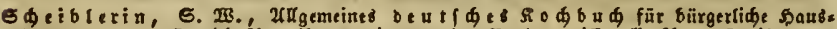

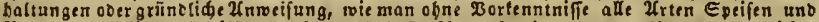

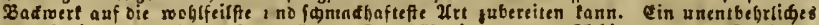

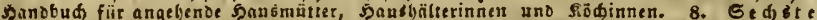
ou $r$ क $а$ म 3 thitr.

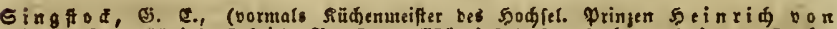

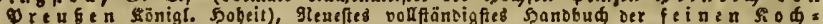

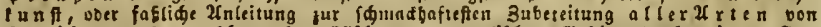

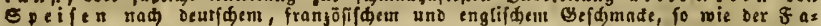

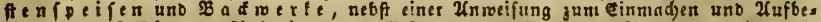
wabren ber Früdte, zur 2Tnfertigung bes Geftornen, Der Gilees, Der Eyrupe, Det Gietränfe

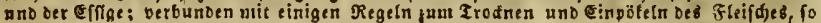

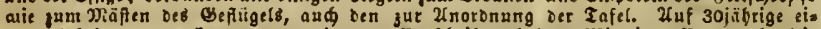
gene Erfahrang gegritnbet, und ntit 2391 Borjdriften belegt. Mit ciner Borrebe beglei.

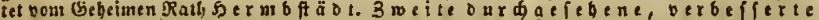

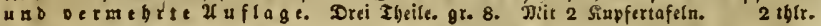

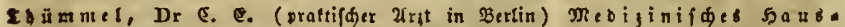
b u d jur Dütfe bei borfommende: firantheitsfälen für Se oern a $n$; insbefondere

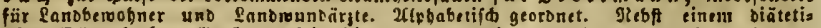

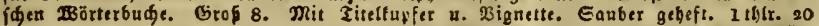
for. od. 1 thlt. 16 gest.

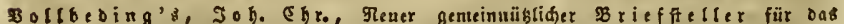

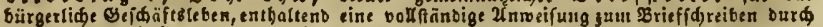

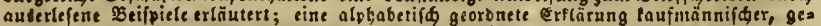

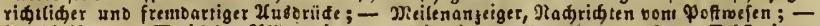
*oridriften fu Wedfeln, 2ffignationen, Dbligationen, Bertrïger Znhange von den Titulaturen in Der Sünigl. Orenf. Stanten. 8. F ü nfte verbefs ferte $\mathcal{U}$ uflage. Mit cineur neuen Titelfupfer. ( 35 comprefic Sogen.) 25 fgr. oder 20 gुr.

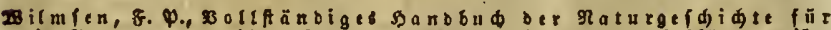

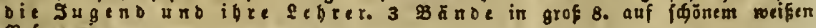
Refenpapier.

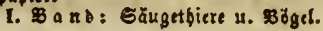




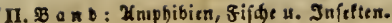

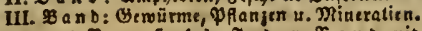

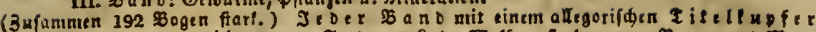

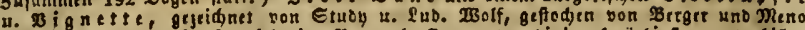

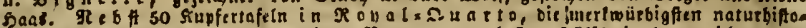

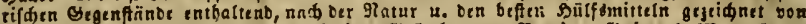

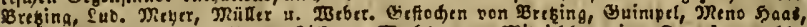

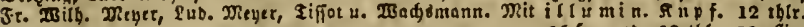
15 fgr. ob. 12 thte. $12 \mathrm{~g} \mathrm{Gr}_{\mathrm{r}}$.

Dafirtbe Wett nit \{ क war fen $R$ up fets.

9 thit. Dofitlbe o $\mathrm{n}$ t Rup $\mathrm{t}$ t. sthlr. 15 fgr. ob. 5 thtr. $12 \mathrm{ger}$.

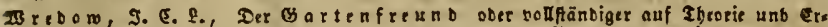

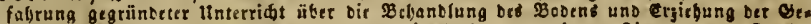

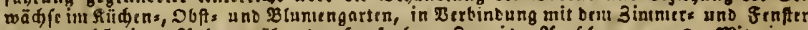

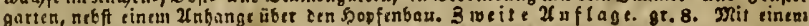
allegor. Titeltupfer unb \$ignettc. Gich.

2 tbits.

\section{Epraḑlefren uno 230 rterbúdaer.}

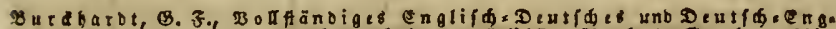

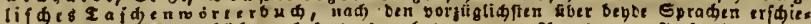

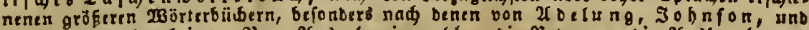

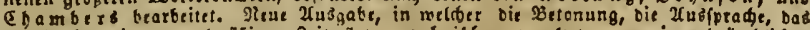

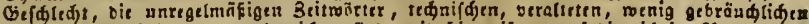

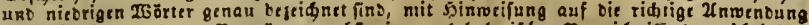

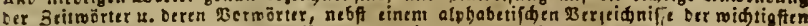

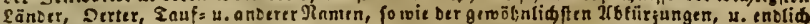

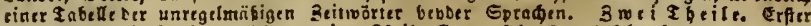

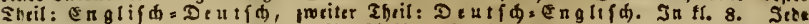
Eeite in otri Epatten aub ber Petlfdstift. Eauber gebeftet. 2 thitr. To for. obez 2 thit. 8 g

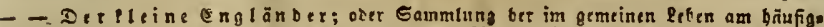

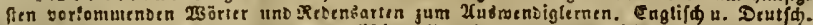

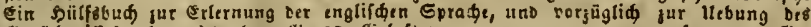
Getähtniffes, berausigegeber. Gir. 12. Gebeftet.

$10 \mathrm{fgr}_{\mathrm{g}} 00.8 \mathrm{~g} \mathrm{Gi}$.

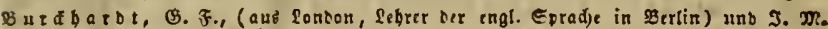

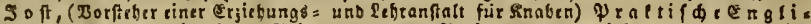

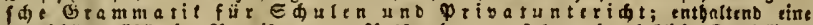

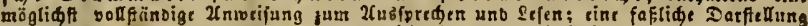

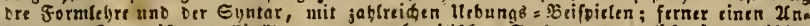

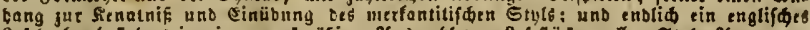

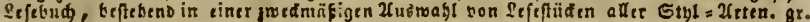
8. ( 41 comprefie $\mathfrak{B} \circ \mathrm{gen})$. toist.

Sfe, U., Der Heine Italiener; ober Eantmlung ber fum Spreden nötbigftu,

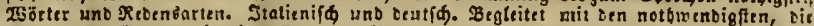

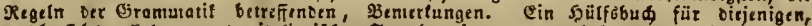

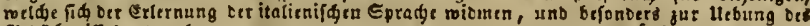
B̈tbä́gtnifíts. 12. geh.

$121 \sqrt{2}$ fgr. obet $10 \mathrm{~g}$ sit.

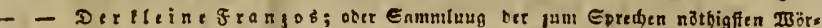

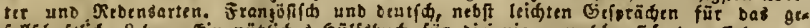

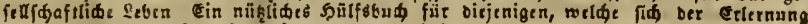
ser franjoffíten Eprade wiomen, ano befonbers gur llebung ies Gebädtnifies.

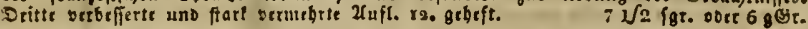

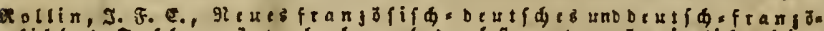
fif

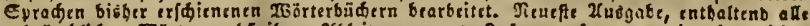

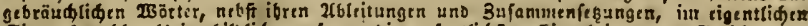

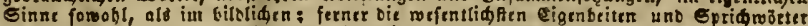

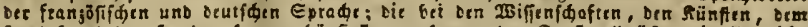

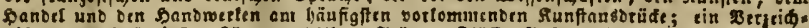

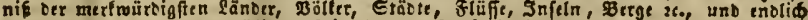
rine Eabetle ber untegrlmn̈figen Sritwörter. Swri Ibrift. It. 8vo. Sebe Erite in 3 Epalten, mit neuen Perififriften gebrudt. Eauber gebeftet. 1 tbit. $221 / 2$ far. ob.

1 thit. $18 \mathrm{~g}$ St.

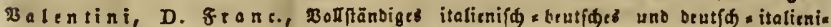

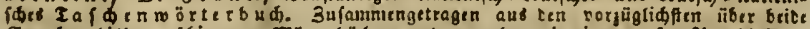

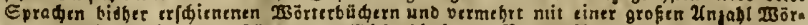

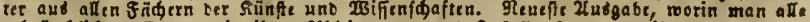

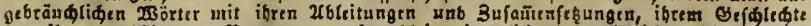
ano ibren berf́biebenen Bebutungen, forobl im eigentliden als bitolimen Einne, nebs

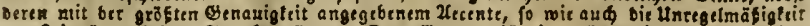

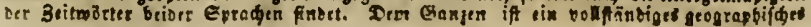




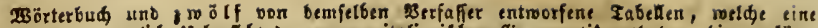
furfe uno beuttide lteberfidt ber ganjen itafienifhen Brammatit enthaften, binjugefügt.

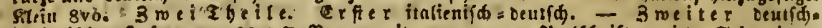
itafienif́d. Sufanımen $65 \mathrm{l} / 2$ sgagen mit gan\} neuen Đertfdriften, jede Eeite in 3 Epalten georuăt. Franzon

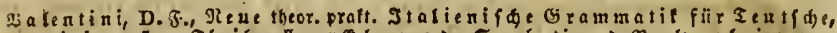
marin im erfter ₹belle alle zur Crlernung ber Eprade bienenbe Regeln nad einer gan

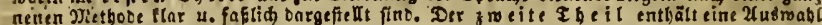
unterbaltender 2luffäbe in beiben Eprahen; einige ber im gemeinen seben gebräudtis

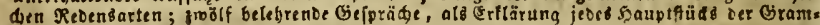
matil, uno einen 2 feris ber Gefdidte oer italienifden Sprade und iteratur. \$um Gebrailn in Equlen unb beint Eelbftunterridte: 41 Bogen in ganz grof 8. auf oas befte engl. Drudpapier gebeud.

2 thlt. 15 fge. 00. 2 thlt. 12 ger

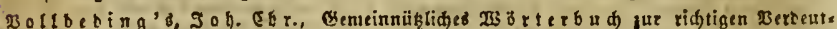

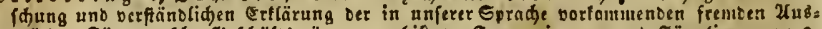

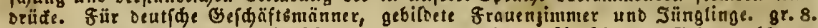

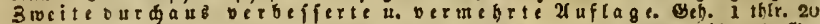

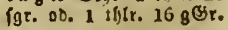

- - greue lleine theoretifdastaftifde Deutfde Evradtebre jum

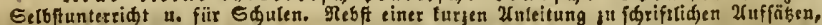

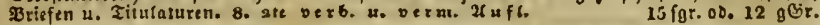

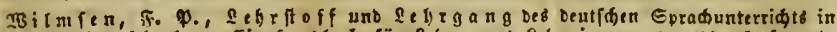

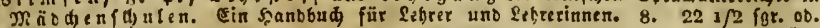
18 gojr.

Dolnetfiter, Rufiffher, fïr ben sö̈rger und Lanomann, worin bie notbivendigs

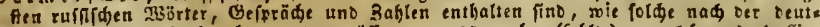

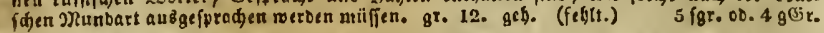

\section{Bildungsfdriften für bie erwadyenere Singend.}

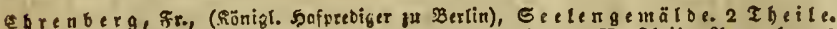

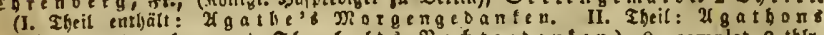

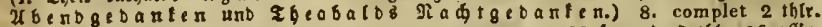
20 fgr. ot. 2 tfile. 16 g@r.

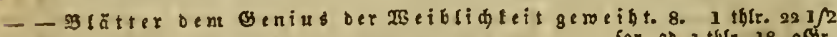
fgr. ob. 1 thitr. 18 ger.

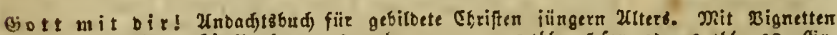
und sinem fibönen Yitelfupfer. gr. 8 . gel).

$1 \mathrm{tblx}, 15$ fgr. oder 1 thlt. $12 \mathrm{~g}$ sir.

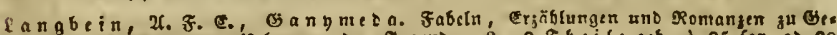
bädtnifs = uno Rebes uebungen Der Jugend. 8. 2 The ile geh. a 25 fgr. 00. 20 şir. cpl.

1 thit. 20 fgr. 00. 1 iffr. 16 gotr.

- De

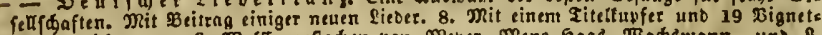

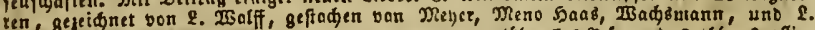

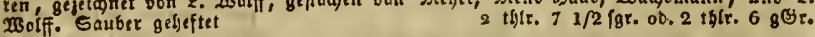

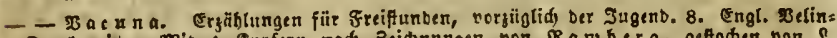

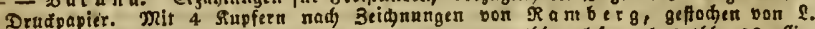
Deber jun. Eauber geljeftet. $\quad 1$ thlt. 15 fgr. ob. 1 thfe. 12 gSr.

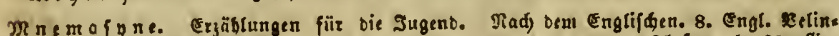
Druapap. Eauber gelfeftet. 25 fgr. ob. 20 gङr.

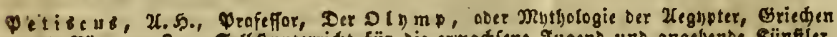
unb Romer. 3 um Eelbftunterridit für oie eriwahlene Jugend uno angelsenbe Riunftlet.

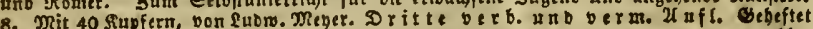
8. 1 thlt.

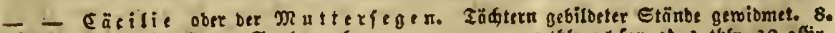

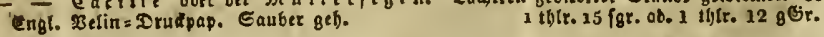

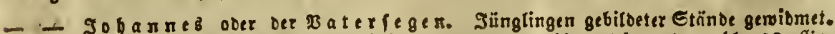

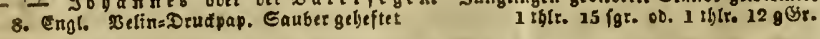

- - Men $\{$ d en mext h in seifoielen aut ber Gsfdidste unb bexi trigtider seben. Der Jugent zut lebreiden ltnterbnltung Dargeftelt. 500 Eeiten in gr. 8 . auf meifem

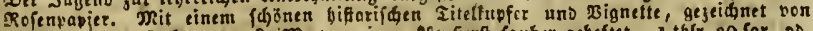

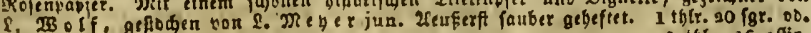
1 thlt. $16 \mathrm{gOB}$. 


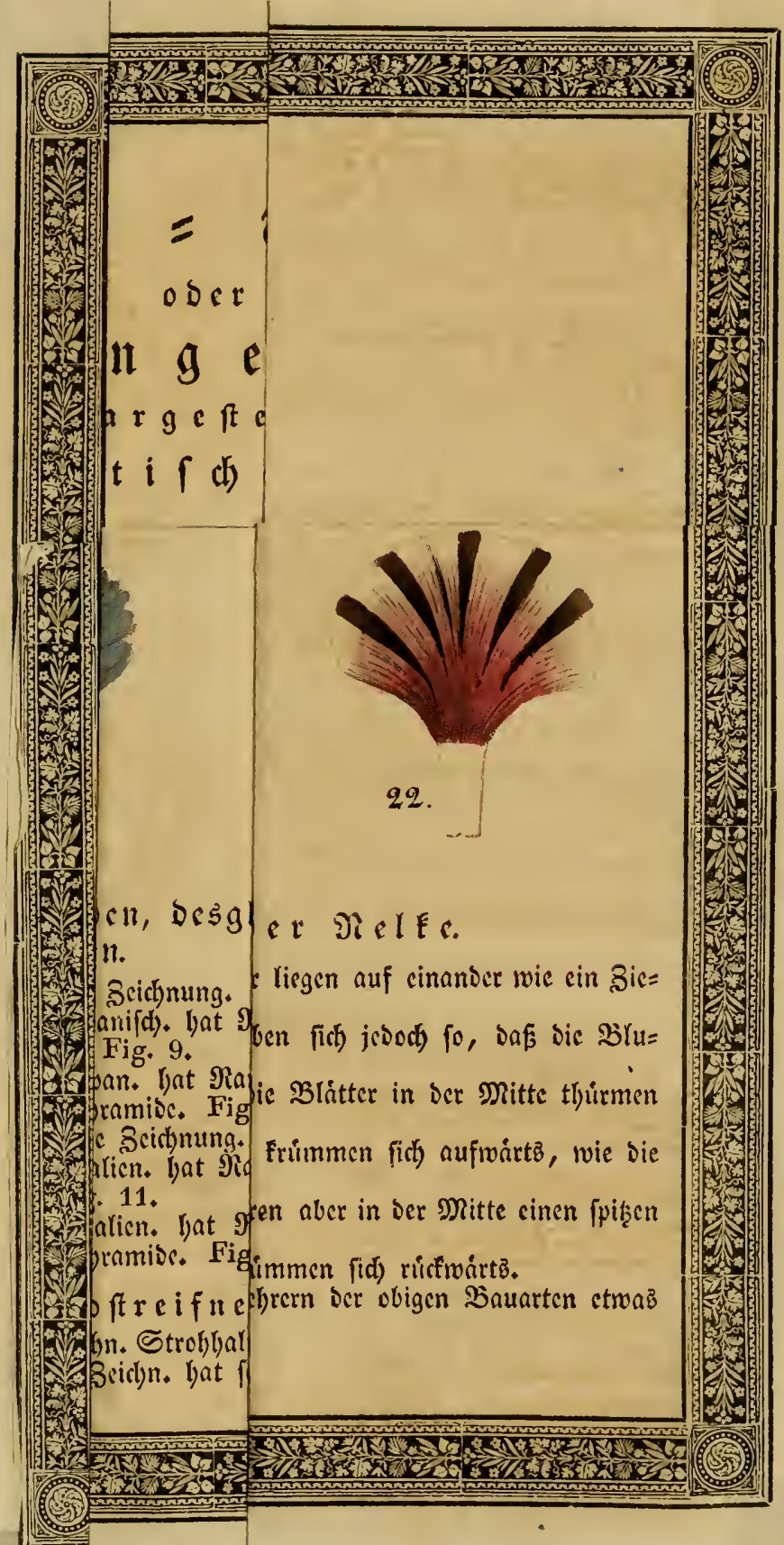




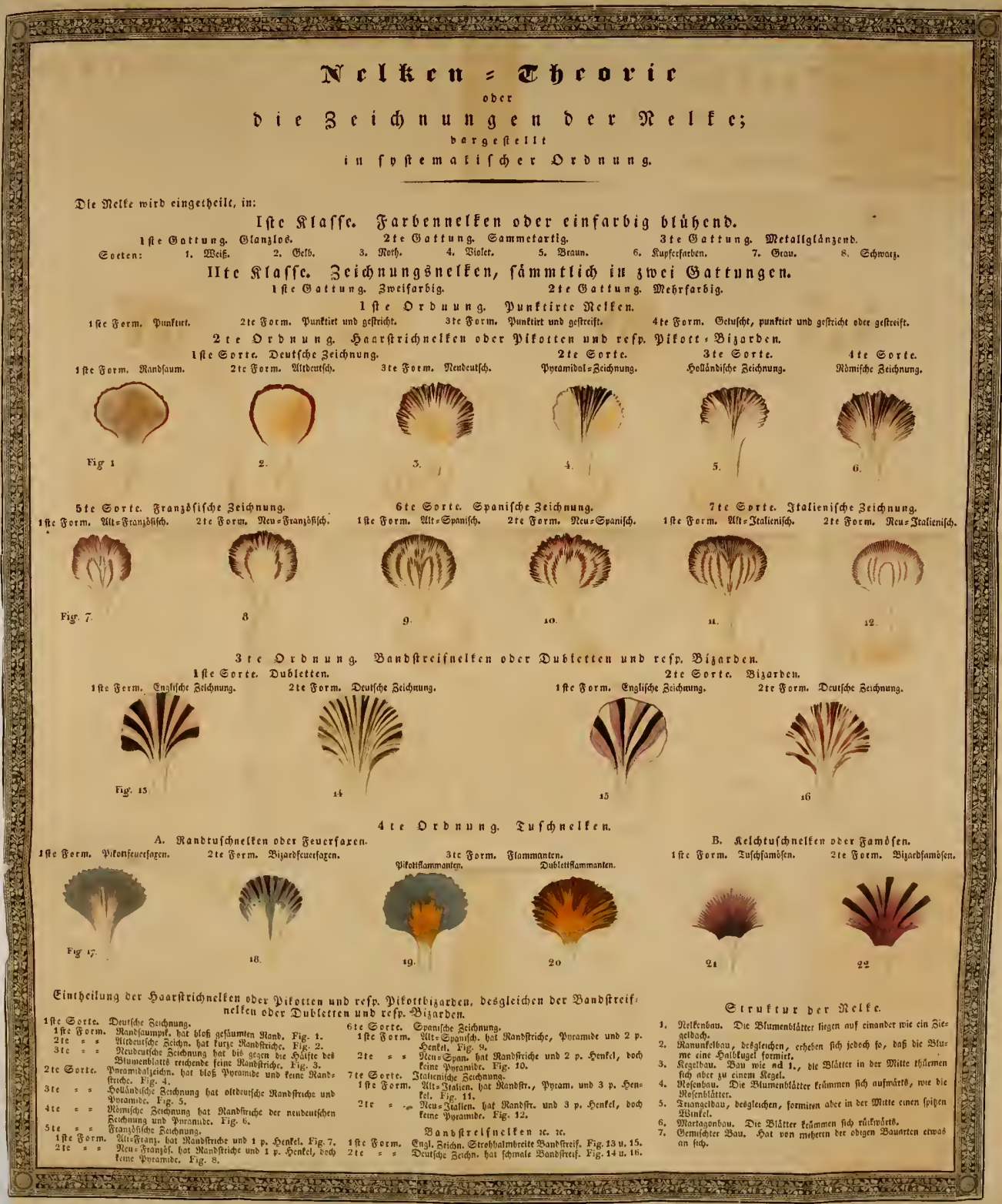





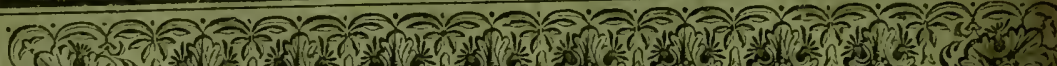

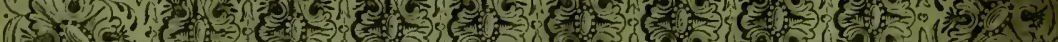

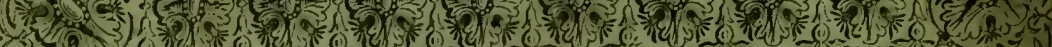

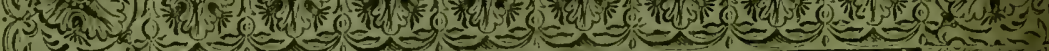
$(1,0=0,0$

(1) $1010-1)$

(1)

(

(43)

( (i)

$(1)-10$

$(0,140,5)$

(

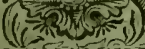

(1)

(1 5 र) on

$(1)=0$

(

( $\left(\frac{\pi}{2}\right)$

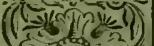

:3)

rom

1 to on

:2य

तह

तो 1 तै

ax: $(1=0.10$

Mu $=010$

युग

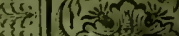

.

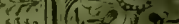

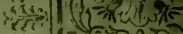

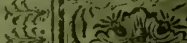

काषेत

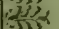

$\left.(-\pi) w_{1}-1\right)$

( 1 in

( जits (c)

$(1=-9)$ (N)

$\left((-1)\right.$ M $^{2}$ )

( $)$ No

( trive?

antos?

$(c)$

(

( 3 年

(

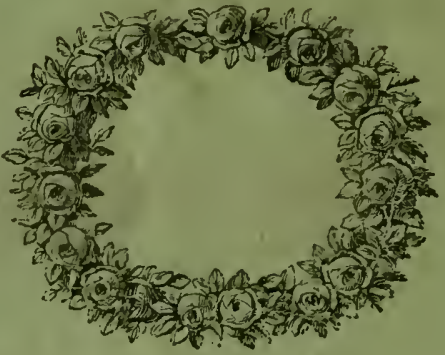

पारा

bet:

मis?

सरी

รर. $3=9 r^{2}=$

ins

is?

23is

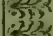

is

im

iग

है।?

$\frac{213}{33}$

$3 \sum_{2}$

23

23

233

sly.

3.

सहै?

(I)

"बi:

सहरे

ref:

रूप:

स्ले?

ris.

पर्ये:

हरा:

का

माद्र

ars

रुल

ris.

जहत?

लris

पys

सि.

"दि?

कर.

we

ris.

रादि

तर

rect

जि:

राजे

राएक

$(-2 u,-5)$

(1) 151 (v)

( $\frac{5}{2}(-1)$

$(1,1,142)$

( त)

ing

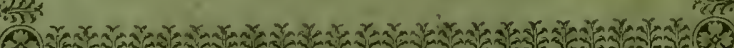

0

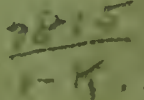

troor

$l_{i=0}$

(S

$3 x^{2}$

$=5$

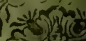

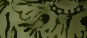

(

हse

(1) $=910$

(1

$(1=x)$ sis

(1) sin

$(1=9), 3=$

(1) तै

$(1-\pi) \times 5=$

(

Evit

(1)

(40) ปลง

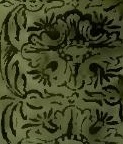

(v) और

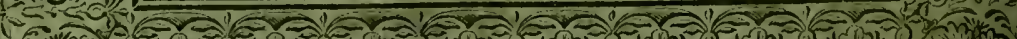

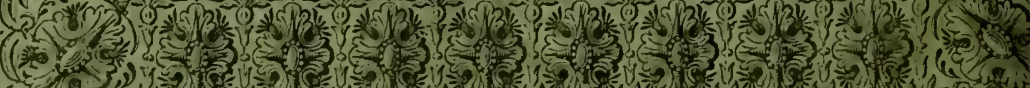
( (4 





\section{QL 105. D5 S77}

/System der Garten-Nelke, gestutzt auf d

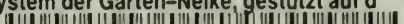


